\title{
EFECTO DE LA ABLACIÓN RESTRINGIDA DE LA CORTEZA AUDITIVA SOBRE EL COLÍCULO INFERIOR EN LA RATA
}

TESIS DOCTORAL

Cheryl Clarkson Paredes 


\section{EFECTO DE LA ABLACIÓN RESTRINGIDA DE LA CORTEZA AUDITIVA SOBRE EL COLÍCULO INFERIOR EN LA RATA}

Memoria presentada por Cheryl Clarkson Paredes para optar al grado de Doctor pot la Universidad de Salamanca

Director:

Prof. Dr. Miguel Merchan Cifuentes 
Dr. MIGUEL MERCHÁN CIFUENTES, CATEDRÁTICO DEL DEPARTAMENTO DE BIOLOGÍA CELULAR Y PATOLOGÍA DE LA UNIVERSIDAD DE SALAMANCA

\section{CERTIFICA}

Que la tesis doctoral titulada:

EFECTO DE LA ABLACIÓN RESTRINGIDA DE LA CORTEZA AUDITIVA SOBRE EL COLÍCULO INFERIOR EN LA RATA

Es el trabajo de investigación realizado por Dña. Cheryl Clarkson Paredes bajo mi dirección durante los últimos cuatro años.

La memoria de este estudio recoge un análisis exhaustivo y detallado de los cambios postlesionales a largo plazo en el Colículo inferior tras ablación de la corteza auditiva.

Los datos presentados en esta memoria constituyen una aportación original y han permitido un avance significativo en el conocimiento de la plasticidad postlesional en el sistema auditivo adulto.

Por todo ello, consideró que esta tesis reúne la calidad y rigor científicos necesarios para que sea defendida en la Universidad de Salamanca como requisito para que Dña. Cheryl Clarkson Paredes opte al grado de Doctor por la Universidad de Salamanca.

Y para que así conste, firmo el presente certificado en Salamanca a 26 de octubre de 2009 .

\section{Prof. Miguel Merchán Cifuentes}

VNIVERSiTAS

SALAMANIINI

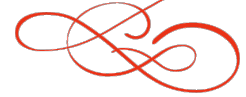




\section{AGRADECIMIENTOS}

A mis padres, por su apoyo incondicional en todas mis quimeras, desplazamientos e ideas, porque nunca me han cuestionado de forma negativa y porque siempre han sido el pilar que me sostiene. Aunque en estos momentos por la distancia la comunicación es menos física, siempre están presentes para mí, y cada pequeño logro mío es un gran logro para ellos. A mis hermanas y a mi sobrina, porque han sido mi polo a tierra, y me han acompañado en cada pasito que he ido dando en este largo camino recorrido, ayudándome a levantar cuando las fuerzas flaquearon.

A mi tutor de tesis doctoral, Dr. Miguel Merchán, porque me ha formado como investigadora, y porque sus pequeños vicios investigativos serán también siempre mis pequeños vicios investigativos. Agradecerle su paciencia y tranquilidad para guiarme por el camino de las Nerurociencias y por enseñarme que todavía me queda mucho por aprender. A Nacho, porque además de ser el mejor técnico que una doctoranda puede desear, es el mejor psicólogo, amigo y en muchas ocasiones paño de lágrimas que alguien con mi carácter puede tener. A Biviana por estar ahí, sea de día o de noche, de lunes a domingo, todo el mundo necesita una verdadera amiga y compañera de laboratorio así, sobre todo cuando tenemos lejos a nuestras familias, nos convertimos en una pequeña familia, por tal razón también le agradezco a todos aquellos amigos "salmantinos" que me han acompañado a lo largo de estos años, a Jonny, a Inés, a Melissa, a Mónica y a Eve.

A Lita, por ayudarme siempre en todo lo que he necesitado, no solo a nivel científico sino también como persona, gracias por comprender que a veces se necesita el toque femenino. A todos los que trabajan en el Incyl en sistema auditivo, porque son las personas con las que comparto el día a día investigativo, Flora, Marco, Manolo, Olga, Orlando, Med, Tao, Auxi, Verónica, a todos los integrantes del laboratorio del Dr. López-Poveda, por ayudarme siempre cuando lo necesite, incluso cuando el tiempo apremiaba. Al Dr. Arévalo y a Javier Herrero por su invaluable ayuda profesional. No quiero olvidarme de nadie, por eso les agradezco infinitamente a todos aquellos que de forma directa o indirectamente hayan aportado un granito de arena para que yo pudiese cumplir esta meta. GRACIAS! 


\section{INTRODUCCIÓN}

El Colículo Inferior: Citoarquitectura y Conexiones...................................9

Vía Auditiva Ascendente al Colículo inferior .................................................99

Vía Auditiva Descendente al colículo inferior...............................................12

Conexiones comisurales y conexiones intrínsecas o locales............................15

Proyecciones de las subdivisiones del Colículo Inferior..................................16

Reflejo Acústico del Sobresalto e Inhibición Por Estímulo Previo.................17

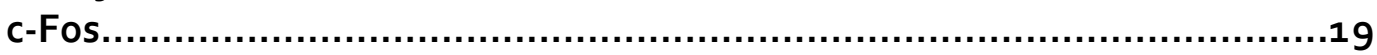

Calcio y Calretinina.........................................................................20

Receptores lonotrópicos de Glutamato...............................................22

Plasticidad Neuronal y cambios postlesionales en el Colículo Inferior..........25

\section{HIPÓTESIS Y OBJETIVOS}

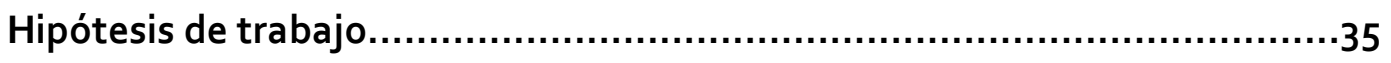

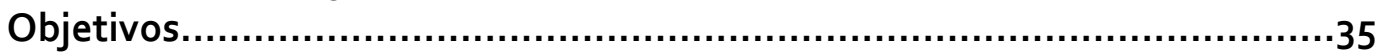

\section{MATERIALES Y MÉTODOS}

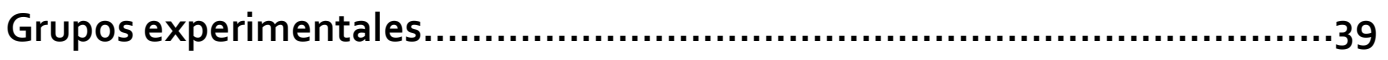

Procedimientos Quirúrgicos...........................................................41

Lesión de las Cortezas Auditivas (Áreas primaria y secundarias) .....................41

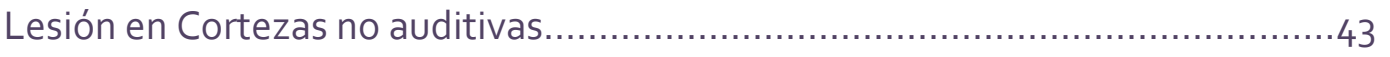

Inyección del Trazador neuroanatómico...................................................43

Extracción de los Colículos inferiores para las técnicas de análisis molecular y

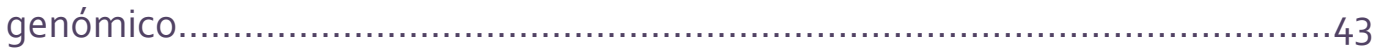

Respuestas auditivas del tronco cerebral (ABRs)................................46

Tipo de estudio.......................................................................... 46

Reflejo Auditivo del Sobresalto (RAS) - Inhibición Por Estímulo Previo (IPP).........47

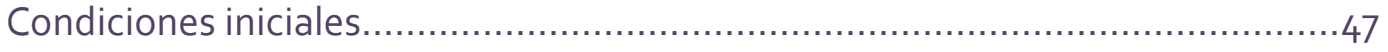

Sistema de medición del Reflejo Auditivo de Sobresalto................................47

Procedimiento de análisis del RAS/IPP .................................................. 48

Análisis estadístico para los valores del RAS/IPP ......................................48

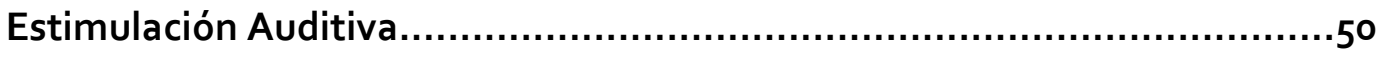

Técnicas Histológicas...................................................................51

Procedimientos de Fijación y Corte ................................................ 51

Métodos de Tinción.................................................................... 52

- Revelado del trazador Neuroanatómico Dextrano Biotinado..................52

- Revelado inmunohistoquímico para SMI-32 ..................................52

- Revelado inmunohistoquímico para c-Fos.........................................52

- Revelado inmunohistoquímico para Calretinina.................................54

- Tinción con Nissl..................................................................... 54

Métodos de Análisis.......................................................................58

Análisis Morfométrico y de ubicación de las lesiones en la Corteza Auditiva......58 
Representación gráfica de las lesiones en cada uno de los casos experimentalesLesión corteza auditiva y regiones no-auditivas............................................60

Análisis de la inmunotinción para c-Fos................................................60

- Cálculo del número de núcleos c-Fos positivos (estereología)...............60

- Morfometría y densitometría para c-Fos............................................65

Análisis de la expresión de la proteína Calretinina en el Colículo Inferior...........66

- Cálculo del número de neuronas CR-inmunorreactivas.......................67

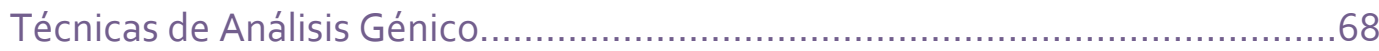

- Extracción de RNA total................................................................68

- Transcripción Reversa- Reacción en cadena de la Polimerasa (RT-PCR).69

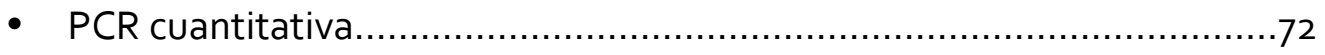

- Análisis estadístico para los estudios génicos en el $\mathrm{Cl}$...........................73

\section{RESULTADOS}

Localización de las lesiones..........................................................77

En Cortezas Auditivas.............................................................................. 77

Controles con lesión en Cortezas No-Auditivas .............................................77

Respuesta auditiva del tallo cerebral (ABRs).......................................77

Exploración de la respuesta refleja auditivo-motora...............................83

Reflejo auditivo de sobresalto (RAS) ..................................................8 83

Reflejo auditivo de sobresalto con presentación de un pulso sonoro previoInhibición por estímulo previo (IPP) ...................................................... 83

Expresión de c-Fos en el Colículo Inferior tras lesión cortical auditiva..........87

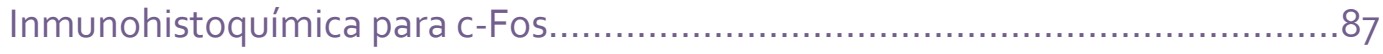

Análisis cuantitativo para c-Fos - Densitometría..........................................94

Análisis cuantitativo para c-Fos -Morfometría...........................................95

Análisis cuantitativo para c-Fos -Estereología............................................95

Inmunohistoquímica para Calretinina.................................................98

Estudio cuantitativo para Calretinina (Estereología)...................................101

Receptores lonotrópicos de Glutamato I RT-PCR semicuantitativa y

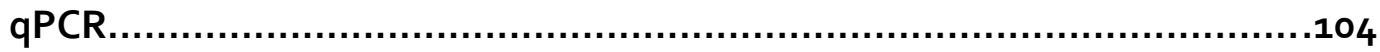

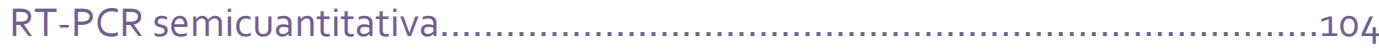

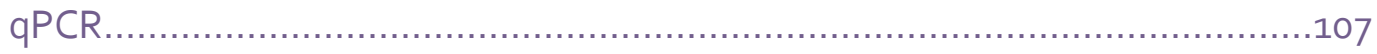

\section{DISCUSIÓN}

Pruebas funcionales - ABRs- RAS/ IPP ............................................113

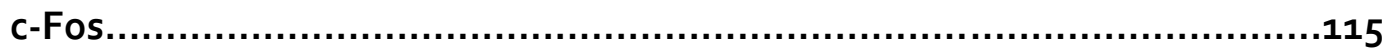

Calcio y Calretinina.................................................................118

Receptores lonotrópicos de Glutamato........................................122

CONCLUSIONES

Conclusiones...........................................................................127

Conclusión General....................................................................128

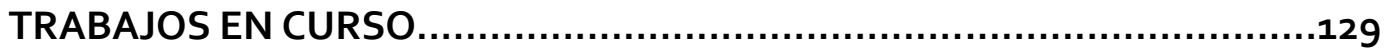

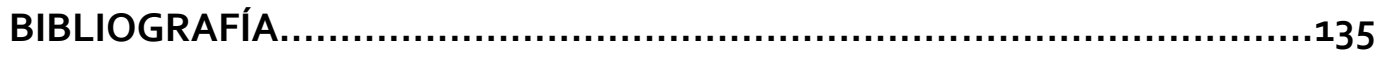



ABR, Respuesta Auditiva del Tronco-encefálico;

Au1, Corteza Auditiva Primaria;

AuD, Corteza Auditiva Dorsal;

AuV, Corteza Auditiva Ventral;

BDA, Dextrano Biotinado;

CA, Corteza Auditiva;

CDCl, Corteza Dorsal del Colículo Inferior;

CECl, Corteza Externa del Colículo Inferior;

c-Fos-IRr, c-Fos-inmunorreactivos;

$\mathrm{Cl}$, Colículo Inferior;

COS, Complejo Olivar superior;

CR, Calretinina;

CR-IRr, Calretinina-Inmunorreactivas;

CS, Colículo Superior;

CSM, Corteza SensoriMotora;

DAB, 3,3' tetrahidrocloruro de diaminobencidina;

DEPC, Dietilpirocarbonato;

dNTP, Desoxinucleótidos tri-fosfatos.

EEI, Estimulación Eléctrica Intracoclear;

iGluRs, Receptores Ionotrópicos de Glutamato;

IPP, Inhibición por Estímulo Previo;

LL, Lemnisco Lateral;

LTD, Depresión a Largo Plazo;

LTP, Potenciación a Largo Plazo;

MRGV, Mapa de Representación de Valores de Grises;

NC, Núcleos Cocleares;

$\mathrm{NCCl}$, Núcleo Central del Colículo Inferior;

NCD, Núcleo Coclear Dorsal;

NCV, Núcleo Coclear Ventral;

NDLL, Núcleo Dorsal del Lemnisco Lateral;

NPS, Núcleo Paraolivar Superior;

NVCT, Núcleo Ventral del Cuerpo del Trapezoide;

NVLL, Núcleo Ventral del Lemnisco Lateral;

OLS, Oliva Lateral Superior;

OSM, Oliva Superior Medial;

Pcc, Proyección Cortico-Colicular;

pl, Postlesión;

PLC, Proteínas Ligadoras de Calcio;

PM, Peso Molecular;

PnC, Núcleo Pontino Reticular Caudal;

PPTG, Núcleo Tegmental Pedúnculo-Pontino;

qPCR, PCR cuantitativa o real time PCR;

rAMPA, Receptores AMPA;

RAS, Reflejo Auditivo del Sobresalto;

rKA, Receptores Kainatos; 
rNMDA, Receptores NMDA;

RT-PCR, Transcripción Reversa- Reacción en Cadena de la Polimerasa;

SNC, Sistema Nervioso Central;

TBS, Tris Buffer Salina;

Tris-HCL, Tris (hidroximetil) aminometano más ácido clorhídrico;

VNTB, Núcleo Ventral del Cuerpo del Trapezoide; 
PREÁMBULO 
Existen numerosos estudios previos que demuestran la alta capacidad del Sistema Nervioso Central Auditivo para reorganizarse, tras cambios inducidos por la deprivación sensorial durante las etapas tempranas del desarrollo (revisión en Kandler, 2004; Keuroghlian y Knudsen, 2007). En el adulto, el volumen de información acerca de este tema es menor, pero se ha comprobado que existe un potencial plástico, que puede ser inducido por estímulos tales como el ambiente enriquecido acústicamente (Noreña y cols., 2006), los paradigmas de entrenamiento-comportamiento (Edeline y Weinberger, 1991 a,b, 1992; Gao y Suga, 1998, 2000; Ma y Suga, 2005; Rutkowski y Weinberger, 2005), la adaptación tras deaferentación sensorial (Holt y cols., 2005, 2006; Illing y cols., 2005; Illing y Reisch, 2006; Rubio, 2006) y, en menor número, tras lesiones en la corteza cerebral auditiva (Druga y Syka, 2001; Bowen y cols., 2003; Rybalko y cols., 2006; Clarkson y cols., 2009).

Se conocen diferentes aspectos clínicos y neurocientíficos que hacen importante el estudio de la adaptación postlesional del cerebro medio. Alrededor de 110.000 sordos, niños y adultos, se benefician actualmente del empleo de implantes cocleares (Fallon y cols., 2008). Aún así, las utilidades que el uso de estas prótesis aporta depende de la habilidad del cerebro para aprender a clasificar de nuevo la actividad neuronal evocada tras estimulación eléctrica de la cóclea (Kral y Tillein, 2006). En pocas palabras, su éxito depende de la capacidad plástica de toda la vía auditiva, incluyendo estructuras subcorticales tan importantes como el Colículo Inferior. De esta forma, resulta obvia la importancia de ayudar a comprender la habilidad del cerebro adulto, para adaptarse tanto a nuevos escenarios de estimulación, como a alteraciones inducidas por lesiones. Por otra parte, la capacidad de adaptación del Colículo Inferior frente a traumatismos cobra especial relevancia con la aparición de las modernas estrategias de tratamiento de las sorderas neurosensoriales basadas en la implantación de electrodos penetrantes en el cerebro medio. En estos pacientes, se produce la combinación de una pequeña lesión quirúrgica, producto de la penetración de los electrodos, con un nuevo procedimiento de despolarización basado en la estimulación eléctrica directa de las neuronas del Colículo Inferior (Lim y cols, 2009). La aplicación de esta estrategia ha sido posible, en la clínica, solamente en un reducido número de enfermos afectados de neurofibromatosis de tipo II (Lenarz y cols., 2006; Samii y cols., 2007), y aún no ha alcanzado la eficacia de los implantes cocleares (Lim y cols., 2008). La estimulación directa del cerebro medio, como también la recuperación de la función auditiva tras lesiones en la vía central, requerirá, para ser comprendida y mejorada en el futuro, de un conocimiento más profundo del Colículo Inferior en al menos dos aspectos importantes:

1. Su reorganización tras el acto quirúrgico que conlleva la penetración del implante y la estimulación por los electrodos. 
2. El comportamiento de sus neuronas y circuitos frente a los cambios en el balance de excitación/inhibición que supone la estimulación eléctrica directa.

En este sentido, es importante resaltar un hecho que recientemente se ha puesto en evidencia, y es que las neuronas, para trasmitir un mensaje efectivo requieren mantener un punto de equilibrio dinámico en la actividad sináptica (set point level), fuera del cual pueden entrar en silencio (Marder y Prinz, 2002). Para conseguir mantener este equilibrio se activan mecanismos moleculares mediados por rutas de señalización calcio-dependientes, que son capaces de modificar de forma activa el número y la condición de las proteínas de membrana sinápticas y extrasinápticas implicadas en la transmisión de señales eléctricas (Para una revisión: Turrigiano, 2008)

Esta forma de plasticidad en la cual las neuronas reaccionan frente a una noxa o un bloqueo buscando un equilibrio dinámico, es una función necesaria para recuperar su actividad, y lo logran ya sea variando su estado eléctrico y/ó la fuerza de la respuesta sináptica (sinaptic strenght). A este fenómeno se le conoce con el término de plasticidad homeostática (Turrigiano, 1999; Turrigiano y Nelson, 2000; Turrigiano, 2007; Maffei y Turrigiano, 2008). El concepto de plasticidad homeostática es de indudable interés para la Neurociencia actual y, más concretamente, para ayudar a comprender algunos resultados de este trabajo de tesis doctoral. Este concepto ha sido desarrollado fundamentalmente a partir del análisis de neuronas individuales, pero también es aplicable a las redes neuronales, que al parecer son capaces de ajustar en conjunto su neurotransmisión y la conductancia de las membranas, en busca del punto de equilibrio frente a una alteración del balance de actividad (Turrigiano, 2008).

En este trabajo de tesis doctoral pretendemos utilizar este nuevo concepto, como se verá más adelante, para interpretar algunos de los cambios observados por nosotros. Pretendemos progresar partiendo de nuestros resultados, hacia la caracterización en el futuro de un modelo de plasticidad homeostática in toto o in vivo, útil para hallar soluciones terapéuticas, que busquen mejorar la capacidad de recuperación espontánea, hasta alcanzar los puntos de equilibrio homeostáticos, no solo de las células nerviosas a nivel individual, sino también de los circuitos y redes neuronales. Como se explicará de forma más detallada a lo largo de la introducción, en este estudio nos planteamos inducir un fuerte disbalance de señales, mediante la eliminación unilateral de la proyección descendente desde la corteza auditiva al colículo inferior. Para ello, aprovechamos dos ventajas que a estos efectos ofrece este paradigma experimental, que son:

1. El carácter exclusivamente excitatorio de la proyección deaferentada (proyección corticofugal), que permite asegurar una pérdida neta 
importante de terminales glutamatérgicas en una de las dianas más importante de la proyección (el Colículo Inferior).

2. La gran convergencia de señales excitatorias e inhibitorias que, por su localización anatómica y esquema de conexiones de la vía, se genera en este núcleo auditivo.

En la introducción analizaremos los puntos más importantes que deben ser valorados para apoyar nuestra hipótesis experimental, a los efectos de conocer a fondo el terreno teórico sobre el cual se fundamenta nuestro trabajo. Para finalizar, realizaremos las preguntas que surgen de este análisis previo, que a su vez den lugar a una definición de los objetivos concretos y una metodología que han hecho posible la consecución de los resultados que presentamos en apartados siguientes.

Queremos aclarar al lector, que esta Tesis Doctoral, como la mayoría de los estudios experimentales, representa solamente una instantánea o un momento en el tiempo de un trabajo en curso. Por ello advertimos que se incluirán en este manuscrito, resultados totalmente elaborados y publicados, resultados en fase de publicación y otros preliminares, separados en un apéndice final, que tendrán continuidad en el futuro, y que responden a nuevas preguntas surgidas en el devenir del primer análisis de la hipótesis de partida. 
INTRODUCCIÓN 


\section{El Colículo Inferior: Citoarquitectura y Conexiones.}

El Colículo inferior $(\mathrm{Cl})$ es un núcleo con una posición clave en las vías auditivas, ya que es una estación de relevo para la inmensa mayoría de proyecciones ascendentes y descendentes del Sistema Nervioso Central Auditivo (Tokunaga y cols., 1984). Esta estructura cuenta, además, con un denso sistema de fibras comisurales que interconectan ambos colículos, al igual que otro de fibras intrínsecas que interconenctan sus tres subdivisiones (rata: Saldaña y Merchán, 1992). Las proyecciones del Cl utilizan neurotransmisores excitatorios- Glutamato (Adams y Wenthold, 1979; Faingold y cols., 1992; SaintMarie, 1996), inhibitorios -GABA y Glicina (Moore y Moore, 1987; Sanes y cols., 1987; Saint-Marie y Baker, 1990; Merchán y cols., 2005) y otros como AcetilColina (Morley y Happe, 2000; Motts y Schofield, 2009), Serotonina (Klepper y Herbert, 1991; Thompson y cols., 1994; Wright y cols., 1995; Hurley y cols., 2002), Noradrenalina (Klepper y Herbert, 1991; Thompson y cols., 1994), Histamina (Inagaki y cols., 1990) y Óxido Nítrico (Coote y Rees, 2008; Wu y cols., 2008).

En la corteza auditiva (CA), como en otras vías sensoriales, se diferencia un área de procesamiento sensorial (espectral, temporal y binaural) puro (vía lemniscal o nuclear -core: eje auditivo) y otra de integración polisensorial (vía no-lemniscal o periférica -belt: eje de integración) (Reale e Iming, 1980; Kaas y Hacket, 2000; Rutkowski y cols., 2003; Nishimura y cols., 2007). Por extensión, es posible distinguir en el resto de la vía auditiva, áreas centrales o lemniscales encargadas del procesamiento auditivo, y otras de interrelación con otros sistemas o para la generación de reflejos auditivo-motores (regiones paralemniscales, sagulum, núcleo del brachium, etc). En particular, en el $\mathrm{Cl}$ resulta especialmente evidente, la existencia de una región de integración polisensorial (cortezas) y otra de procesamiento auditivo (núcleo central). De este modo, se identifican tres áreas funcional y citoarquitecturalmente distintas: El núcleo central $(\mathrm{NCCl})$, especializado en el procesamiento central de la información lemmiscal o eje auditivo (v.s.) y las cortezas externa (CECl) y dorsal $(\mathrm{CDCl})$ pertenecientes al eje de integración polisensorial y premotor (Faye-Lund y Osen, 1985).

\section{Vía Auditiva Ascendente al Colículo inferior.}

Hasta el $\mathrm{Cl}$ ascienden proyecciones de diferentes núcleos de la vía auditiva baja (Figura 1). Los núcleos cocleares (NC) son el primer centro de relevo de la vía auditiva ascendente, y es el $\mathrm{Cl}$ una diana importante de sus proyecciones, tanto del núcleo ventral como del núcleo dorsal (Cant y Benson, 2003). Así, las neuronas estrelladas/multipolares tipo I o T del Núcleo Coclear Ventral (NCV) proyectan directamente al NCCl del lado contralateral (Beyerl, 1978; Adams y Wenthold, 1979; Brunso-Bechtold y cols., 1981; Alibardi, 1998). 


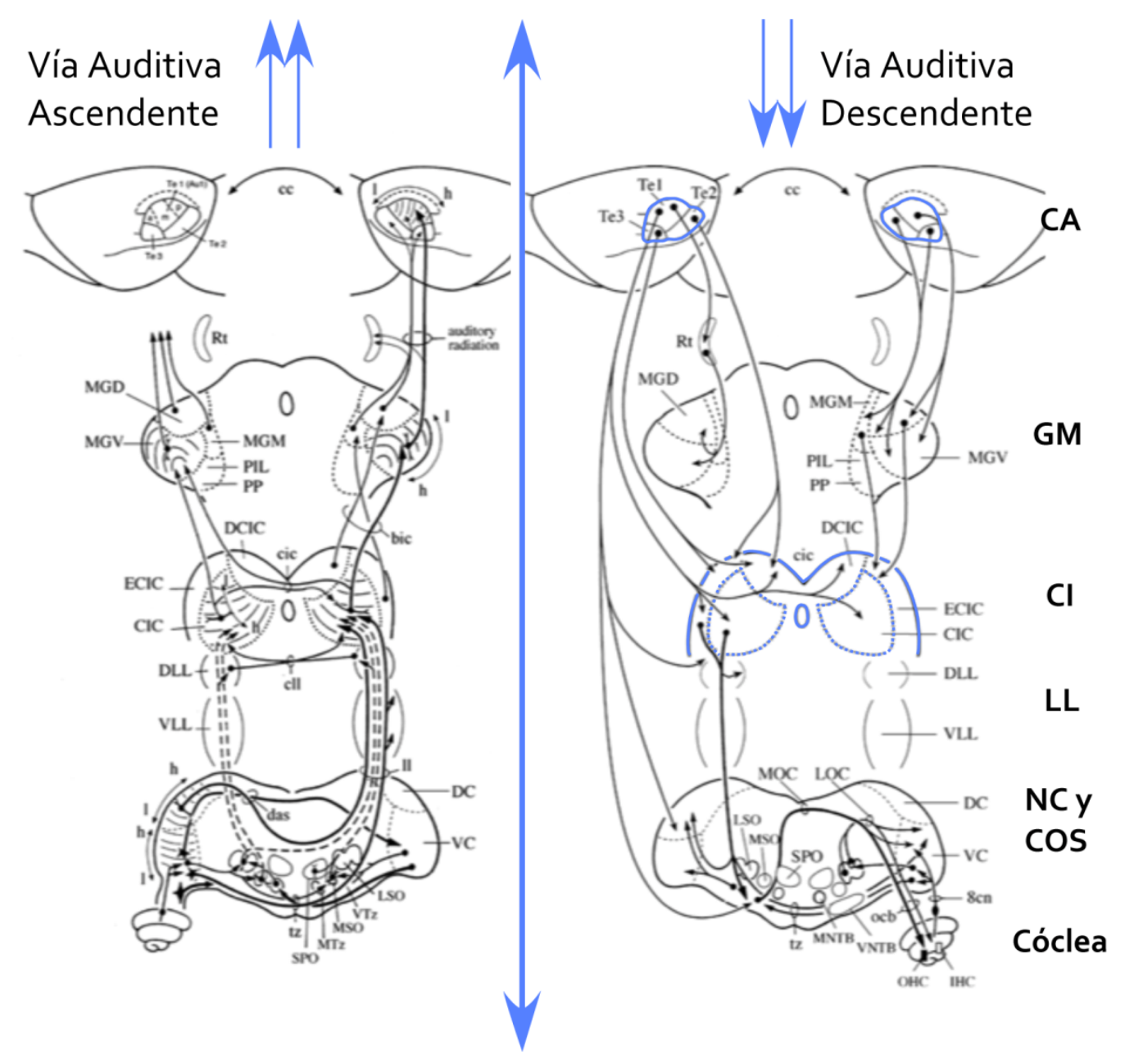

FIGURA 1. Representación esquemática de las vías auditivas ascendentes y descendentes de la rata. (Modificada por Malmierca y Merchán, 2004; de los esquemas de Brodal, 1981; y Herbert, 1991-para las cortezas auditivas).

CA Corteza Auditiva

Cl Colículo Inferior

COS Complejo Olivar Superior

GMT Geniculado Medial del Tálamo

LL Lemnisco Lateral

NC Núcleos cocleares 
Esta proyección es generalmente considerada excitatoria y glutamatérgica (Helfert y col., 1991; Wenthold, 1991; Wenthold y col., 1993). El Núcleo coclear dorsal (NCD) proyecta principalmente por la estría acústica dorsal al $\mathrm{Cl}$ contralateral (Beyerl, 1978), y contribuyen a su respuesta excitatoria (Davis, 2002). En otras especies como el gato, se ha comprobado también una pequeña proyección al Cl ipsilateral (Brunso-Bechtold y cols., 1981; Oliver y Morest, 1984).

En la rata, el Complejo Olivar Superior (COS) está conformado por 5 núcleos, 4 de los cuales tienen límites muy fácilmente identificables: el núcleo paraolivar superior, la oliva lateral superior, la oliva superior medial y el núcleo del cuerpo del trapezoide la distribución difusa de sus neuronas. El COS envía proyecciones al $\mathrm{Cl}$ desde cuatro de sus núcleos (Warr, 1975). Uno de ellos, la Oliva Lateral Superior (OLS), proyecta bilateralmente al NCCI (Stotler, 1953; Adams y Wenthold, 1979; Schneiderman y Henkel, 1987; Coleman y Clerici, 1987; Saint-Marie y cols., 1989; Henkel y Brunso-Bechtold, 1993). En diferentes especies, incluida la rata, las proyecciones ipsilaterales son principalmente glicinérgicas (gato: Glendenning y Baker, 1988; Saint-Marie y cols., 1989; cobayo: Saint-Marie y Baker, 1990) y probablemente inhibitorias, en contraste con las células que proyectan al lado contralateral que son glicina-negativas y por lo tanto potencialmente excitatorias (Saint-Marie y cols., 1989; Saint-Marie y Baker, 1990). El núcleo Olivar Superior Medial (OSM), proyecta ipsilateralmente al $\mathrm{NCCl}$, vía segmento interno del lemnisco lateral (Henkel y Spangler, 1983). Estas neuronas son GABA -y Glicina- inmunonegativas (rata: Kulesza y Berrebi, 2000), y por lo tanto la proyección es probablemente excitatoria. El núcleo Paraolivar Superior (NPS) en la rata, proyecta ipsilateralmente al Cl (Faye-Lund, 1986; Friauf y Kandler, 1990; Saldaña y Berrebi, 2000). En esta misma especie, González-Hernández y cols., (1996) establecen que ésta es una proyección heterogénea con respecto a los tipos neuronales inmunocitoquímicos. Describen neuronas GABA inmunorreactivas, $y$ otras glicina inmunorreactivas; mientras que Kulesza y Berrebi (2000) concluyen que el NPS en las ratas contiene una población homogénea de neuronas GABAinmunorreactivas. Finalmente, como parte de la región periolivar, neuronas del núcleo ventral del cuerpo del trapezoide (NVCT) envían una proyección ipsilateral al $\mathrm{Cl}$ (Coleman y Clerici, 1987), y estas neuronas son positivas para GABA o Glicina (Roberts y Ribak, 1987; Helfert y cols., 1989; Henkel y BrunsoBechtold, 1995; Winer y cols., 1995).

Los dos núcleos del Lemnisco Lateral (LL), el núcleo Ventral (NVLL) y el núcleo Dorsal (NDLL) (Held, 1893; Ramón y Cajal, 1909-1911) proyectan al Cl. En la rata, el NVLL tiene células que se disponen en láminas topográficamente organizadas (Merchán y Berbel, 1996). Las células del NVLL son Glicina y GABA inmunorreactivas en su tercio más ventral y probablemente excitatorias en el dorsal (Riquelme y cols., 2001). Este núcleo envía una proyección unilateral al Cl 
(Adams y Wenthold, 1979; Brunso-Bechtold y cols., 1981; Kudo, 1981; Zook y Casseday, 1987; Ross y cols., 1988).

El NDLL es posiblemente la principal fuente de influencia inhibitoria en el tallo cerebral de los mamíferos (Bajo y col., 1993). Estudios inmunocitoquímicos han mostrado que las neuronas del NDLL son inmunorreactivas para GABA y GAD (Adams y Mugnaini, 1984; Thompson y col., 1985; Moore y Moore, 1987; Roberts y Ribak, 1987; Winer y col., 1995). La proyección eferente termina bilateralmente en el núcleo central del $\mathrm{Cl}$, aunque la proyección contralateral es la predominante (Van Noort, 1969; Adams y Wenthold, 1979; Brunso-Bechtold y col., 1981; Kudo, 1981; Willard y Martin, 1984; Covey y Casseday, 1986; Coleman y Clerici, 1987; Zook y Cassedey, 1987; Ross y col., 1988; Saint-Marie y Baker, 1990; Hutson y col., 1991; Bajo y col, 1993). Sus axones ascienden y se ramifican en paralelo a las láminas fibrodendríticas (Bajo y col., 1993). Estos autores describen en la rata, tras realizar inyecciones en el NDLL del trazador neuroanatómico Leuco-Aglutinina de Phaseolus Vulgaris, campos terminales marcados en el $\mathrm{CECl}$, localizados fundamentalmente en la capa 3 (capa profunda).

Vía Auditiva Descendente al colículo inferior.

La corteza auditiva ocupa una extensa área en la región temporal de la rata, y ha sido objeto de numerosos estudios de parcelación cortical (Krieg, 1947; Zilles, 1985; Zilles y Wree, 1985; Swanson, 1992). En los últimos años, Paxinos y Watson (2005) trazaron un esquema de parcelación cortical, aglutinando los criterios de Zilles (1985), Zilles y Wree (1985), Swanson (1992, 2004), Palomero-Gallagher y Zilles (2004). De esta forma, los autores identificaron 3 grandes regiones auditivas: La corteza auditiva primaria (Au1), la corteza auditiva dorsal (AuD) y la corteza auditiva ventral (AuV). Por tratarse de la nomenclatura hoy en día más aceptada, será la utilizada durante la redacción de este manuscrito.

Spangler y Warr (1991) describen las proyecciones descendentes como una cadena continúa que coexiste con circuitos locales, y que cuenta con 3 niveles principales: el primero, formado por fibras corticogeniculadas, corticocoliculares y corticopontinas; el segundo integrado por fibras que se originan en el $\mathrm{Cl}$, y que constituyen las proyecciones colículolivares y colículococleares, y un tercer nivel que da lugar a la proyección olivococlear (Figura 1).

La CA es, por lo tanto, el origen de un gran sistema de proyecciones descendentes, que alcanzan diferentes dianas en un conjunto de núcleos auditivos, en la llamada vía auditiva descendente. Existen datos experimentales, que confirman que ésta participa en la localización de sonidos (Neff y cols., 1975) o procesamiento binaural (Stecker y cols., 2005), en la plasticidad representacional (Moucha y cols., 2005), y en la reorganización 
relacionada con la experiencia (Pollok y cols., 2005). Aún con los datos que se conocen, la influencia específica de esta zona de la corteza en el refinamiento del procesamiento de señales auditivas sobre estructuras subcorticales no es, a día de hoy, bien comprendida (Winer y Lee, 2007). No obstante, se sabe que el sistema auditivo corticofugal actúa de forma clara sobre el procesamiento sensorial en su conjunto (Sun y cols., 1996), sobre el comportamiento motor por medio de sus dianas en los ganglios basales y en otras estructuras promotoras (Schuller y cols., 1991; Beneyto y Prieto, 2001); sobre el Reflejo Auditivo del Sobresalto (Yeomans y Frankland, 1996) o sobre los state dependent changes (Steriade, 2000). Además, estudios recientes sugieren que esta proyección cortical puede afectar directamente a las neuronas coliculares, no solo por vía descendente, sino que también puede afectar las señales ascendentes al $\mathrm{Cl}$, ya que la CA proyecta directamente a otros núcleos, como el complejo olivar superior, específicamente sobre neuronas que a la vez proyectan al $\mathrm{Cl}$ (Schofield y Coomes-Peterson, 2005; Coomes-Peterson y Schofield, 2007).

La proyección corticocolicular (Pcc) de los mamíferos- objeto central de nuestro estudio-, proviene no solo del área Au1, sino que diversos autores refieren que también envían aferencias las cortezas auditivas secundarias (AuV y AuD) (Diamond y col., 1969; Rockel y Jones, 1973; Oliver y Hall, 1978; Beyerl, 1978; Faye-Lund y Osen, 1985; Arnault y Roger, 1990; Herbert y col., 1991). Las neuritas que lo conforman se originan principalmente de las neuronas piramidales de la capa V (rata: Beyerl, 1978; Games y Winer, 1988; Weedman y Ryugo, 1996; gato: Kelly y Wong, 1981; Meredith y Clemo, 1989; Winer y Prieto, 2001; hurón: Bajo y cols., 2007) y, en menor grado (cerca del 10\% de toda la proyección ipsilateral), de las neuronas de la capa VI (rata: Games y Winer, 1988; Doucet y cols., 2003; gato: Prieto y Winer, 1999; gerbo: Bajo y Moore, 2005; hurón: Bajo y cols., 2007; cobayo: Schofield, 2009).

La Pcc tiene conexiones directas y cruzadas que generan campos terminales en el $\mathrm{Cl}$, que se distribuyen principalmente en las cortezas (Kuypers y Lawrence, 1967; Forbes y Moskowitz, 1974; Ravizza y cols., 1976; FitzPatrick e Imig, 1978; Casseday y cols., 1979; Andersen y cols., 1980; Kelly y Wong, 1981; Druga y Syka, 1984 a, b; Faye-Lund, 1985; Coleman y Clerici, 1987; Arnault y Roger, 1990; Herbert y cols., 1991; Vaudano y cols., 1991), y también en el NCCl, según otros autores(FitzPatrick e Iming, 1978; Feliciano y Saldaña, 1991; Saldaña y cols., 1996; Winer y cols., 1998; Druga y Syka, 2001; Bajo y Moore, 2005). En definitiva, conviene resaltar que según los estudios de trazado de vías, la Pcc de la rata termina de forma bilateral en todas las subdivisiones del $\mathrm{Cl}$, exceptuando la $\mathrm{CECl}$ contralateral, y sus campos terminales siguen un patrón de organización cocleotópico, bandeado, bilateral, simétrico y concéntrico (Saldaña y cols., 1996) (Figura 2). 
Campos terminales Cortico-Coliculares

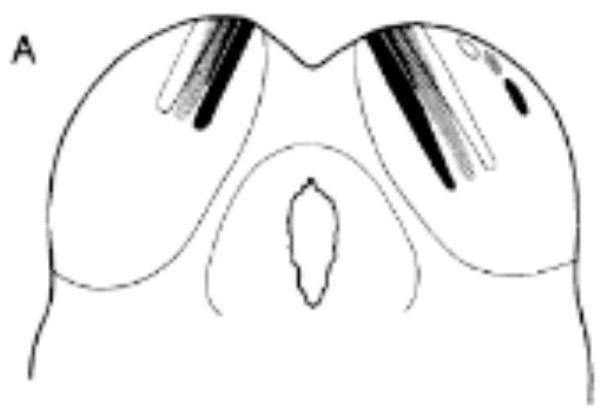

B

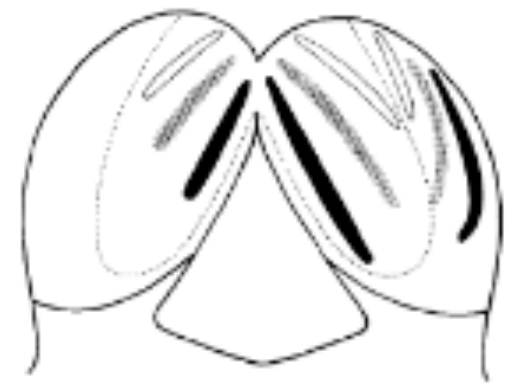

C

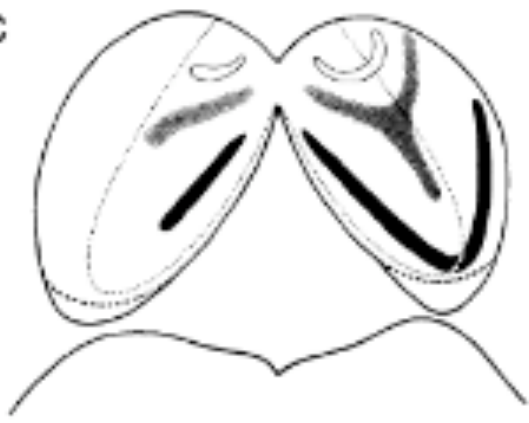

Campos terminales intracoliculares

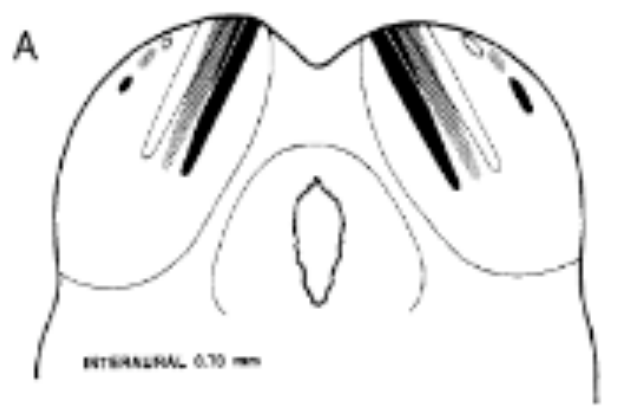

B

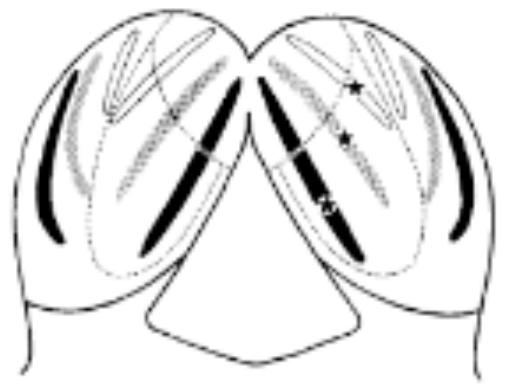

atckaves to.to $\mathrm{ma}$

C

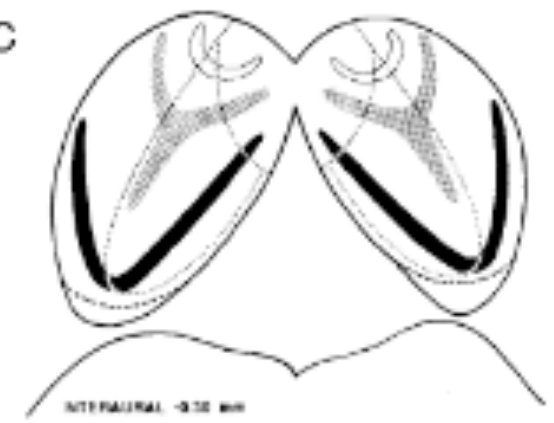

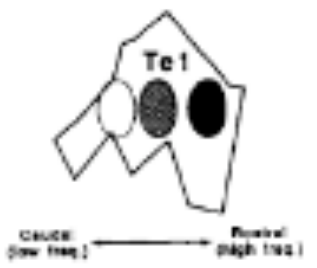

FIGURA 2.

Columna izquierda: Representación esquemática de la disposición de los campos terminales corticocoliculares, a diferentes niveles interaurales, tras inyección de trazadores en tres regiones del eje rostro-caudal (ver inset) (Saldaña y cols., 1996).

Columna derecha: Diagrama de la distribución de los campos terminales intracoliculares. Las estrellas (B), indican el sitio de inyección en distintas regiones tonotópicas del núcleo central del colículo inferior (Saldaña y Merchán, 1992). 
Sun y cols., (2007) describen que la Pcc actúa a modo de filtro de las respuestas neuronales al sonido en términos de frecuencia, amplitud y dominios espacial y temporal. También esta proyección puede mejorar la sensibilidad para ciertas combinaciones sonoras (Yan y Suga, 1996; Zhang y cols., 1997; Jen y cols., 1998; Jen y Zhang, 1999; Chowdhury y Suga, 2000) e inducir cambios plásticos en las neuronas del Cl (Zhou y Jen, 2000; Ma y Suga, 2001 a,b; Suga y cols., 2002).

En cuanto al tipo de neurotransmisor que utiliza esta proyección, Jones y Rockel, (1973) y Feliciano y Potashner (1995), observaron axones terminales sobre el $\mathrm{Cl}$ que contenían vesículas sinápticas redondeadas y uniones sinápticas asimétricas, características asociadas a la transmisión excitatoria (Uchizono, 1985). En términos generales es aceptado por la mayoría de los autores, que se trata de una vía Glutamato (Glu) /Aspartato (Asp). De este modo, Oliver y cols., (1983), describen que tras inyecciones de D-Aspartato, éste es acumulado por neuronas marcadas retrógradamente que expresan transporte con alta afinidad para Glu y/o Asp. Autores como Fahn, (1976); Contreras y Bachelard (1979) y Adams y Wenthold, (1979), refieren que el Cl tiene abundantes sinápsis glutamatérgicas, pues contiene altas concentraciones de Glu, además de terminales sinápticos Glu-inmunorreactivos (Caspary y Helfert, 1993), mecanismos para lanzar Glu y D-[ ${ }_{3} \mathrm{H}$ ] Asp (Caspary y cols., 1990; Goldsmith y cols., 1995; Suneja y cols., 1995) y receptores glutamatérgicos (Petralia y Wenthold, 1992; Smith, 1992). En resumen, podemos asumir que la Pcc utiliza de forma singular el glutamato como neurotransmisor (Jones y Rockel, 1973; Feliciano y Potashner, 1995; Saldaña y cols., 1996), proporcionando una influencia excitatoria directa sobre las neuronas coliculares ascendentes, y una influencia inhibitoria indirecta cuando contacta con las interneuronas coliculares GABAérgicas (Mitani y cols., 1983).

Conexiones comisurales y conexiones intrínsecas o locales.

Las fibras comisurales conforman un sistema de plexos axonales laminares que conectan cada punto del $\mathrm{NCCl}$ con regiones extensas de las tres subdivisiones del $\mathrm{Cl}$ de forma bilateral (Saldaña y Merchán, 1992) (Figura 2). Estos autores, tras inyección unilateral en el $\mathrm{Cl}$ del trazador anterógrado Phaseolus vulgaris-leucoaglutinina, observaron bilateralmente la aparición de una banda principal y una banda externa organizadas cocleotópicamente.

Aunque se conoce que es una proyección muy densa, poco se sabe acerca del significado de este patrón de organización. Dadas las funciones conocidas de las subdivisiones del $\mathrm{Cl}$, Saldaña y Merchán (1992) sugieren que las bandas principales deben tener por objeto elaborar la información espectral y temporal del sonido, mientras que las bandas externas podrían participar en la integración polisensorial. Malmierca y cols., (2005), tras inyección unilateral de ácido kinurénico en el $\mathrm{Cl}$, y utilizando el análisis de respuesta evocada al sonido en 
neuronas del $\mathrm{Cl}$ contralateral, indicaron que una de las funciones de la comisura del $\mathrm{Cl}$ puede ser la de modular el refinamiento de las respuestas a la estimulación acústica. También aplicando microinyecciones de ácido kinurénico para inactivar neuronas del $\mathrm{Cl}$ en rata, Malmierca y cols., (2003), demostraron que las proyecciones comisurales influyen en las propiedades de respuesta a las frecuencias en las neuronas del $\mathrm{Cl}$ in vivo. Se conoce además, que una parte de esta proyección es probablemente glutamatérgica (Saint-Marie, 1996) y otra parte (al menos un 20\%) tiene un componente inhibitorio GABAérgico (Oliver y cols., 1994; Merchán y cols., 2005; Hernández y cols., 2006).

Finalmente, cabe resaltar que las fibras intrínsecas forman conexiones bilaterales y simétricas entre las subdivisiones del Cl (Saldaña y Merchán, 1992). Dentro del $\mathrm{NCCl}$, las fibras intrínsecas forman láminas paralelas a los contornos de isofrecuencia del $\mathrm{Cl}$, que se extienden hasta las zonas corticales ( $\mathrm{DCCl}$ y $\mathrm{ECCl}$ ) (Saldaña y Merchán, 1992; Malmierca y cols., 2001). Además, esta proyección parece ser, al menos en rata, tan densa, como cualquier otra proyección aferente proveniente de núcleos subcoliculares (Saldaña y Merchán, 1992).

\section{Proyecciones de las subdivisiones del Colículo Inferior}

EI NCCI recibe toda la proyección lemniscal (Beyerl, 1978; Druga y Syka, 1984), y envía una proyección directa a la $\mathrm{CECl}$, una proyección ascendente a la división ventral del cuerpo geniculado medial del tálamo, y conexiones descendentes a los núcleos del complejo olivar superior y núcleos cocleares (Huffman y Henson, 1990). La CECl, por su parte, recibe axones procedentes no solo de estructuras auditivas como los NCs y el COS (Loftus y cols., 2004, 2008; Cant y Benson 2006, 2008), sino también de estructuras somatosensoriales como el núcleo espinal trigeminal (Zhou y Shore, 2006; Jain y Shore, 2006), la médula espinal (Aitkin y cols., 1978), el núcleo de la columna dorsal (Tokunaga y cols., 1984) y los núcleos cuneautus y gracilis (Coleman y Clerici, 1987). La CECl a su vez, proyecta a territorios relacionados con la producción de respuestas sensorimotoras, a regiones específicas del colículo superior (Carey y Webster, 1971; Druga y Syka, 1984c, Covey y cols., 1987; Zhang y cols., 1987), al núcleo Pontino dorsolateral (Moore y Goldberg, 1966; Carey y Webster, 1971; Aitkin y Boyd, 1978; Kawamura y Brodal, 1973; Kawamura, 1975) y al cerebelo (Hoddevik y cols., 1977; Kawamura y Hashikawa, 1981).

La $\mathrm{CDCl}$, recibe pocas proyecciones directas de núcleos auditivos subcoliculares, la mayoría de sus conexiones provienen de las proyecciones comisurales del $\mathrm{Cl}$ contralateral, de las proyecciones intrínsecas del $\mathrm{NCCl}$ ipsilateral y de la CECI (v.s.), y de las proyecciones descendentes de la corteza auditiva (Andersen y cols., 1980; Faye-Lund y Osen 1985; Saldaña y Merchán, 1992; Bajo y Moore, 2005; Sun y Wu, 2008). Esta subdivisión proyecta, fundamentalmente, al núcleo Geniculado Medial del Tálamo, en su división dorsal (Huffman y Henson, 1990). 


\section{Reflejo Acústico del Sobresalto e Inhibición Por Estímulo Previo.}

El Reflejo Acústico del Sobresalto (RAS) es un comportamiento simple protectivo mediado por circuitos neuronales oligosinápticos identificados y que se localiza en el tallo cerebral pontino (Koch y Schnitzler, 1997). El RAS es una respuesta defensiva, originada por un estímulo auditivo de alta intensidad, que produce una contracción muscular generalizada, que se traduce en una abrupta postura de replegamiento corporal -crouch-like- (Pilz y cols., 1987; Hoffman y cols., 1990).

En roedores el circuito neuronal que media el RAS, está formado por los aferentes primarios del nervio auditivo (VIII par craneal), las neuronas de la raíz coclear, el núcleo Pontino Reticular Caudal (PnC), y las interneuronas y motoneuronas espinales (Davis y cols., 1982; Koch, 1999), faciales y craneales (Lee y cols., 1996). El pequeño número de estaciones de relevo de este circuito, determina un escaso retraso sináptico y justifica la latencia muy corta (10ms) del reflejo (Casella y cols., 1986; Caeser y cols., 1989).

Hoffman y Searle (1965) describieron por primera vez una disminución en la amplitud del RAS tras la presentación de un sonido de menor intensidad 20$500 \mathrm{~ms}$ previo al estímulo desencadenante del reflejo. A este fenómeno, que se produce también por estímulos precedentes visuales o táctiles (Koch, 1999), se le conoce como Inhibición por estímulo previo (IPP). La IPP tiene como característica que produce una muy fuerte inhibición de la amplitud del reflejo (80-90\%) que se observa cuando la duración del prepulso es de 10-20 ms (Reijmers y Peeters, 1994) y se utilizan intervalos entre estímulos entre los 40 y 150 ms (Hoffman y Searle, 1965; Li y cols., 1998 a,b). La IPP es realzada con el incremento de las intensidades del prepulso con respecto a los umbrales del RAS (Hoffman y Searle, 1968; Hoffman y Wible, 1970; Hoffman, 1984; Li y cols., 1998a). Además, la inhibición de parte de la amplitud de la respuesta del RAS ocurre desde el primer trial de la prueba (Hoffman y Wible, 1970) y no muestra aprendizaje.

Los circuitos que median la IPP no se conocen por completo, pero sí es conocido que el Colículo inferior y en particular su corteza lateral es importante a la hora de procesar la respuesta motora (Koch y Schnitzler, 1997; Koch, 1999). Diversos autores han comprobado que tras realizar lesiones en el $\mathrm{Cl}$ se producen cambios en el efecto de la IPP sobre el RAS y en la amplitud del reflejo (Leitner y Cohen, 1985; Li y cols., 1998 a,b; Li y Yue, 2002). Basándose en datos previos (Fendt y cols., 1994, Koch y Schnitzler, 1997; Fendt, 1999; Koch, 1999) se ha propuesto que en la generación de la IPP está implicado un circuito en el que interviene el $\mathrm{Cl}$, que activa el Colículo superior (CS) y, éste, a través del núcleo tegmental pedúnculopontino (PPTG), inhibe mediante una proyección colinérgica al PnC (núcleo pre-motor) (Gómez-Nieto y cols., 2008). Swerdlow y 
cols., (2001) proponen además que la IPP debe estar regulada por circuitos descendentes de centros superiores como los del sistema límbico y la corteza frontal.

Recientemente y tras experimentos de estimulación múltiple y de análisis de las latencias Yeomans y cols., (2006), han propuesto para la IPP, la existencia de un circuito rápido integrado por el $\mathrm{Cl}$ - Núcleo intercomisural - $\mathrm{CS}$, y otro más lento originado desde las capas profundas del CS. Por tanto, parece evidente que en el cerebro medio tanto el CS (Fendt y cols., 1994, 2001) como el $\mathrm{Cl}$ (Leitner y Cohen, 1985), tienen un papel funcional demostrado en la inducción de la IPP. Sin embargo, no hay acuerdo sobre en qué medida se trata de una respuesta fundamentalmente cerebro-medio/tronco-encefálica o con participación de niveles jerárquicos superiores, tales como el tálamo y la corteza. En este sentido Hunter y Willot (1993), tras deaferentación bilateral de la CA, comprobaron que el umbral, la amplitud y la latencia del RAS no se veían afectados. Sin embargo, estos autores muestran en sus resultados, aumentos en los umbrales de intensidad un mes después de la lesión. Otros autores, tras ablación bilateral de la CA observaron cambios en la sensibilidad a la intensidad del sonido en los fenómenos de gap detection (Buchtel y Stewart, 1989; Ison y cols., 1991; Kelly y cols., 1996; Bowen y cols., 2003). Bowen y cols., (2003) comprobaron que estas alteraciones fueron más evidentes un mes después de la lesión y se recuperaron parcialmente a los dos meses pl. Por otro lado, lesiones en áreas corticales no auditivas también muestran cambios importantes en la IPP. Goto y cols., (2002), tras inyecciones bilaterales de ácido iboténico en la corteza entorrinal de la rata y tras 21 días pl observó que se afectó la IPP sin alterar la amplitud del RAS.

Li y Yue (2002) observaron que la IPP representa, no solo un proceso protectivo automático del sensorimotor gating, sino también se relaciona con procesos de atención selectiva controlados por la corteza cerebral. Por otra parte, en el hombre, diferentes autores han reportado modificaciones tanto del RAS como de la IPP en patologías que afectan a la corteza cerebral, tales como la esquizofrenia o la enfermedad de Huntington (Lewis, 1997; Impagnatiello y cols., 1998; Benes y cols., 2000; Koch y Robins, 2001; Callicot y cols., 2003; Ishikawa y cols., 2004; Mueller y Miador-Woodruff, 2004).

En resumen, podríamos decir que la medida del RAS/IPP en alteraciones espontáneas o inducidas de la corteza auditiva es un procedimiento válido para estudiar el estado funcional del sistema nervioso de los mamíferos, incluido el hombre (Davis y cols., 1982; Koch y Schinitzler, 1997; Koch, 1999). 


\section{c-Fos}

Los genes de expresión temprana (IEG immediate-early gene), al no requerir síntesis de novo de proteínas (Herrera y Robertson, 1996), pueden ser rápidamente activados como una respuesta primaria al desencadenamiento de cascadas de señalización intracelular (Soloaga y cols., 2003). Se sabe que c-Fos es una fosfoproteína nuclear que forma parte de estos IEG, y que constituye heterodímeros principalmente con el factor de transcripción c-jun (Sng y cols., 2004). c-Fos es una proteína codificada por genes que contienen cuatro exones y tres intrones (van Straaten y cols., 1983) y que se extienden aproximadamente 4 kb y codifican una proteína de 380 aminoácidos con un tamaño de 55 a 62 kDa (Herdegen y cols., 1998; Platenik y cols., 2000).

La inducción de IEG, específicamente de c-Fos, es una de las herramientas más utilizadas para la identificación y mapeo anatómico funcional de células y circuitos que se activan en respuesta a diferentes estímulos (Greenberg y Ziff, 1984; Ceccatelli y cols., 1989; Bullit, 1990). Esto es debido en parte a que c-Fos es expresado a bajos niveles en el cerebro bajo condiciones basales, $y$, por lo tanto, es una técnica de alta sensibilidad para detectar pequeños cambios en la actividad neuronal (Hughes y cols., 1992). La expresión de c-Fos es, además, inducida estereotípicamente en respuesta a diferentes señales intracelulares, que incluyen iones, neurotransmisores y factores de crecimiento; su respuesta es transitoria y su detección no es complicada (Kovács, 2008). También existen estudios que indican que la transcripción de factores Egr-1 y c-Fos en las neuronas del cerebro de los mamíferos de los adultos, es un indicativo del remodelado axo-dendrítico (Cole y cols., 1989; Rampon y cols., 2000).

Diversos autores han estudiado la expresión o el mapeo de c-Fos en el sistema auditivo. Esta proteína se expresa en los núcleos cocleares, tanto en condiciones basales como tras estimulación eléctrica o con sonido (Hillman y cols., 1997, Vischer y cols., 1994, Saito y cols., 1999; Illing y cols., 2002). También se ha observado la expresión de ésta proteína en el COS por inmunocitoquímica (Adams, 1995-estimulación por sonido), y en el NDLL por hibridación in situ (Saint-Marie y cols., 1999-estimulación por sonido).

Específicamente en el $\mathrm{Cl}$, la mayoría de autores que han estudiado la expresión de c-Fos, han encontrado cambios cualitativos o cuantitativos tras la utilización de diversos paradigmas de estimulación acústica (Nagase y cols., 2000, 2003; Zhang y cols., 2003; Nakamura y cols., 2005; Lu y cols., 2009; Sun y cols., 2009). Además, diferentes autores coinciden también en que este aumento es dependiente de la intensidad del estímulo sonoro (Sato y cols., 1993; Adams, 1995; Brown y Liv, 1995), y en particular, para nuestro diseño experimental, que c-Fos es un buen marcador tras estimulación con tonos puros (Ehret y Fischer, 1991; Friauf, 1992; Rouillier y cols., 1992; Pierson y SnyderKeller, 1994; Saint-Marie y cols., 1999). 
Uno de los paradigmas experimentales de lesión en el que ha sido muy utilizado el estudio inmunocitoquímico de c-Fos en el sistema auditivo es la estimulación eléctrica del nervio coclear, combinada con la ablación coclear (Nakamura y cols., 2003, 2005), o con la inducción de sordera por aplicación de sulfato de neomicina (Saito y cols., 1999; Nagase y cols., 2000, 2003), o tras la remoción del hueso del martillo (Reisch y cols., 2007). La manipulación experimental de la vía auditiva descendente y el análisis con c-Fos ha sido abordado por Guo y cols., (2007), que estudiaron sus variaciones de inmunorreactividad en el cuerpo Geniculado medial tras sobreactivación de la CA por inyección de bicuculina. Sun y cols., $(2007,2009)$ realizaron un análisis parecido (practicando la sobreactivación de la CA con bicuculina) pero estudiando el $\mathrm{Cl}$. Estos autores observaron tras estimulación auditiva con tonos puros o ráfagas (burst), que se produce un aumento en el número de neuronas cFos inmunorreactivas en el lado ipsilateral a la región cortical bloqueada.

Por lo tanto, son muchos los datos que avalan la utilización de c-Fos como una buena herramienta para cuantificar cambios en la actividad neuronal auditiva, $y$, más específicamente, en aquellos producidos por modificaciones en la vía corticofuga.

\section{Calcio y Calretinina.}

La homeostasis del Calcio es esencial tanto para la viabilidad como para un apropiado funcionamiento de las neuronas del sistema auditivo (Förster e Illing, 2000, Zettel y cols., 2001). Cuando se produce un fenómeno de deprivación sensorial en el sistema auditivo, las neuronas afectadas sufren alteraciones en su fisiología, morfología y en el metabolismo (Rubel y cols., 1990; Caicedo y cols., 1997). Parte de estas alteraciones neuronales pueden ser producto del incremento de las concentraciones intracelulares de este ión como resultado de la pérdida de señales (Zirpel y cols., 1995, 1998, 2000; Caicedo y cols., 1997; Stack y Code, 2000; Fuentes Santamaría y cols., 2003; Alvarado y cols., 2005).

Muchas formas de plasticidad sináptica expresada en el sistema nervioso central dependen inicialmente del incremento intracelular del $\mathrm{Ca}^{2+}$, que funciona como un segundo mensajero dependiente de actividad en cambios sinápticosespecíficos (Xia y Storm, 2005). Los niveles de $\mathrm{Ca}^{2+}$ intracelular son determinados por el balance entre las reacciones "on" que introducen este ión en el citoplasma y de las reacciones "off" a través de las cuales esta señal es removida con los iones por la acción combinada de tampones, bombas e intercambio iónico (Berridge y cols., 2003). Las proteínas ligadoras de $\mathrm{Ca}^{2+}$ (PLC) se activan cuando la concentración de $\mathrm{Ca}^{2+}$ intracelular se incrementa de $10^{-5}$ hasta $10^{-6}$ (Ikura, 1996). En este caso, estas proteínas pueden actuar de dos formas, tanto como facilitadores intracelulares de la difusión del $\mathrm{Ca}^{2+}$ y/ó como sistemas de tamponamiento (Kim y cols., 2006). En particular, la Calretinina (CR) 
es una PLC de la familia de las EF-Hand que puede actuar a la vez como un $\mathrm{Ca}^{2+}$ tampón, siendo ésta su función más conocida (Baimbridge y cols., 1992; Ikura, 1996), pero también se sabe que puede actuar como un $\mathrm{Ca}^{2+}$ modulador de procesos dependientes de $\mathrm{Ca}^{2+}$ (Billing-Marczak y Kuznicki, 1999), y como un $\mathrm{Ca}^{2+}$ sensor (Mockel y Fischer, 1994; Kuznicki y cols., 1996; Schurmans y cols., 1997; Billing-Marczak y cols., 1999; Isaacs y cols., 2000). Además, es capaz de trasladar una concentración de $\mathrm{Ca}^{2+}$ a cascadas de señalización intracelular y actuar como un $\mathrm{Ca}^{2+}$ tampón transportador/rápido, capaz de regular la señalización de este ión sobre una distancia de nanómetros en los sitios presinápticos (Edmonds y cols., 2000), característica muy importante en un sistema de ritmos de descarga tan rápido y preciso como el auditivo.

El excesivo influjo de Calcio o el lanzamiento de éste desde los depósitos intracelulares pueden elevar la carga del ión hasta que se exceda la capacidad de los mecanismos $\mathrm{Ca}^{2+}$-regulatorios. Lukas y Jones (1994) describieron que, in vitro, las neuronas de la corteza cerebral que contenían $C R$ eran relativamente más resistentes a la muerte celular inducida por excitotoxinas, que incluían la aplicación de agonistas de los receptores NMDA, Kainato y glutamato. Estos resultados soportaron la idea del rol que cumplen las PLC en el mantenimiento de la homeostasis del calcio durante períodos de supervivencia tras lesión en los que se incremente el influjo de este ión. Mientras que la Calbindina y la Parvalbúmina parecen actuar como tampones del Calcio que se incrementan en respuesta al incremento de los niveles internos del catión (Zettel y cols., 1997), diversos autores indican que la Calretinina puede tener un rol más complicado en la regulación del Calcio (Billing-Marczak y Kuznicki, 1999; Hack y cols., 2000) y puede responder además a cambios en los niveles de actividad neural (Braun, 1990; Sans y cols., 1995; Winsky y Jacobowitz, 1995; Caicedo y cols., 1997).

Existen diversos estudios previos que indican que los cambios en la regulación y expresión de $C R$ se relacionan con efectos postlesionales en el sistema auditivo de los mamíferos. Fuentes-Santamaría y cols., (2003) demostraron en hurón, que tras ablación coclear unilateral, se produce un aumento en la densidad y extensión de los plexos CR inmunorreactivos en el Cl contralateral a la lesión. Por otro lado, Zettel y cols., (2001), observaron en la $\mathrm{CECl}$, tras inducir una lesión bilateral por inyección intracoclear de kanamicina en old hearing CBA-mice, una disminución en el número de neuronas CR inmunopositivas, concluyendo que la expresión de esta proteína puede estar regulada por cambios en la actividad neural. Por otro lado, es interesante resaltar la ventaja que reporta la utilización en un modelo de deaferentación cortical la CR como marcador de lesión en el $\mathrm{Cl}$, dado que su inmunorreactividad es débil en el núcleo central y es alta en las cortezas, que concuerdan con una distribución en los territorios más inervados por la Pcc (ie. CDCl y CECI) (Saldaña y cols., 1996; Druga y cols., 1997). 


\section{Receptores lonotrópicos de Glutamato.}

Los receptores ionotrópicos de Glutamato (iGluRs) son canales de ión ligando-bloqueado (Dingledine y cols., 1999) presentes en la membrana postsináptica, que median la mayoría de la neurotransmisión excitatoria del sistema nervioso central, incluyendo las vías auditivas (Collingridge y Lester, 1989; Sewell, 1997; Parks, 2000). El glutamato es, además, el principal neurotransmisor excitatorio en el $\mathrm{Cl}$ (Feliciano y Potashner, 1995; Caicedo y Eybalin, 1999; Helfert y cols., 1999; Parks, 2000; Faingold, 2002; Tadros y cols., 2007). Se conocen 3 subtipos de iGluRs: Los N-Methyl-D-aspartate- NMDA y los no-NMDA que son la familia de los alpha-amino-3-hydroxy-5-methyl-4isoxazolepropionic acid- AMPA y la familia de los Kainatos. Estas subunidades existen como complejos macromoleculares que se combinan en el ensamblaje de receptores de membrana (Bleakman y Lodge, 1998; Michaelis, 1998; Dingledine y cols., 1999; Bigge, 1999). Además, su biosíntesis es regulada por cascadas intracelulares de transducción de diferentes señales (Bigge, 1999).

Los receptores AMPA (rAMPA) están compuestos por las subunidades GluR1, GluR2, GluR3 y GluR4 (Seeburg, 1993; Hollman y Heinemann, 1994; Westbrook, 1994), que ensamblan receptores nativos con composición heteromérica y que contribuyen al componente rápido de las corrientes postsinápticas excitatorias (Bigge, 1999). Estos receptores muestran una activación, una desactivación y una desensibilización que ocurre dentro del rango de los milisegundos. Por el contrario, los canales con receptores NMDA (rNMDA), que están compuestos por las subunidades $N R_{1}, N_{2} A-N R 2 D$ y los $\mathrm{NR}_{3} \mathrm{~A}-\mathrm{B}$, muestran unas propiedades cinéticas más lentas (Misra y cols., 2000; Cull-Candy y cols., 2001; Mcllhinney y cols., 2003). Todos los rNMDA parecen funcionar con un ensamblaje heteromérico compuesto por múltiples subunidades NR1 (obligatorio para la actividad del canal) con, al menos, uno de los tipos de las subunidades NR2 (le confiere al canal la especificidad y la función); la subunidad NR3 no forma sola receptores funcionales, pero puede coensamblar con complejos NR1/NR2 (Das y cols., 1998; Pérez-Otaño y cols., 2001; Cull-Candy y cols., 2001).

El último grupo identificado de los iGluRs, y por lo tanto los que cuentan con más interrogantes en su estudio, son los receptores kainatos (rKA). Estos receptores están compuestos por dos familias de subunidades relacionadas: los GluR5-7 y los KA-1 y KA-2; cuyos receptores nativos son combinaciones tetraméricas, posiblemente de ambas combinaciones: homoméricos y heteroméricos. La composición de los rKA nativos aún permanece poco claro. Se conoce que los GluR5-7 pueden formar receptores homoméricos funcionales como también en combinación con KA1-2 conformando ya receptores heteroméricos con diferentes propiedades (Bleakman y cols., 2002; Alt y cols., 2004; Kew y Kemp, 2005). 
Cada uno de los iGluRs puede activar canales selectivos a un ión-catión permeables a $\mathrm{Na}^{+}$y $\mathrm{K}^{+}$, con diferentes grados de permeabilidad e impedir la permeabilidad a los cationes divalentes $\mathrm{Mg}^{2+}$ y $\mathrm{Ca}^{2+}$ (Mayer y Westbrook, 1987; Arundine y Tymianski, 2003; Mayer y Armstrong, 2004).

Entre las subunidades de los rAMPA se conoce que es la GluR2 la que controla importantes propiedades del receptor como son la permeabilidad al $\mathrm{Ca}^{2+}$, la conductancia del canal y su rectificación (Burnashev y cols., 1992; Bowie y Mayer, 1995; Kamboj y cols., 1995; Duprat y cols., 2003). En condiciones fisiológicas, GluR2 es expresado ampliamente en el Sistema Nervioso Central, y la mayoría de los rAMPA que contienen o expresan GluR2, exhiben poca permeabilidad al $\mathrm{Ca}^{2+} \mathrm{o}$ a cualquier otro catión divalente (Arundine y Tymianski, 2003). Experimentos en ratones que no contienen el gen para GluR2 revelan que a pesar del incremento en el influjo del $\mathrm{Ca}^{2+}$ en neuronas $\mathrm{CA} 1$, éstas no exhiben lesiones neuropatológicas que sugieran excitotoxicidad (Jia y cols., 1996; Arundine y Tymianski, 2003), planteando que la permeabilidad al $\mathrm{Ca}^{2+}$ por sí misma no es un determinante único de vulnerabilidad neurotóxica. Además se sabe, que el Calcio es un importante mensajero intracelular que gobierna funciones celulares como la diferenciación y el crecimiento celular, la excitabilidad de la membrana, la exocitosis y la actividad sináptica (Arundine y Tymianski, 2003). Por lo tanto, el mantenimiento de los niveles intracelulares debe mantenerse mediante mecanismos bien ajustados, ya que es bien conocido que un mal funcionamiento o una sobrecarga del sistema que regula la homeostasis del calcio resulta en una rápida neurodegeneración (Choi, 1988; Siesjö y Bengtsson, 1989; Lukas y Jones, 1994).

Los rNMDA presentan una alta permeabilidad al $\mathrm{Ca}^{2+}$ (Mayer y cols., 1984; Mayer y Westbrook, 1987; Ascher y Nowak, 1988; Burnashev y cols., 1995; CullCandy y cols., 2001). Cuatro combinaciones diferentes de sus subunidades confieren al receptor alta permeabilidad al $\mathrm{Ca}^{2+}$ y muestran diferencias claras en la sensibilidad al bloqueo del $\mathrm{Mg}^{2+}$ (Monyer y cols., 1994). Por tanto, la permeabilidad depende de la configuración con la subunidad NR1 de los receptores y cada uno de los 4 tipos de subunidades NR2 (A-D). Además, cuando un receptor contiene la combinación de $\mathrm{NR}_{1} / \mathrm{NR}_{2}$ más $\mathrm{NR}_{3}$, esta última subunidad también puede suprimir la conductancia unitaria del canal y la relativa permeabilidad al $\mathrm{Ca}^{2+}$ de los receptores que contienen la combinación NR1/NR2 (Ciabarra y cols., 1995; Nishi y cols., 2001; Matsuda y cols., 2002; Sasaki y cols., 2002; Kew y Armstrong., 2005).

En los rKA solo las subunidades GluK5 y GluK6 pueden editar su RNAm para que cambie un aminoácido en el poro del canal y regule las propiedades de permeabilidad (Sommer y cols., 1991; Huettner, 2003). Estas dos subunidades, al igual que la AMPA-GluR2, codifican en su secuencia genómica una glutamina residual en el sitio de edición del $p$-loop que es convertido por una edición en un código para arginina (Sommer y cols., 1991). Editando este sitio Q/R se 
determina la conductancia y la permeabilidad al calcio de los canales. Los receptores no editados completamente exhiben una relativa alta permeabilidad al calcio (Egebjerg y Heinemann, 1993; Burnashev y cols., 1995, 1996) y una alta conductancia unitaria (Howe, 1996; Swanson y cols., 1996) cuando se comparan con receptores que incluyen una o más subunidades editadas.

En la actualidad, los iGluRs son objeto de numerosos estudios, en los cuales, se les relaciona directamente con la plasticidad neuronal, principalmente con fenómenos de plasticidad homeostática- synaptic scaling (Turrigiano, 1999; Brewer y cols., 2009; Gainey y cols., 2009) y fenómenos de plasticidad Hebbiana, como son la LTP (Frey y cols., 2009; Wang y cols., 2009) y la LTD (Toyoda y cols., 2007; Griffiths y cols., 2008).

Los mecanismos de mayor expresión del synaptic scaling son exactamente los cambios postsinápticos en la acumulación de los receptores glutamatérgicos, tanto los del tipo AMPA (Lissin y cols., 1998; O'Brien y cols., 1998; Turrigiano y cols., 1998; Wierenga y cols., 2005; Shepherd y cols., 2006; Stellwagen y Malenka, 2006), como los de tipo NMDA (Mu y cols., 2003; Rao y Craig, 1997; Watt y cols., 2000). Además de la acumulación y el tráfico de estas subunidades/receptores que modulan los procesos de plasticidad sináptica, la plasticidad homeostática también es un fenómeno Calcio-dependiente, y bien es conocido que los iGluRs, principalmente los NMDA y los AMPA (GluR2), modulan parte de la entrada de $\mathrm{Ca}^{2+} \mathrm{y}$, por consiguiente, las variaciones intracelulares de este ión (v.s.).

Existen múltiples evidencias que indican que las lesiones corticales provocan alteraciones en la biosíntesis y las expresión de las subunidades de los iGluRs en los núcleos dianas subcorticales y que estos cambios se producen a lo largo de ventanas temporales largas tras lesión. De este modo Wüllner y cols., (1994), comprobaron que la ablación unilateral de la corteza frontal resulta en la alteración de los genes que codifican las subunidades de los iGluRs: AMPA (GluR1-4) y NMDA (NMDA1 y NMDA2A-B en la neuronas del estriado dorsolateral. Estos autores observaron 3 días postlesión ( $\mathrm{pl}$ ) una leve disminución, y a los 15 y 60 días pl un marcado aumento en la expresión de las subunidades de los iGluRs. Kayadjanian y cols., (1996), tras lesión bilateral de la corteza sensorimotora (CSM) y mediante técnicas de hibridación in situ constataron un aumento en los niveles de rNMDAA2B mRNA, 3 semanas pl, en el área del estriado que es diana de la proyección CSM. Del mismo modo Qü y cols., (1998) tras lesión por isquemia de parte de la corteza motora y somatosensorial primaria y secundaria observaron una disminución en los sitios de captación para los radioligandos $\left[{ }^{3} \mathrm{H}\right] \mathrm{AMPA}$ y $\left[{ }^{3} \mathrm{H}\right]$ Kainato en los núcleos talámicos ventroposterior medial y lateral del lado contralateral a la zona de lesión, con respecto al lado ipsilateral. Tarazi y cols., (1999) reportaron en rata, tras ablación unilateral de la corteza frontal un descenso en los núcleos caudado-putamen y accumbens en el binding de los rNMDA del $20 \%$ y $16 \%$ 
respectivamente. Finalmente Kopniczky y cols., (2005) tras análisis por inmunohistoquímica mostraron que lesiones en la corteza entorrinal producían en el hipocampo cambios en la expresión de los iGluRs 40 días pl, así como para los rNMDA y los rKA.

Diversos autores han observado modificaciones en la expresión de los iGluRs en el Cl tras ablación coclear (Suneja y cols., 2000; Holt y cols., 2005). Suneja y cols., 2000 tras lesión unilateral coclear en cobayos observaron en el $\mathrm{NCCl}$ y en la $\mathrm{CDCl}$ que los lugares unión (binding sites) para los rAMPA (GluR2-3) disminuían en períodos cortos pl (2-31 días) y luego aumentaban a los 60 días pl. A los 147 días pl observaron con la técnica de binding que los valores retornaban a los niveles controles. Para la CECI los valores de estas subunidades permanecieron cerca de los niveles controles, excepto a los 147 días pl, donde se observó un descenso del 10\%. Estos autores atribuyen estas oscilaciones a que la población intracelular de los rAMPA podría estar alterada por mecanismos que regulan tanto la biosíntesis como la actividad de los mismos. También consideran que el número y/o actividad de los rAMPA depende de la actividad del nervio, en este caso abolida por la ablación coclear, y que estos cambios eran transitorios, pues se recuperaron hasta alcanzar los niveles de los controles. Holt y cols., (2005), tras lesión bilateral de la cóclea en ratas, y utilizando dispositivos de análisis genómico (MicroArrays de DNA) observaron una gran cantidad de genes que cambiaron entre los 3 y los 21 días pl. Utilizando qRT-PCR encontraron en todos los grupos postlesión ( 3,21 y 90 días) un aumento en los niveles de expresión con respecto al control para las subunidades AMPA: GluR2 y GluR3 y para la Kainato K2, aunque en todos los casos los niveles de expresión fueron menores para los 90 días que para los 3 y 21 días. Realizaron además pruebas de inmunomarcaje para GluR2/3 y solo encontraron un modesto incremento a los go días pl.

En resumen, podemos concluir que existe abundante información que nos indica que los cambios en la síntesis o el tráfico de los iGluRs en el $\mathrm{Cl}$ tras deaferentación o lesión de la vía auditiva son un buen indicador para conocer la evolución de sus cambios adaptativos.

\section{Plasticidad Neuronal y cambios postlesionales en el Colículo Inferior.}

Actualmente, la palabra Plasticidad sin adjetivo que la acompañe es un término ambiguo con múltiples acepciones, que es aplicable para analizar y comprender diversos paradigmas experimentales en Neurociencia (Calford, 2002). Se define en general, como la capacidad intrínseca del sistema nervioso de variar de manera activa o dinámica su estructura, organización y/ó función, en respuesta a circunstancias cambiantes, tales como las derivadas del desarrollo o maduración de los circuitos, así como de sus enfermedades, traumatismos, o simplemente por cambios en la actividad neuronal (Arbuthnott y cols., 2000). En cuanto a las raíces históricas, y a la evolución del concepto de 
Plasticidad Neuronal, se conoce que William James planteó la utilización de este término en 1890, y definió este fenómeno como los cambios en las vías nerviosas asociadas con el establecimiento de hábitos. Cercano a esta época, Eugenio Tanzi (1893) propuso las articulaciones entre las neuronas como posible origen de la plasticidad neuronal. Ernesto Lugaro (1898, 1906, 1909), fue el primero en relacionar la plasticidad neuronal con la plasticidad sináptica y Santiago Ramón y Cajal (1894 a,b), el encargado de establecer que la plasticidad es el resultado de la formación de nuevas conexiones entre neuronas, además de postular que la capacidad plástica de las células tiende a variar en diferentes períodos de vida, siendo muy evidente en el desarrollo y juventud, y menos en la madurez, hasta desaparecer casi completamente en la vejez.

Se conoce, que la capacidad de reorganización del cerebro adulto es menor que la de los cerebros en desarrollo. Sin embargo, dentro de la corteza cerebral, al menos para algunos sistemas (cortezas primarias sensoriales), se mantiene una dinámica de cambios tras estímulo que es alta, incluso en la madurez (Hess, 2004). Concretamente, en el sistema auditivo, se han demostrado cambios plásticos en animales adultos tras la utilización de numerosos paradigmas experimentales (principalmente referidos al análisis espectral -frequency tunning- y la tonotopía -tonotopicity-) en diferentes estaciones de la vía auditiva (Irvine y cols., 2006; Keuroghlian y Knudsen, 2007). Esta Plasticidad, en el SNC de los mamíferos maduros, es a menudo inducida por alteraciones en la actividad neuronal. Esta respuesta llamada "plasticidad dependiente de actividad" puede involucrar cambios en los neurotransmisores y en los receptores postsinápticos, que a su vez modifiquen las respuestas neuronales y el procesamiento de la información en los sistemas auditivos (Holt y cols., 2005).

Los mecanismos celulares que están envueltos en los fenómenos de plasticidad cerebral, han sido descritos principalmente en modelos animales. Algunos de estos corresponden a modificaciones funcionales en los circuitos cerebrales (unmasking, existing synapsis, releasing inhibition) y otros corresponden a la creación de nuevas conexiones en las redes neuronales (synapse sprouting) (Bach-y-Rita, 1988; Cotman y Nieto-San Pedro, 1985; Finger y Stein, 1982; Vital-Durand y Jeannerod, 1975). Conviene recalcar, que algunas modificaciones en la actividad neuronal tras estímulos o tras lesiones, no deben considerarse incluidas en el término de plasticidad, principalmente cuando se trata de un efecto pasivo producto solamente de la deprivación o alteración funcional (Irvine y cols., 2006). En este sentido, el carácter dinámico de los cambios morfológicos o funcionales del sistema nervioso tras influjo externo, es una cualidad imprescindible para el concepto de plasticidad.

Un planteamiento novedoso e interesante, es que el sistema nervioso está sujeto a dos requerimientos totalmente opuestos: La necesidad de cambiar y la necesidad de estabilizarse (Turrigiano, 1999). Específicamente, los procesos activos que mantienen el ambiente interno del cuerpo, cercano a cierto nivel de 
estabilidad (set point level), es lo que se conoce en biología como Homeostasis. Estos fenómenos homeostáticos, aparecen como respuesta a cambios en el ambiente intracelular o extracelular, y buscan a través de cambios en diversos parámetros fisiológicos, recuperar el equilibrio de una forma dinámica y multiparamétrica, con el fin de mantener una fisiología constante del sistema. En la actualidad, se ha aplicado este concepto general a los modos de ajuste de la actividad neuronal en el sistema nervioso. En este sentido se ha desarrollado mucho la idea de la tendencia al equilibrio en diversos aspectos de la función de neuronas en redes, y se ha puesto en relación con el concepto de plasticidad Hebbiana. De este modo, podría afirmarse, que estos dos mecanismos: la plasticidad Hebbiana y la plasticidad Homeostática, actúan de forma opuesta, ya que la primera es considerada como un fenómeno de retroalimentación positiva, es decir su objetivo es que las neuronas respondan de una forma determinada (excitación o inhibición) de manera indefinida, mientras que la segunda, es considerada un mecanismo de retroalimentación negativa, porque fija un nivel de actividad (set point level) que debe ser alcanzado a través de cambios compensatorios (Turrigiano, 1999, 2007; Turrigiano y Nelson, 2000; Rabinowitch y Segev, 2008). Desarrollaremos y aclararemos seguidamente este concepto.

La plasticidad Hebbiana se basa en el postulado de Hebb (1949), que propone, que cuando una neurona toma parte repetidamente en la activación de otra neurona, la eficacia de las conexiones entre ambas se incrementa. La plasticidad Hebbiana, en la forma de potenciación (long-term potentiation LTP) y depresión a largo plazo (long-term depression LTD), provee algunas bases importantes para los modelos de memoria y aprendizaje (Abbot y Nelson, 2000). Actuando independientemente en cada sinápsis, la plasticidad Hebbiana es muy potente, pero también genera problemas de estabilidad (Miller, 1996). Así, se conoce que sus procesos de retroalimentación-positiva, influencian a las neuronas haciendo las sinapsis que son efectivas aún más efectivas, y a las menos efectivas aún más débiles. En conjunto, estos fenómenos, que son la base de la plasticidad Hebbiana, tienden a desestabilizar la velocidad de disparo postsináptico reduciéndola a cero o incrementándola excesivamente (Abbott y Nelson, 2000; van Rossum y Turrigiano, 2000). La actividad generada por los fenómenos de LTP y LTD está regulada, a la vez, por mecanismos de control homeostáticos destinados a mantener una actividad neuronal dentro de rangos fisiológicos (Bliem y cols., 2008). En estas mismas neuronas, se pueden producir simultáneamente los mecanismos hebbianos y los fenómenos de plasticidad homeostática, que son mucho más lentos, pero más perdurables en el tiempo (Rabinowitch y Segev, 2006, 2008; Wu y Mel, 2009).

Uno de los mecanismos reguladores propuestos para entender los fenómenos de plasticidad homeostática, son la variación del número de sinápsis, o los cambios en la eficacia de las mismas (strenght). Es por lo tanto, en el fondo, un fenómeno basado en la activación de procesos regulatorios que utilizan las 
neuronas para equilibrar la fuerza sináptica (regulación de síntesis y transporte de vesículas y neurotransmisores, ritmo de liberación, receptores postsinápticos, etc.) y la excitabilidad intrínseca de la membrana (canales voltaje-dependientes y demás elementos implicados en el mantenimiento de las propiedades bioeléctricas). Estos mecanismos se sitúan dentro de un rango operacional óptimo (set-point level), en orden de modular la eficacia de la integración dendrítica (Turrigiano, 1999). De esta forma, las neuronas pueden medir los cambios en su propia velocidad de disparo, y escalar globalmente el peso sináptico al incremento o al descenso de la actividad de las redes neuronales (Turrigiano y Nelson, 2004).

Se sabe además, que el mantenimiento homeostático depende del balance entre la inhibición y la excitación, y por lo tanto, los cambios en este balance, pueden tener un gran impacto en el refinamiento de las respuestas neuronales y la función de los circuitos sensoriales dependientes de actividad (Maffei y cols., 2004). Esta forma de plasticidad se vincula en gran medida a las propiedades de membrana y de disparo neuronal (Marder y Prinz, 2003; Zhang y Linden, 2003). Así, su éxito depende, de poder implementar cambios en: la eficacia sináptica (synaptic scaling) (Turrigiano y Nelson., 2004; Davis, 2006), en el número de sinápsis y dendritas (Kirov y Harris, 1999; Wieringa y cols., 2006); en la expresión de receptores excitatorios- AMPA y NMDA, e inhibitorios- GABA (quantal scaling) (Watt y cols., 2000; Turrigiano y Nelson, 2004; Franks e Isaacson, 2005; Pérez-Otaño y cols., 2005); en la cantidad de neurotransmisor liberado por las vesículas (Murthy y cols., 2001); en la sensibilidad postsináptica al neurotransmisor (Turrigiano y Nelson, 1998; O'Brien y cols., 1998; Davis y Bezprozvanny, 2001) y en la conductancia de la membrana a través de cambios en los canales voltaje-dependientes (Davis y Bezprozvanny, 2001).

Para mantener los niveles de actividad eléctrica dentro de los rangos óptimos (set point level), la neurona utiliza monitores o sensores de actividad, uno de los más importantes es la señalización $\mathrm{Ca}^{2+}$-dependiente. LeMasson y cols., (1993) crearon un modelo neuronal en el que la máxima conductancia de los canales iónicos, dependía de las concentraciones intracelulares de este ión. Cuando se llevó este modelo a la máxima conductancia dependiente de actividad, el modelo se comportó variando su conductancia para mantener el rango de actividad tras la perturbación. Para activar procesos de homeostáticos, las neuronas tienen la capacidad de crecer, cambiar de forma y variar el número de sinápsis establecidas, lo que implica un constante recambio de canales iónicos que determinan propiedades eléctricas de disparo de novo de las neuronas (Turrigiano, 1999). Estas propiedades de disparo de las neuronas, dependen a la vez de señales intracelulares como la concentración de Calcio (v.s.). Así, cuando la concentración de $\mathrm{Ca}^{2+}$ disminuye, la conductancia se modifica para incrementar el disparo, aumentando de este modo los niveles de este ión. Al contrario, cuando la actividad es alta, y los niveles de $\mathrm{Ca}^{2+}$ están elevados, la conductancia se modifica para disminuir la actividad neuronal y 
Low activity

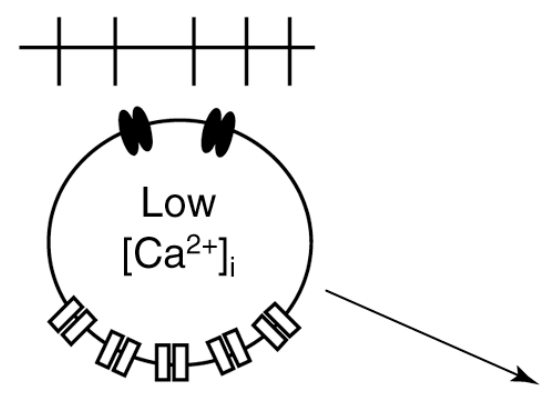

M Inward-current channel

प0u Outward-current channel
High activity

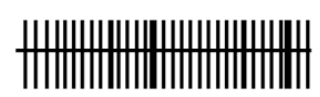

Target activity
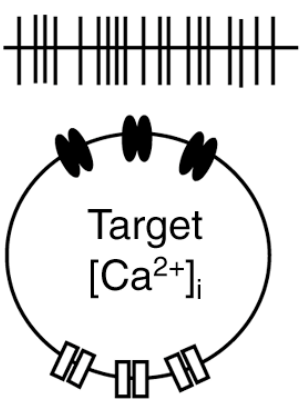

FIGURA 3. Modificación del balance de corrientes de entrada y salida dependiente de actividad.

Diagrama en el que se muestra que la concentración intracelular de Calcio puede regular el balance de las corrientes (inward y outward) generadas por una neuronas, para mantenerlo dentro de un rango específico. Durante períodos de baja actividad (figura de la izquierda) caen las concentraciones de este ión, y se producen cambios compensatorios para incrementar las corrientes de entrada y disminuir las de salida, lo que aumenta la excitabilidad de la neurona, elevando su disparo y llevando a la neurona nuevamente (figura central) a unas concentraciones óptimas de calcio intracelular. Por el contrario, si la actividad es muy alta y las concentraciones de calcio excenden el rango óptimo, las corrientes de entrada decrecen y se aumentan las de salida (figura derecha), produciendo un descenso en la excitabilidad de la neurona y ésta vuelve a los rangos óptimos de calcio para el funcionamiento (figura central). Tomado de Turrigiano, 1999. 
permitir que bombas y canales reequilibren la concentración de este ión (Figura 3). Estos fenómenos compensatorios durante los procesos de synaptic scaling, se basan en la capacidad de las neuronas de detectar sus propios cambios en el disparo a través de sensores $\mathrm{Ca}^{2+}$-dependientes (Thiagarajan y Lindskog, 2005; Ibata y cols., 2008). Los sensores mediante rutas de señalización específicas, actúan sobre la biosíntesis de proteínas para regular el tráfico de receptores, con el fin de aumentar o disminuir su cantidad en las regiones post-sinápticos. Estos cambios dinámicos controlan el retorno de las neuronas a niveles eficientes de actividad- set point level (Turrigiano, 2008), creándose por tanto, un mecanismo automático de retroalimentación $\mathrm{Ca}^{2+}$ - actividad - biosíntesis y ensamblado de proteínas de membrana, que conlleven a su vez a la estabilización de la descarga. En resumen, podríamos decir que mediante estos mecanismos, los fenómenos de plasticidad homeostática permiten a los circuitos neuronales estabilizar la función a pesar de fluctuaciones en sus aferencias (Deeg, 2009).

Aunque se sabe que la capacidad de remodelación de la corteza cerebral es muy alta, se conoce que esta propiedad no se restringe únicamente a esta parte del SNC (Toga y Mazziotta, 2002). Específicamente, dentro del sistema auditivo, diversos estudios han demostrado que tras estimulación eléctrica o inactivación de las cortezas, se producen cambios en las respuestas electrofisiológicas de las neuronas auditivas corticales y subcorticales, debidos a la alteración de la modulación corticofugal (Suga, 2008). Sin embargo, son pocos los estudios sobre los cambios metabólicos, genéticos o estructurales del efecto de la deprivación corticofuga sobre el $\mathrm{Cl}$.

Se conoce que, tras ablación coclear, el balance entre la inhibición y la excitación en la respuesta de las neuronas del $\mathrm{Cl}$ se ve alterado (Holt y cols., 2005). Podríamos concluir, que existen datos suficientes para determinar que este disbalance en el $\mathrm{Cl}$, produce variaciones en la synaptic strenght, inhibitory strength y en las respuestas evocadas (Bledsoe y cols., 1995; Wang y cols., 1996; Mossop y cols., 2000; Vale y Sanes, 2002), asociados con cambios en los aminoácidos excitatorios e inhibitorios y en sus receptores. En este sentido, se han descrito modificaciones sustanciales en la producción (Raza y cols., 1994; Milbrandt y cols., 2000; Mossop y cols., 2000), en el lanzamiento de GABA (Bledsoe y cols., 1995; Caspary y cols., 1995), y en sus receptores postsinápticos (Caspary y cols., 1995; Milbrandt y cols., 2000; Vale y Sanes, 2000). Por otra parte, el mantenimiento de este balance entre señales excitatorias/inhibitorias en las neuronas coliculares es también importante para la codificación de las propiedades del sonido en el sistema auditivo (Moore, 1991; Kelly y Zhang 2002; Pollak y cols., 2002). Se conoce además, que en el $\mathrm{Cl}$, la ablación funcional de la corteza auditiva produce un disbalance de excitación/inhibición que resulta en la alteración de la amplitud y la latencia de las respuestas neuronales (NwabuezeOgbo y cols., 2002; Popelar y cols., 2003). 
En Ratas adultas, tras lesiones de la corteza auditiva, ha sido demostrado procesos de recuperación funcional a largo plazo en el Cl (Druga y Syka, 2001; Bowen y cols., 2003; Rybalko y cols., 2006; Clarkson y cols., 2009). En este sentido, Druga y Syka (2001), tras ablación unilateral de la CA observaron una disminución en la tinción para NADPH-diaforasa en las neuronas y en el neuropilo de las cortezas del $\mathrm{Cl}$. Estos autores indicaron que sus resultados se podrían relacionar con la abolición de la influencia glutamatérgica corticocolicular y de las vías comisurales, sugiriendo que el descenso de esta enzima perteneciente a la ruta del óxido nítrico, se debe a cambios adaptativos en los circuitos del $\mathrm{Cl}$. Por otra parte, la potencial reparación de estos circuitos de la Pcc ha sido puesta en evidencia por Bowen y cols., (2003) que comprobaron que tras lesión cortical bilateral, se produce una recuperación espontánea de la respuesta de las neuronas del $\mathrm{Cl}$ (temporal acuity, thresholds and gap detection) tras dos meses postlesión, y sugieren que estos cambios pueden ser producto del desequilibrio en la influencia de la Pcc sobre la actividad del Cl. Rybalko y cols., (2006) señalaron tras ablaciones unilaterales o bilaterales de la CA un déficit en la habilidad para discriminar entre estímulos de frecuencia modulada, habilidad que se recuperaba con el entrenamiento. Clarkson y cols., (2009) describen tras ablación cortical auditiva unilateral, una disminución marcada en las respuestas de los Auditory Brainstem Responses y del Reflejo Auditivo del Sobresalto/Inhibición por estímulo previo, a los 15 días pl y una recuperación parcial de esta respuesta a los 90 días pl.

En resumen existen estudios previos que permiten considerar que la ablación de la corteza cerebral auditiva induce cambios lesionales y reparación en los diferentes núcleos de la vía y más en particular en el $\mathrm{Cl}$. Este núcleo es una estación de relevo obligatoria para las vías auditivas ascendentes y descendentes y es además, un lugar de convergencia de proyecciones. Siguiendo los postulados de la adaptación homeostática (v.s.), la inducción de un desequilibrio en el balance de excitación e inhibición en este núcleo producido por la pérdida parcial de la Pcc ocasionará la inactivación funcional de la vía auditiva de manera temporal. Así, la tendencia a la compensación postlesional en el $\mathrm{Cl}$, produce en el tiempo variaciones en los receptores postsinápticos de glutamato y en las proteínas asociadas con en el calcio que reflejan el reajuste homeostático del sistema. 
HIPÓTESIS Y OBJETIVOS 


\section{Hipótesis de trabajo}

Es conocida la existencia de una fuerte proyección glutamatérgica directa desde la Corteza Cerebral Auditiva al Colículo Inferior. La pérdida de una parte de la misma, produce cambios funcionales en este núcleo inducidos, entre otros posibles fenómenos, por la alteración de los receptores de glutamato. Los cambios tras deaferentación, de los receptores ionotrópicos de glutamato inducen alteraciones en el balance de calcio de las células afectadas que activan proteínas tamponadoras y rutas de señalización que regulan la síntesis y el tráfico de los mismos. Los cambios postlesionales pueden ser reversibles al mantenerse intacta una parte de la proyección Cortico-Colicular.

\section{Objetivos}

- Valorar el efecto y la reversibilidad de una lesión parcial de la proyección Cortico-Colicular en la actividad del colículo inferior.

- Conocer el estado de la regulación de los receptores ionotrópicos de glutamato en el Colículo Inferior tras la ablación parcial de la Corteza Auditiva y su evolución en el tiempo

- Analizar los cambios en la regulación del calcio intracelular mediante el estudio de las proteínas ligadoras de calcio (Calretinina). De producirse cambios, valorar la evolución temporal de la regulación de esta proteína ligadora de calcio en las neuronas del Colículo Inferior. 
MATERIALES Y MÉTODOS 


\section{Grupos experimentales.}

Para comprobar los cambios producidos tras deaferentación unilateral de la proyección corticocolicular, utilizamos en esta investigación, 115 ratas Wistar, macho (grupos controles y experimentales), con un peso inicial entre 220 y 260 g, y de 12 a 14 semanas de edad (Tabla $N^{\circ} 1$ ), suministradas porel Servicio de Experimentación Animal de la Universidad de Salamanca. El mantenimiento de los animales durante su tiempo de supervivencia y la ejecución de cada uno de los procedimientos quirúrgicos necesarios para el estudio, se llevaron a cabo de acuerdo a las normas para la regulación y protección de los animales usados para propósitos científicos (DOCE L 222; 24-08-1999) y a las guías establecidas por el Comité de Cuidado Animal de la Universidad de Salamanca.

Tabla No 1. Grupos experimentales $(n=115)$

\begin{tabular}{|c|c|c|c|c|c|}
\hline Grupo & $n=$ & $\begin{array}{c}\text { Zona de } \\
\text { Lesión/inyección }\end{array}$ & $\begin{array}{c}\text { Super- } \\
\text { vivencia pl }\end{array}$ & Metodología/Técnicas & Método de análisis \\
\hline 1 & 2 & $\begin{array}{c}\text { lesión CA-izq } \\
\text { Inyección CA-der }\end{array}$ & 15 días & $\begin{array}{l}\text { - InmhistoQ-SMl32 } \\
\text { - tinción Nissl }\end{array}$ & $\begin{array}{l}\text { patrones citoarqui- } \\
\text { artecturales de las CAs }\end{array}$ \\
\hline 2 & 4 & Control & ----- & ABRs & $\begin{array}{l}\text { Registro longitudinal: } \\
15 \text { y } 90 \text { días pl }\end{array}$ \\
\hline 3 & 4 & lesión CA -izq & 90 días & ABRs & $\begin{array}{l}\text { Registro longitudinal: } \\
15 \text { y } 90 \text { días } \mathrm{pl}\end{array}$ \\
\hline 4 & 10 & Control & ----- & RAS/IPP & $\begin{array}{l}\text { Registro longitudinal: } \\
15,90,180 \text { y } 240 \text { días } \\
\text { pl. }\end{array}$ \\
\hline 5 & 10 & lesión CA -izq & 240 días & RAS/IPP & $\begin{array}{l}\text { Registro longitudinal: } \\
15,90,180 \text { y } 240 \text { días } \\
\text { pl. }\end{array}$ \\
\hline 6 & 3 & $\begin{array}{c}\text { Controllnmhisto } \\
\text { Q }\end{array}$ & ---- & $\begin{array}{l}\text { InmhistoQ-c-Fos, } \\
\text { diferentes } \\
\text { anticuerpos }\end{array}$ & $\begin{array}{l}\text { Análisis visual del } \\
\text { marcaje }\end{array}$ \\
\hline 7 & 3 & $\begin{array}{c}\text { Control- } \\
\text { sobreEstimulado }\end{array}$ & ---- & $\begin{array}{ll}\text { - } & \text { Estimulación } \\
\text { auditiva } \\
\text { - } \\
\text { InmhistoQ-c-Fos }\end{array}$ & $\begin{array}{l}\text { - } \quad \text { Estereología } \\
\text { - } \quad \text { densitometría: } \\
\text { nivel gris/perímetro }\end{array}$ \\
\hline 8 & 3 & lesión CA -izq & 15 días & $\begin{array}{ll}\text { - } & \text { Estimulación } \\
\text { auditiva } \\
\text { - InmhistoQ-c-Fos }\end{array}$ & $\begin{array}{l}\text { - } \quad \text { Estereología } \\
\text { - densitometría: } \\
\text { nivel gris/perímetro }\end{array}$ \\
\hline 9 & 3 & lesión CA -izq & 90 días & $\begin{array}{ll}\text { - } & \text { Estimulación } \\
\text { auditiva } \\
\text { - } \\
\text { InmhistoQ-c-Fos }\end{array}$ & $\begin{array}{l}\text { - } \quad \text { Estereología } \\
\text { - } \quad \text { densitometría: } \\
\text { nivel gris/perímetro }\end{array}$ \\
\hline 10 & 4 & Control & ---- & $\begin{array}{l}\text { InmhistoQ- } \\
\text { Calretinina }\end{array}$ & Estereología \\
\hline 11 & 4 & lesión CA -izq & 15 días & $\begin{array}{l}\text { InmhistoQ - } \\
\text { Calretinina }\end{array}$ & Estereología \\
\hline
\end{tabular}




\begin{tabular}{|c|c|c|c|c|c|}
\hline Grupo & $n=$ & $\begin{array}{l}\text { Zona de } \\
\text { Lesión/inyección }\end{array}$ & $\begin{array}{l}\text { Super- } \\
\text { vivencia pl }\end{array}$ & Metodología/Técnicas & Método de análisis \\
\hline 12 & 4 & lesión CA -izq & 90 días & $\begin{array}{l}\text { InmhistoQ- } \\
\text { Calretinina }\end{array}$ & Estereología \\
\hline 13 & 4 & lesión CA -izq & 180 días & $\begin{array}{l}\text { InmhistoQ- } \\
\text { Calretinina }\end{array}$ & Estereología \\
\hline 14 & 4 & lesión CA -izq & 240 días & $\begin{array}{l}\text { InmhistoQ- } \\
\text { Calretinina }\end{array}$ & Estereología \\
\hline 15 & 6 & $\begin{array}{l}\text { Control: Lesión } \\
\text { corteza Motora y } \\
\text { Somatosensorial }\end{array}$ & 15 días & $\begin{array}{ll}\text { - } & \text { RAS/IPP } \\
\text { - } & \text { SqRT-PCR }\end{array}$ & $\begin{array}{l}\text { - } \quad \text { Registro } 15 \text { días } \\
\text { - } \quad \text { Semicuantificación }\end{array}$ \\
\hline 16 & 6 & Control & ---- & SqRT-PCR & Semicuantificación \\
\hline 17 & 6 & lesión CA -izq & 15 días & SqRT-PCR & Semicuantificación \\
\hline 18 & 6 & lesión CA - izq & 90 días & SqRT-PCR & Semicuantificación \\
\hline 19 & 6 & lesión CA -izq & 180 días & SqRT-PCR & Semicuantificación \\
\hline 20 & 6 & Control & --- & qPCR & $\begin{array}{l}\text { - } \quad \text { Cuantificación } \\
\text { - t-Student }\end{array}$ \\
\hline 21 & 6 & lesión CA -izq & 15 días & qPCR & $\begin{array}{l}\text { - } \quad \text { Cuantificación } \\
\text { - t-Student }\end{array}$ \\
\hline 22 & 6 & lesión CA -izq & 90 días & $\mathrm{qPCR}$ & $\begin{array}{l}\text { - Cuantificación } \\
\text { - t-Student }\end{array}$ \\
\hline 23 & 6 & lesión CA -izq & 180 días & qPCR & $\begin{array}{l}\text { - Cuantificación } \\
\text { - t-Student }\end{array}$ \\
\hline 24 & 3 & Control & --- & MicroArrays & Análisis estadístico \\
\hline 25 & 3 & lesión CA-izq & 15 días & MicroArrays & Análisis estadístico \\
\hline 26 & 3 & lesión CA-izq & 90 días & MicroArrays & Análisis estadístico \\
\hline
\end{tabular}

ABRs Respuestas Auditivas del Tronco-Encefálico

CA Corteza Auditiva

InmnohistoQ inmunohistoquímica

pl postlesión

qPCR Reacción en Cadena de la Polimerasa-cuantitativa o real time

RAS/IPP Reflejo Auditivo del Sobresalto/Inhibición por estímulo previo

SqRT-PCRTranscripción Reversa- Reacción en Cadena de la Polimerasa semicuantitativa 


\section{Procedimientos Quirúrgicos.}

Lesión de las Cortezas Auditivas (Áreas primaria y secundarias).

Los animales de los grupos lesionados fueron deprivados de alimentos en las 8 horas previas a la cirugía y, a continuación, se anestesiaron profundamente (vía intramuscular) con una mezcla de clorhidrato de Ketamina $(30 \mathrm{mg} / \mathrm{Kg}$, Imalgene ${ }^{\circledR}$ 1000, Rhone Méreuse, Lyon, Francia) y clorhidrato de Xilacina (5 $\mathrm{mg} / \mathrm{Kg}$ Rompún ${ }^{\circledR}$, Bayer, Leverkusen, Alemania). Los animales se colocaron sobre una manta térmica con el fin de mantener una temperatura corporal constante y se comprobó su arreflexia tras la anestesia. A continuación, se fijaron en el aparato estereotáxico para animales pequeños (\#9oo, David Kopf Ins., Tujinga, CA, EEUU), manteniendo la posición cráneo plano flat-skull (Paxinos y Watson, 2005), con el fin de situar los puntos bregma y lambda en el mismo plano coronal y obtener así un punto cráneo-métrico de referencia para localizar las coordenadas estereotáxicas.

Como siguiente paso se realizó una desinfección del campo quirúrgico con povidona yodada, en donde se expuso la superficie craneal a través de una incisión en la línea media. Se procedió a retirar el tejido fibroso subyacente y a desinsertar parte de los músculos temporales y masticatorios del lado izquierdo. A continuación, y utilizando un micromanipulador estereotáxico (SM 11, Narishige, Tokio, Japón) se corroboró la posición de cráneo plano (Paxinos y Watson, 2005) en cada uno de los animales fijados, buscando la concordancia entre el punto cero de la punta de la micropipeta (ajustada al micromanipulador), con el punto Lambda- referencia cráneo-métrica, cero interaural, utilizada para la localización de las coordenadas estereotáxicas (Figura 4).

Con la guía del micromanipulador, se marcaron en la superficie del hueso temporal, 6 coordenadas estereotáxicas: 3 anteroposteriores y 3 laterales (Paxinos and Watson, 2005) (Figura 4), que delimitaron un rectángulo guía para la apertura de una ventana ósea (eje dorso-ventral: $3 \mathrm{~mm}$ y eje rostro-caudal: $2 \mathrm{~mm}$ ). A continuación, las meninges fueron seccionadas y se procedió a la aspiración suave y controlada de las cortezas auditivas, irrigando todo el proceso quirúrgico con solución salina fría. Tras la aspiración, se colocó en la zona lesionada un hemostático absorbible y se posicionó nuevamente el rectángulo óseo que cubría la zona. Para finalizar, se unieron los bordes de la incisión en el escalpo con grapas quirúrgicas y se colocó sobre la herida un microbicida antiséptico.

El proceso de recuperación postquirúrgico de los animales fue monitorizado constantemente, colocándolos cerca de una fuente de calor y consintiéndoles el libre acceso a comida y agua. Durante todo el tiempo de supervivencia de los animales se comprobó periódicamente su estado de salud y 

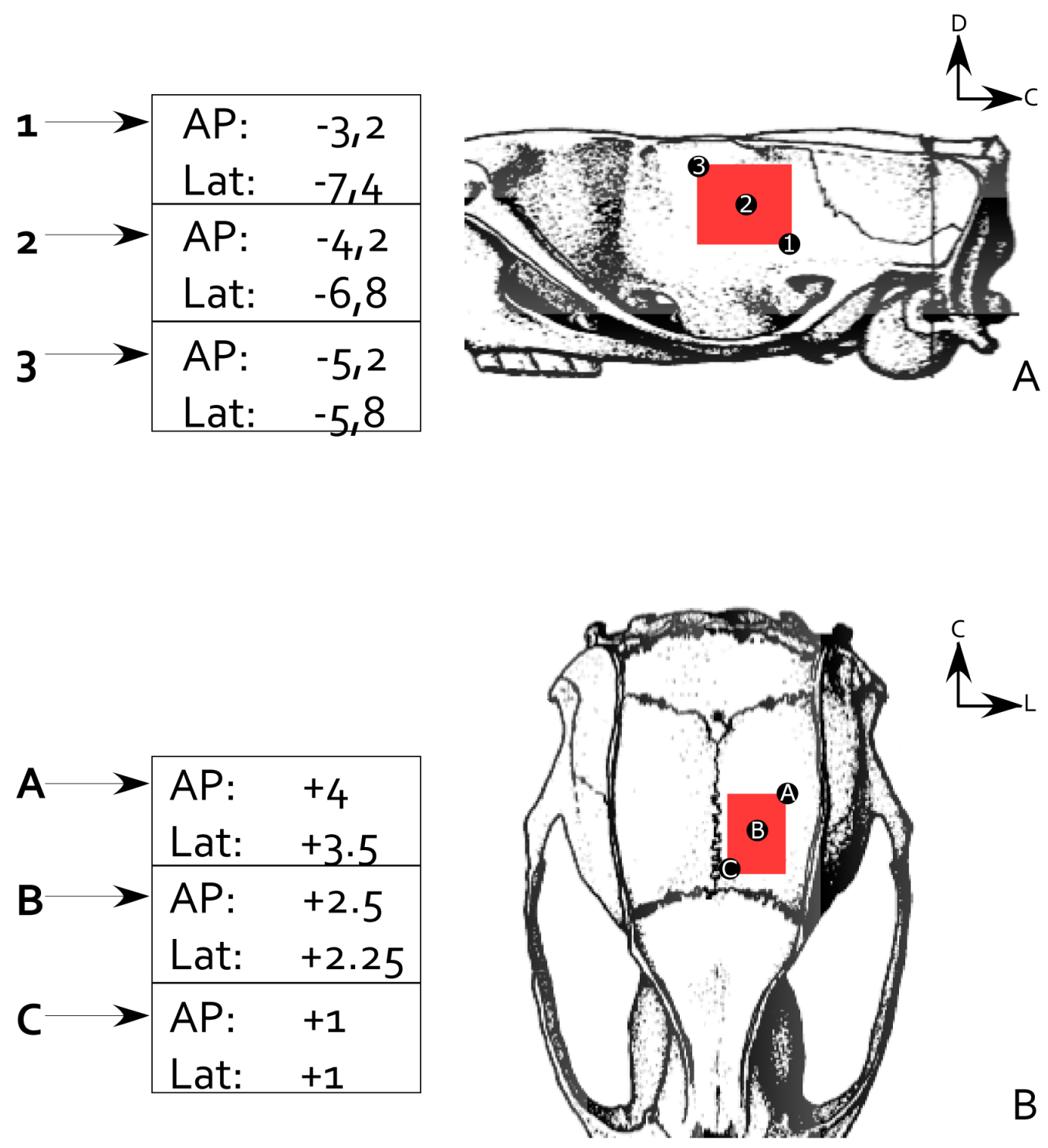

FIGURA 4.

coordenadas estereotáxicas para las cortezas auditivas (A) y no auditivas (B), tomadas de Paxinos y Watson (2005). La ubicación de estos puntos sirvieron como guía para practicar la ventana ósea en la calota craneal.

(A). Visión lateral del cráneo de una rata, en donde se observa la localización de la ventana ósea. Esta guía abarca las regiones auditivas primaria y secundarias (dorsal y ventral).

(B). Visión coronal del cráneo de una rata, en el que se observa la localización de la ventana ósea, que sirve de referencia para la lesión que abarca regiones no auditivas: parte de la corteza motora primaria y secundaria, y parte de la corteza somatosensorial (regiones hind y trunk). 
de estabulización, siguiendo las normas dictadas por el Servicio de Experimentación Animal de la Universidad de Salamanca.

Lesión en Cortezas no auditivas.

Como control para valorar la especificidad de la lesión cortical, se ejecutó el mismo protocolo quirúrgico descrito en el epígrafe anterior (v.s.), modificando únicamente la posición de la ventana ósea que delimitó la zona de aspiración (Figura 4B), y que se ajustaron a zonas no auditivas: las coordenadas estereotáxicas seleccionadas (Paxinos y Watson, 2005) correspondieron a la superficie más dorsal del cerebro (área de tamaño equivalente a la de la ablación de la (A) y en coordenadas que abarcaron parte de la corteza motora primaria y secundaria y regiones somatosensoriales (regiónhindlimb y trunk).

Inyección del Trazador neuroanatómico.

Para comprobar la ubicación y extensión de las lesiones en nuestros casos experimentales, en comparación con las coordenadas estereotáxicas establecidas por Paxinos y Watson (2005), para los límites de las cortezas auditivas, dos animales lesionados (Grupo 1, Tabla $\mathrm{N}_{1}$ ) recibieron, 10 días previos al sacrificio, una inyección de Dextrano biotinado al 10\% (BDA), en las coordenadas correspondientes al límite dorsal de la corteza auditiva ventral $(\mathrm{AuV})$ en el lado derecho (contralateral) a la zona de aspiración (Figura 5).

El trazador Dextrano Biotinado (BDA- 10000 daltons PM; Molecular Probes, Oregon, EEUU) fue inyectado por iontoforesis y a través de una micropipeta de vidrio con un diámetro de punta de $20-25 \mu \mathrm{m}$. Para la iontoforesis se aplicaron pulsos positivos de corriente de 5 Microamperios- pulsos de 7 seg On- 7 seg Off, durante 20 minutos, y 10 minutos de reposo postinyección. Una vez realizada la inyección, y utilizando agujas entomológicas conectadas al micromanipulador, se marcaron (por penetración en el tejido) los puntos Lambda y Bregma. Igualmente se insertaron dos agujas en la corteza parietal, situándolas a $1 \mathrm{~mm}$ de distancia entre ellas, para realizar posteriormente el cálculo del índice de retracción de los tejidos.

En estos animales se realizaron los procesos de fijación, corte e inmunohistoquímica que se describirán en los apartados de fijación y corte, y métodos histológicos de tinción ( $v$.i.).

Extracción de los Colículos inferiores para las técnicas de análisis molecular y genómico.

Todos los animales destinados para el estudio de la RT-PCR (semicuantitativa y cuantitativa) de los receptores ionotrópicos de glutamato y estudios génicos de MicroArrays, recibieron una sobredosis con Pentobarbital sódico al 6\% (50 mg/kg de peso). A continuación, los animales fueron 


\section{FIGURA 5.}

Microfotografías que ilustran el proceso de construcción de un mapa de referencias citoarquitecturales para la localización de las lesiones corticales. (A) Los límites entre las diferentes áreas corticales fueron determinados por comparación entre secciones seriadas teñidas alternativamente para SMI-32 y Nissl. Los patrones citoarquitecturales de la corteza auditiva y las cortezas adyacentes (somatosensorial y visual) son ilustrados en un nivel caudal y en uno rostral. Nótese además que es posible distinguir las distintas capas que conforman estas regiones. (B) Microfotografías de tres secciones seriadas de un caso del grupo 1 (Tabla $N^{\circ} 1$ ), inmunoteñido para SMI-32, en donde se observa que las diferentes subdivisiones corticales pueden ser fácilmente apreciadas. Las coordenadas de los límites de la CA y de la fisura rinal fueron transferidas a un sistema de coordenadas cartesianas. La inyección en el límite dorsal de la corteza auditiva ventral-lado derecho, produce campos terminales marcados en la corteza contralateral (remanente intacto) y en el geniculado medial del tálamo (flechas) y se observa además la zona de lesión cortical (estrella) en el lado izquierdo, en la que no se afecta la sustancia blanca subyacente.

Abreviaturas

Au1 Corteza Auditiva Primaria

AuD Corteza Auditiva Dorsal

AuV Corteza Auditiva Ventral

Ect Corteza Ectorrinal

LPtA Corteza deAsociación Parietal Lateral

PtPD Corteza Parietal Posterodorsal

PtPR Corteza Parietal Posterorostral

rF Fisura Rinal

S1BF Corteza Somatosensorial Primaria, campo barrel

S2 Corteza Somatosensorial Secundaria

V1 Corteza Visual Primaria

V1M Corteza Visual primaria, Monocular

V1B Corteza Visual Primaria, Binocular

V2L Corteza Visual Secundaria, Lateral 


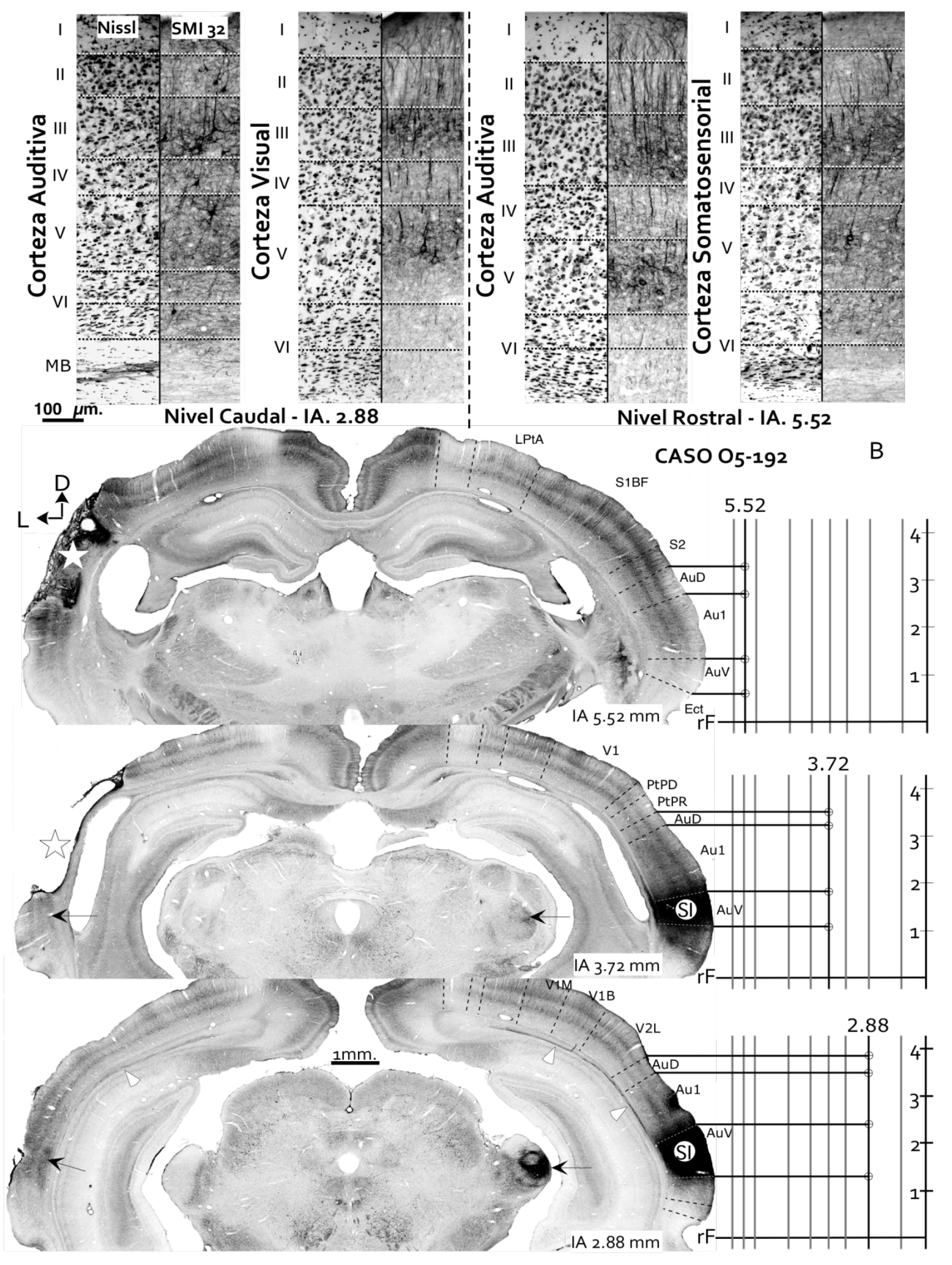


decapitados y los cerebros fueron extraídos cuidadosamente del cráneo, irrigando continuamente el tejido durante todo el procedimiento con una solución de Krebs (imitando el medio fisiológico). Como siguiente paso, los colículos inferiores bilaterales fueron seccionados y colocados en TRIZOL ${ }^{\circledR}$ reagent (Gibco BRL, Gaithersburg, MD, EEUU), para su almacenaje en frío.

\section{Respuestas auditivas del tronco cerebral (ABRs).}

Las pruebas de los ABRs fueron realizadas en el Instituto de Investigaciones Biomédicas "Alberto Sols", en el Servicio de Evaluación Neurofuncional no Invasiva, con el objetivo de valorar cuantitativamente la funcionalidad de las vías auditivas. Con estas pruebas se analizaron principalmente dos parámetros: el umbral auditivo, y la velocidad de conducción del estímulo sonoro. En este estudio, se utilizaron dos tipos de estímulos sonoros diferentes: clicks y tonos puros.

Las mediciones fueron realizadas en los animales de los grupos 2 y $3, n=8$ (Tabla 1) en dos ocasiones, la primera, cuando el grupo 3 cumplió los 15 días de supervivencia pl, y la segunda vez, cuando el grupo 3 cumplió 90 días de supervivencia pl (estudio longitudinal). Cada uno de los especímenes fueron colocados bajo anestesia (ketamina $75 \mathrm{mg} / \mathrm{kg}$ y medetomidina $0.5 \mathrm{mg} / \mathrm{kg}$ ), en el interior de una caja de registro sonoamortiguada dotada con un sistema de mantenimiento para la temperatura corporal y un transductor electroacústico (tweeter). Para la obtención de los potenciales bioeléctricos se empleó una estación de trabajo de potenciales evocados auditivos (Tucker Davis Technologies, Alachua FL, EEUU). Las señales auditivas fueron generadas utilizando el programa SigGeRP' ${ }^{\text {тM }}$ (Tucker-Davis ${ }^{\text {TM }}$ Technologies, FL, EEUU), y los estímulos sonoros además, fueron calibrados utilizando el programa analizador SigCal ${ }^{\mathrm{TM}}$ (Tucker-Davis ${ }^{\mathrm{TM}}$ Technologies, FL, EEUU)y un micrófono $1 / 4$ pulgada (ACO Pacifics,Belmont, CA, EEUU).Los tres electrodos de registro (activo, referencia y tierra) se colocaron subcutáneamente en posiciones estándar (Cediel y cols., 2006).

Tipo de estudio.

En todos los animales, se realizó un estudio de tipo medio, que consistió en:

- estimulación con sonido click, utilizando una velocidad de 30 pulsos por segundo (pps), con una duración de $0.1 \mathrm{~ms}$.

- objetivo $\rightarrow$ determinar el umbral auditivo, las latencias de los picos I al V y las latencias interpico características (I-II, II-IV y I-IV), con el fin de precisar la sensibilidad global auditiva del órgano periférico.

- Estimulación con tonos puros, (8-28 kHz) a velocidad 50 pps y duración de $5 \mathrm{~ms}$ (2.5 $\mathrm{ms}$ de rampa) 
- objetivo $\rightarrow$ obtención de los audiogramas individuales.

La duración de la ventana de registro fue de 10 ms, y se accionó mediante un pulso calculado desde el RP2 hasta el inicio del estímulo. Los umbrales auditivos para cada animal fueron determinados reduciendo gradualmente la intensidad del estímulo en $10 \mathrm{~dB}$, hasta que no se registraron respuestas apropiadas. Como siguiente paso, la intensidad del estímulo fue incrementada gradualmente en $5010 \mathrm{~dB}$ hasta que la respuesta pudo ser identificada nuevamente. De esta forma, el umbral lo definimos como la menor intensidad en la aparecían respuestas latency-appropriate con una amplitud mayor a la media del ruido de fondo +2 la desviación estándar.

Las respuestas de los especímenes fueron analizadas utilizando el programa BioSigRP ${ }^{\text {тM }}$ (Tucker-Davis ${ }^{\mathrm{TM}}$ Technologies, FL, EEUU). Al finalizar el estudio los animales fueron sacrificados, prefundidos y procesados para la ubicación de las lesiones en la corteza auditiva (v.i.).

\section{Reflejo Auditivo del Sobresalto (RAS) - Inhibición Por Estímulo Previo (IPP).}

\section{Condiciones iniciales.}

Con el fin de comprobar si existían cambios en la respuesta del RAS/IPP tras deaferentación de la proyección corticocolicular, evaluamos estas reacciones tanto en animales experimentales (lesiones en corteza auditiva y lesiones en regiones no auditivas), como en casos controles, a diferentes tiempos de supervivencia postlesión: 15, 90 y 180 días (estudio longitudinal). Las sesiones para evaluar la amplitud del RAS, el porcentaje de IPP y las latencias de estas respuestas, se realizaron en los animales de los grupos 4, 5 y 15, $n=26$ (Tabla No 1). Todos los animales se encontraban colocados en jaulas individuales, con libre acceso a comida y agua, y en adecuadas condiciones de estabulación. Además, el día previo a las pruebas los animales eran trasladados a un cuarto aislado, con condiciones ambientales estables (ritmos circadianos- ciclosde luz/oscuridad de 12 horas) con el fin de disminuir interferencias provocadas por el entorno, que podrían reducir la fiabilidad de los resultados.

Sistema de medición del Reflejo Auditivo de Sobresalto.

Al inicio de las sesiones, y utilizando el sistema SR-LAB ${ }^{\text {TM }}$ (San Diego Instruments, Inc. San Diego, CA, EEUU) se colocó suavemente cada una de las ratas en un cilindro de plexiglás-no restrictivo (tamaño estándar) que se ubicó a su vez, dentro de una cabina de aislamiento acústico $(38 \times 40.5 \times 58.5 \mathrm{~cm})$ con ventilación e iluminación propia, este sistema también incluía un dispositivo de generación de sonidos para la producción de ruidos blancos, diferente del sistema que produce los ruidos de fondo. 
En cada una de las sesiones, se le permitió al animal un período de aclimatación ( $5 \mathrm{~min}$ ), bajo un ruido blanco de fondo ( $60 \mathrm{~dB} \mathrm{SPL}$ ). A este periodo de aclimatación le siguieron 64 estímulos auditivos por sesión, al azar y según un cuadro latino (Figura 6). Cada sesión consistió en 16 registros sin pre-estímulo (sólo con intensidades de $115 \mathrm{~dB}$ ), para determinar los valores del RAS (Amplitud y Latencia). Para la evaluación de la IPP se presentaron 48 estímulos auditivos de $115 \mathrm{~dB}$ precedidos por estímulos de ruidos blancos de $20 \mathrm{~ms}$ de duración y de tres intensidades diferentes $(65,70$ y $80 \mathrm{~dB}$ NP) (Figura 6). El movimiento del animal al sobresaltarse por los estímulos acústicos fue recogido por un acelerómetro piezoeléctrico colocado debajo del tubo de plexiglás, y cuyas vibraciones registradas por el sobresalto del animal, fueron convertidas en señales eléctricas análogas, que se tradujeron gracias a un programa del sistema (Microsoft Windows ${ }^{\circledR}$ ), en las medidas que nos permitieron obtener los parámetros de latencia y amplitud del RAS/IPP.

Procedimiento de análisis del RAS/IPP.

La magnitud porcentual de la IPP se calculó para cada intensidad del prepulso $(65,70$ y 80 dB NP) según la siguiente fórmula:

(amplitud del RAS sin estímulo previo)-(amplitud del RAS con estímulo previo)

$\mathrm{IPP}=$ (amplitud del RAS en ensayos sin estímulo previo)

Análisis estadístico para los valores del RAS/IPP.

Los datos provenientes de la evaluación del RAS/IPP se analizaron empleando el programa estadístico SPSS 15.0 (Modelos lineales generales, multivariantes y univariantes) y, utilizando la prueba de Games-Howell, se realizó el análisis de la varianza para muestras independientes con el fin de establecer comparaciones entre los parámetros del RAS/IPP de los diferentes grupos estudiados. Los datos cuantitativos en todos los casos que se mostrarán son expresados como el valor medio y su error estándar, con un intervalo de confianza del $95 \%$. 


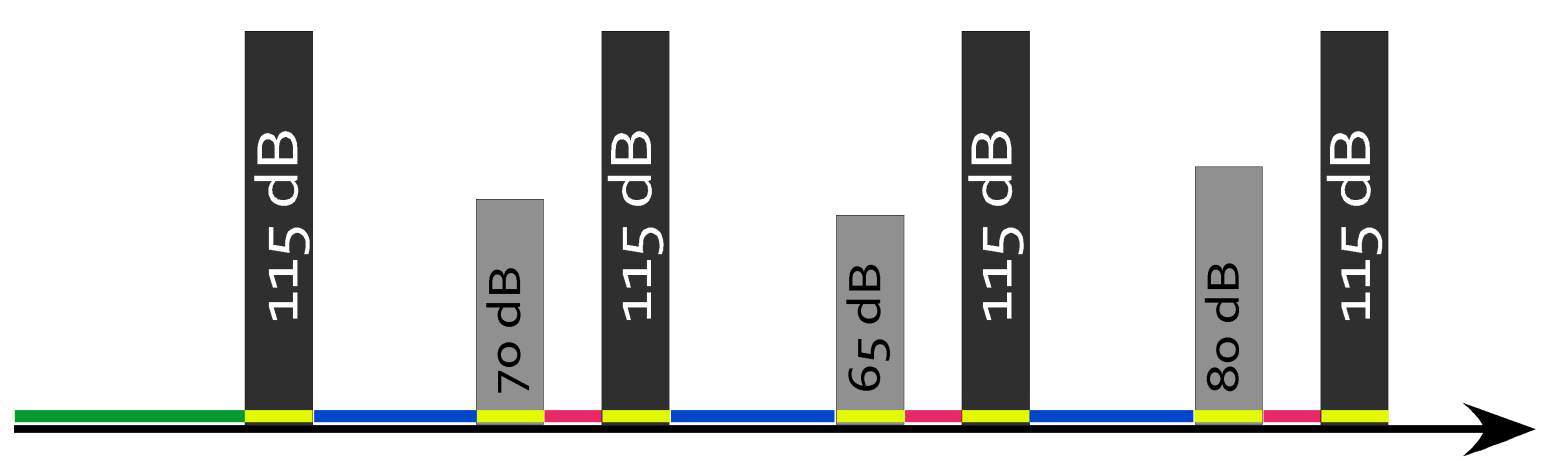

\section{FIGURA 6.}

Esquema que representa parte del cuadro latino o matriz, que se les presenta a los casos experimentales durante la aplicación de las pruebas audiomotoras: Reflejo Auditivo del Sobresalto e Inhibición por estímulo previo.

_ período de aclimatación (Ruido de fondo, $60 \mathrm{~dB} S P L$ ) por 5 minutos.

duración del estímulo auditivo (pulso $115 \mathrm{~dB})$ o pre-pulsos $(65,70$ y $80 \mathrm{~dB}): 20 \mathrm{~ms}$.

tiempo entre el pre-pulso de variable intensidad: 65,70 y $80 \mathrm{~dB}$ y el pulso (115 dB): $30 \mathrm{seg}$.

ISI, intervalo inter-estímulo (tiempo entre el pre-pulso y el pulso): $50 \mathrm{~ms}$. 


\section{Estimulación Auditiva.}

La estimulación sonora se efectuó en los animales de los grupos 7,8 y 9,n=9 (Tabla $\mathrm{N}^{\circ} 1$ ). Los especímenes fueron estabulados individualmente y de forma apropiada en una zona aislada del animalario sin ningún tipo de estímulo sonoro 72 horas previas al experimento. Durante todo el intervalo de tiempo en el cual los animales fueron estimulados con sonido éstos permanecieron bajo anestesia, utilizando Uretano al $20 \%$ ( $1.5 \mathrm{~g} / \mathrm{kg}$ vía intraperitoneal). Los animales se colocaron en jaulas individuales suspendidas dentro de una pequeña caja de exposición de sonido sin lados paralelos construida en nuestro taller siguiendo los postulados de Yoshida y cols., (2000). El estímulo acústico fue generado por una fuente de ruido hecha a medida, la señal sonora fue amplificada, y luego emitida por cuatro altavoces de campo abierto (Mac Audio Electronic GmbH \& Co. KG, Alemania) colocados en las paredes de la caja de sonido. Los niveles de exposición sonora se midieron dentro de la caja, antes y después de cada estimulación sonora, utilizando un micrófono condensador de [1/2]-pulgada, colocado en una posición equivalente a la posición de la cabeza de los animales (Brüel and Kjær 4191, Nærum, Dinamarca).

El protocolo de estimulación empleando fue el siguiente:

+Frecuencia fundamental: $\quad 5.0 \mathrm{kHz}$

+ Duración del estímulo: $300 \mathrm{~ms}$ cada $800 \mathrm{~ms}$

+ Rampa: $10 \mathrm{~ms}$

+ Frecuencia de repetición: $1.25 \mathrm{~S}$

+ Tiempo de estimulación: 60 minutos

+ Intensidad del estímulo: $80 \mathrm{~dB}$

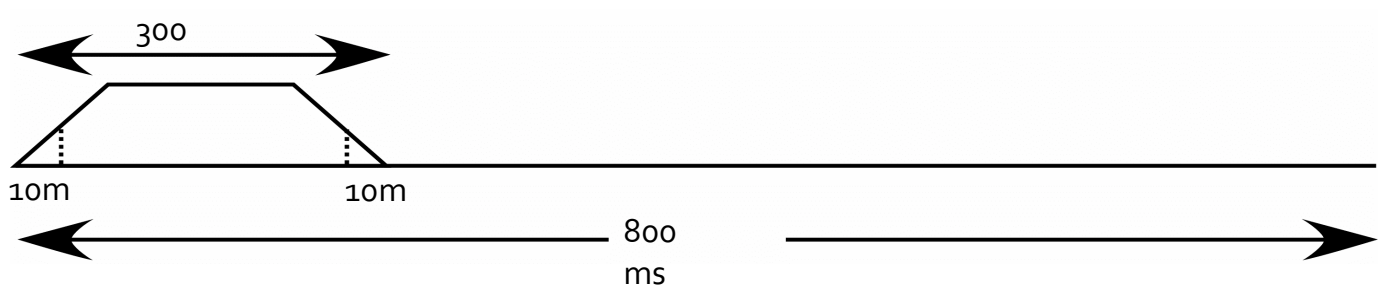

Tras el proceso de estimulación auditiva, los animales se mantuvieron en reposo y sin ningún tipo de estimulación sonora durante 100 minutos. Transcurrido este tiempo, y bajo los efectos anestésicos del uretano se perfundieron siguiendo protocolos estándares ( $v . i)$. 


\section{Técnicas Histológicas.}

\section{Procedimientos de Fijación y Corte.}

Se realizó una apertura de la caja torácica, procediéndose a la perfusión transcardíaca (vía Aorta), y por flujo constante, de $300 \mathrm{ml}$ de una solución buffer de lavado (Ringer con pH 6.9 a $36^{\circ} \mathrm{C}$, que contenía Heparina al $0.01 \%$ ); seguido por la perfusión de una solución fijadora (1 litro, a temperatura ambiente), que contenía Paraformaldehído al 4\%, Glutaraldehído al $0.25 \%$ (en los casos de inyección de BDA) y $15 \%$ de ácido pícricoa saturación en PB 0.1M (para la calretinina).

Después del proceso de fijación, los animales fueron decapitados y los cerebros fueron extraídos delicadamente del cráneo. Estos cerebros, previa retirada de las meninges, fueron colocados en moldes para ratas de 200-400 (Brain matrix rodent, Bionalaytical Systems, Inc, West Lafayette, IN, EEUU) que nos permitieron tener una visión sagital y coronal estándar de los cerebros. Se tomaron fotografías de los cerebros enteros lesionados, en los planos sagital y coronal, junto a una escala de referencia y utilizando una cámara digital Olympus CAMEDIA, C-506o Wide zoom 4X, 5.1 MP y CCD: 1/1.8.

A continuación, los cerebros fueron tallados en el molde coronal (ranuras de $1 \mathrm{~mm}$ ) buscando obtener planos de corte semejantes en todos los casos experimentales. Además, paradeterminar correctamente la posición de las secciones se realizó un tracto en el lado derecho con una aguja entomológica, tanto en la corteza cerebral como en el tallo. Como siguiente paso, los bloques de cerebro obtenidos tras el proceso de tallado y marcados en el lado derecho (contralateral a la zona de lesión), se sumergieron en la misma solución fijadora de la perfusión, conservándose dos horas para su post-fijación. Pasado este intervalo de tiempo, y para su crioprotección, fueron sumergidos en una solución de Sacarosa al $30 \%$ en $\mathrm{PB}$ al $0.1 \mathrm{M}, \mathrm{pH} 7.4$ y a $4^{\circ} \mathrm{C}$, durante 48 horas, y en agitación constante.

Los bloques de cerebro fueron cortados utilizando un microtomo de congelación (HM 430 Sliding, MICROM International, Walldorf, Alemania), y empleando un plano coronal estándar se obtuvieron secciones histológicas seriadas de $40 \mu \mathrm{m}$ de grosor. Los cortes fueron depositados en diez pocillos numerados de forma secuencial, que contenían una solución de $\mathrm{PB}$ 0.1M, pH 7.4. 
Métodos de Tinción.

Para reconocer los límites citoarquitecturales de las cortezas auditivas, las secciones seriadas de los casos experimentales (grupo 1 , Tabla $N^{\circ} 1$ ) se inmunotiñeron de forma alternativa con anticuerpos contra Neurofilament Heavy (SMI-32), Calretinina (CR), y tinción de Nissl. Además, para confeccionar un mapa cortical auditivo para la ubicación de las lesiones ( $v$.i.), se utilizó el trazador neuroanatómico Dextrano biotinado (BDA). En los casos de los grupos 6-9 (Tabla $N^{\circ} 1$ ), las secciones fueron teñidas alternadamente con un anticuerpo contra c-Fos y tinción de Nissl, mientras que en los casos de los grupos 10-14 (Tabla $\mathrm{N}^{\circ} 1$ ), las secciones se tiñeron de forma alternativa con un anticuerpo contra Calretinina y tinción de Nissl. En los animales de los grupos 3, 5, 15-26 (Tabla $\mathrm{N}^{\circ} 1$ ) en los que no se realizó una perfusión transcardíaca, sino una postfijación, ya que su destino eran procesos de biología molecular y/ó la localización de la zona de lesión dentro de los límites de la CA, las secciones fueron teñidas con Nissl.

- Revelado del trazador Neuroanatómico Dextrano Biotinado.

Las secciones histológicas fueron lavadas con Tris buffer salina (TBS) 0.05 $\mathrm{M}, \mathrm{pH} 8.0$ (2X15 min) e incubadas durante 180 minutos en el complejo $A B C$ (Avidin Biotin Peroxidase, Vectastain Standard ABC Kit; Vector laboratorios, Burling, CA, EEUU). A continuación, se lavaron nuevamente los cortes con una solución que contenía TBS (0.05M) y Tritón Tx-100 (0.5\%) -TBS-Tx, pH 8.0 (2x15 min) y con Tris (hidroximetil) aminometano más ácido clorhídrico (Tris- $\mathrm{HCl}$ ) a pH 8.0 (2X15 min). Luego de la incubación y los lavados de las secciones histológicas, éstas fueron reveladas utilizando el cromógeno 3,3' tetrahidrocloruro de diaminobencidina (DAB \#D-9015, Sigma-Aldrich, Inc) unido a Níquel-Amonio-Sulfato al $0.16 \%$ y $\mathrm{H}_{2} \mathrm{O}_{2}$ al $0.006 \%$ para intensificar la reacción con metales pesados.

- Revelado inmunohistoquímico para SMI-32.

Para el tratamiento de las secciones histológicas destinadas al revelado con SMI-32 se llevó a cabo el protocolo que se detalla en la Tabla No 2.A continuación, las secciones histológicas fueron montadas sobre portaobjetos gelatinizados $0.2 \%$, en una solución tamponada de Tris- $\mathrm{HCl}(0.05 \mathrm{M}, \mathrm{pH} 8)$, colocadas sobre una estufa a $35^{\circ} \mathrm{C}$ durante 48 horas y luego fueron deshidratadas. Los portaobjetos fueron cubiertos (cubreobjetos) y sellados con un medio de montaje- Entellan ${ }^{\circledR}$ Neu.La omisión del anticuerpo primario en estas preparaciones, y en las que utilizamos otros anticuerpos, resultó en ninguna inmunotinción positiva para éstos.

- Revelado inmunohistoquímico para c-Fos.

En los cinco pocillos con secciones histológicas reservadas para la inmunotinción de la proteína c-Fos, se siguió idéntico protocolo que el detallado 
Tabla No 2. Protocolo de Inmunohistoquímica para SMI-32.

\begin{tabular}{|c|c|c|c|c|c|c|}
\hline & Procedimiento & Solución & $\begin{array}{l}\text { Especifi- } \\
\text { caciones }\end{array}$ & tiempo & $\begin{array}{l}\text { Agita- } \\
\text { ción }\end{array}$ & $\begin{array}{l}\text { Incu- } \\
\text { bación }\end{array}$ \\
\hline 1 & Lavado & TBS & $\begin{array}{l}0.05 \mathrm{M} \\
\mathrm{pH} 7.6\end{array}$ & $\begin{array}{l}1 \times 15 \\
\min \end{array}$ & $x$ & \\
\hline 2 & $\begin{array}{c}\text { Inhibición de la } \\
\text { Peroxidasa } \\
\text { endógena }\end{array}$ & $\begin{array}{l}\text { Metanol+ } \\
\mathrm{H}_{2} \mathrm{O}_{2} \text { en PB }\end{array}$ & $\begin{array}{l}10 \% \\
3 \% \\
0.1 \mathrm{M}\end{array}$ & $10 \mathrm{~min}$ & & $X$ \\
\hline 3 & Lavado & TBS-Tx & $\begin{array}{l}0,05 \mathrm{M} \\
\mathrm{pH} 7.6\end{array}$ & $\begin{array}{l}3 \times 15 \\
\min \end{array}$ & $X$ & \\
\hline 4 & $\begin{array}{c}\text { Bloqueo } \\
\text { marcaje } \\
\text { Inespecífico }\end{array}$ & $\begin{array}{l}\text { Fetal Calf } \\
\text { Serum }\end{array}$ & $\begin{array}{c}\text { 3\% en TBS } \\
0.05 \mathrm{M}- \\
\text { Tritón X-100 }\end{array}$ & 1 hora & $x$ & $x$ \\
\hline 5 & $\begin{array}{l}\text { ANTICUERPO } \\
\text { PRIMARIO }\end{array}$ & $\begin{array}{c}\text { SMI-32 } \\
\text { Antineuro- } \\
\text { filamento H } \\
\text { (ratón) }\end{array}$ & $\begin{array}{c}{[1 / 8000]} \\
4^{\circ} \mathrm{C}\end{array}$ & $\begin{array}{c}48 \\
\text { horas }\end{array}$ & $X$ & $X$ \\
\hline 6 & Lavado & TBS - Tx & $\begin{array}{l}0.05 \mathrm{M} \\
\mathrm{pH} 7.6\end{array}$ & $\begin{array}{l}3 \times 15 \\
\min \end{array}$ & $x$ & \\
\hline 7 & $\begin{array}{l}\text { ANTICUERPO } \\
\text { SECUNDARIO }\end{array}$ & $\begin{array}{l}\text { Horse anti- } \\
\text { mouse }\end{array}$ & $\begin{array}{c}{[1 / 200]} \\
\text { To ambiente }\end{array}$ & $120 \mathrm{~min}$ & $x$ & $x$ \\
\hline 8 & Lavado & TBS-Tx & $\begin{array}{l}0.05 \mathrm{M} \\
\mathrm{pH} 7.6\end{array}$ & $\begin{array}{l}3 \times 15 \\
\min \end{array}$ & $x$ & \\
\hline 9 & $\begin{array}{l}\text { Localizar el } \\
\text { antígeno }\end{array}$ & $A B C$ & To ambiente & $90 \mathrm{~min}$ & $x$ & $x$ \\
\hline 10 & Lavado & Tris-HCl & $\begin{array}{l}0.05 \mathrm{M} \\
\mathrm{pH} 7.6\end{array}$ & $\begin{array}{l}3 \times 10 \\
\min \end{array}$ & $x$ & \\
\hline 11 & Revelado & $\begin{array}{l}\mathrm{DAB}+ \\
\mathrm{H}_{2} \mathrm{O}_{2}\end{array}$ & $0.006 \%$ & $\begin{array}{l}\text { juicio } \\
\text { opera- } \\
\text { dor }\end{array}$ & & \\
\hline 12 & Lavado & Tris- $\mathrm{HCl}$ & $\begin{array}{l}0.05 \mathrm{M} \\
\mathrm{pH} 7.6\end{array}$ & $\begin{array}{l}3 \times 10 \\
\min \end{array}$ & $x$ & \\
\hline
\end{tabular}


para el anticuerpo SMI-32. Sólamente se modificaron los tipos de anticuerpos (primario y secundario). El protocolo que seguimos se detalla en la Tabla № 3 . También se describe en este apartado, los cuatro anticuerpos primarios de diferentes casas comerciales para c-Fos utilizados en el grupo $6\left(n=3\right.$, Tabla $\left.\mathrm{N}^{0} 1\right)$.

Las secciones inmunoteñidas fueron montadas en portaobjetos, secadas, deshidratadas y selladas siguiendo el protocolo descrito para el anticuerpo SMI32 (v.s.).

- Revelado inmunohistoquímico para Calretinina.

Para los pocillos con secciones histológicas cuyo destino era la inmunotinción con las proteínas ligadoras de calcio, se siguió idéntico protocolo que el detallado para SMI-32, solamente se modificaron los tipos de anticuerpos (1rio y 2rio). El protocolo que seguimos se detalla en la Tabla $\mathrm{N}^{\circ} 4$.

Las secciones inmunoteñidas fueron montadas en portaobjetos, secadas, deshidratadas y selladas siguiendo el protocolo descrito para el anticuerpo SMI32 y c-Fos (v.s.).

- Tinción con Nissl.

Las secciones histológicas fueron teñidas con Violeta de Cresilo al 1\% (C1791, Sigma-Aldrich, Inc) por al menos 5 minutos (hasta que las secciones tomaron una coloración violeta oscura- juicio del operador). El proceso continuó con el siguiente protocolo para la diferenciación y deshidratación del tejido que se describe en la Tabla $\mathrm{N}^{\circ} 5$. 
Tabla No 3. Protocolo de Inmunohistoquímica para c-Fos.

\begin{tabular}{|c|c|c|c|c|c|c|}
\hline & Procedimiento & Solución & $\begin{array}{l}\text { Especifi- } \\
\text { Caciones }\end{array}$ & tiempo & $\begin{array}{l}\text { Agita- } \\
\text { ción }\end{array}$ & $\begin{array}{l}\text { Incuba- } \\
\text { ción }\end{array}$ \\
\hline 1 & Lavado & TBS & $\begin{array}{l}0.05 \mathrm{M} \\
\mathrm{pH} 7.6\end{array}$ & $1 \times 15 \mathrm{~min}$ & $X$ & \\
\hline 2 & $\begin{array}{c}\text { Inhibición de la } \\
\text { Peroxidasa } \\
\text { endógena }\end{array}$ & $\begin{array}{c}\text { Metanol+ } \\
\mathrm{H}_{2} \mathrm{O}_{2} \text { en PB }\end{array}$ & $\begin{array}{l}10 \% \\
3 \% \\
0.1 \mathrm{M}\end{array}$ & $\begin{array}{l}30 \\
\min \end{array}$ & & $X$ \\
\hline 3 & Lavado & TBS-Tx & $\begin{array}{l}0.05 \mathrm{M} \\
\mathrm{pH} 7.6\end{array}$ & $\begin{array}{l}3 \times 15 \\
\min \end{array}$ & $X$ & \\
\hline 4 & $\begin{array}{c}\text { Bloqueo } \\
\text { marcaje } \\
\text { Inespecífico }\end{array}$ & $\begin{array}{l}\text { Fetal Calf } \\
\text { Serum }\end{array}$ & $\begin{array}{c}\text { 3\% en TBS } \\
0.05 \mathrm{M}-\text { Tritón } \\
\text { X-100 }\end{array}$ & 1 hora & $x$ & $x$ \\
\hline $5^{a}$ & $\begin{array}{c}\text { ANTICUERPO } \\
\text { PRIMARIO- } \\
\text { c-Fos }^{\text {a }}\end{array}$ & $\begin{array}{c}\text { Ab-5 } \\
\text { Onocogene } \\
\text { Research }\end{array}$ & {$[1: 2500]$} & $\begin{array}{c}72 \text { horas } \\
4^{\circ} \mathrm{C}\end{array}$ & $X$ & $X$ \\
\hline $5^{b}$ & $\begin{array}{c}\text { ANTICUERPO } \\
\text { PRIMARIO- } \\
\text { c-Fos }^{\text {b }}\end{array}$ & $\begin{array}{c}\text { Santa Cruz } \\
\text { Biotecnologi } \\
\text { c SC-52 }\end{array}$ & {$[1: 2500]$} & $\begin{array}{c}72 \text { horas } \\
4^{\circ} \mathrm{C}\end{array}$ & $X$ & $X$ \\
\hline $5^{c}$ & $\begin{array}{c}\text { ANTICUERPO } \\
\text { PRIMARIO- } \\
\text { c-Fos }^{c}\end{array}$ & $\begin{array}{c}\text { Santa Cruz } \\
\text { Biotecnologi } \\
\text { c SC-253 }\end{array}$ & {$[1: 2500]$} & $\begin{array}{c}72 \text { horas } \\
4^{\circ} \mathrm{C}\end{array}$ & $x$ & $X$ \\
\hline $5^{d}$ & $\begin{array}{c}\text { ANTICUERPO } \\
\text { PRIMARIO- } \\
\text { c-Fos }^{\text {d }}\end{array}$ & $\begin{array}{c}\text { Santa Cruz } \\
\text { Biotecnologi } \\
\text { c SC-7202 }\end{array}$ & [1:2500] & $\begin{array}{c}72 \text { horas } \\
4^{\circ} \mathrm{C}\end{array}$ & $x$ & $X$ \\
\hline 6 & Lavado & TBS - Tx & $\begin{array}{l}0.05 \mathrm{M} \\
\mathrm{pH} 7.6\end{array}$ & $3 \times 15 \mathrm{~min}$ & $X$ & \\
\hline $7^{a}$ & $\begin{array}{c}\text { ANTICUERPO } \\
\text { SECUNDARIO- } \\
\text { c-Fos }\end{array}$ & $\begin{array}{l}\text { Anti lgG } \\
\text { biotinado } \\
\text { Conejo }\end{array}$ & $\begin{array}{c}{[1 / 200]} \\
\text { TBS } 0.1 \mathrm{M}+ \\
\text { Tritón-Tx } 0.3\end{array}$ & $\begin{array}{c}120 \mathrm{~min} \\
\mathrm{~T}^{\circ} \\
\text { ambient } \\
\mathrm{e}\end{array}$ & $x$ & $X$ \\
\hline 8 & Lavado & TBS-Tx & $\begin{array}{l}0.05 \mathrm{M} \\
\mathrm{pH} 7.6\end{array}$ & $3 \times 15 \mathrm{~min}$ & $X$ & \\
\hline 9 & $\begin{array}{c}\text { Localizar el } \\
\text { antígeno }\end{array}$ & $A B C$ & To ambiente & $90 \mathrm{~min}$ & $x$ & $X$ \\
\hline 10 & Lavado & Tris- $\mathrm{HCl}$ & $\begin{array}{l}0.05 \mathrm{M} \\
\mathrm{pH} 7.6\end{array}$ & $3 \times 10 \mathrm{~min}$ & $X$ & \\
\hline 11 & Revelado & $\begin{array}{c}\text { DAB+ } \\
\text { Ni Amonio } \\
\text { Sulfato + } \\
\mathrm{H}_{2} \mathrm{O}_{2}\end{array}$ & $\begin{array}{c}0.16 \% \\
0.006 \%\end{array}$ & $\begin{array}{c}\text { juicio } \\
\text { operador }\end{array}$ & & \\
\hline 12 & Lavado & Tris- $\mathrm{HCl}$ & $\begin{array}{l}0.05 \mathrm{M} \\
\mathrm{pH} 7.6\end{array}$ & $\begin{array}{l}3 \times 10 \\
\min \end{array}$ & $X$ & \\
\hline
\end{tabular}


Tabla No 4.Protocolo de Inmunohistoquímica para Calretinina

\begin{tabular}{|c|c|c|c|c|c|c|}
\hline & Procedimiento & Solución & $\begin{array}{l}\text { Especifi- } \\
\text { Caciones }\end{array}$ & tiempo & $\begin{array}{l}\text { Agita- } \\
\text { ción. }\end{array}$ & $\begin{array}{l}\text { Incu- } \\
\text { bación }\end{array}$ \\
\hline 1 & Lavado & TBS & $\begin{array}{l}0.05 \mathrm{M} \\
\mathrm{pH} 7.6\end{array}$ & $\begin{array}{l}1 \times 15 \\
\min \end{array}$ & $X$ & \\
\hline 2 & $\begin{array}{c}\text { Inhibición de la } \\
\text { Peroxidasa } \\
\text { endógena }\end{array}$ & $\begin{array}{l}\text { Metanol+ } \\
\mathrm{H}_{2} \mathrm{O}_{2} \text { en PB }\end{array}$ & $\begin{array}{l}10 \% \\
3 \% \\
0.1 \mathrm{M}\end{array}$ & $\begin{array}{l}10 \\
\min \end{array}$ & & $X$ \\
\hline 3 & Lavado & TBS-Tx & $\begin{array}{l}0.05 \mathrm{M} \\
\mathrm{pH} 7.6\end{array}$ & $\begin{array}{l}3 \times 15 \\
\min \end{array}$ & $x$ & \\
\hline 4 & $\begin{array}{l}\text { Bloqueo marcaje } \\
\text { Inespecífico }\end{array}$ & $\begin{array}{l}\text { Fetal Calf } \\
\text { Serum }\end{array}$ & $\begin{array}{c}\text { 3\% en TBS } \\
0.05 \mathrm{M}-\text { Tritón } \\
\text { X-100 }\end{array}$ & 1 hora & $X$ & $x$ \\
\hline 5 & $\begin{array}{l}\text { ANTICUERPO } \\
\text { PRIMARIO- } \\
\text { CALRETININA }\end{array}$ & $\begin{array}{l}\text { Swant } \\
7694 / 4 \\
\text { Conejo }\end{array}$ & $\begin{array}{c}{[1 / 2000]} \\
\text { TBS } 0.05 \mathrm{M}+ \\
\text { Tritón-Tx } 0.3\end{array}$ & $\begin{array}{c}4^{8} \\
\text { horas } \\
4^{\circ} \mathrm{C}\end{array}$ & $X$ & $X$ \\
\hline 6 & Lavado & TBS -Tx & $\begin{array}{l}0.05 \mathrm{M} \\
\mathrm{pH} 7.6\end{array}$ & $\begin{array}{l}3 \times 15 \\
\min \end{array}$ & $x$ & \\
\hline 7 & $\begin{array}{l}\text { ANTICUERPO } \\
\text { SECUNDARIO- } \\
\text { CALRETININA }\end{array}$ & $\begin{array}{l}\text { Anti lgG } \\
\text { biotinado } \\
\text { Conejo }\end{array}$ & $\begin{array}{c}\text { [1/200] } \\
\text { TBS } 0.1 \mathrm{M}+ \\
\text { Tritón-Tx } 0.3\end{array}$ & $\begin{array}{c}120 \text { min } \\
\mathrm{T}^{\circ} \\
\text { ambien } \\
\text { te }\end{array}$ & $X$ & $x$ \\
\hline 8 & Lavado & TBS-Tx & $\begin{array}{l}0.05 \mathrm{M} \\
\mathrm{pH} 7.6\end{array}$ & $\begin{array}{l}3 \times 15 \\
\min \end{array}$ & $x$ & \\
\hline 9 & $\begin{array}{l}\text { Localizar el } \\
\text { antígeno }\end{array}$ & $A B C$ & To ambiente & $90 \mathrm{~min}$ & X & $X$ \\
\hline 10 & Lavado & Tris- $\mathrm{HCl}$ & $\begin{array}{l}0.05 \mathrm{M} \\
\mathrm{pH} 7.6\end{array}$ & $\begin{array}{l}3 \times 10 \\
\min \end{array}$ & $x$ & \\
\hline 11 & Revelado & $\begin{array}{l}\mathrm{DAB}+ \\
\mathrm{H}_{2} \mathrm{O}_{2}\end{array}$ & $0.006 \%$ & $\begin{array}{l}\text { juicio } \\
\text { operad } \\
\text { or }\end{array}$ & & \\
\hline 12 & Lavado & Tris- $\mathrm{HCl}$ & $\begin{array}{l}0.05 \mathrm{M} \\
\mathrm{pH} 7.6\end{array}$ & $\begin{array}{l}3 \times 10 \\
\min \end{array}$ & $x$ & \\
\hline
\end{tabular}


Tabla No 5. Protocolo para Inmunocitoquímica- Nissl

\begin{tabular}{|c|c|c|c|c|}
\hline $\begin{array}{l}\text { Número } \\
\text { de Veces }\end{array}$ & Procedimiento & Tiempo & Solución & $\%$ \\
\hline 2 & Lavados & $5 \mathrm{seg}$ & Agua destilada & \\
\hline 1 & Lavado & $30 \mathrm{seg}$ & Etanol & $50 \%$ \\
\hline 1 & Lavado & $30 \mathrm{seg}$ & Etanol & $70 \%$ \\
\hline 1 & Diferenciar & $30 \mathrm{seg}$ & $\begin{array}{c}\text { Etanol+ } \\
\text { Ácido Acético }\end{array}$ & $\begin{array}{l}96 \% \\
0,5 \%\end{array}$ \\
\hline 2 & Deshidrataciones & $20 \mathrm{seg}$ & Etanol & $100 \%$ \\
\hline 1 & Diferenciar & $30 \mathrm{seg}$ & Cloroformo & \\
\hline 2 & Deshidrataciones & $30 \mathrm{seg}$ & Etanol & $100 \%$ \\
\hline 3 & Aclarados & $5 \mathrm{~min}$ & Xileno & \\
\hline
\end{tabular}




\section{Métodos de Análisis.}

Análisis Morfométrico y de ubicación de las lesiones en la Corteza Auditiva.

Como esquema-plantilla para representar cada una de las lesiones, respecto a las subdivisiones citoarquitecturales de la corteza auditiva de la rata, se elaboró un mapa de la superficie lateral temporal del cerebro, utilizando para ello los casos controles con inyección del trazador BDA, grupo 1 (Tabla No 1 , $n=2$ ) y secciones seriadas consecutivas inmunoteñidas para SMI-32, CRy Nissl. Con este fin, se identificaron por microscopía óptica en las secciones seriadas inmunoteñidas (v.s.) los patrones citoarquitecturales característicos de las cortezas auditivas y las cortezas adyacentes (Figura 5 ). Escogimos de todas las secciones seriadas en sentido rostro-caudal, las equivalentes con los niveles interaurales: $2.16^{(1)} ; 2.88^{(2)} ; 3.36^{(3)} ; 3.72^{(4)} ; 4.08^{(5)} ; 4.56^{(6)} ; 5.28^{(7)} ; 5.52^{(8)}$ y $5.76^{(9)} \mathrm{mm}$ ilustradas por Paxinos y Watson (2005). Se dibujó con cámara clara el contorno de la sustancia gris cortical, y se marcaron con puntos, el lugar exacto en dónde se apreciaron los cambios en lo patrones citoarquitecturales, que determinaron los límites de la CA (Figura 5). Finalmente, se midió la distancia entre cada uno de estos puntos y el centro de la fisura rinal, trasladando estas medidas a un plano cartesiano en cada una de las secciones interaurales, representadas por finas líneas verticales (Figura $7 \mathrm{~A}$ ). La plantilla-esquema obtenida tras el análisis de nuestras secciones se comparó con un mapa dibujado a partir de los diagramas de las secciones del atlas de Paxinos y Watson (2005) (Figura 7B). Se tuvieron en cuenta, además, los criterios de Doron y cols., (2002) para ampliar en nuestro esquema el borde más caudal de A1 (su región P).

Para superponer y comparar nuestro mapa citoarquitectural de superficie con el de Paxinos y Watson (2005) se calcularon las diferencias de retracción de las secciones en cada caso experimental. El índice de retracción se dedujo seleccionando 5 secciones histológicas equivalentes a los niveles interaurales (0.20; $1.00 ; 1.70 ; 3.10$ y 4.48 mm), midiendo en la línea media de nuestras secciones la distancia comprendida entre el borde más dorsal y el más ventral de cada una ellas y comparando estas medidas con las obtenidas de idéntica forma del atlas (Paxinos y Watson, 2005). El índice de corrección por retracción de las secciones aplicado a la plantilla-esquema, fue la media de los porcentajes obtenidos de nuestros casos lesionados (18.79\%) y osciló en toda la serie experimental entre el $15.86 \%$ y el $21.13 \%$. 


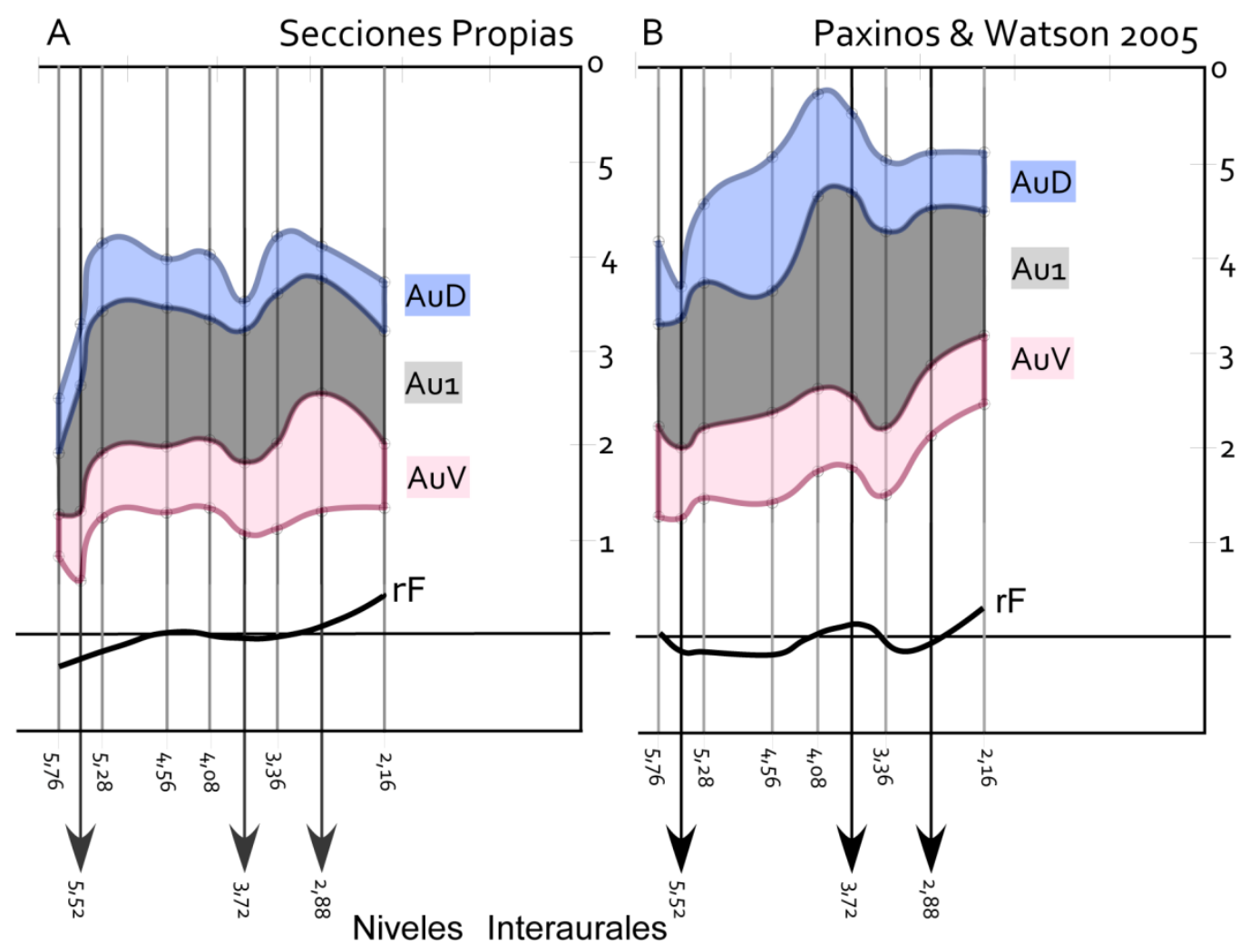

\section{FIGURA 7.}

Diagrama que muestra una visión lateral de los límites de lascortezas auditivas aplanadas de la rata, en toda su extensión rostro-caudal.(A) Utilizando nuestras propiassecciones histológicas y nuestro índice de retracción. (B)Utilizando los valores estereotáxicos de Paxinos y Watson, (2005). Sobre el diagrama representado en el lado izquierdo(A) localizaremos todaslas lesiones corticales. Los niveles interaurales que aparecen marcados con flechas son los mismos niveles que mostramos en la Figura 5 con microfotografías.

Au1 Corteza Auditiva Primaria

AuD Corteza Auditiva Dorsal

AuV Corteza Auditiva Ventral

rF Fisura Rinal 
En cada uno de los casos lesionados se identificaron las secciones histológicas que contenían los límites rostral y caudal de la zona de lesión y tres niveles intermedios. En cada una de estas secciones, con previa identificación del nivel interaural, se midió la distancia entre la superficie de la corteza y el borde más dorsal de la lesión, la extensión de la lesión y la distancia entre el borde ventral de la zona de lesión y el centro de la fisura rinal. Estas medidas se trasladaron como puntos al plano de referencia antes citado y se unieron de forma continua confeccionando la silueta de la lesión. Estas siluetas se superpusieron con el esquema obtenido del área de las CAs elaborado por los casos del grupo 1 (Tabla No 1), y utilizando la herramienta area dimensioning del programa Canvas 11 (ACD Systems Ltd) se midió el porcentaje de área cortical auditiva afectada por la lesión (Figura 8).

Finalmente, y de nuevo para la ilustración, se tomaron fotografías de las superficies temporales de todos los casos lesionados obtenidas en los Brain matrix rodent (v.s.), y con el programa Canvas 11 (ACD Systems Ltd) se escaló la foto del cerebro según el índice de retracción de las secciones histológicas (v.s.), se realizó además una segunda escalada de la fotografía, para que $1 \mathrm{~mm}$ del esquema-plantilla fuese igual a $1 \mathrm{~mm}$ de la regla de referencia de la fotografía. A continuación,se realizó la superposición de la fisura rinal y el cero Interaural entre el esquema de la lesión (realizado con las 5 secciones histológicas (v.s.,) y el mapa de parcelación cortical de referencia). Se siguió idéntica metodología para la localización de lesiones en regiones no auditivas, pero en estos casos se tomaron como referencia principal el punto Bregma y la sutura sagital (Figura 9).

\section{Análisis de la inmunotinción para c-Fos.}

Para la cuantificación de las neuronas inmunorreactivas para c-Fos se aplicaron técnicas de análisis estereológico, morfométrico y densitométrico, sobre imágenes (mosaicos fotográficos) obtenidas utilizando el programa de Neurolucida 8.o (Micro Bright Field, Inc, Vermont, EEUU), específicamente la prueba Acquiring virtual slides. Para este fin primero se dibujó el contorno de la estructura que se deseaba fotografiar, utilizando un objetivo de bajo aumento

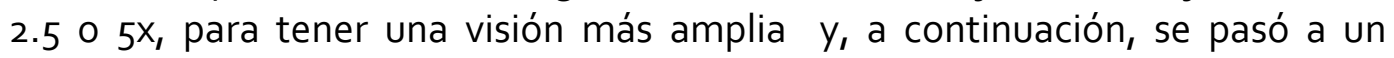
objetivo de mayor aumento, en nuestro caso en particular un objetivo de 20x, y se aplicó la prueba. Se obtuvieron mosaicos que incluían múltiples fotografías con muy alta resolución.

- Cálculo del número de núcleos c-Fos positivos (estereología).

Para evaluar mediante técnicas estereológicas el número de neuronas c-Fos inmunorreactivas en cada una de las subdivisiones del $\mathrm{Cl}$, se siguió idéntico 


\section{FIGURA 8.}

Representación gráfica de la localización de todas las lesiones en cortezas auditivas, organizadas por grupos experimentales, y superpuestas sobre el esquema-plantilla realizado en nuestras propias secciones, con nuestros propios índices de retracción, utilizando los casos del grupo 1 , Tabla $\mathrm{No}_{1}$, teñidos contra SMI-32 y Nissl. Cada una de los contornos en colores representa una zona de lesión "real". En cada uno de los apartados, se describe además la extensión en porcentaje de la afectación en cada uno de los casos intragrupos. 
Localización de las lesiones en las Cortezas Auditivas

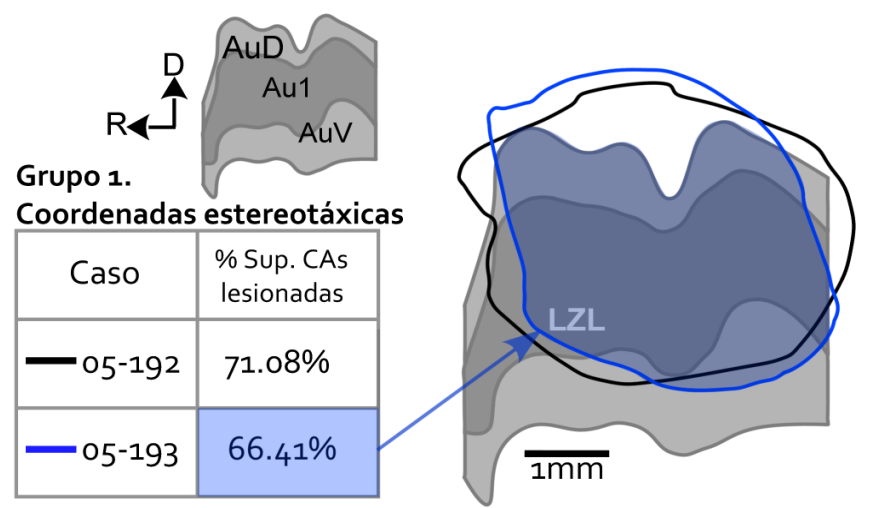

Grupo 5 a.
RAS/IPP
\begin{tabular}{|c|c|}
\hline Caso & $\begin{array}{c}\% \text { Sup. CAs } \\
\text { lesionadas }\end{array}$ \\
\hline $07-102$ & $67.24 \%$ \\
\hline $07-213$ & $53.77 \%$ \\
\hline $07-215$ & $68.46 \%$ \\
\hline $07-255$ & $71.21 \%$ \\
\hline $07-256$ & $71.09 \%$ \\
\hline
\end{tabular}

\section{Grupo 8.}

c-Fos 15 días pl

\begin{tabular}{|c|c|}
\hline C-Fos 15 dias pl \\
\hline Caso & $\begin{array}{c}\% \text { Sup. CAs } \\
\text { lesionadas }\end{array}$ \\
\hline $09-012$ & $68,26 \%$ \\
\hline $09-013$ & $77.70 \%$ \\
\hline $09-014$ & $58.30 \%$ \\
\hline $09-015$ & $65.47 \%$ \\
\hline
\end{tabular}

Grupo 11.

Calretinina 15 días $\mathrm{pl}$

\begin{tabular}{|c|c|}
\hline Caso & $\begin{array}{c}\% \text { Sup. CAs } \\
\text { lesionadas }\end{array}$ \\
\hline $05-214$ & $69.53 \%$ \\
\hline $06-001$ & $84.21 \%$ \\
\hline $06-005$ & $88.17 \%$ \\
\hline $06-108$ & $86.44 \%$ \\
\hline
\end{tabular}

\section{Grupo 13.}

Calretinina 180 días pl
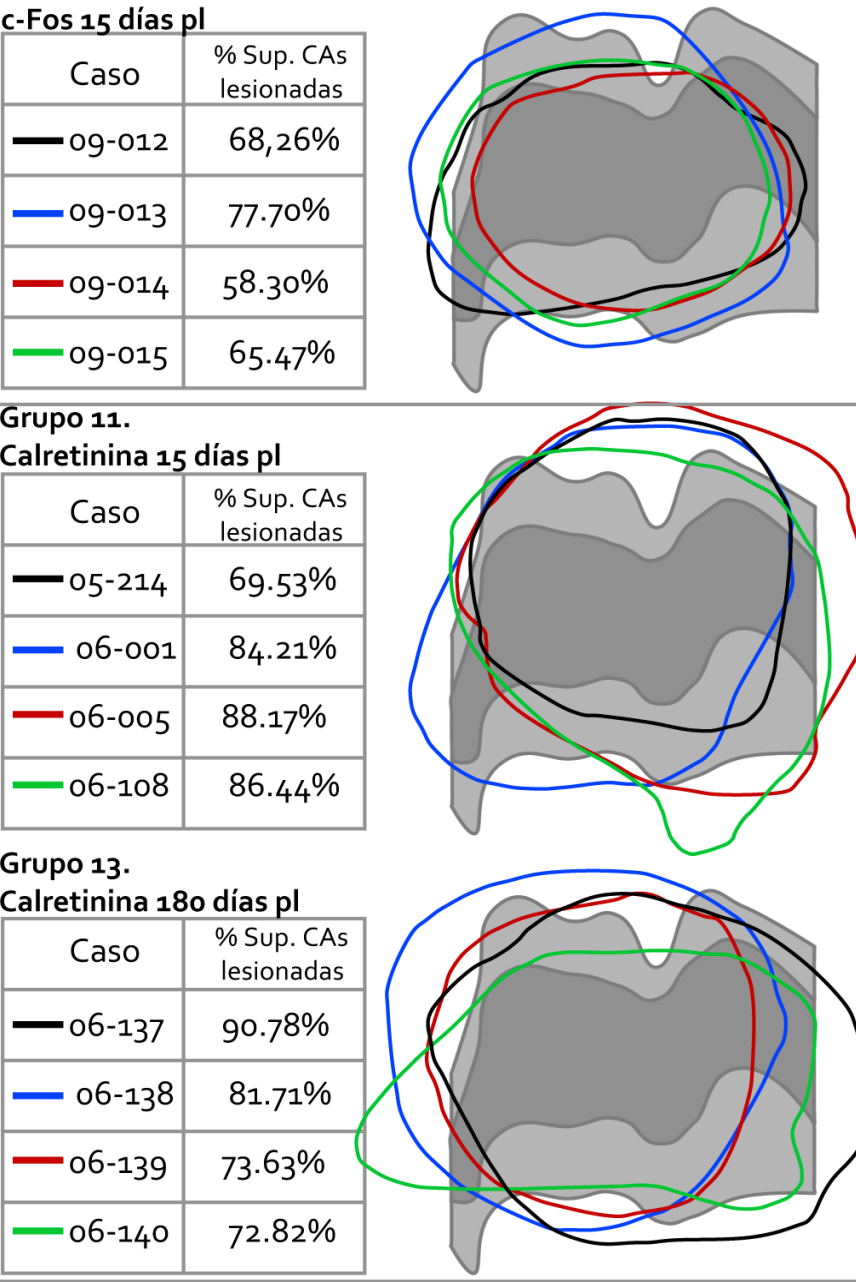

Grupo 3.

Potenciales evocados del tronco

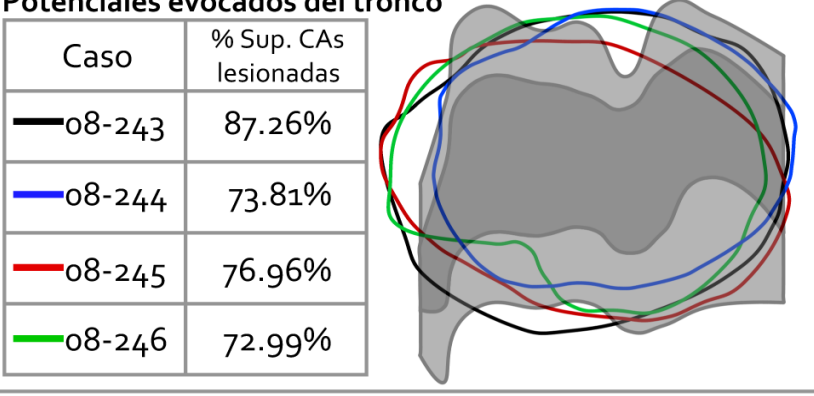

Grupo 5b.

RAS/IPP

\begin{tabular}{|c|c|}
\hline RAS/IPP & $\begin{array}{c}\% \text { Sup. CAs } \\
\text { lesionadas }\end{array}$ \\
\hline$-07-310$ & $61.11 \%$ \\
\hline$-07-311$ & $63.99 \%$ \\
\hline$-07-406$ & $60.01 \%$ \\
\hline$-08-070$ & $60.41 \%$ \\
\hline$-08-071$ & $76.85 \%$ \\
\hline
\end{tabular}

Grupo 9.

c-Fos go días pl
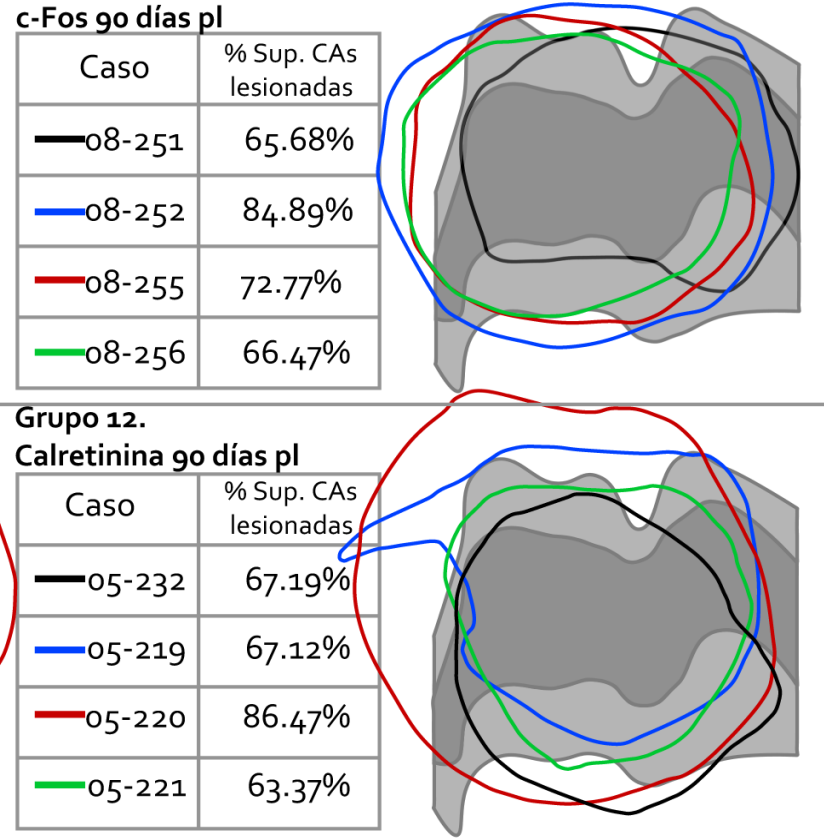

\section{Grupo 14.}

Calretinina 240 dias $\mathrm{pl}$

\begin{tabular}{|l|r|}
\hline Caso & $\begin{array}{c}\% \text { Sup. CAs } \\
\text { lesionadas }\end{array}$ \\
\hline $07-167$ & $72.73 \%$ \\
\hline $07-168$ & $63.24 \%$ \\
\hline $07-169$ & $78.68 \%$ \\
\hline $07-201$ & $71.78 \%$ \\
\hline
\end{tabular}

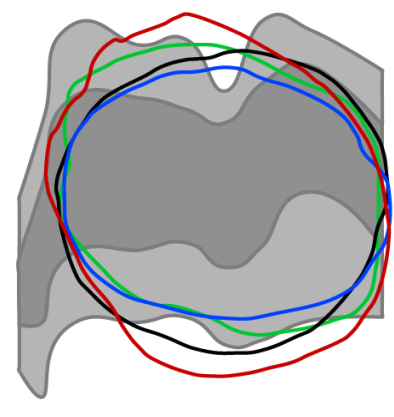




\section{Localización de las lesiones en las Cortezas Auditivas}

Grupo 17.

Sq RT-PCR-15 dias pl

\begin{tabular}{|c|c|}
\hline Caso & $\begin{array}{c}\% \text { Sup. CAs } \\
\text { lesionadas }\end{array}$ \\
\hline$-08-026$ & $82.37 \%$ \\
\hline $08-027$ & $86.73 \%$ \\
\hline$-08-028$ & $79.87 \%$ \\
\hline$-08-029$ & $84.32 \%$ \\
\hline$-08-030$ & $77.96 \%$ \\
\hline$-08-031$ & $76.89 \%$ \\
\hline
\end{tabular}

\section{Grupo 19.}

Sq RT-PCR-180 dias pl

\begin{tabular}{|c|c|}
\hline Caso & $\begin{array}{c}\% \text { Sup. CAs } \\
\text { lesionadas }\end{array}$ \\
\hline$-07-098$ & $62.51 \%$ \\
\hline $07-099$ & $62.20 \%$ \\
\hline $07-102$ & $68.14 \%$ \\
\hline $07-103$ & $68.50 \%$ \\
\hline $05-232$ & $74.82 \%$ \\
\hline $05-242$ & $79.87 \%$ \\
\hline
\end{tabular}

\section{Grupo 22.}

real time RT-PCR-go días pl

\begin{tabular}{|c|c|}
\hline Caso & $\begin{array}{c}\% \text { Sup. CAs } \\
\text { lesionadas }\end{array}$ \\
\hline 08-229 & $91.02 \%$ \\
\hline o8-231 & $92.28 \%$ \\
\hline 08-232 & $93.91 \%$ \\
\hline$-08-233$ & $75.24 \%$ \\
\hline$-08-234$ & $81.63 \%$ \\
\hline o9-023 & $76.90 \%$ \\
\hline
\end{tabular}

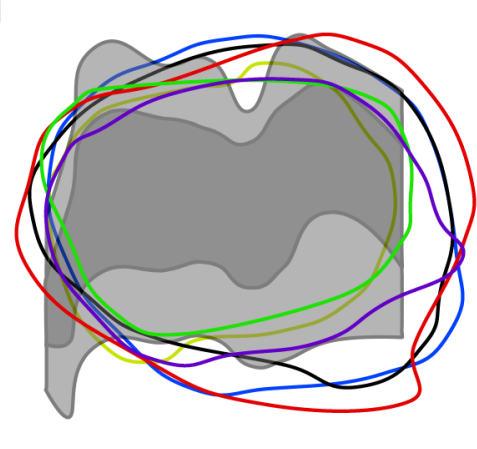

\section{Grupo 25.}

MicroArrays 15 días pl

\begin{tabular}{|c|c|}
\hline MicroArrays 15 días pl \\
\hline Caso & $\begin{array}{c}\% \text { Sup. CAs } \\
\text { lesionadas }\end{array}$ \\
\hline $09-020$ & $60.40 \%$ \\
\hline $09-021$ & $75.40 \%$ \\
\hline $09-024$ & $73.41 \%$ \\
\hline
\end{tabular}

$\overline{1 \mathrm{~mm}}$

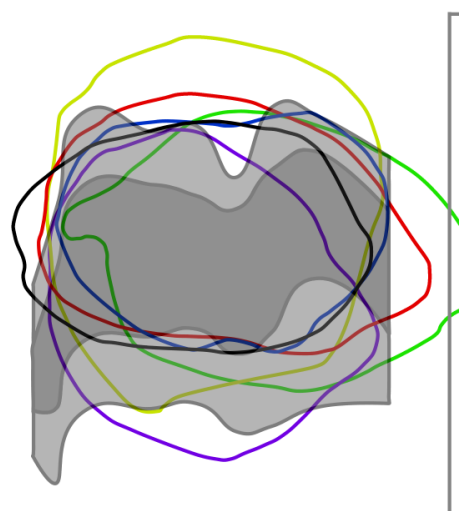

Grupo 18.

Sq RT-PCR-go días pl

\begin{tabular}{|c|c|}
\hline Caso & $\begin{array}{c}\% \text { Sup. CAs } \\
\text { lesionadas }\end{array}$ \\
\hline$-08-074$ & $57.08 \%$ \\
\hline$-08-075$ & $92.23 \%$ \\
\hline$-08-076$ & $67.38 \%$ \\
\hline$-08-247$ & $84.81 \%$ \\
\hline$-08-249$ & $60.16 \%$ \\
\hline$-08-250$ & $62.31 \%$ \\
\hline
\end{tabular}

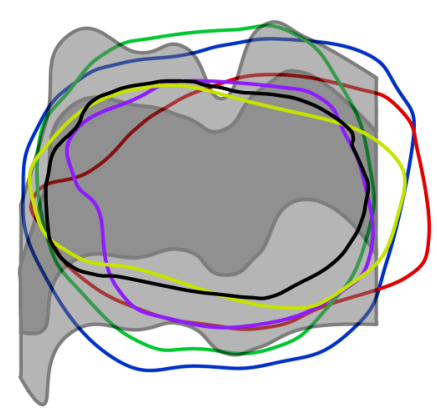

\begin{tabular}{|c|c|}
\hline \multicolumn{2}{|c|}{$\begin{array}{l}\text { Grupo } 21 . \\
\text { real time RT-PCR-15 días p }\end{array}$} \\
\hline Caso & $\begin{array}{l}\text { \% Sup. CAs } \\
\text { lesionadas }\end{array}$ \\
\hline$-08-072$ & $83.09 \%$ \\
\hline $08-257$ & $70.60 \%$ \\
\hline $08-258$ & $67.48 \%$ \\
\hline - 08-259 & $72.45 \%$ \\
\hline$-08-261$ & $68.92 \%$ \\
\hline$-08-262$ & $69.95 \%$ \\
\hline
\end{tabular}

Grupo 23.

real time RT-PCR-180 días pl

\begin{tabular}{|c|c|}
\hline Caso & $\begin{array}{c}\% \text { Sup. CAs } \\
\text { lesionadas }\end{array}$ \\
\hline 06-182 & $74.52 \%$ \\
\hline $06-183$ & $75.21 \%$ \\
\hline $06-185$ & $70.47 \%$ \\
\hline $07-099$ & $65.32 \%$ \\
\hline $07-165$ & $70.32 \%$ \\
\hline $07-166$ & $82.44 \%$ \\
\hline
\end{tabular}

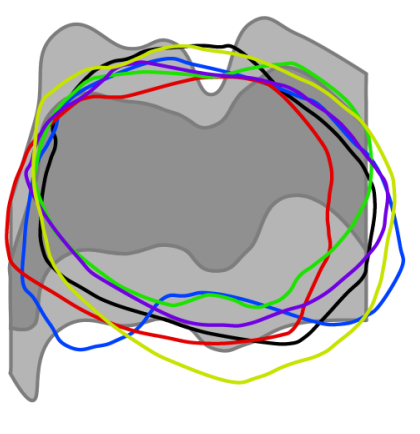

Grupo 26.

MicroArrays go días pl

\begin{tabular}{|c|c|}
\hline MicroArrays 90 días pl \\
\hline Caso & $\begin{array}{c}\text { \% Sup. CAs } \\
\text { lesionadas }\end{array}$ \\
\hline $08-236$ & $92.96 \%$ \\
\hline $08-258$ & $62.56 \%$ \\
\hline $08-261$ & $67.05 \%$ \\
\hline
\end{tabular}



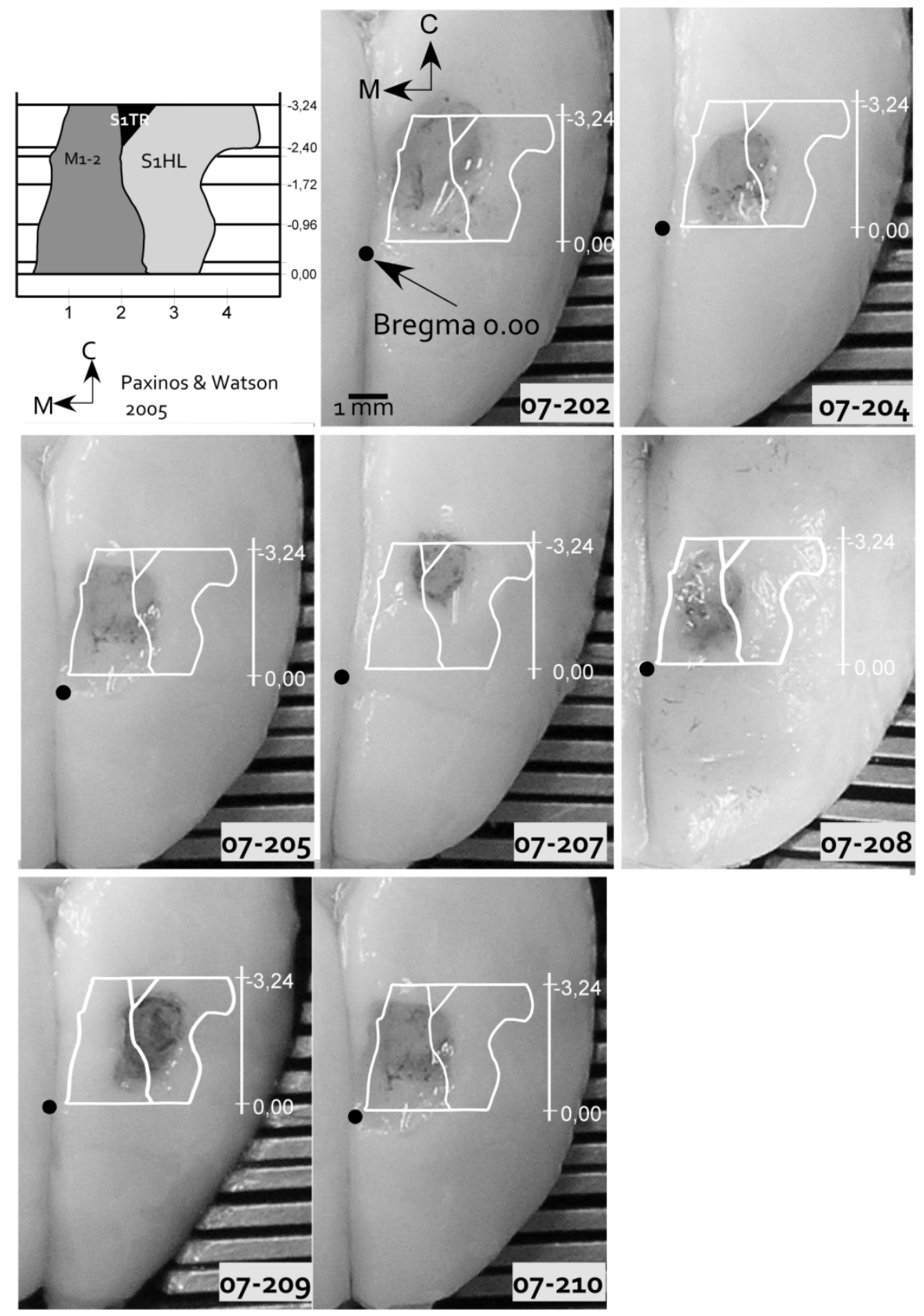

\section{FIGURA 9.}

Fotografías coronales de los cerebros de animales ablacionados en regionesnoauditivas. Estas lesiones abarcaron parte de las cortezas somatosensoriales primarias $\left(\mathrm{S}_{1} \mathrm{HL}, \mathrm{S}_{1} \mathrm{TR}\right)$ y parte de las cortezas motoras primaria y secundaria ( $M_{1}$ y $M_{2}$ ). La principal línea de orientación en estos casos es el punto Bregma $\mathrm{O}, \mathrm{O} \mathrm{mm}$ (punto), determinado por la inserción de una aguja entomológica guiada por estereotaxia justo antes del sacrificio. 
protocolo al descrito para la proteína Calretinina (v.i.). Solo variaron, tras realizar la prueba preliminary population estimates, los parámetros de dimensión del recuadro de contaje y de la distancia $(X, Y)$ de la plantilla. Los parámetros se modificaron tanto entre subdivisiones del colículo inferior, como entre cada grupo experimental, variación debida a las diferentes densidades de células cFos inmunorreactivas entre las subdivisiones.

Grupo Control estimulado

\begin{tabular}{|c|c|c|c|}
\hline Subdivisión & $\begin{array}{c}\text { Dimensiones recuadro } \\
\text { de conteo }\end{array}$ & Distancia X & Distancia Y \\
\hline Cortezas Dorsal y Externa & $40 \times 40$ & 120 & 120 \\
\hline Núcleo central & $40 \times 40$ & 100 & 100 \\
\hline
\end{tabular}

Grupo 15 días postlesión

\begin{tabular}{|c|c|c|c|}
\hline Subdivisión & $\begin{array}{c}\text { Dimensiones recuadro } \\
\text { de conteo }\end{array}$ & Distancia X & Distancia Y \\
\hline Cortezas Dorsal & $40 \times 40$ & 100 & 100 \\
\hline Corteza Externa & $40 \times 40$ & 95 & 95 \\
\hline Núcleo central & $40 \times 40$ & 95 & 95 \\
\hline
\end{tabular}

Grupo go días postlesión

\begin{tabular}{|c|c|c|c|}
\hline Subdivisión & $\begin{array}{c}\text { Dimensiones recuadro } \\
\text { de conteo }\end{array}$ & Distancia X & Distancia Y \\
\hline Cortezas Dorsal & $40 \times 40$ & 120 & 120 \\
\hline Corteza Externa & $40 \times 40$ & 100 & 100 \\
\hline Núcleo central & $40 \times 40$ & 95 & 95 \\
\hline
\end{tabular}

- Morfometría y densitometría para c-Fos.

Se utilizó para estos análisis el programa Scion ImageJ 1.40g (National Institutes of Health). Se seleccionaron en cada uno de los casos de los grupos experimentales cuatro secciones histológicas correspondientes a los mismos niveles interaurales de corte en el eje rostro-caudal. De ellas se capturaron mosaicos de imágenes (Neurolucida Vs 8.o MicroBrightField, Inc Willinston, VI, EEUU) con el objetivo $X_{20}$ generando documentos de alta resolución en formato de imagen TIFF. 
Para establecer el rango de segmentación se siluetearon y analizaron 700 partículas de los 3 niveles de corte de los animales controles con estimulación auditiva. Se obtuvieron valores promedios de grises situados entre el $\mathrm{O}$ y 86.8 . Se procedió a ajustar mediante control por visualización directa de las secciones (juicio del operador), los valores de segmentación en 6 secciones tomadas aleatoriamente, fijando el rango de segmentación final de núcleos coliculares cFos positivos entre $\mathrm{O}$ y 88 . Con este rango establecido se segmentaron y analizaron todas las secciones en el grupo control y en los experimentales, solicitando al programa Scion Image $1.40 \mathrm{~g}$ el análisis del valor medio de grises, la desviación estándar y el perímetro de las partículas o núcleos c-Fos positivos. Los valores se trasladaron a una base de Excel valorándose los promedios y la desviación estándar.

Análisis de la expresión de la proteína Calretinina en el Colículo Inferior.

Para valorar si la deaferentación de la proyección corticocolicular, que morfológicamente afecta directamente a las tres subdivisiones ipsilaterales y a dos subdivisiones contralaterales de este núcleo, realizamos un análisis del número de neuronas inmunorreactivas para $C R$, bilateralmente, en cada una de

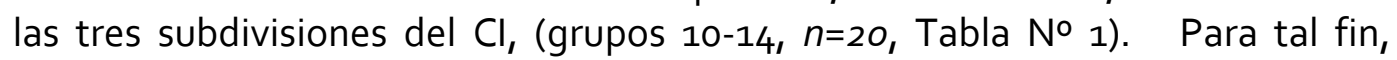
utilizamos el programa Stereoinvestigator 8.o (Micro Bright Field, Inc, Vermont, EEUU), específicamente las pruebas de Estimación preliminar de la población (Preliminary population estimates) y la prueba del Fraccionador Óptico (Optical fractionator).

Como primer paso se enumeró, en cada uno de los casos, el número de cortes en dirección rostro-caudal, en donde se apreciaban estructuralmente los límites del $\mathrm{Cl}$ (con una media de 40 cortes de $40 \mu \mathrm{m}$, en los que se apreciaba claramente este núcleo), numeración indispensable para poder confluir los datos estereológicos de todas las secciones de un animal en un solo valor (serial section manager).

El análisis estereológico se realizó utilizando el programa de análisis Stereoinvestigator 8.o (Micro Bright Field, Inc, Vermont, EEUU), que además controla la platina motorizada Märzhäuser SCAN-series XYZ para una navegación integrada $\left({ }_{3} D\right)$ a través de las secciones histológicas, disminuyendo los errores del operador.Esta platina, a su vez, se montó en un microscopio LEICA DMRB que tenía incorporado una video cámara CX 9000 (MicroBrightField, Inc Willinston, VI, EEUU), que enviaba imágenes en vivo al programa integrado para su posterior análisis en una pantalla de alta resolución. Se utilizó, además, un objetivo Plan - apocromático de X100/1.40-0.7, $\infty / 0.17 / D$ de inmersión en aceite para el conteo de las células. 
- Cálculo del número de neuronas CR-inmunorreactivas.

Para realizar el análisis estereológico se utilizó la prueba del Fraccionador óptico (West y cols., 1991), que combina la prueba del disector óptico con el muestreo fraccionador y que nos permitió estimar un número de neuronas en una región específica, las subdivisiones del colículo inferior. Esta estimación no se afectó por la retracción del tejido, ya que la prueba tiene como parámetros obligatorios registrar el grosor de corte de las secciones y el grosor real de las mismas. De esta forma, primero, se enumeraron los cortes que incluían el $\mathrm{Cl}$, y a partir de este número calculamos como periodicidad o intervalo de análisis $=4$, es decir, se contaron en 1 de cada 4 cortes histológicos las células inmunorreactivas para Calretinina. Estos cortes fueron medidos con antelación variando el eje $Z$ (profundidad) con el objetivo x100 en, por lo menos, 3 puntos diferentes de cada $\mathrm{Cl}$ para determinar el grosor real de las secciones, posterior a los procesos de fijación, montaje y deshidratación, valor indispensable para la prueba estereológica, además de establecer la zona de guarda o protegida (guard zone), que es la región comprendida entre la parte superior de la sección y la parte superior del recuadro de conteo, y que no se incluye dentro de la profundidad de foco, con el fin de evitar las irregularidades que ocurren en la superficie de la sección histológica. En nuestros casos, el valor de esta zona protegida fue de 3 $\mu \mathrm{m}$.

A continuación, recurrimos a una prueba contenida en el programa (Preliminary Population Estimates), que nos ayudó a establecer las dimensiones del recuadro de contaje y el número de recuadros incluidos en el muestreo de cada sección, determinado gracias al estimado inicial de la densidad celular en una pequeña área representativa del tejido. Además se tuvo en cuenta, que el tamaño del recuadro se debía ajustar a la densidad celular del área (en nuestro caso, cada una de las tres subdivisiones del $\mathrm{Cl}$ ), pues no es aconsejable contar más de 4 partículas en cada uno de los recuadros, y las cortezas del $\mathrm{Cl}$ presentan una mayor densidad de células CR positivas que el núcleo central.

Parámetros utilizados para el conteo de neuronas $\mathrm{CR} / \mathrm{IRr}$ en el $\mathrm{Cl}$.

\begin{tabular}{|c|c|c|c|}
\hline Subdivisión & $\begin{array}{c}\text { Dimensiones recuadro } \\
\text { de contaje }\end{array}$ & Distancia X & Distancia Y \\
\hline Cortezas Dorsal y Externa & $40 \times 40$ & 102,8 & 122 \\
\hline Núcleo central & $50 \times 50$ & 135 & 135 \\
\hline
\end{tabular}

En las secciones de los casos estudiados la silueta del $\mathrm{Cl}$ fue dibujada previamente utilizando un dispositivo de cámara clara, procediendo a marcar dentro del contorno externo de la estructura, las tres subdivisiones citoarquitecturales: corteza dorsal, corteza externa y núcleo central, utilizando como referencia secciones consecutivas teñidas con el método de Nissl. Los dibujos sirvieron como referencia para delimitar las tres subdivisiones 
citoarquitecturales siguiendo los postulados establecidos por Faye-Lund y Osen (1985) y modificados por Saldaña y Merchán (1992). Con estos dibujos-guías, y utilizando un objetivo de $5 \mathrm{x}$, se dibujaron los contornos de las subdivisiones a estimar, utilizando el programa Stereoinvestigator 8.o.

Las células solo fueron contadas como inmunorreactivas-positivas si estaban a foco dentro del grosor real de la sección (exceptuando la zona de guarda: $3 \mu \mathrm{m}$ ) y si estaban dentro del recuadro de conteo y cumplían con las reglas de conteo (counting rules), que incluyen: que las partículas estén dentro de la profundidad del foco, exceptuando las zonas de guarda, y que ninguna parte de la célula toque las líneas prohibidas dentro del cuadro de conteo, que son la línea izquierda y la línea inferior. Utilizando estas simples reglas, se contaron un mínimo de 250 células inmunorreactivas para $C R$ en cada una de las tres estructuras- subdivisiones del $\mathrm{Cl}$, utilizando la prueba Optical Fractionator (West, y cols., 1991).

Los valores utilizados para los promedios fueron los mostrados por el Estimated Total by Optical Fractionator. Además se calculó para cada uno de los casos el coeficiente de error de Gundersen $\mathrm{m}=1$ (Gundersen, 1999) y se incluyeron solo casos con valores entre el 0.4- 0.6.

Técnicas de Análisis Génico.

Las reacciones de RT-PCR permiten medir la expresión génica, gracias a la amplificación de moléculas dianas de mRNA, mediante la transcripción reversa del RNA a cDNA. Siendo esta técnica mucho más sensible que otras (Northern blot, ensayos de protección de RNAsa, hibridación in situ, ensayos de nucleasas $\mathrm{S}_{1}$ ), y además requiriendo menor cantidad de RNA. La real-time-PCR está basada en la fluorescencia, técnica que permite que la cantidad de producto formado sea monitorizado durante la reacción (La cantidad de señal fluorescente que es generada refleja la cantidad de producto formado).

\section{- Extracción de RNA total}

Una vez extraídos los $\mathrm{Cl}$ de forma bilateral de los grupos controles (grupos 15 , 16, 20 y 24 Tabla No 1) y de los lesionados (grupos 17-19, 21-23, y 25-26 Tabla No 1), se purificó el RNA total de este tejido utilizando el reactivo TRIZOL ${ }^{\circledR}$ (Gibco BRL). Para ello, se utilizó $500 \mathrm{ml}$ de Trizol por cada colículo inferior, y se procedió a la homogeneización del mismo mediante un homogeneizador Brinkmann Polytron. Tras incubar el preparado durante 5 min a temperatura ambiente, se realizó la extracción selectiva del RNA por separación de fases mediante la adición de $200 \mu \mathrm{l}$ de cloroformo por cada $\mathrm{ml}$ de Trizol y centrifugación a $12000 \mathrm{~g}$ durante $15 \mathrm{~min}$ a $4^{\circ} \mathrm{C}$. El RNA obtenido en la fase acuosa superior se precipitó con un volumen de isopropanol igual a la mitad del Trizol utilizado en el primer paso. Se centrifugó a $12000 \mathrm{~g}$ durante $10 \mathrm{~min}$ a $4^{\circ} \mathrm{C}$, 
se eliminó el sobrenadante y se secó el RNA, y, finalmente, se resuspendió en agua tratada con DEPC (dietilpirocarbonato $0.1 \%$, Sigma), incubando a $60^{\circ} \mathrm{C}$ durante 10 min para favorecer la disolución del mismo en caso de ser necesario. Posteriormente, se cuantificó y determinó la "calidad" del RNA purificado, que consiste encomprobar si el RNA extraído no se había degradado. Proceso que se realizó mediante el análisis de una alícuota de cada una de las muestras (RNA purificados) en un RNA 6000 NanoLabChip (Agilent) utilizando un Bioanalizador 2100 (Agilent). Los resultados obtenidos demostraron la buena "calidad" de los RNAs al visualizar nítidamente las bandas de rRNA $18 \mathrm{~S}$ y $28 \mathrm{~S}$.

- Transcripción Reversa- Reacción en cadena de la Polimerasa (RT-PCR)

Las RT-PCRs llevadas a cabo se realizaron en dos pasos; el primer paso consistió en la retrotranscripción de los RNA mensajeros (síntesis de CDNA), y un segundo paso en el que se realizó la amplificación selectiva mediante la técnica de la reacción en cadena de la polimerasa (PCR).Para llevar a cabo la síntesis de CDNA se utilizó el kit ImProm-II ${ }^{T M}$ Reverse Transcripción System (Promega) siguiendo las especificaciones del fabricante. Inicialmente se desnaturalizó por calor una mezcla de $5 \mu \mathrm{g}$ de RNA total y $0.5 \mu \mathrm{g}$ del oligo-dT a $70^{\circ} \mathrm{C}$ durante $5 \mathrm{~min}$, tras lo cual se enfrió en hielo. Esta reacción se añadió a una mezcla preparada previamente que contenía $1 \mu$ l de transcriptasa inversa ImProm- $/ I^{\mathrm{TM}}, 4 \mathrm{ml}$ de buffer $5 \times I m$ Prom- $/ I^{\mathrm{TM}}, \mathrm{MgCl}_{2} 2 \mathrm{mM}$, una mezcla de dNTP (desoxinucleótidos trifosfato) $0.5 \mathrm{mM}, 20 \mathrm{U}$ del inhibidor de ribonucleasas Recombinant RNasin ${ }^{\circledR} \mathrm{y}$ agua libre de $\mathrm{RNasas}$ ( $\mathrm{ddH}_{2} \mathrm{O}$ tratada con DEPC) hasta un volumen final de $15 \mu \mathrm{H}$. La reacción se sometió durante $5 \mathrm{~min}$ a $25^{\circ} \mathrm{C}$, para que el cebador se anillara con el RNA molde. Posteriormente se incubó a $42^{\circ} \mathrm{C}$ durante $1 \mathrm{~h}$, para que la transcriptasa sintetizase el cDNA. Finalmente la transcriptasa inversa se inactivó incubando $15 \mathrm{~min}$ a $70^{\circ} \mathrm{C}$ las mezclas de reacción.

A continuación se realizaron distintas reacciones en cadena de la polimerasa (PCRs) siguiendo el protocolo que se detalla a continuación. Se añadieron al tubo de reacción $25 \mu$ de Tampón necesario para que actúe la Taq DNA polimerasa, $\mathrm{MgCl}_{2} 1.5 \mathrm{mM}$, dNTPs $0.2 \mathrm{mM}$ y $5 \mathrm{U}$ de Taq DNA polimerasa (Promega), $250 \mathrm{ng}$ de cDNA y 20 pmol de cada cebador específico (Tabla No 6) de cada reacción. En todas las PCRs llevadas a cabo siempre se realizó una reacción sin DNA molde como control negativo. Asimismo, como control interno de la cantidad de CDNA empleada en las PCRs, se amplificó por PCR parte del cDNA correspondiente al gen de la $\beta$-Actina (GenBank No NM_031144), el cual se expresa constitutivamente y a niveles de expresión aproximadamente iguales en todos los tejidos y condiciones. La reacción de amplificación se llevó a cabo en un termociclador Perkin Elmer (Geneamp ${ }^{\circledR}$ PCR system 9700). 
Tabla No 6.Cebadores de PCRpara todos los iGluR (RT-PCR semicuantitativa y cuantitativa).

\begin{tabular}{|c|c|c|c|c|c|c|c|c|}
\hline $\begin{array}{c}\text { Gen } \\
\text { Target }\end{array}$ & $\begin{array}{l}\text { Número } \\
\text { GenBank* }\end{array}$ & Cebador Forward & $\begin{array}{c}\text { cDNA } \\
\text { Forward* }\end{array}$ & Cebador Reverse & $\begin{array}{c}\text { ADNc } \\
\text { Reverso* }\end{array}$ & $\begin{array}{l}\text { Tamaño } \\
\text { producto }\end{array}$ & $\mathrm{T}^{\mathrm{a}}$ & $\begin{array}{l}\text { Uso del } \\
\text { Cebador }\end{array}$ \\
\hline \multicolumn{9}{|l|}{$\underline{\text { AMPA }}$} \\
\hline GluR 1 & NM_031608 & TTCTGCACCGGTTTTCTAGG & $219-238$ & CGCATGTTCCTGTGATTGTT & 298-317 & 99 & 60 & * \\
\hline GluR 2 & NM_017261 & CGGCAGCTCAGCTAAAAACT & $173-192$ & TTGTAGCTGGTGGCTGTTGA & $243-262$ & 90 & 60 & \\
\hline GluR3 & NM_032990 & ATTGCTGATGGTGCAATGAC & $2834-2853$ & TTTGCATTGTCGCAAGTCTC & $2909-2928$ & 95 & 53 & \\
\hline GluR4 & NM_017263 & GGCAGAGCCGTCTGTGTTCA & $2255-2275$ & CAGGGCTTTCGCTGCTCAAT & $2361-2380$ & 126 & 53 & \\
\hline \multicolumn{9}{|l|}{ NMDA } \\
\hline $\mathrm{NR}_{1}$ & NM_017010 & TGGCACCACTGACCATCAAC & $1806-1825$ & TCCAGTGTGCTCCTGGGAAT & $1901-1920$ & 115 & 60 & * \\
\hline $\mathrm{NR}_{2} \mathrm{~A}$ & NM_012573 & TCAAGGACAGGGAACGGCTA & $4160-4179$ & AGGATTATCGGAGGCGTGGT & $4301-4320$ & 161 & 60 & \\
\hline $\mathrm{NR}_{2} \mathrm{~B}$ & NM_012574 & GCAAGCTTCCGTCATGCTCA & $806-825$ & CCAGCCCACGAAGCTGTTCT & $922-941$ & 136 & 58 & \\
\hline $\mathrm{NR}_{2} \mathrm{C}$ & NM_012575 & CGGATCTCACCGCAGACTCA & $3206-3225$ & CGGTTGTTGCCCCAGTTCTC & $3322-3341$ & 136 & 58 & \\
\hline $\mathrm{NR} 2 \mathrm{D}$ & NM_022797 & GCCATCGGCTCTCTCACCAT & $2336-2355$ & AGGAAGGCAGAGGGGGACAC & $2444-2463$ & 128 & 58 & \\
\hline $\mathrm{NR}_{3} \mathrm{~A}$ & AFo73379 & AGAGCCAGGGCGAAATGATG & $1075-1094$ & TCTGACTCTCCCGCGGAAAC & $1154-1173$ & 99 & 58 & \\
\hline
\end{tabular}




\begin{tabular}{|c|c|c|c|c|c|c|c|c|}
\hline $\begin{array}{c}\text { Gen } \\
\text { Target }\end{array}$ & $\begin{array}{l}\text { Número } \\
\text { GenBank* }\end{array}$ & Cebador Forward & $\begin{array}{c}\text { cDNA } \\
\text { Forward* }\end{array}$ & Cebador Reverse & $\begin{array}{c}\text { ADNc } \\
\text { Reverso* }\end{array}$ & $\begin{array}{l}\text { Tamaño } \\
\text { producto }\end{array}$ & $\mathrm{T}^{\mathrm{a}}$ & $\begin{array}{l}\text { Uso del } \\
\text { Cebador }\end{array}$ \\
\hline $\mathrm{NR}_{3} \mathrm{~B}$ & NM_133308 & GCTTGTGGCTCAGGCACTCA & $969-990$ & GTTGCCTCAGATCCGCCTGT & $1057-1076$ & 108 & 58 & \\
\hline \multicolumn{9}{|l|}{$\underline{\text { Kainato }}$} \\
\hline GluR5 & NM_017241 & GGGGAATGGAATGGGATGGT & $1718-1737$ & CAGGGTCATGAAGGGCTTGG & $1821-1840$ & 123 & 58 & \\
\hline GluR6 & NM_019309 & CTGAGCTCATGCCCAAAGCA & $2171-2191$ & CGACTCCATGCGTTCCACAG & $2279-2298$ & 128 & 60 & * \\
\hline GluR7 & NM_181373 & ACTCCGCAAGACAGCGGAAC & $2672-2693$ & GGAGGCTGTGGCTTGTGCTT & $2803-2822$ & 111 & 58 & \\
\hline GluRd1 & NM_024378 & CACCGCATCTCTTCCCTGCT & $1034-1053$ & TCCGGTCTTCCAGCTTCCTG & $1144-1164$ & 130 & 58 & \\
\hline GluRd2 & NM_024379 & TTCGCATGAAGGGGCTGAAT & $2383-2402$ & GCCTGCTTGGGACTCCAGAA & $2476-2495$ & 113 & 58 & \\
\hline
\end{tabular}

(*). La localización del cebador en las secuencias para la rata del GenBank y su temperatura de desnaturalización son indicadas. 
El programa de amplificación de las PCRs constó de un primer paso de desnaturalización inicial ( 1 ciclo a $95^{\circ} \mathrm{C}$ durante $5 \mathrm{~min}$.), seguido de una desnaturalización a $95^{\circ} \mathrm{C}$ durante $30 \mathrm{seg}$, anillamiento a $53-60^{\circ} \mathrm{C}$ (dependiendo de la pareja de cebadores utilizados) durante $30 \mathrm{seg}$ y una extensión durante $60 \mathrm{seg}$ (estas tres etapas se repitieron durante 35 ciclos), finalmente un único ciclo de extensión final durante $10 \mathrm{~min}$ a $72^{\circ} \mathrm{C}$.

Los productos de la PCR fueron sometidos a electroforesis en geles de agarosa embebidos en TBE 1 X (40 mM Tris-acetato, 1 mM EDTA, pH 8.0). Previamente, el producto de reacción fue mezclado con tampón de carga que contenía dos colorantes, el xyleno-cianol y bromofenol que migran aproximadamente con fragmentos de $5.0 \mathrm{y}$ $0.5 \mathrm{~kb}$ respectivamente en geles de agarosa al $0.8 \%$. Paralelamente, en los geles se incluyó un marcador de peso molecular, que consistió en DNA del fago fX-174 digerido con la endonucleasa Haelll y que genera fragmentos de tamaño: 1.35, 1.08, 0.87, 0.63, $0.31,0.28,0.27,0.23,0.19,0.12$ y $0.07 \mathrm{~kb}$.

La visualización del DNA tras la migración se realizó incubando el gel en una solución de bromuro de etidio $(0.5 \mu \mathrm{g} / \mathrm{ml})$ durante $20 \mathrm{~min}$. Este colorante actúa intercalándose entre las bases nitrogenadas del DNA y emitiendo fluorescencia al exponerse a la luz ultravioleta. El patrón de migración de fragmentos se registró con una cámara digital (Kodak DC29o) bajo iluminación UV, usando el programa Kodak Digital Science $1 D$.

\section{- PCR cuantitativa.}

Además, para evaluar la regulación temporal de los cambios plásticos en los iGluRs, utilizamos la técnica de PCR cuantitativa, que nos permitió evaluar de forma cuantitativa dos subunidades representativasde cada uno de los 3 tipos de iGluRs. Se escogió para los rAMPA las subunidades GluR1 y GluR2; para los rNMDA: NR1 y NR2A y para los rKainatos: GluR5 y GluR6

La técnica de real time PCR o PCR cuantitativa ( $q P C R$ ) fue hecha utilizando $1 \mathrm{ng}$ de CDNA de cada una de las muestras, aplicando el método de SYBR-Green (fluorocromo no específico). Esta molécula actúa intercalándose en el surco menor de la doble hélice del DNA, y en esas condiciones la emisión de su fluorescencia (con pico máximo a $520 \mathrm{~nm}$ ), es detectada por el termociclador, permitiendo un seguimiento del proceso en tiempo real.A medida que pasan los ciclos, el producto de PCR, y por tanto la señal detectada, aumentan de forma exponencial, hasta que los reactivos comienzan a agotarse o se produce la inhibición por producto final.

En nuestros experimentos, El SYBR-Green fue incluido en un Master Mix $2 \mathrm{X}$ [tinción SYBR-Green, dNTPs, la referencia pasiva (ROX), La polimerasa DNA[AmpliTaqı Gold] de Applied Biosystems (Alcobendas, Madrid, España). El volumen final para cada una de las reacciones fue de $20-\mu \mathrm{l}$ : $10-\mu \mathrm{l}$ de la mezcla maestra, $0.8 \mu \mathrm{l}$ para cada oligonucleótido. Empleando $7.4 \mu \mathrm{l}$ de agua miliQ y $1 \mu \mathrm{l}$ de cDNA en la concentración deseada (1.10 0 $25 \mathrm{ng} / \mathrm{ml}$ ). Una curva estándar fue construida para cada uno de los experimentos conlas siguientes diluciones seriadas de 
cDNA: $10 \mathrm{ng} / \mathrm{ml}, 1 \mathrm{ng} / \mathrm{ml}, 0.1 \mathrm{ng} / \mathrm{ml}$ and $0.01 \mathrm{ng} / \mathrm{ml}$. La reacción de amplificación se realizó utilizando el sistema de detección $\mathrm{ABI}$ Prism 7300 (Applied Biosystems), con las siguientes condiciones: $10 \mathrm{~min}$ a $95^{\circ} \mathrm{C}$, seguido por 37 ciclos de $15 \mathrm{~S}$ a $95^{\circ} \mathrm{C}$ y $1 \mathrm{~min}$ a $60^{\circ} \mathrm{C}$. Así mismo, se realizó una curva de disociación de los productos de PCR obtenidos para determinar su especificidad.

El número de moléculas de cDNA fue calculado por comparación con la curva estándar de cantidades conocidas de los productos correspondientes de la PCR. Tres reacciones de PCR fueron realizadas para cada una de las muestras, y cada experimento fue repetido en 3 ocasiones. Se utilizó además, el gen housekeepingß-actina (GenBank accession No. NM_031144), como un control endógeno y una muestra control libre de RNA (negativo). Para eliminar la posibilidad de que fragmentos amplificados fuesen resultados del DNAgenómico, los cebadores diseñados fueron interexónicos.

- Análisis estadístico para los estudios génicos en el $\mathrm{Cl}$.

El nivel de expresión de cada gen analizado se calculó como la media \pm la desviación estándar (SD). El nivel de expresión de los grupos lesionados fue comparado estadísticamente con la media del grupo control, utilizando la distribución de $t$ de Student no pareada, asumiendo varianzas desiguales; * $p \leq 0.05 ; * * p \leq 0.005$ and *** $p \leq 0.001$. 
RESULTADOS 


\section{Localización de las lesiones.}

\section{En Cortezas Auditivas.}

En los 80 animales con ablación unilateral de las CAs (Tabla $N^{\circ} 1$ ), se analizó la localización de las lesiones siguiendo una metodología basada en el estudio citoarquitectural de secciones seriadas (Figura 5). Como condición previa consideramos como casos válidos, en esta investigación, aquellos en los que se observó una zona de lesión que afectase a las 3 regiones auditivas (Au1, AuD y $\mathrm{AuV}$ ) y que en profundidad incluyese, como mínimo, hasta la capa $V$ cortical, sin afectar la sustancia blanca subyacente. Se observaron variaciones, tanto en la extensión como en la localización de las lesiones, pero la mayoría de ellas afectaron ampliamente a las cortezas auditivas primarias y secundarias (Figura 8). El porcentaje de superficie de lesión de las CAs varió entre el $53.77 \%$ y el 93.91\%, con un promedio de afectación del 73,71\% (Tabla Nº 7).

El estudio histológico también mostró, en todos los grupos experimentales con ablación, bordes de lesión limpios y netos y ausencia de infiltrados inflamatorios (Figura 10). Aunque la mayor superficie de lesión en todos los casos estuvo circunscrita a los límites de las CAs, también se afectaron levemente las cortezas adyacentes, tanto en el eje rostro-caudal (corteza Temporal Asociativa, $n=20$; Corteza Somatosensorial secundaria, $n=14$ ) como en el eje dorso-ventral (Cortezas somatosensoriales o Cortezas parietales y visuales, $n=30$; Corteza Ectorrinal y Temporal Asociativa, $n=17$ ) (Figura 8).

Controles con lesión en Cortezas No-Auditivas.

En este grupo se observó que las zonas de lesiones afectaron principalmente a parte de la corteza motora primaria y secundaria y a parte de la corteza somatosensorial (Figura 9). En cuanto a la profundidad de las lesiones, éstas se vieron restringidas a las capas intermedias y profundas de la corteza y no se observó en ningún caso daños a la sustancia blanca subyacente.

\section{Respuesta auditiva del tallo cerebral (ABRs)}

Estas pruebas fueron realizadas para valorar de forma longitudinal el estado funcional de la vía auditiva en los diferentes grupos experimentales de forma longitudinal (15 y 90 días pl, grupos 2 y 3, Tabla $N^{\circ} 1$ ). Se analizó el umbral auditivo y los cambios en la velocidad de conducción de los estímulos sonoros (latencia) en los distintos escalones de la vía auditiva tras estimulación con click y tonos puros.

En los animales controles $(n=4)$ observamos umbrales inferiores a $30 \mathrm{~dB}$ SPL (Figura $11 \mathrm{~A}$ ), que está dentro de los rangos normales para esta especie. Sin embargo, en los animales lesionados con 15 días pl encontramos un aumento 


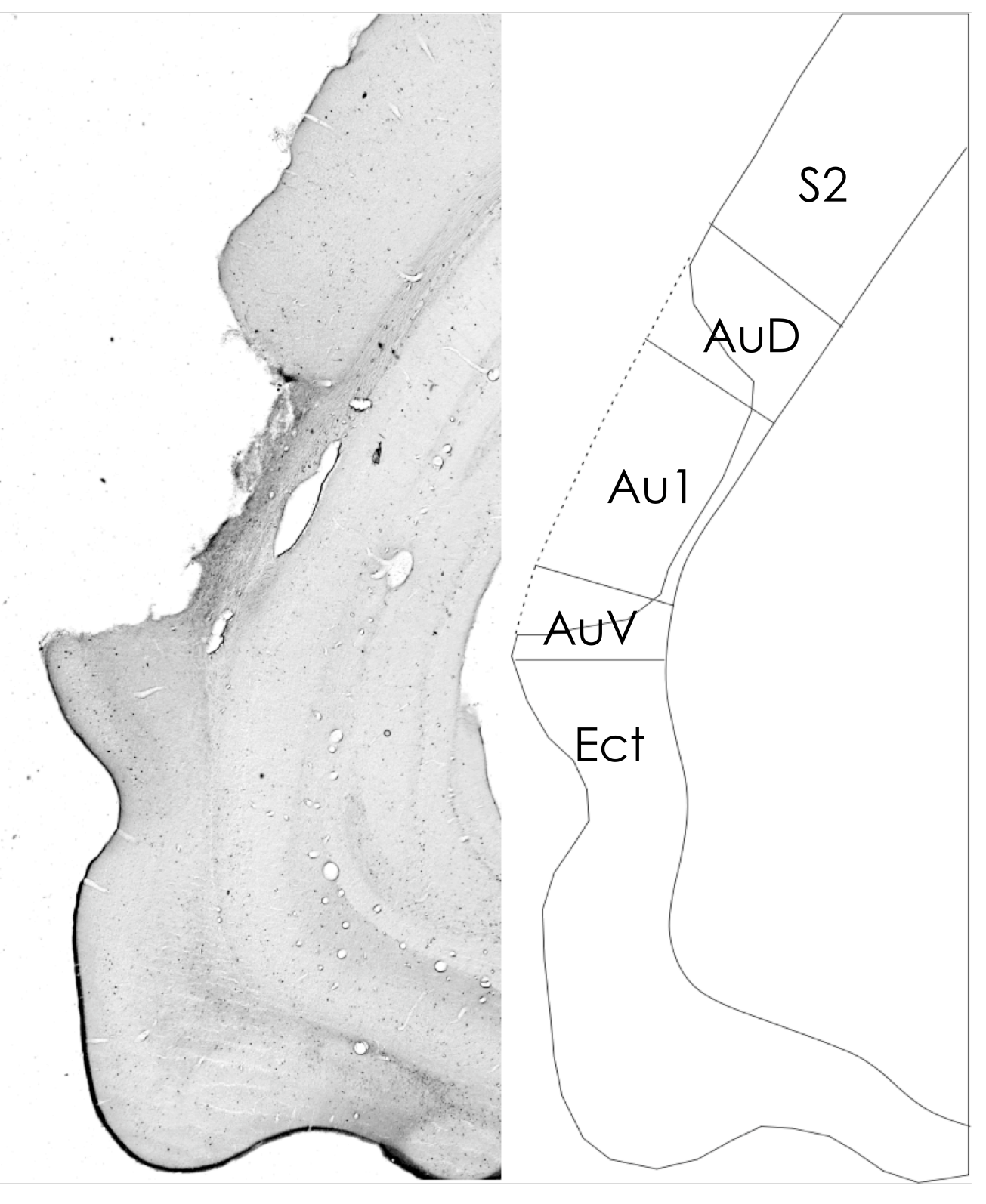

FIGURA 10.

Microfotografía de una zona típica de lesión en la corteza auditiva (teñida con calretinina), con su correspondiente representación gráfica, en donde se indican los límites de las cortezas lesionadas y las adyacentes y el contorno de la lesión. Nótese la ablación no afecta a la sustancia blanca subyacente. Nivel interaural $5.64 \mathrm{~mm}$. 
estadísticamente significativo del $48 \%$ en el valor de los umbrales (Figura $11 \mathrm{~A}$ ). En los casos lesionados (estudio longitudinal), pero con un tiempo de supervivencia de 90 días $\mathrm{pl}$, se advirtió un aumento en los valores promedio del umbral auditivo con respecto al grupo control del $14.91 \%$, incremento que no fue estadísticamente significativo (Figura 11A).

Cuando evaluamos estos mismos casos ( 15 y $90 \mathrm{~d}$ pl) tras estimulación con tonos puros y analizando diferentes frecuencias de estimulación $(8,16,20$ y 28 $\mathrm{kHz}$ ), observamos que el grupo control mostró umbrales en torno a los $40 \mathrm{~dB}$ $\mathrm{SPL}$ (Figura 11B), con valores más bajos para las frecuencias medias (16 y 20 $\mathrm{kHz}$ ) y que está dentro del rango normal para la especie. En los animales lesionados con 15 días de supervivencia pl, encontramos un marcado incremento en el umbral para todas las frecuencias analizadas, afectando principalmente a las altas- 20 y $28 \mathrm{~dB}$ (Figura $11 B$ ). En este mismo grupo, pero a los 90 días $\mathrm{pl}$, encontramos una recuperación de los valores para todas las frecuencias analizadas en los umbrales auditivos, que no mostraron diferencias significativas con el grupo control (Figura 11B).

Además se analizaron en el tiempo, las amplitudes para cada una de las ondas características de los ABRs (Figura $11 \mathrm{C}$ ) para niveles sonoros comprendidos entre los 30 y los $90 \mathrm{~dB}$ SPL. En este parámetro se observó una muy marcada disminución en la amplitud de todas las ondas (I-V) en los animales del grupo de 15 días pl, y una recuperación de esta amplitud a los 90 días pl, muy similar al grupo control (Figura 11C).

También se analizaron las latencias interpicos (tiempo transcurrido desde la emisión del estímulo sonoro hasta la aparición de los picos de las ondas características en los ABRs, que se corresponden con: I: ganglio coclear y nervio auditivo, II: núcleos cocleares, III: complejo olivar superior, IV: lemnisco lateral y V: colículo inferior) tras estimulación con sonido tipo click, para los pico I a $\mathrm{V}$ y las latencias interpicos I-II, II-IV y I-IV. Los animales controles presentaron las latencias características para esta especie (Figura 11D), mientras que al compararlos con el grupo de 15 días pl, se observó un valor promedio de latencia superior al del grupo control (que no resultó estadísticamente significativo), especialmente para los picos III, IV y V (Figura 11D). Los valores de las latencia interpico II-IV y I-V también se mostraron aumentados con respecto al grupo control, pero en ninguno de los casos estos aumentos fueron estadísticamente significativos (Figura 11D). En este mismo grupo lesionado, pero a los 90 días (estudio longitudinal), se encontraron valores de latencia similares a los del grupo control (Figura 11D). 
FIGURA 11. Respuestas Auditivas del Tronco del encéfalo (ABRs)-estudio longitudinal.

(A) Gráfica que muestra la evolución temporal de los cambios en los umbrales auditivos evaluados utilizando la técnica de los ABRs, para la estimulación de los grupos experimentales se utilizaron sonidos de tipo click. Nótese que existen diferencias estadísticamente significativas entre el grupo control y el grupo de 15 días pl. Mientras que en el grupo de los 90 días pl hay una recuperación clara de la capacidad de respuesta muy cercana a los valores controles. (B) Respuestas tras estimulación con tonos burst- Audiograma. A los 15 días pl se observan diferencias significativas en relación con el grupo control, mientras que nuevamente a los go días pl éstos presentan unas respuestas similares al control. (C) Gráfica comparativa entre las distintas amplitudes de onda, representativa de cada una de las estaciones de la vía auditiva. Nótese a los 15 días pl una disminución muy significativa en la amplitud de todas las ondas (I-V), que se recupera tras go días de supervivencia pl. (D) Gráfica de las diferentes latencias interpicos entre los grupos estudiados. Se observa que aunque las diferencias no son significativas, el grupo de los 15 días pl es el que tiene un ligero aumento de este parámetro evaluado. 
Figura 11. Grupos 2 y $3\left(\operatorname{Tabla~}^{\circ}{ }_{1}, \mathrm{n}=4\right)$
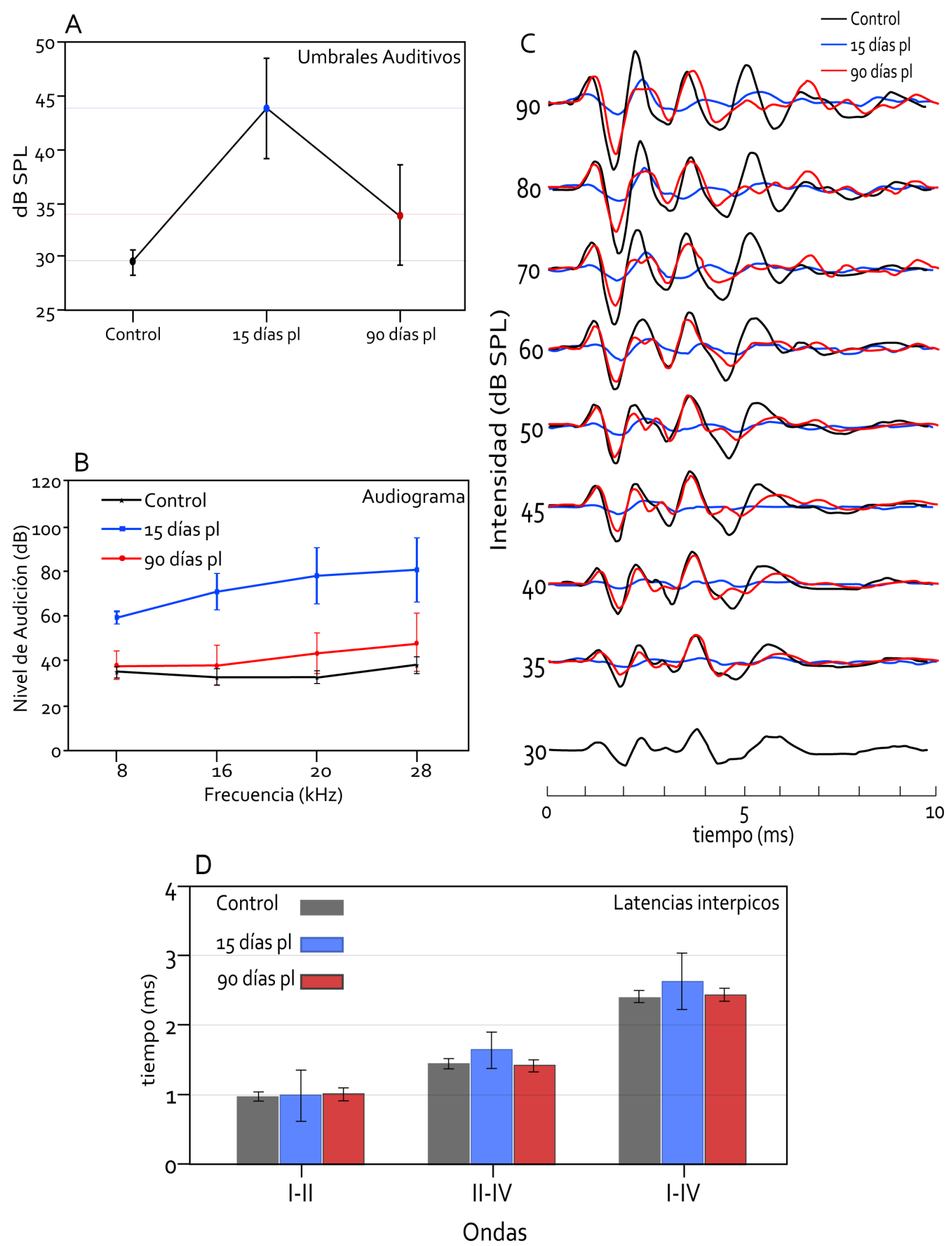
estadísticamente significativo del $48 \%$ en el valor de los umbrales (Figura $11 \mathrm{~A}$ ). En los casos lesionados (estudio longitudinal), pero con un tiempo de supervivencia de 90 días $\mathrm{pl}$, se advirtió un aumento en los valores promedio del umbral auditivo con respecto al grupo control del $14.91 \%$, incremento que no fue estadísticamente significativo (Figura 11A).

Cuando evaluamos estos mismos casos ( 15 y $90 \mathrm{~d}$ pl) tras estimulación con tonos puros y analizando diferentes frecuencias de estimulación $(8,16,20$ y 28 $\mathrm{kHz}$ ), observamos que el grupo control mostró umbrales en torno a los $40 \mathrm{~dB}$ $\mathrm{SPL}$ (Figura 11B), con valores más bajos para las frecuencias medias ( 16 y 20 $\mathrm{kHz}$ ) que están dentro del rango normal para la especie. En los animales lesionados con 15 días de supervivencia pl, encontramos un marcado incremento en el umbral para todas las frecuencias analizadas, afectando principalmente a las altas- 20 y $28 \mathrm{~dB}$ (Figura $11 B$ ). En este mismo grupo, pero a los 90 días $\mathrm{pl}$, encontramos una recuperación de los valores para todas las frecuencias analizadas en los umbrales auditivos, que no mostraron diferencias significativas con el grupo control (Figura 11B).

Además se analizaron en el tiempo, las amplitudes para cada una de las ondas características de los ABRs (Figura $11 \mathrm{C}$ ) para niveles sonoros comprendidos entre los 30 y los $90 \mathrm{~dB}$ SPL. En este parámetro se observó una muy marcada disminución en la amplitud de todas las ondas (I-V) en los animales del grupo de 15 días pl, y una recuperación de esta amplitud a los 90 días pl, muy similar al grupo control (Figura 11C).

También se analizaron las latencias interpicos (tiempo transcurrido desde la emisión del estímulo sonoro hasta la aparición de los picos de las ondas características en los ABRs, que se corresponden con: I: ganglio coclear y nervio auditivo, II: núcleos cocleares, III: complejo olivar superior, IV: lemnisco lateral y V: colículo inferior) tras estimulación con sonido tipo click, para los pico I a $\mathrm{V}$ y las latencias interpicos I-II, II-IV y I-IV. Los animales controles presentaron las latencias características para esta especie (Figura 11D), mientras que al compararlos con el grupo de 15 días pl, se observó un valor promedio de latencia superior al del grupo control (que no resultó estadísticamente significativo), especialmente para los picos III, IV y V (Figura 11D). Los valores de las latencia interpico II-IV y I-V también se mostraron aumentados con respecto al grupo control, pero en ninguno de los casos fueron estadísticamente significativos estos aumentos (Figura 11D). En este mismo grupo lesionado, pero a los 90 días, se encontraron valores de latencia similares a los del grupo control (Figura 11D). 


\section{Exploración de la respuesta refleja auditivo-motora.}

\section{Reflejo auditivo de sobresalto (RAS).}

Se realizó la evaluación de los parámetros del RAS en los animales controles (grupo 4, $n=10$, Tabla $\mathrm{N}^{0}$ ) en comparación con el grupo de lesionados (grupo $5, n=10$, Tabla $\mathrm{N}^{\circ} 1$ ), durante tres tiempos de supervivencia pl (15, 90 y 180 días). También se efectuaron estas pruebas en los casos del grupo de 15 días $\mathrm{pl}\left(\mathrm{n}=7\right.$, Tabla $\left.\mathrm{N}^{\circ} 1_{1}\right)$ con lesiones en regiones no-auditivas. El estudio de las medias de los valores de la amplitud del RAS, inducido por un estímulo de 115 dB SPL, nos permitió observar que, al comparar el grupo de 15 días pl con respecto a los controles, la amplitud mostró una disminución brusca y muy significativa del RAS, del 66.78\% (Figura 12A). Cuando se analizaron estos casos lesionados a los 90 días $\mathrm{pl}$, se observó una recuperación parcial de la amplitud, ya que la disminución con respecto al grupo control fue del 50.73\% (Figura 12A), mientras que en el grupo de los 180 días $\mathrm{pl}$ no se observaron diferencias significativas en la amplitud de la respuesta con respecto a la media de los controles (Figura 12A). En el grupo de los animales con lesiones en regiones noauditivas, no se encontraron diferencias estadísticamente significativas con respecto al grupo control (Figura $13 \mathrm{~A}$ )

Utilizando este mismo estímulo auditivo de $115 \mathrm{~dB}$, pero evaluando otro parámetro, la latencia, se encontró que las diferencias en los valores de las medias no fueron significativos entre el grupo control y los grupos lesionados de 15 y 180 días (Figura 12B). Sin embargo, en el grupo de los 90 días pl encontramos un aumento significativo en el tiempo de respuesta del $41.68 \%$, es decir, la respuesta se produjo con un retraso de 18.1 milisegundos (Figura 12B). En el grupo de lesiones en cortezas no auditivas no se observaron modificaciones en los valores de las latencias (Figura 13B).

Reflejo auditivo de sobresalto con presentación de un pulso sonoro previoInhibición por estímulo previo (IPP)

El análisis del porcentaje de inhibición de la amplitud del RAS (115 dB), empleando distintos pre-estímulos $(65,70$ y $80 \mathrm{~dB})$, mostró en el grupo de 15 días pl cambios significativos en el porcentaje de inhibición a cualquiera de las tres intensidades de pre-estímulo (Figura $14 \mathrm{~A}-\mathrm{C}$ ). En este grupo, utilizando un estímulo sonoro de $80 \mathrm{~dB}$, encontramos una disminución del porcentaje de inhibición del $85.74 \%$ con respecto a los casos controles. Con los prepulsos de 70 y $65 \mathrm{~dB}$ de intensidad el decremento fue, respectivamente, del $81.39 \%$ y del $83.7 \%$, siendo en todos los casos significativo (Figura $14 \mathrm{~A}-\mathrm{C}$ ). Por el contrario, a los 90 y 180 días $\mathrm{pl}$, solo encontramos cambios estadísticamente significativos (prueba Games-Howell) cuando utilizamos el prepulso de 80 dB (Figura $14 \mathrm{~A}-\mathrm{C}$ ), 

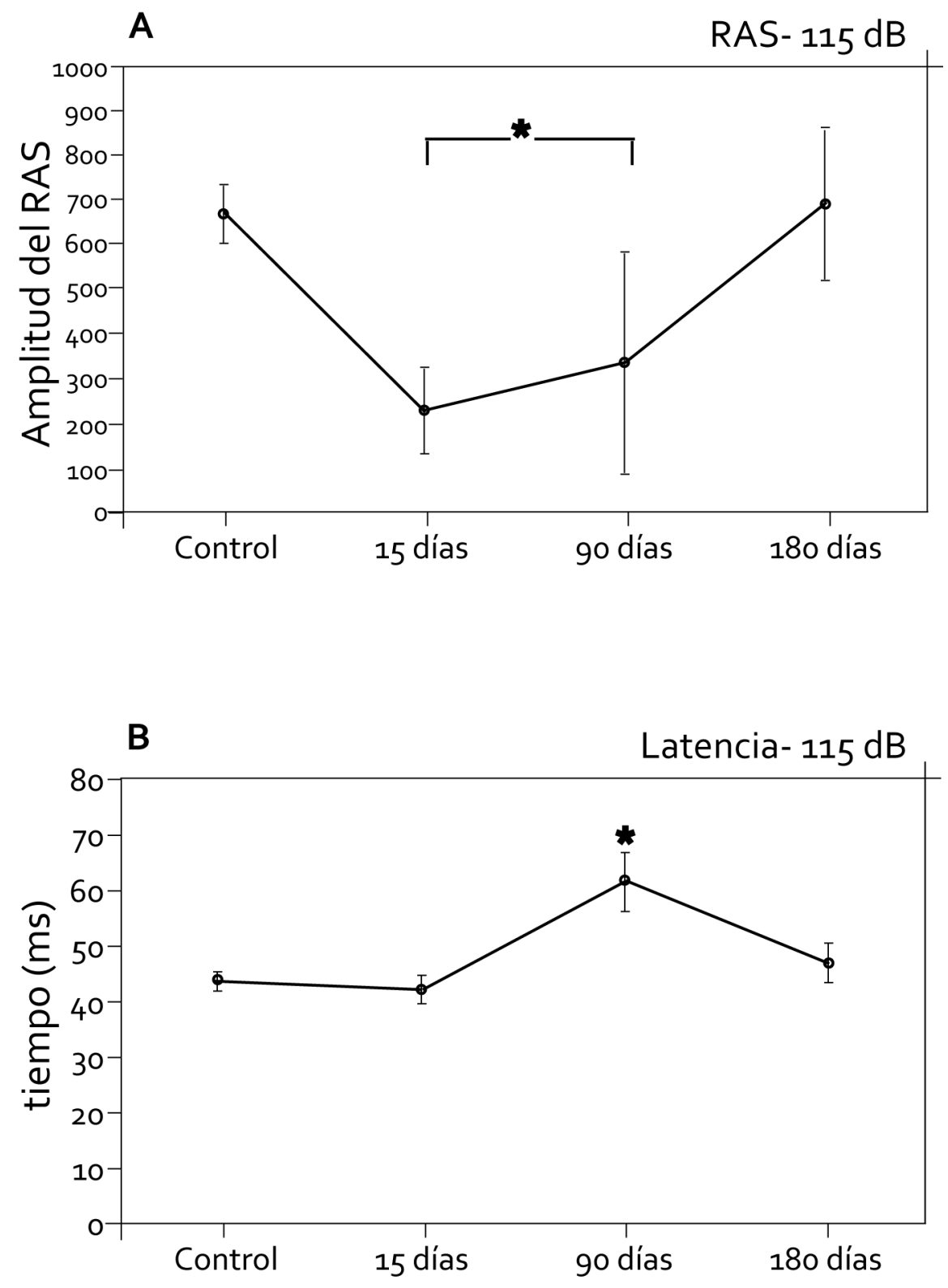

FIGURA 12.

(A) Variaciones longitudinales en la amplitud de las respuestas para el Reflejo Auditivo del Sobresalto, utilizando estímulos de $115 \mathrm{~dB}$ SPL, en grupos controles y experimentales. Nótese el descenso muy significativo en la amplitud en el grupo de 15 días pl y la recuperación paulatina de éste, hasta llegar a los 180 días pl a igual nivel que el grupo control.

(B) Estudio de los tiempos de latencia cuando se aplica un estímulo único de 115 dB SPL. En esta gráfica se observa que solo hay diferencias significativas en la velocidad de conducción a los 90 días postlesión. 

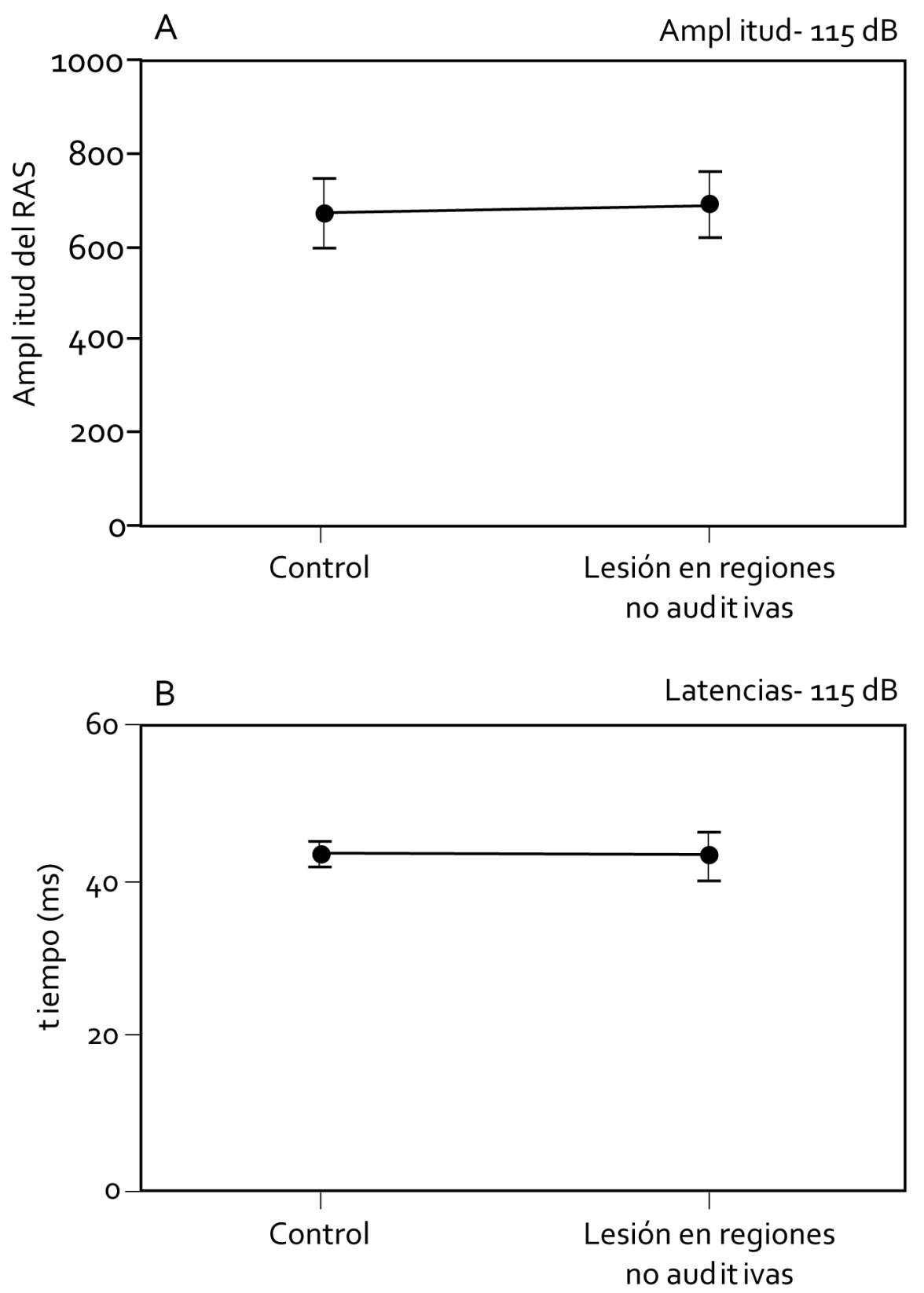

\section{FIGURA 13.}

(A) Variaciones longitudinales en la amplitud de las respuestas para el Reflejo Auditivo del Sobresalto, utilizando estímulos de $115 \mathrm{~dB} S P L$, en el grupo con lesión en regiones motoras y somatosensoriales (control no-auditivo). Nótese que no hay diferencias significativas en la amplitud de la respuesta del RAS.

(B) Estudio de los tiempos de latencia cuando se aplica un estímulo único de 115 dB SPL. En esta gráfica se observa que tampoco hay diferencias en el tiempo de respuesta entre los animales controles y los lesionados en corteza motora y somatosensorial. 
$(4)$

Inhibición por estímulo previo

Latencias
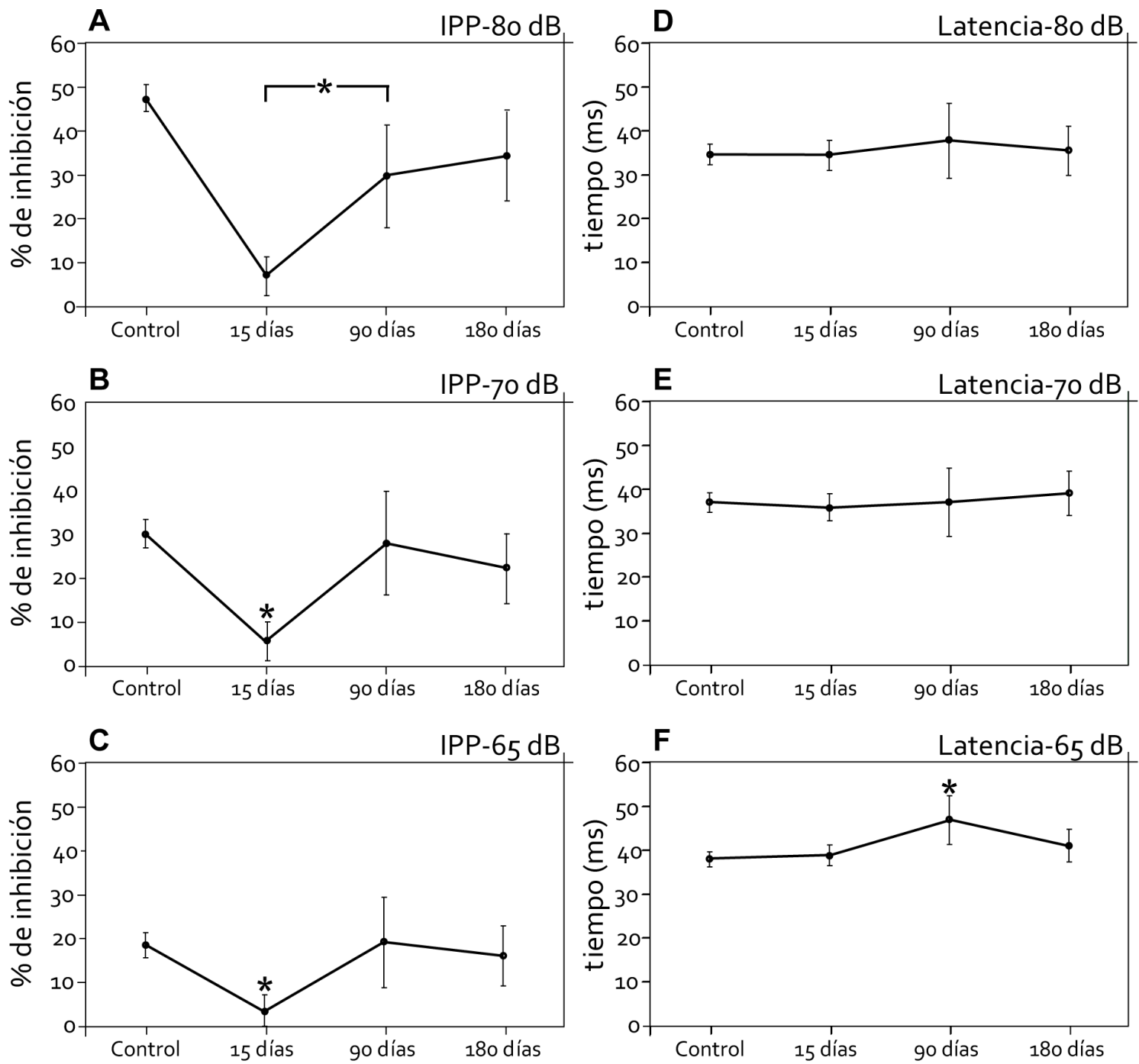

FIGURA 14. Porcentajes de inhibición por estímulo previo de la amplitud del Reflejo Auditivo del Sobresalto y Latencias- diferentes intensidades.

(A-C). Variaciones longitudinales de la media de porcentajes de inhibición del RAS, utilizando pre-estímulos de diferentes intensidades. Nótese la evidente disminución significativa de la amplitud de la respuesta a los 15 días pl, y su progresivo incremento hasta los 180 días pl.

(D-F). Representación gráfica de los cambios en las latencias, utilizando diferentes intensidades de pre-estímulo, en el estudio de esta variable no se observan modificaciones significativas (prueba de Games-Howell) con respecto a los controles, exceptúando el grupo de 90 días pl-65 dB SPL. 
con disminuciones del $37.85 \%$ y del $27.89 \%$ respectivamente. Estos datos muestran una recuperación clara de la IPP en tiempos más largos de supervivencia pl, y utilizando pre-estímulos menores ( 65 y $70 \mathrm{~dB} \mathrm{SPL}$ ).

Cuando se evaluaron los valores de las latencias para las 3 diferentes intensidades del pre-estímulo, observamos que no hay cambios significativos entre los grupos lesionados y los controles (Figura $14 \mathrm{D}-\mathrm{F}$ ), excepto para el grupo de los 90 días pl, cuando utilizamos un pre-pulso de $65 \mathrm{~dB}$, donde encontramos un aumento en el tiempo de latencia del 23.34\% (Figura 14F).

Se evaluó, además, en los grupos experimentales, el efecto que se produce sobre el porcentaje de inhibición por estímulo previo del RAS al utilizar diferentes intensidades (ruido blanco: 65,70 y $80 \mathrm{~dB} S P L$ ) en los pulsos preestímulo. En el grupo control respecto a los lesionados con un tiempo de supervivencia de 180 días no se observaron diferencias estadísticamente significativas en el porcentaje de respuesta a la IPP a ninguna intensidad. Sin embargo, en los grupos de 15 y 90 días pl, al utilizar pre-estímulos menores de $80 \mathrm{~dB}(65$ y 70$)$, se observó que disminuía significativamente el porcentaje de inhibición sobre la amplitud del RAS (Figura 15).

\section{Expresión de c-Fos en el Colículo Inferior tras lesión cortical auditiva}

Inmunohistoquímica para c-Fos

Tras estimulación acústica en el grupo de animales controles (grupo $7, n=3$; Tabla $\mathrm{N}^{\circ} 1$ ), encontramos una distribución homogénea en el $\mathrm{Cl}$ de los núcleos neuronales c-Fos positivos, principalmente concentrados en la zonas más dorsales de las tres subdivisiones del $\mathrm{Cl}$ (Figura 16A). En estos casos controles, la mayor densidad de núcleos positivos se observó en la capa 1 de la $\mathrm{CDCl}$ y en la zona dorsal del $\mathrm{NCCl}$.

En el grupo estimulado con ablación de la CA y tiempo de supervivencia de 15 días pl (grupo 8, $n=3$; Tabla $N^{\circ} 1$ ), hallamos una disminución marcada en los núcleos c-Fos positivos en todo el $\mathrm{Cl}$, siendo este descenso más evidente en la zona de la $\mathrm{CDCl}$, principalmente en la región central de esta subdivisión (Figura 16B). En el $\mathrm{NCCl}$ se observó en la zona ventro-medial una acumulación de núcleos c-Fos positivos más oscuros (Figura 16B). En este grupo, también hallamos un ligero incremento en el marcaje del fondo (Figura 16B). Para el grupo de los 90 días pl (grupo 9, $n=3$; Tabla $N^{\circ} 1$ ), hallamos una gran similitud con respecto a los controles en la distribución de los núcleos c-Fos positivos para las tres subdivisiones del $\mathrm{Cl}$, aunque se observó también una banda en la posición ventro-medial del $\mathrm{NCCl}$, pero mucho menos densa que en el grupo de los 15 días pl (Figura 16C). 


\section{FIGURA 15.}

Gráfico en el que se representa los resultados sobre la sensibilidad de los grupos en diferentes tiempos postlesión ( 15,90 y 180 días), para discriminar entre las diferentes intensidades utilizadas para los pre-estímulos $(65,70$ y $80 \mathrm{~dB} S P L)$. Nótese que el grupo de 15 días pl muestra una incapacidad para discriminar entre las diferentes intensidades. Esta capacidad de responder adecuadamente se recupera progresivamente hasta niveles del control en los casos de 180 días postlesión. 


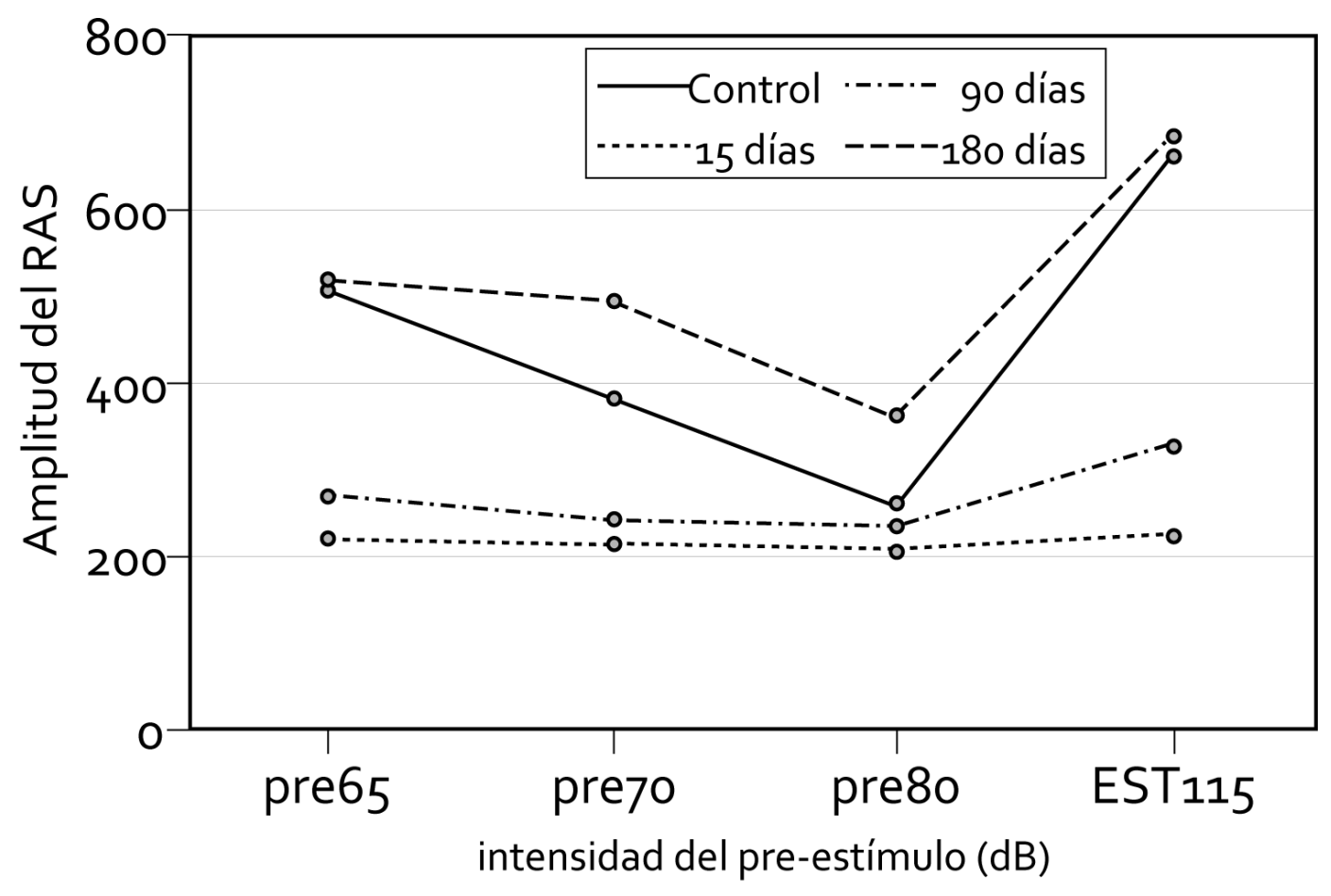




\section{FIGURA 16.}

Microfotografías de los colículos inferiores $(\mathrm{Cl})$ bilaterales representativos para cada uno de los tres casos experimentales para c-Fos. En el grupo control (A), se observa una mayor distribución de núcleos c-Fos positivos en las zonas dorsales del $\mathrm{Cl}$ y menor densidad en la parte ventral, las tres subdivisiones presentan abundantes marcas, pero se observa mayor densidad de inmunorreacción para las zonas externas de la corteza dorsal. (B) El grupo de los 15 días pl muestra un claro descenso en los núcleos c-Fos positivos, principalmente en el núcleo central del $\mathrm{Cl}$, al igual que en las regiones de la corteza dorsal que colinda con el núcleo central, es en estos casos en donde aparece una "banda" de núcleos inmunorreactivos muy oscuros, que no se teñían con tal intensidad en los controles, en estos casos se observa un aumento en la tinción de fondo. (C) En el grupo de go días pl, se observa una recuperación de los núcleos teñidos para c-Fos con respecto a los 15 días pl, sin llegar a los niveles de los controles. Aunque los núcleos son más dispersos que para los controles, la distribución es la misma, con la diferencia que a los go días aún permanece esta banda en la zona ventro medial del núcleo central. 


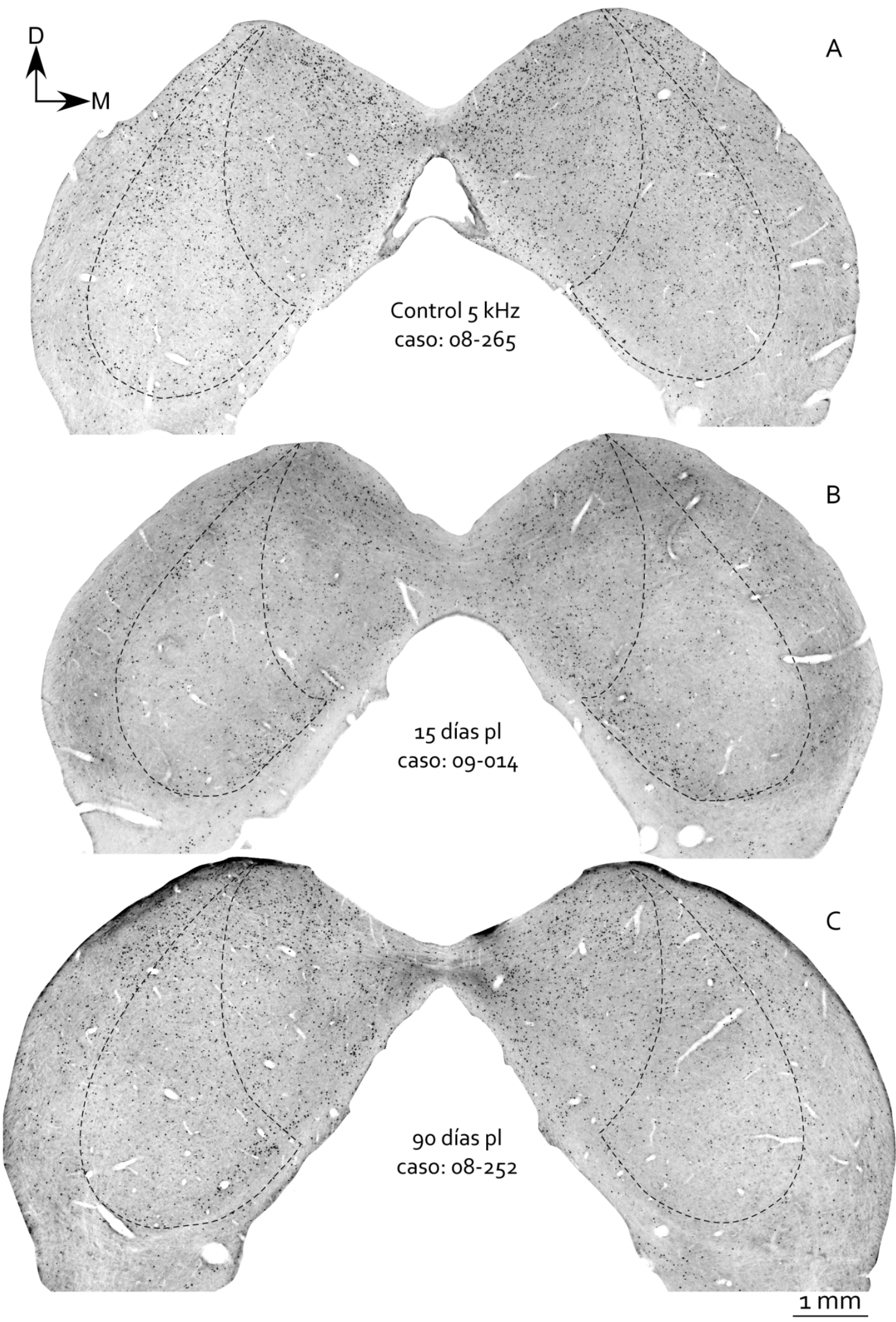




\section{FIGURA 17.}

Representación de la distribución de los núcleos c-Fos inmunorreactivos del $\mathrm{Cl}$ en un caso representativo de cada grupo estimulado con sonido (control, 15 y 90 días postlesión). En estos mapas cada círculo representa un núcleo c-Fos positivo y la intensidad del color refleja los valores de gris según la escala. Nótese el descenso en la densidad de las partículas en el grupo a los 15 días pl y la recuperación de la intensidad de las mismas en el grupo de go días pl. 


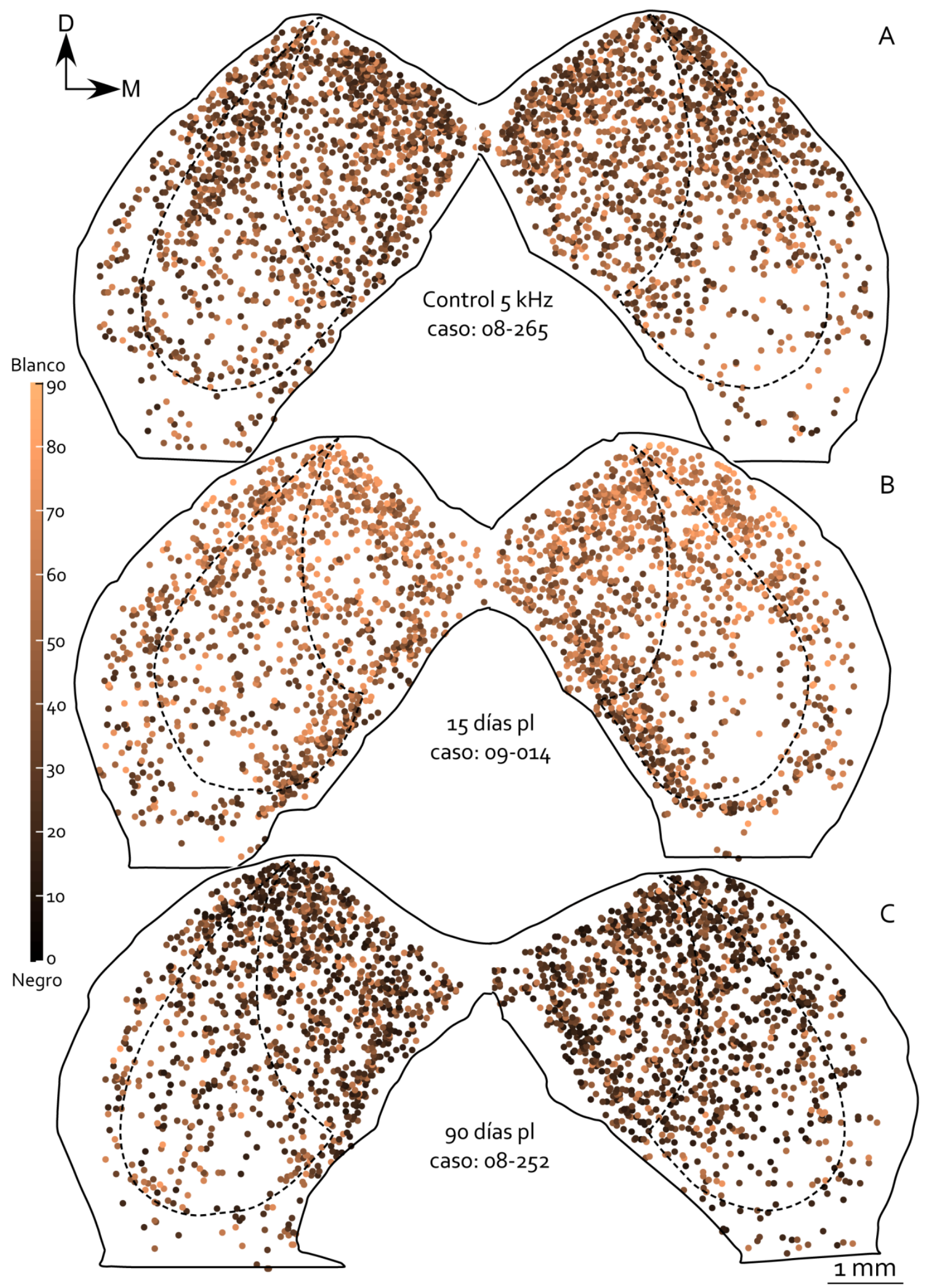


Tras la segmentación de partículas c-Fos positivas en el $\mathrm{Cl}$ y el traslado de los valores a mapas de representación de valores de grises (MRVG) en los casos controles, observamos que hay una mezcla de partículas claras y oscuras en las tres subdivisiones del $\mathrm{Cl}$, que siguen la distribución topográfica referida en el apartado anterior (Figura $17 \mathrm{~A}$ ). Observamos también que las neuronas de la $\mathrm{CDCl}$, en su zona más medial, presentaron una mayor densidad de núcleos c-Fos positivos, con valores de grises más bajos (más oscuros). Estos valores contrastaron claramente con los más altos (más claros) de las partículas localizadas en las regiones más ventrales del Cl (Figura 17A).

En los casos con estimulación auditiva y 15 días pl, se observó en los MRVGs un descenso muy marcado en la densidad de las partículas en todas las subdivisiones del $\mathrm{Cl}$ (Figura 17B). En este mismo grupo experimental destacó una banda de partículas muy densas con localización en la zona ventro-medial del $\mathrm{Cl}$ (Figura 17B). En el grupo de 90 días pl observamos unos MRVGs con partículas que seguían una distribución y rango de densidades de grises casi idéntica a las del grupo control (Figura $17 \mathrm{C}$ ). Al comparar los valores de los niveles de grises de los núcleos c-Fos positivos (rango: $0-88$ ) entre los grupos experimentales (Tabla $N^{\circ} 8$ ), encontramos que a los 15 días pl hay un aumento significativo del $23.76 \%$ en los promedios de grises con respecto al control, mientras que no hay diferencias significativas entre los valores del grupo control y los 90 días pl. Además, encontramos para el grupo de los 15 días pl una disminución del $65.08 \%$ en el número de neuronas segmentadas por densitometría en un rango entre $\mathrm{O}$ y 88 , mientras que para los 90 días pl esta disminución, con respecto al grupo control, fue del 30.70\% (Tabla No 8).

Tabla No 8. Análisis por segmentación de gama de grises (valor estimado por el análisis de partículas de forma aleatoria entre o-88) en las neuronas (núcleos) cFos positivas en el colículo inferior- promedio \pm desviación estándar.

\begin{tabular}{|c|c|c|c|}
\hline \multicolumn{1}{|c|}{ Variable } & Control & 15 días pl & 90 días pl \\
\hline \begin{tabular}{c|c|c|} 
Media de nivel de \\
grises
\end{tabular} & $38,72 \pm 1,87$ & $47,92 \pm 0,70$ & $39,64 \pm 3,28$ \\
\hline \begin{tabular}{c|c|c|} 
No de núcleos C- \\
Fos (+) 0-88
\end{tabular} & 28435 & 9927 & 19704 \\
\hline Perímetro nuclear & $52,09 \pm 1,09$ & $50,80 \pm 0,19$ & $56,87 \pm 0,73$ \\
\hline
\end{tabular}




\section{Análisis cuantitativo para c-Fos -Morfometría.}

Otro parámetro que evaluamos en estos grupos experimentales, fue el perímetro de los núcleos c-Fos positivos segmentados para los valores que consideramos positivos para la inmunorreacción para c-Fos (rango: O-88). De este modo encontramos una disminución significativa del $3.86 \%$ en el perímetro nuclear en el grupo de los 15 días pl al compararlo con el grupo control. Sin embargo, en el grupo 90 días pl, observamos un aumento significativo del perímetro del $9.18 \%$. Estos datos fueron significativos al situarse los valores de los promedios por encima de los controles tras añadir o restar 2 veces la desviación estándar.

Análisis cuantitativo para c-Fos -Estereología.

Tras el recuento estereológico, analizando los $\mathrm{Cl}$ de forma bilateral (sumatoria), en el grupo control se observó un promedio de partículas (núcleos positivos) entre todos los animales del grupo $7(n=3)$ contadas, de $155326 \pm$ 5.324 , mientras que en el grupo 15 días pl se obtuvo un valor de sólo $61810 \pm$ 10.04; en el grupo de 90 días pl fue de $99978 \pm 6.16$ neuronas (Figura 18A). De esta forma, al calcular los porcentajes, encontramos, con respecto al grupo control, que a los 15 días pl hay un descenso en núcleos inmunorreactivos del $60.21 \%$ y a los 90 días $\mathrm{pl}$, un descenso del $35.63 \%$. Al comparar también los grupos lesionados ( 15 y 90 días) entre sí, encontramos un aumento, a los 90 días pl, en el número de núcleos positivos coliculares del $24.58 \%$. Cuando analizamos estos mismos casos, pero entre el $\mathrm{Cl}$ izquierdo (ipsilateral a la zona de lesión) y el $\mathrm{Cl}$ derecho (contralateral), encontramos que no hay diferencias significativas entre los diferentes grupos experimentales (Figura 18B).

Al estudiar el $\mathrm{Cl}$ en su conjunto (ambos lados), pero de modo diferenciado para las tres subdivisiones citoarquitecturales del $\mathrm{Cl}$, encontramos que la $\mathrm{CDCl}$ del grupo control exhibió valores promedio para todos los animales del grupo de $78631 \pm 813.24$ núcleos c-Fos positivos, siendo este valor de $24398 \pm 2111$ para el grupo 15 días pl y de $45411 \pm 1722$ para el grupo de los 90 días pl (Figura 19A). Al calcular los porcentajes con estos valores, encontramos una disminución respecto a los controles del $68.98 \%$ en el grupo de 15 días pl, y un descenso del $42.25 \%$ en el de 90 días pl. También comparamos el número de partículas c-Fos positivas entre los grupos lesionados entre sí, y encontramos un aumento a los 90 días pl con respecto a los 15 días pl del 38.75\%. Para la $\mathrm{CECl}$, encontramos que el valor de ésta fue, en el grupo control, de $38951 \pm 637.46$ núcleos c-Fos positivos; para el grupo de los 15 días este valor fue de $13283 \pm 1115.14$ núcleos y para el grupo de los 90 días pl fue de $26604 \pm 991.57$ (Figura 19B). De igual forma, calculamos los cambios de forma porcentual y encontramos que, con respecto al grupo control, el grupo de 15 días pl presentó una disminución en el número de núcleos c-Fos positivos del $65.90 \%$, mientras que para el grupo de los 

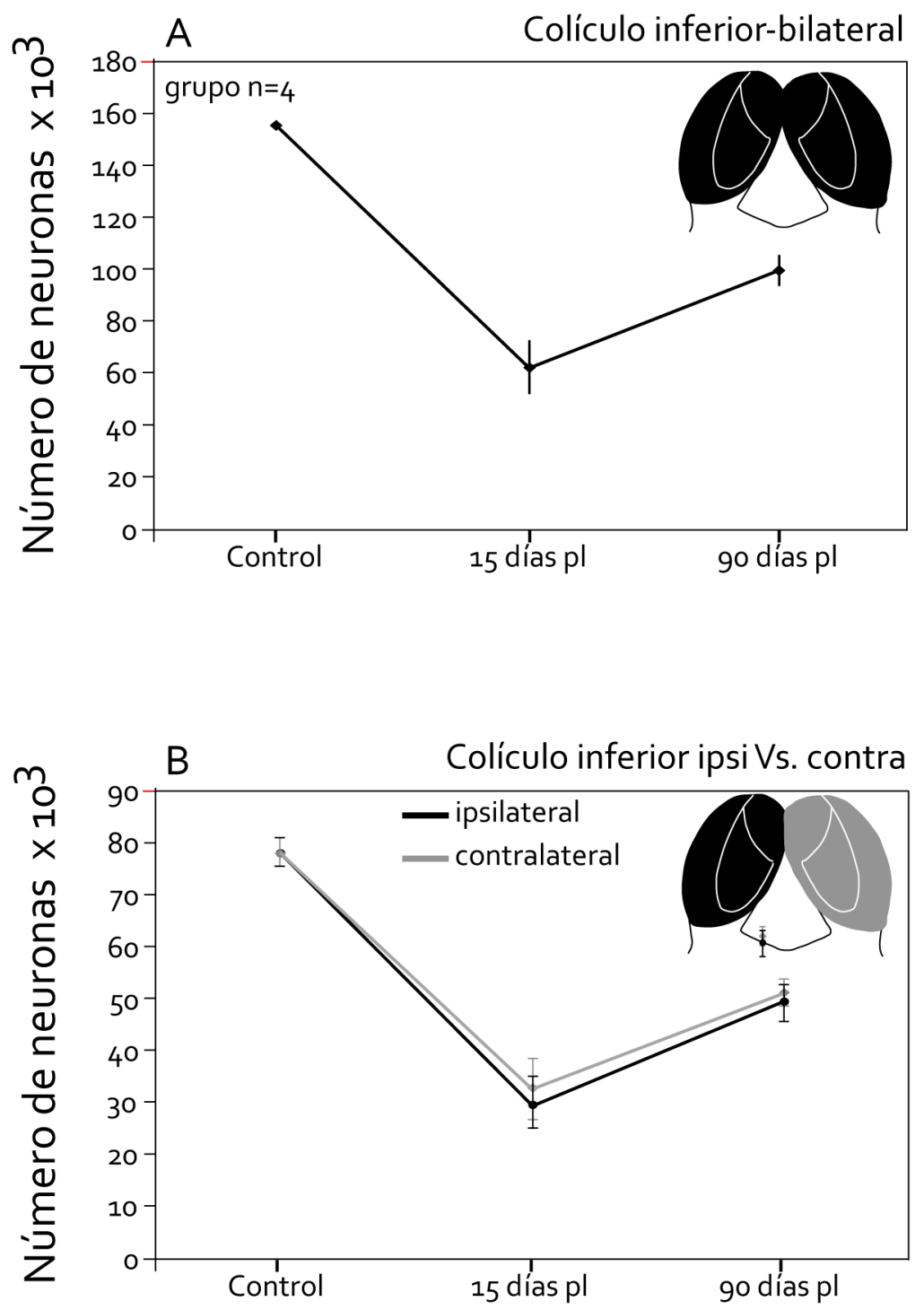

FIGURA 18.

Gráficos que representan el número de núcleos c-Fos positivos en el Colículo Inferior en los grupos controles y lesionados (15 y 90 días). en (A) se representa la sumatoria de ambos colículos (izquierdo-derecho), en donde se observa, un claro descenso en el número de neuronas a los 15 días pl. A los 90 días pl el número de neuronas aumenta con respecto a los 15 días pl, pero la diferencia aún es significativa con respecto al promedio de los controles. (B) Comparación entre los $\mathrm{Cl}$ ipsilateral y contralateral a la zona de lesión, en donde se observa que no hay diferencias significativas entre ambos, en ninguno de los grupos estudiados. 

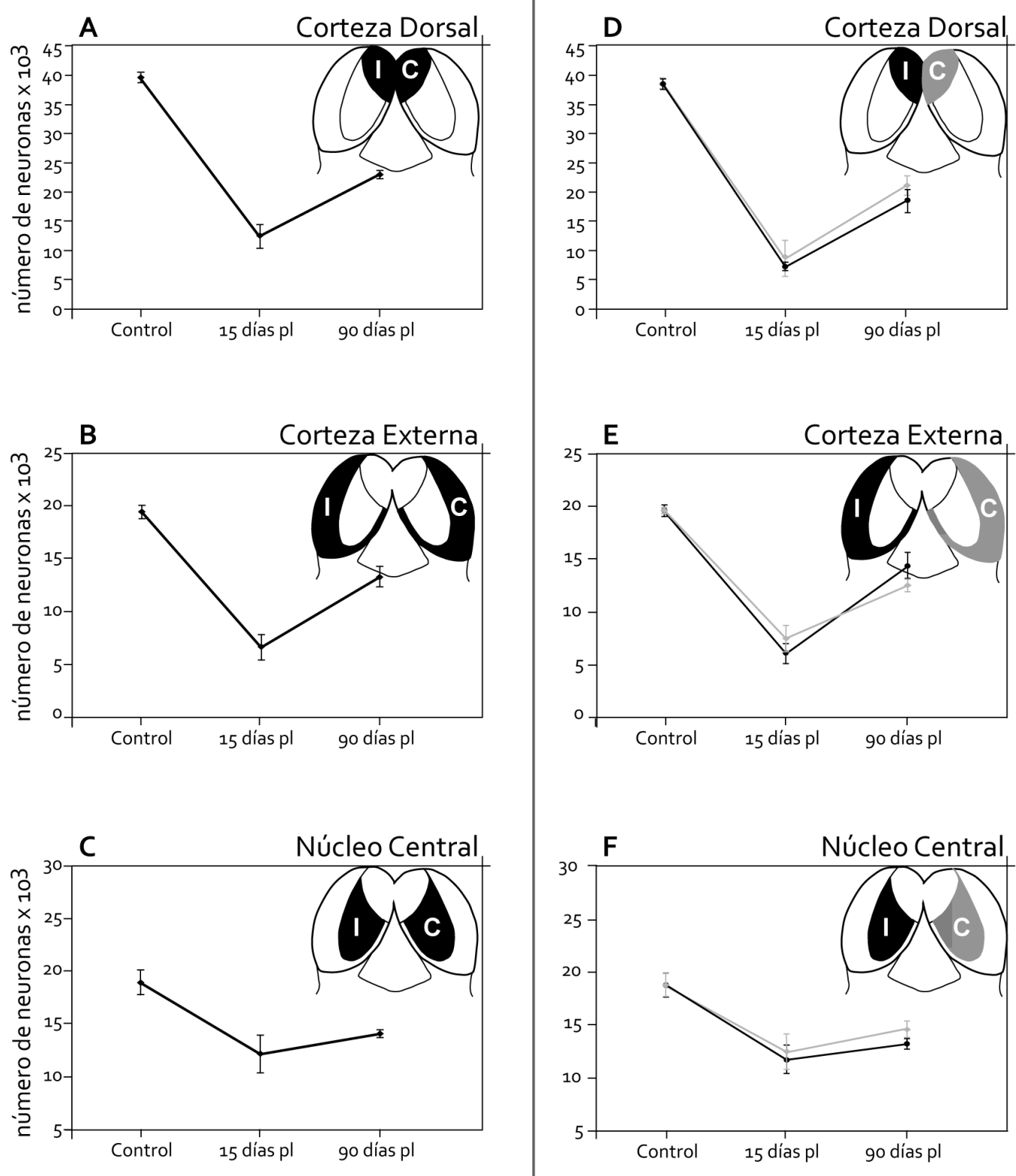

FIGURA 19. Estereología por subdivisiones en el Colículo inferior-c-Fos.

(A-C) Comparación en el número de núcleos c-Fos positivos de forma bilateral en el Colículo inferior. Las tres subdivisiones (A) Corteza Dorsal, (B) Corteza Externa y (C) Núcleo Central, muestran un descenso marcado con respecto a los valores controles; mientras que a los 90 días pl los valores se recuperan en las tres subdivisiones, sin llegar aún a los niveles controles.

(D-F) Comparación en el número de núcleos c-Fos positivos entre las subdivisiones de los colículos ipsilaterales y contralaterales a la zona de lesión. En estos casos, no encontramos diferencias estadísticamente significativas entre el lado ipsilateral y contralateral para ninguna de las tres subdivisiones del Colículo inferior. 
90 días pl esta disminución fue del 31.70\%. Al comparar los cambios entre el grupo de 15 y 90 días pl, observamos un aumento en el promedio del número de partículas positivas en el grupo de los 90 días del 51.90\%. Al estudiar también de forma bilateral al $\mathrm{NCCl}$, encontramos que, para el grupo control, el número de núcleos c-Fos positivos fue de $37743 \pm 1211.47$; en el grupo de 15 días pl este número fue de $24128 \pm 1796$ y para el grupo de los 90 días pl fue de $27962 \pm$ 365.37 (Figura 19C). Al calcular los porcentajes para estos valores del $\mathrm{NCCl}_{\text {, }}$ encontramos que a los 15 días hay una disminución del $36.08 \%$ con respecto al control, mientras que a los 90 días pl esta disminución es del 25.91\%. Entre el grupo de 15 días versus el grupo de 90 días pl, se observó un aumento de núcleos c-Fos positivos del $28.18 \%$. Al analizar si existían diferencias para las subdivisiones del $\mathrm{Cl}$, pero entre el lado ipsilateral y contralateral a la zona de lesión, encontramos ligeras diferencias (Figura $19 \mathrm{D}-\mathrm{F}$ ) entre ambos, pero en ninguno de los casos significativas (media \pm 2 veces SD).

\section{Inmunocitoquímica para Calretinina.}

En el $\mathrm{Cl}$ de los casos controles (grupo 10, $n=4$; Tabla 1), se observaron neuronas CR- inmunorreactivas distribuidas fundamentalmente en la corteza externa y en la dorsal y escasamente en el núcleo central (Figura 20). Así, la inmunotinción de más neuronas en las zonas periféricas del $\mathrm{Cl}$ ofreció una imagen del $\mathrm{Cl}$, en el plano coronal en forma de anillo periférico más denso con un centro claro (Figura 20). En las secciones de los casos controles fue posible identificar, en diferente proporción, todos los tipos celulares descritos en el Cl con diferentes grados de intensidad de inmunorreacción. Los tipos neuronales más abundantes y más intensamente inmunoteñidos fueron las neuronas pequeñas de la cápsula fibrodendrítica de la CECI y las de las capas 1 y 2 de la $\mathrm{CDCl}$ (Figura 20-inset)

La distribución de neuronas CR-IRr en el $\mathrm{Cl}$ de los grupos lesionados, fue, al igual que en los controles, preferente en las regiones periféricas corticales del $\mathrm{Cl}$ (Figura 21). Se observó además una mayor intensidad de tinción y un aumento de neuronas Calretinina inmunorreactivas (CR-IRr) en todas las capas de ambas cortezas (Figura 21). En el núcleo central se observaron, respecto al control, más neuronas marcadas y dispuestas de forma dispersa (Figura 21).

Comparando los casos de 15 días con los de 90 y 180 días pl, se comprobó que el incremento en la inmunotinción de somas y dendritas se incrementó con el tiempo en todas las subdivisiones del $\mathrm{Cl}$ (Figura 21). A los 180 días pl tanto los somas como las dendritas, y en particular en la $\mathrm{CECl}$ ipisilateral a la zona de lesión, mostraron imágenes de dendritas y axones nítidos que no se pudieron observar en el resto de los grupos experimentales, con tantos detalles (Figura 21). 


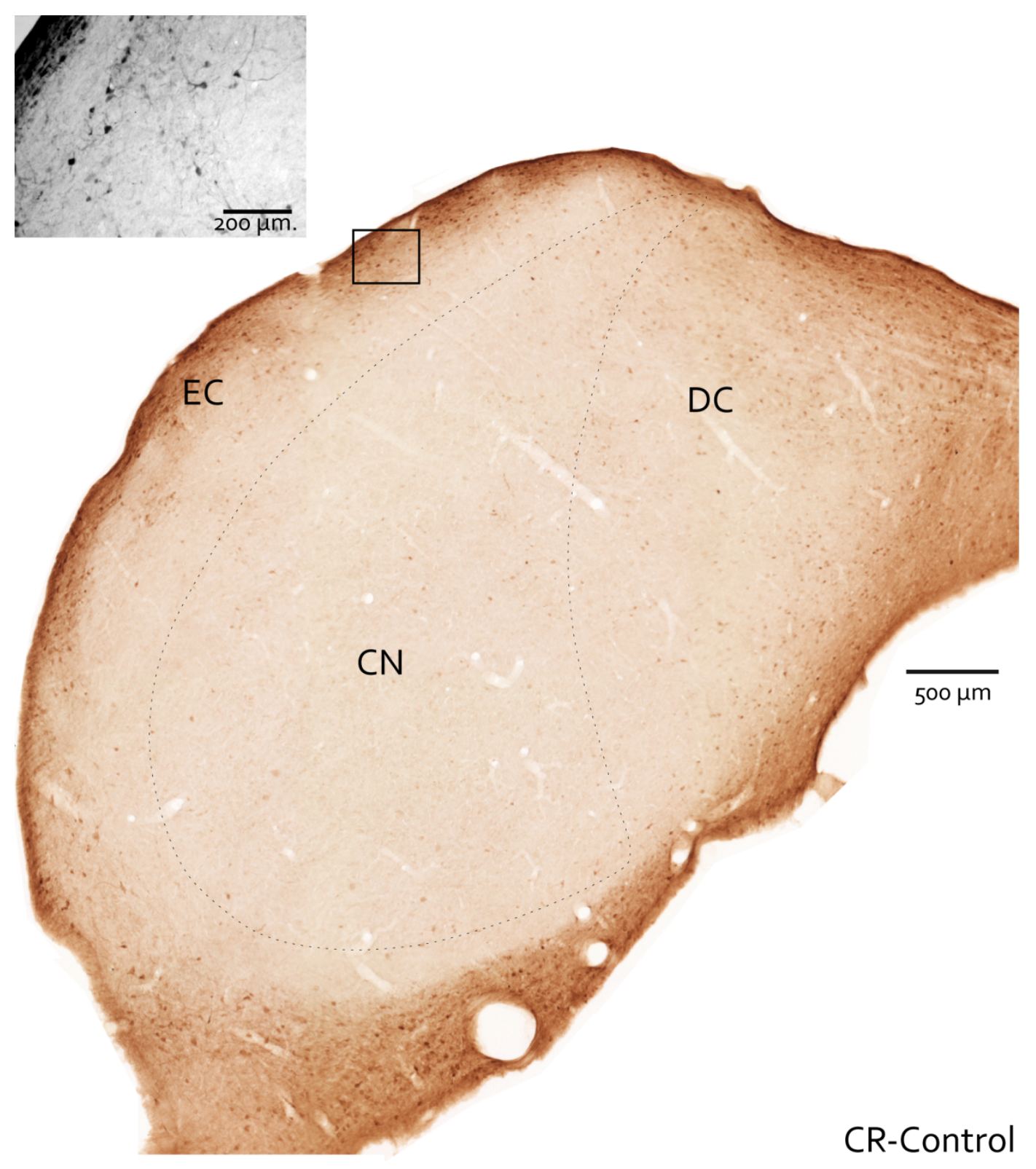

FIGURA 20. Inmunohistoquímica para Calretinina.

Microfotografía de un colículo inferior control, en donde se observa que la inmunorreacción está restringida al área de las cortezas, principalmente en la cápsula fibrodendrítica de la corteza externa (ver inset), mientras que el núcleo central hay una ausencia casi total de neuronas calretinina-inmunorreactivas. 

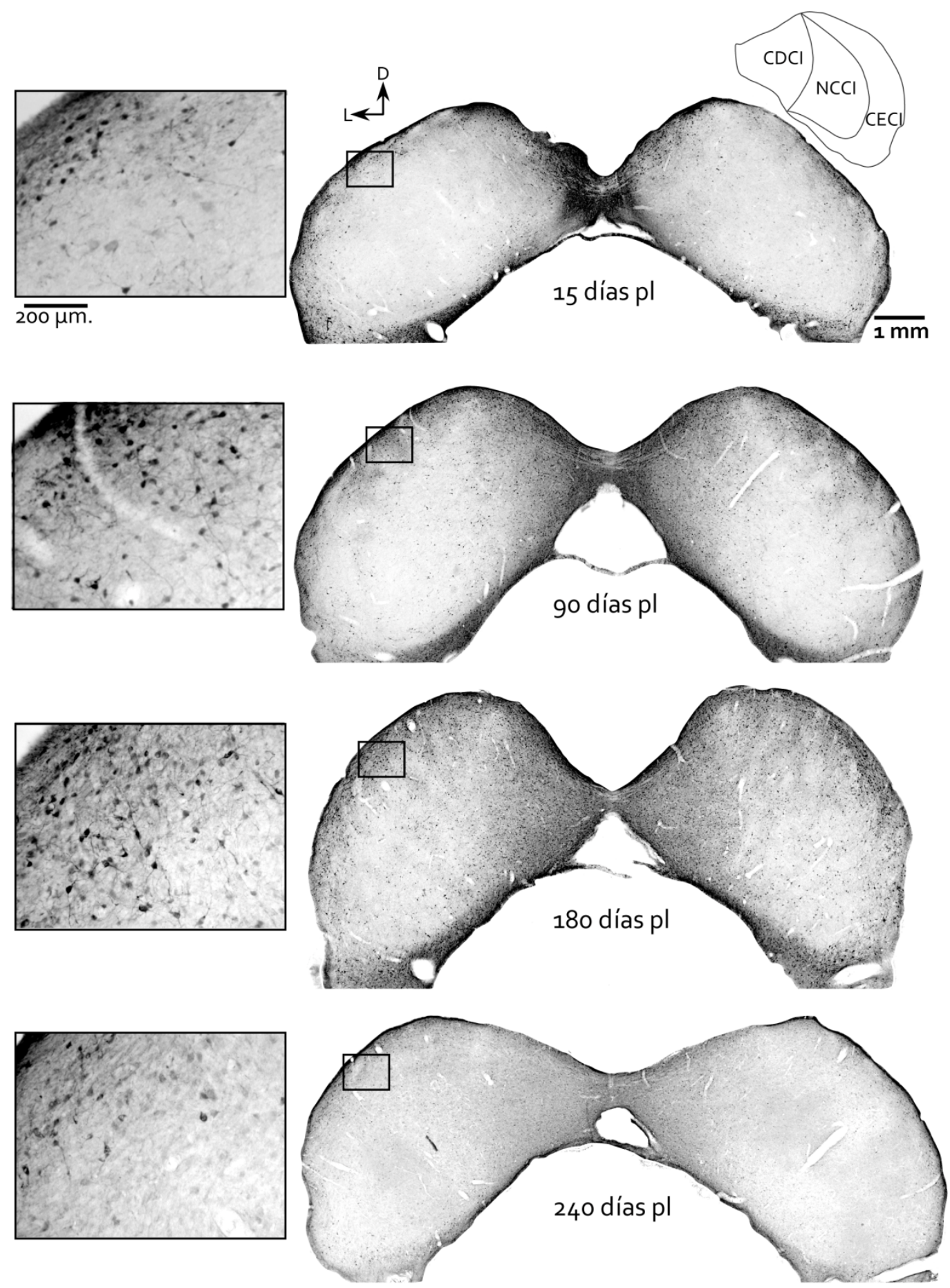

FIGURA 21. Microfotografías de los Colículos Inferiores representativos de todos los grupos experimentales estudiados. En éstos se observa un progresivo incremento en el número e intensidad de la inmunorreacción para calretinina entre los 15 y los 180 días pl, mientras que el grupo de los 240 días pl muestra un claro descenso. 
Los casos analizados 240 días $\mathrm{pl}$, mostraron neuronas con escasos perfiles dendríticos y somas inmunorreactivos con una intensidad de marcaje menor que los caso de 180 días pl (Figura 21). También fue observado en estas secciones un discreto incremento en la inmunorreacción de fondo (Figura 21).

\section{Estudio cuantitativo para Calretinina (Estereología).}

Con el estudio estereológico valoramos, en los diferentes grupos experimentales: control y lesionados (grupos 10-14, $n=4 ;$ Tabla $N^{\circ} 1$ ), el recuento total de neuronas $\mathrm{CR}$-IRr en el $\mathrm{Cl}$, de forma bilateral (sumando las medias de ambos $\mathrm{Cl}$ ) (Figura 22A). Comparamos además, los promedios entre el $\mathrm{Cl}$ ipsilateral y el $\mathrm{Cl}$ contralateral a la zona de lesión en la CA (Figura 22B) y analizamos también los promedios en las tres subdivisiones del $\mathrm{Cl}$ de manera conjunta (Figura 23A-C). Se diferenciaron estos valores entre los lados ipsilateral (izquierdo) y contralateral (derecho) a la zona de lesión (Figura 23D-F). Expondremos secuencialmente, en el orden referido, estas cuatro partes del estudio.

Se analizó el total de neuronas $\mathrm{CR}$-IRr de ambos colículos inferiores tanto del grupo control como de los grupos lesionados (Figura 22A). Se observó, con respecto al grupo control un fuerte incremento progresivo en el número de neuronas CR-positivas en los grupos sacrificados a los 15, 90 y 180 días pl (Figura $22 \mathrm{~A}$ ). Así, en el grupo control se contaron $83543 \pm 3527.67$ neuronas CR-IRr, mientras que en el grupo de los 15 días este promedio fue de $95801 \pm 3799.81, y$, por lo tanto, encontramos un incremento del $14.67 \%$ con respecto al control. En el grupo de 90 días pl la media de neuronas CR-IRr fue de $111963 \pm 1844.18$; Al compararlo porcentualmente con el grupo control, encontramos un aumento del 34.01\%. En el grupo de los 180 días pl se encontró el mayor incremento en el número de neuronas Ir-CR con $148492 \pm 7179$, que en proporción fue del 77.74\%. Por el contrario, el grupo de los 240 días pl reveló un incremento de sólo el $15.82 \%$ ( $96762 \pm 2847.69$ neuronas $C R-I R r)$ con respecto a los controles y un descenso marcado en el número de neuronas $C R-I R r$ con respecto a los grupos de 90 y 180 días pl (Figura 22A).

Se compararon los promedios de neuronas CR-IRr entre los lados ipsilateral y contralateral a zona de lesión (Figura 22B) y no se observaron diferencias entre los valores de los grupos controles y los lesionados a los 15,180 y 240 días pl. Solo se encontró una diferencia significativa (6.9\%) para el grupo de los 90 días pl en el lado contralateral (Figura 22B).

Al comparar las medias por subdivisiones de ambos Cls (Figura $23 \mathrm{~A}-\mathrm{C}$ ), se encontraron para la $\mathrm{CDCl}$ con respecto al grupo control, incrementos significativos en los promedios del número de neuronas CR-positivas, del $22.01 \%, 50.88 \%$ y $111.93 \%$, respectivamente para los grupos de 15,90 y 180 días pl (Figura 23A). En el grupo de los 240 días pl el aumento con respecto al control 

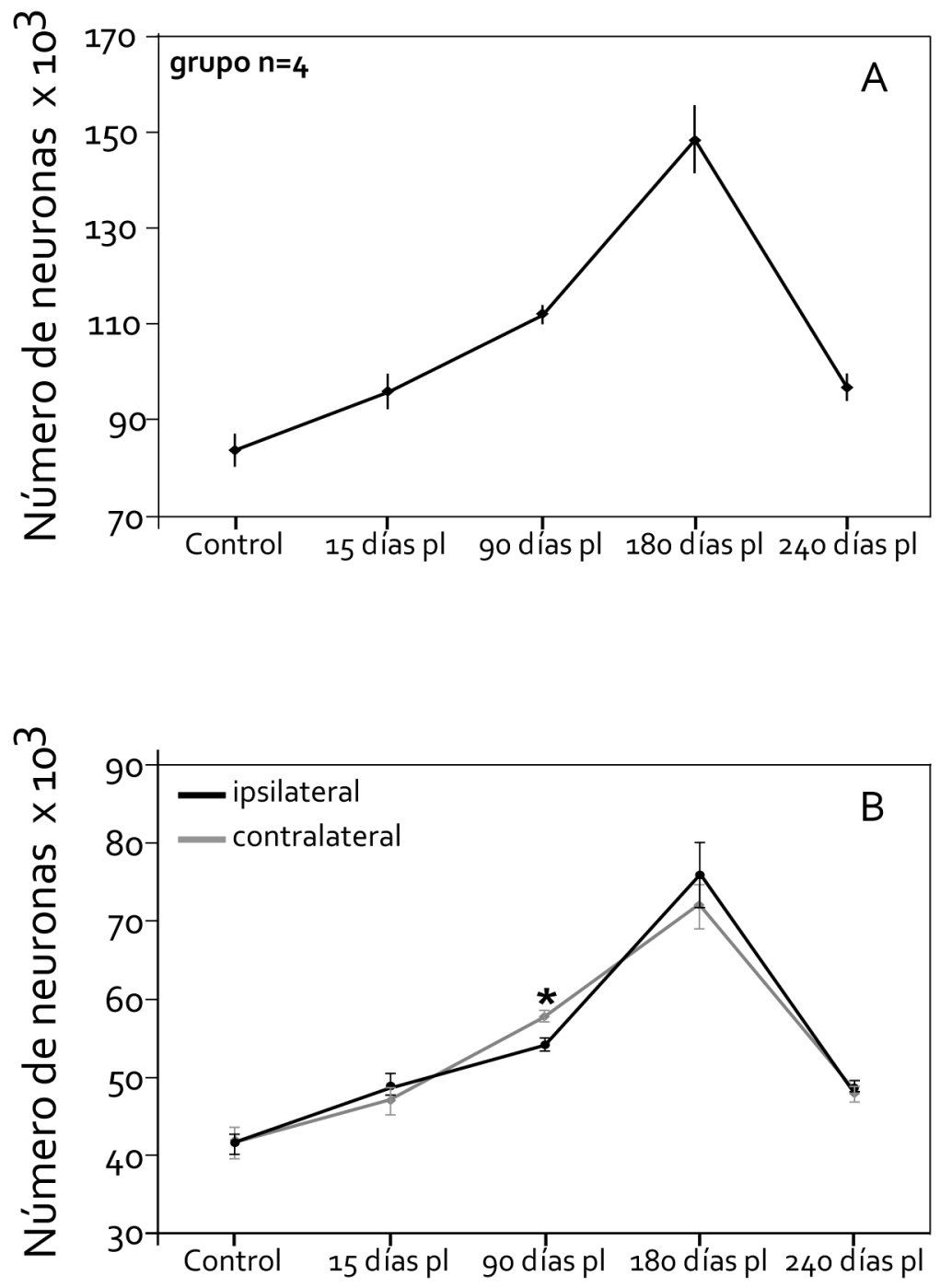

\section{FIGURA 22.}

Representación gráfica del número de neuronas calretinina-inmunorreactivas contadas por técnicas estereológicas en el colículo inferior en función del tiempo de supervivencia postlesión (pl). (A) Gráfica de comparación en el promedio de neuronas en ambos colículos (sumatoria) entre los diferentes tiempos pl. La imagen muestra un incremento exponencial entre los 15 y 180 días pl (en todos los casos significativos) y un descenso a los 240 días pl, hasta casi el promedio de los controles. (B) Comparación de los valores estereológicos entre el colículo inferior ipsilateral y el contralateral a la zona de lesión, en diferentes tiempos pl, sólo se encontraron diferencias estadísticamente significativas a los go días pl. 
$\mathrm{Cl}$ - Subdivisiones

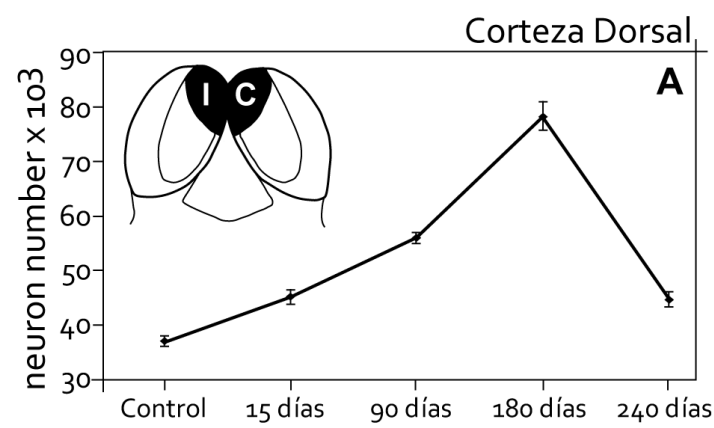

Cl- Ipsi Vs. Contra

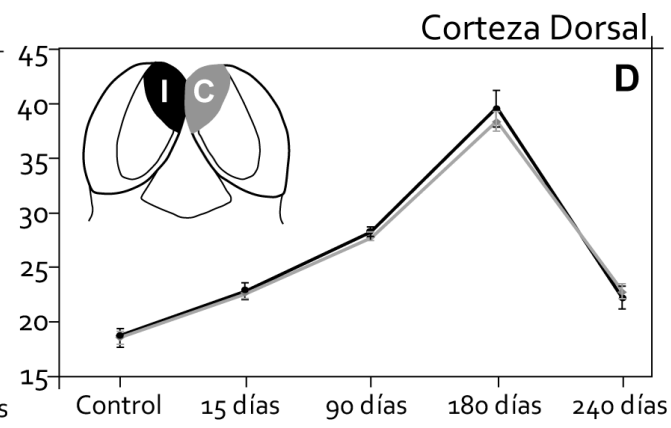

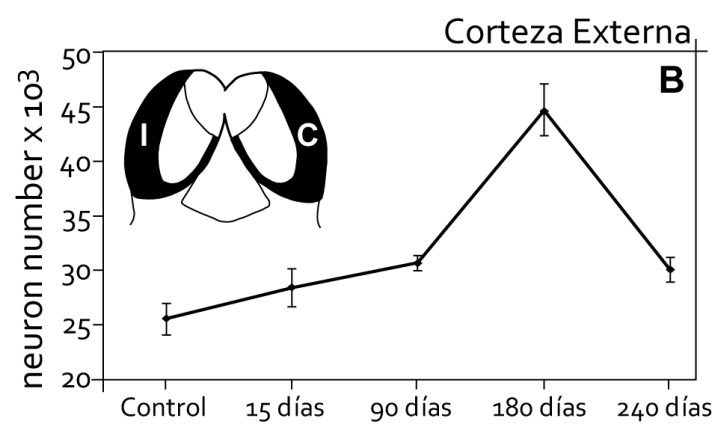
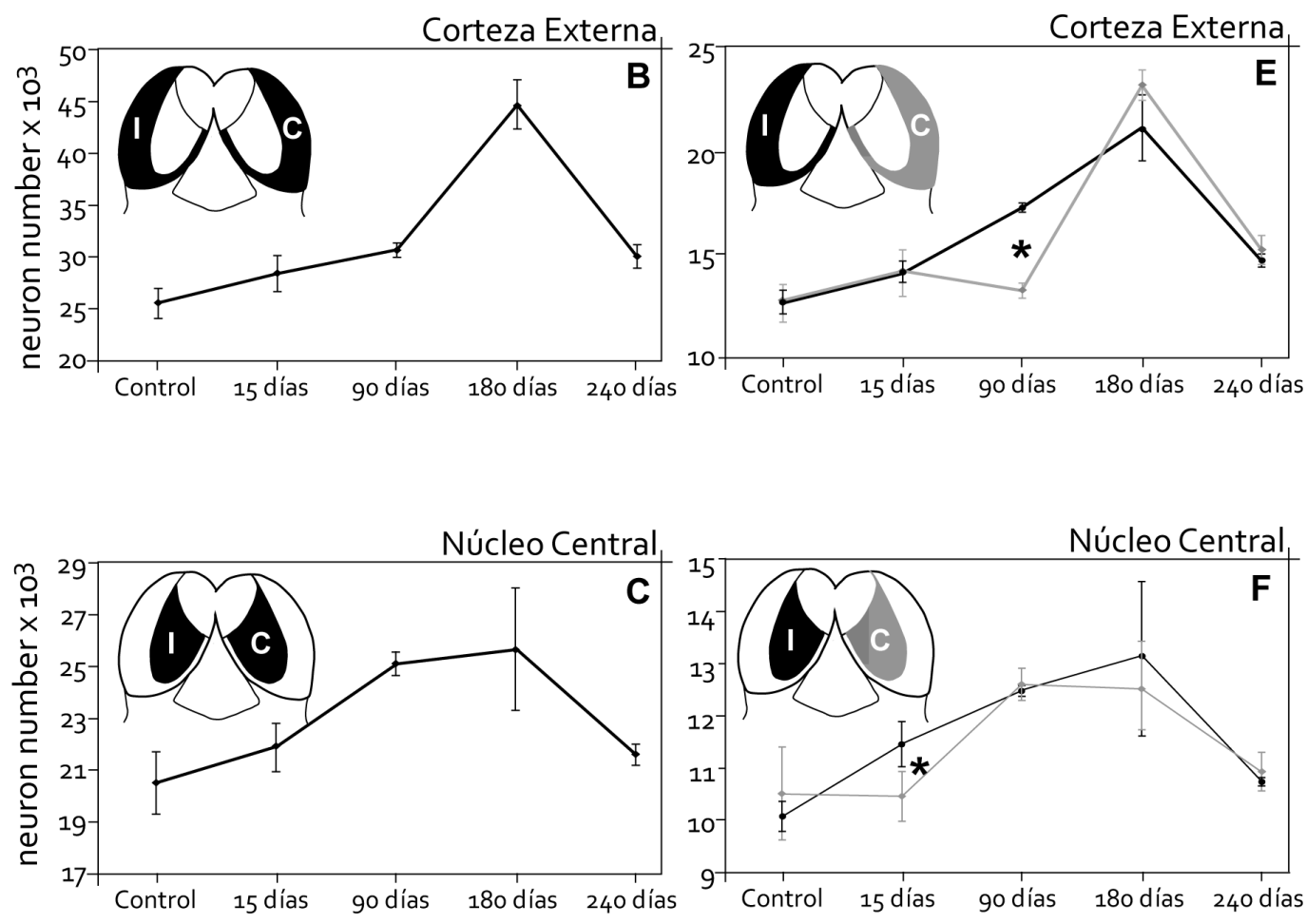

FIGURA 23. Estereología por subdivisiones en el Colículo inferior-Calretinina.

(A-C) Comparación en el número de neuronas positivas para Calretinina de forma bilateral en el Colículo inferior, las tres subdivisiones (A) Corteza Dorsal, (B) Corteza Externa y (C) Núcleo Central, muestran un progresivo incremento entre los grupos 15 y 180 días postlesión $(\mathrm{pl}$ ) con respecto a los valores controles; mientras que a los 240 días pl éstos disminuyen hasta casi el nivel de los controles.

(D-F) Comparación entre el número de neuronas calretinina-inmunorreactivas entre las subdivisiones de los colículos ipsilaterales y contralaterales a la zona de lesión. No encontramos diferencias estadísticamente significativas entre las corteza dorsales (D), en contraste con con la Corteza Externa (E) y el Núcleo Central $(F)$, donde se observaron diferencias evidentes entre ambos lados en el grupo de los 90 días $\mathrm{pl}$ y 15 días $\mathrm{pl}$ respectivamente. 
fue solo del $18.09 \%$. Al comparar el grupo 240 días pl con los otros grupos con ablación de 15,90 y 180 días, encontramos un descenso en las medias del $17.82 \%, 64.45 \%$ y $83.84 \%$ respectivamente (Figura $23 \mathrm{~A}$ ).

Al comparar la suma de los valores promedio de ambas $\mathrm{CECl}$ de los grupos lesionados con respecto a los controles, no observamos variaciones sustanciales a los diferentes tiempos pl, salvo para el grupo de 180 días pl en el que encontramos un aumento del promedio del $81.25 \%$ (Figura $23 \mathrm{~B}$ ).

En el $\mathrm{NCCl}$ (valores de ambos $\mathrm{Cls}$ ) solo se encontraron diferencias entre los casos controles y los lesionados para los grupos de 90 días pl, mostrando un incremento promedio del $24.03 \%$ y en los casos de 180 días pl con un incremento del $27.62 \%$ (Figura $23 \mathrm{C}$ ).

Se analizaron, además, los valores por subdivisiones entre los $\mathrm{Cls}$ comparando el lado ipsilateral con el lado contralateral a la zona de ablación (Figura 23D-F). Para la CDCl no se observaron diferencias entre ninguno de los grupos estudiados (Figura 23D), mientras que para la $\mathrm{CECl}$ se observó, a los 90 días pl, un incremento en el lado contralateral del número de neuronas $C R-I R r$, del $23.27 \%$ (Figura $23 \mathrm{E}$ ). Para el $\mathrm{NCCl}$ solo se halló un pequeño aumento en el lado ipsilateral del $8.75 \%$ con respecto al lado contralateral a los 15 días pl (Figura 23F).

\section{Receptores lonotrópicos de Glutamato / RT-PCR semicuantitativa y qPCR.}

El hemisferio cerebral derecho (contralateral a la lesión) de todos los animales utilizados para los estudios de expresión génica, grupos controles 15 , 16,20 y $24 ;$ y grupos lesionados 17 al 19, 21-23 y del 25-26; $n=64$ (Tabla No 1), fueron seccionados seriadamente en el plano sagital para comprobar citoarquitecturalmente que el tejido extraído par estas técnicas fuese exclusivamente $\mathrm{Cl}$ y no se incluyera ninguna de las estructuras anatómicas vecinas, tales como el núcleo cuneiforme, el sagulum o el NDLL. En todos los casos, el borde ventral del Cl fue observado claramente de tal modo que ningún otro núcleo fue incluido para los estudios moleculares (Figura 24).

Para evaluar si existían modificaciones en la expresión de los iGluRs, se utilizaron las técnicas de RT-PCR semicuantitativa y de qPCR para los tres grupos de receptores (AMPA, NMDA y Kainato).

\section{RT-PCR semicuantitativa.}

Mediante RT-PCR semicuantitativa, se evaluaron todas las subunidades de los iGluRs en el $\mathrm{Cl}_{\text {; }}$ mientras que con la técnica de $\mathrm{qPCR}$, se evaluaron las subunidades constitutivas y las relacionadas con la permeabilidad al $\mathrm{Ca}^{2+}$ (AMPA: GluR1 y GluR2; NMDA: NR1, NR2A; Kainato: GluR5 y GluR6). 


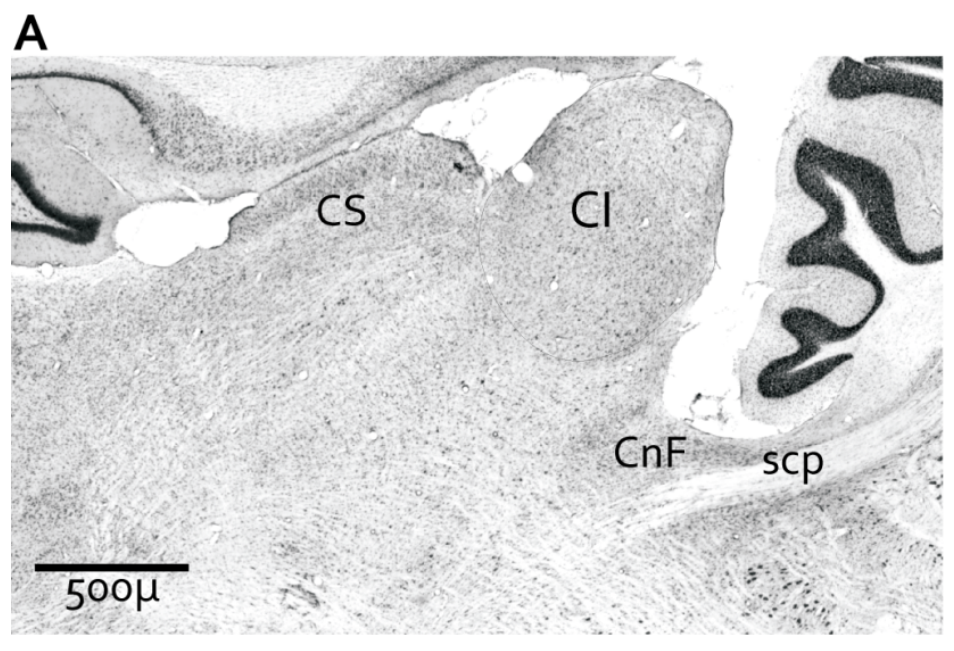

B

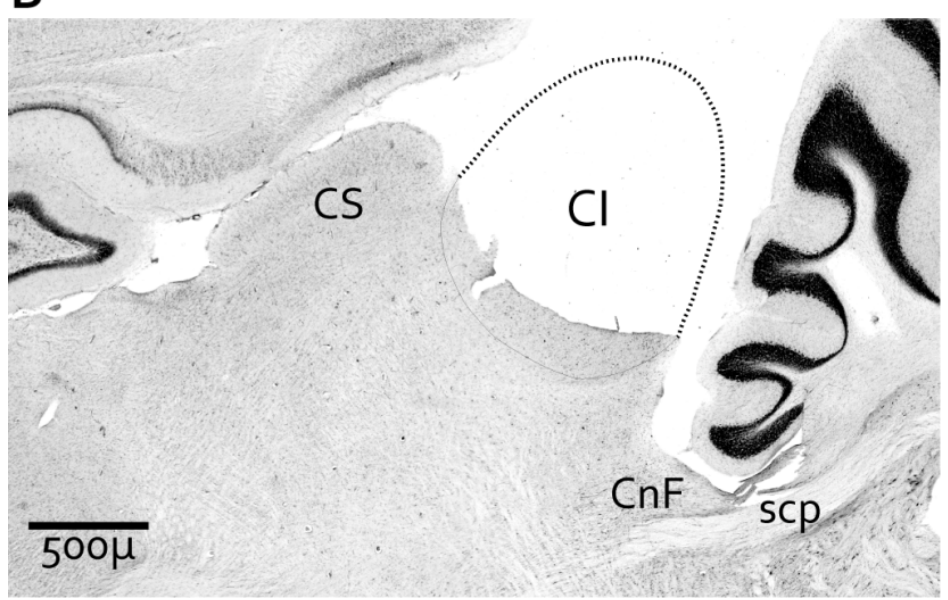

FIGURA 24. Extracción de Colículos Inferiores.

Microfotografías de secciones sagitales teñidas con Nissl (A) caso control y (B) caso lesionado, nivel interaural $1.9 \mathrm{~mm}$, en el que se observa en (A) la localización del colículo inferior y su relación con las estructuras adyacentes, y en (B) línea punteada, delimitamos la posible localización del $\mathrm{Cl}$, en la zona de remoción del núcleo, tejido utilizado o destinado para las técnicas de análisis genómico.

Cl Colículo Inferior

CnF Núcleo Cuneiforme

CS Colículo superior

scp Pedúnculo Cerebelar superior 


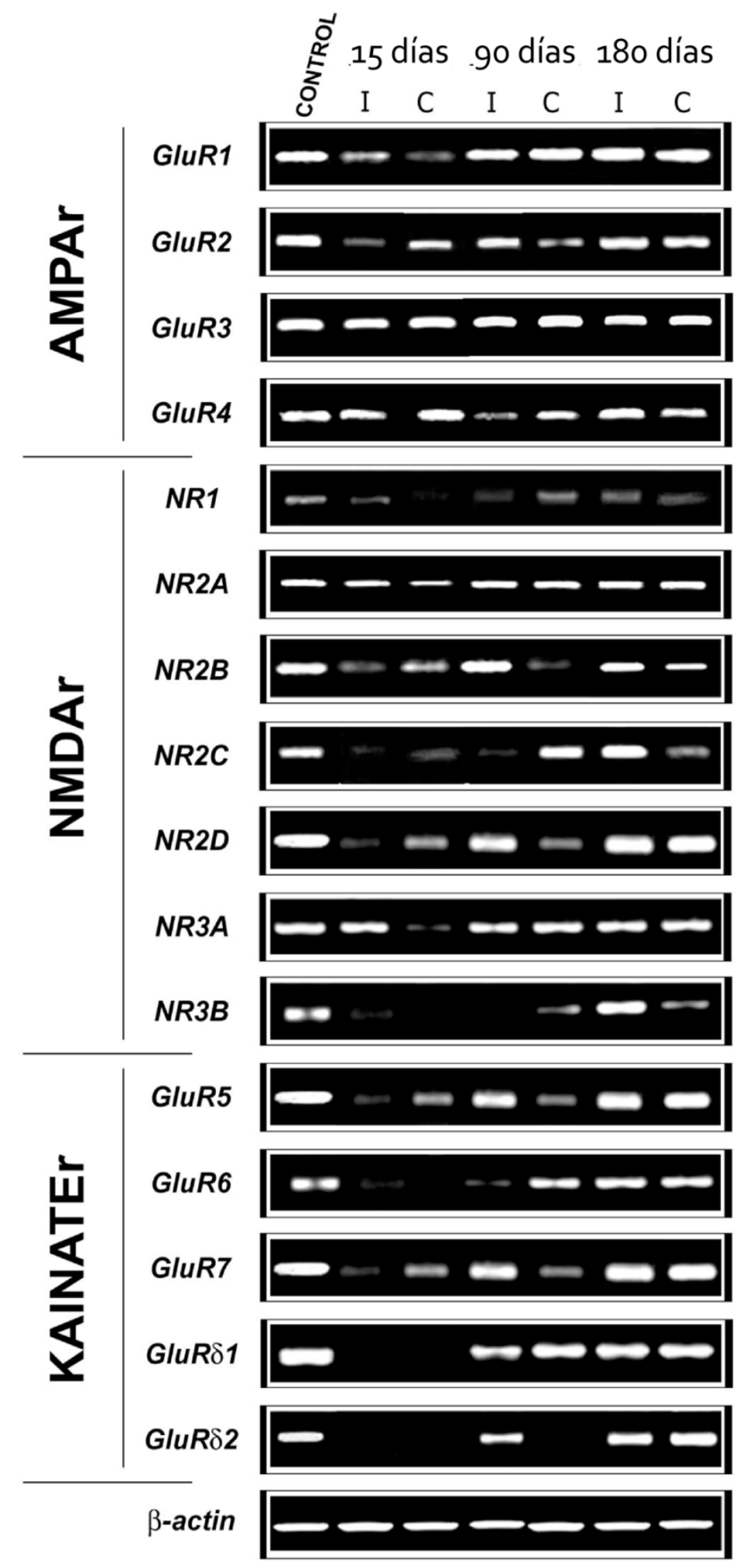

FIGURA 25.

Expresión de las subunidades de los receptores ionotrópicos de glutamato. Obsérvese el descenso en la densidad de la mayoría de subunidades que se observa a los 15 días pl, y la posterior recuperación de los niveles de expresión a los 90 y 180 días $\mathrm{pl}$, hasta casi el nivel del grupo control. 
En el análisis de expresión génica de las subunidades de los iGluRs utilizando la técnica de RT-PCR semicuantitativa, se observó que las células de los Cls de los casos controles (grupo 16, $n=6$; Tabla $N^{\circ} 1$ ), expresaron todas las subunidades de los receptores AMPA (GluR1-4), NMDA (NR1, NR2A-D y NR3A-B) y Kainatos (GluR5-7 y GluRd1-2) (Figura 25). Cuando se realizó igual análisis en el grupo de los 15 días pl (grupo 17, n=6; Tabla 1), se encontró una disminución en la expresión para las subunidades de los iGluRs y un aumento paulatino de esta expresión a los 90 y 180 días postlesión (Figura 25).

Específicamente, para las subunidades AMPA -GluR1 y GluR2, se observó un leve descenso a los 15 días pl con respecto al control, mientras que a los $90 \mathrm{y}$ 180 días $\mathrm{pl}$ los niveles de expresión eran equivalentes a los controles. La subunidad GluR3, no modificó su nivel de expresión génica en ninguno de los grupos estudiados y para la subunidad GluR4 se observó un leve decremento en los niveles de expresión a los 90 días pl (Figura 25).

Para la subunidades NMDA, respecto a NR1 se observó un leve descenso a los 15, 90 y 180 días pl; mientras que la expresión de la subunidad NR2A no se modificó en ninguno de los grupos estudiados. Las subunidades $\mathrm{NR}_{2} \mathrm{~B}_{1} \mathrm{NR}_{2} \mathrm{C}$ y $\mathrm{NR} 2 \mathrm{D}$ mostraron un descenso marcado en la expresión a los 15 días pl y un aumento gradual a los 90 y 180 días pl. La subunidad NR3A mostró solo un leve descenso a los 15 días pl, y la subunidad NR3B exhibió un descenso marcado a los 15 días pl y un aumento progresivo a los 90 y 180 días pl (Figura 25).

Para las subunidades Kainato - GluR5, GluR6 y GluR7, se observó un descenso marcado a los 15 días $\mathrm{pl}$, un aumento moderado a los 90 días $\mathrm{pl}$ y una recuperación aparentemente completa a los 180 días $\mathrm{pl}$ en los niveles de expresión con respecto al control. La subunidad GluR $\delta 1$ y GluR $\delta 2$, mostraron un fuerte descenso en los niveles de expresión a los 15 días, GluR $\delta 1$ se recuperó a los 90 días $\mathrm{pl}$, mientras que los niveles de expresión de GluR 2 se recuperaron hasta los 180 días pl (Figura 25).

Finalmente, en el grupo de animales con lesiones en regiones corticales ubicadas en áreas no auditivas (Grupo $N^{0} 13$, Tabla $N^{0} 1$ ), no se encontraron cambios en la expresión de los diferentes iGluRs (AMPA, NMDA y Kainato) a los 15 días pl (datos no ilustrados) con respecto al grupo control, por lo que no se exploraron en periodos más largos de supervivencia pl.

qPCR.

Con el fin de cuantificar significativamente los cambios en la expresión génica observados previamente (v.s.) en la expresión de los iGluRs en el $\mathrm{Cl}$, se midieron los niveles de transcripción de 6 subunidades iGluRs específicas: AMPA (GluR1 y GluR2), NMDA (NR1 y NR2A) y Kainato (GluR5 y GluR6) en 6 animales del grupo 1 (control) y en los 17 animales lesionados de los grupos 10 (15 días pl), 11 (90 días $\mathrm{pl}$ ), y 12 (180 días pl) (Tabla No 1). 
Para normalizar las diferencias del RNA/CDNa contenidas entre las muestras, aún cuando estaban cuantificadas por métodos espectofotométricos, calculamos los niveles de expresión qPCR relativos entre los genes de interés y un gen housekeeping el cual teóricamente presenta niveles similares de expresión independientemente del tejido, etapa de desarrollo o condición. Por tal razón, utilizamos como gen housekeeping el de la $\boldsymbol{\beta}$-Actina, cuantificando de esta forma los niveles de expresión de cada una de las seis subunidades de los iGluRs con respecto a este gen endógeno en los tres tiempos postlesión estudiados (15, 90 y 180 días).

Así en el análisis de los cuatro grupos experimentales, se observó que los promedios de expresión para las seis subunidades estudiadas variaron en el grupo control entre el 1.72 al 1.92. Para el grupo de los 15 días pl los promedios de expresión de las 6 subunidades de los iGluRs oscilaron entre el 0.79 y el 0.87 ; para el grupo de los 90 días pl los valores fluctuaron entre el 1.02 y el 1.17, mientras que para el grupo de 180 días pl los promedios variaron entre $0.97 \mathrm{y}$ 1.21 (Figura 26), tomando el valor 1, como valor del grupo control.

De todos los grupos experimentales, el de 15 días pl (grupo 10, Tabla No 1 , $n=5$ ) mostró los descensos más significativos ( $t$-Student) con respecto al grupo control, en las 6 subunidades estudiadas, siendo este decremento mayor para los NMDA (NR1 y NR2A) y menor para los Kainatos (GluR5 y GluR6), pero en todos los casos significativo (Figura 26)

Por su parte, en el grupo de los 90 días pl (Grupo 11, Tabla No $1, n=6$ ), se apreció que al igual que en el grupo de los 15 días pl, la expresión era menor con respecto al grupo control para las subunidades GluR1, GluR2, NR1, GluR5 y GluR6, mientras que no se encontraron diferencias significativas en la expresión de la subunidad NR2A entre el grupo control y el de 90 días pl (Figura 26). Finalmente, a los 180 días pl (Grupo 12, Tabla $N^{0} 1, n=6$ ), se observó un incremento en la expresión de todos las subunidades de los iGluR analizadas con respecto a los grupos lesionados de 15 y 90 días $\mathrm{pl}$ y estas diferencias fueron significativas con respecto al grupo control excepto para la subunidad GluR1 (Figura 26). 


\section{Receptores AMPA}
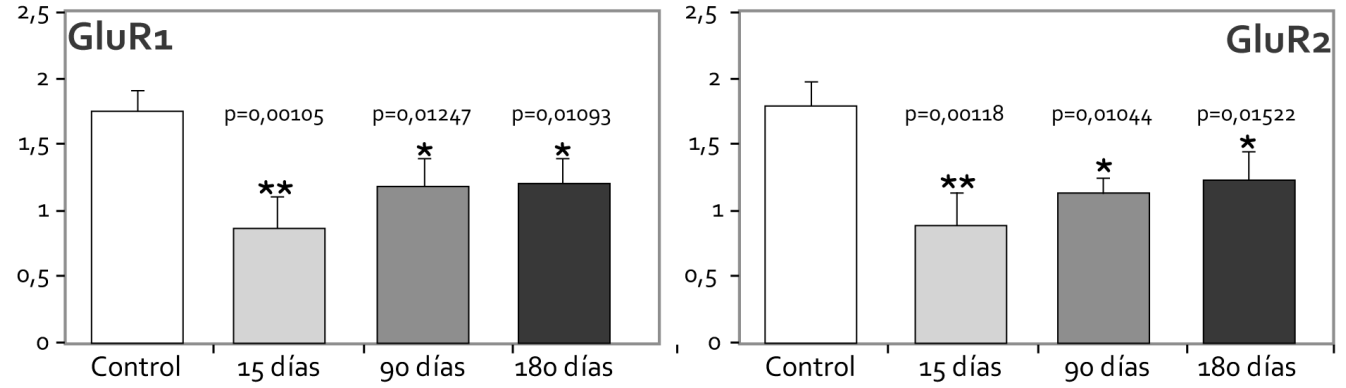

Receptores NMDA
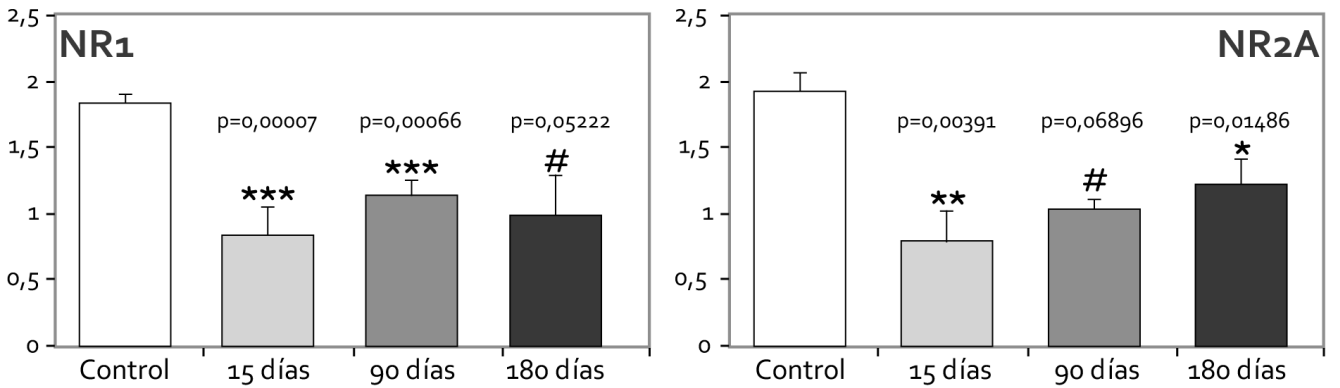

Receptores Kainatos
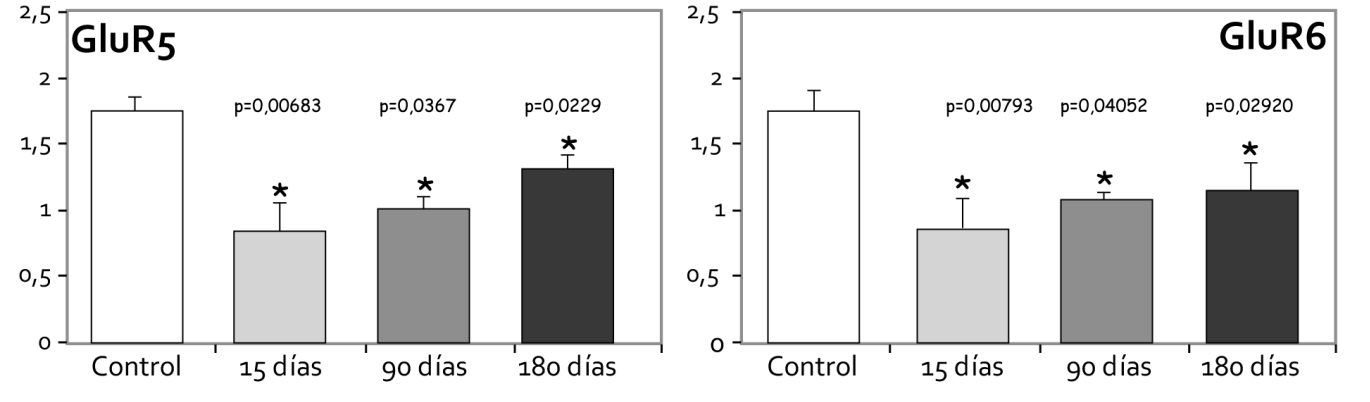

FIGURA 26.

Gráficos de barras que representan los niveles de expresión de las subunidades de los tres tipos de receptores ionotrópicos de glutamato (AMPA, NMDA y Kainatos) estudiadas por qPCR, en grupos control y lesionados ( 15,90 y 180 días). Nótese que es el grupo de los 15 días postlesión el que muestra un mayor descenso en la expresión de todas las subunidades estudiadas, mientras que hay incremento longitudinal entre el grupo de los 90 y 180 días postlesión. 
DISCUSIÓN 
En este trabajo de tesis doctoral se demuestra que tras producir una lesión unilateral en la Corteza Auditiva se origina una pérdida funcional profunda de la actividad de las vías auditivas, y más específicamente en el Colículo Inferior, núcleo en donde convergen la mayoría de proyecciones auditivas ascendentes y descendentes. Esta disfunción se relaciona en el tiempo con la disminución en los niveles de expresión de los receptores ionotrópicos de glutamato y con una alteración en los mecanismos de tamponamiento rápido del calcio intracelular. Las medidas de las pruebas funcionales (ABRs, RAS/IPP, C-Fos), los receptores postsinápticos (RT-PCR y qPCR) y la inmunorreactividad para CR (tamponamiento rápido del $\mathrm{Ca}^{2+}$ ) demuestran además una tendencia común a la recuperación de los valores normales de los parámetros evaluados tras períodos largos de supervivencia postlesión.

\section{Pruebas funcionales - ABRs- RAS/ IPP}

A los 15 días pl se observó un descenso significativo en la amplitud de las respuestas auditivas del tronco-encefálico (ABRs), en todas las ondas de los potenciales evocados, y un aumento significativo del umbral auditivo, lo que implica la existencia de una fuerte influencia de la proyección auditiva descendente sobre la actividad eléctrica evocada por sonido en el tronco del encéfalo. Por otra parte, estos parámetros (amplitud de respuesta y umbrales) en los casos lesionados, pueden recuperar a largo plazo valores iguales que los controles, lo que indicaría que el sistema auditivo adulto conserva una gran capacidad reparativa tras lesión, aún en animales adultos. En nuestros experimentos obtuvimos también datos funcionales que demuestran una disminución de la amplitud de la respuesta del RAS a los 15 y 90 días pl y una recuperación de ésta a los 180 días pl, mientras que las latencias se modificaron ligeramente solo a los 90 días pl. En los animales con lesiones en áreas corticales no auditivas (Figura 13) no se modificó la amplitud y la latencia del RAS o el porcentaje de inhibición cuando se evaluaron estos parámetros a los 15 días pl. Estos resultados reflejan un efecto de la lesión cortical auditiva directa sobre los circuitos o estructuras relacionadas con el RAS o más probablemente un efecto indirecto a través de una alteración en los umbrales auditivos (v.s.).

Es conocido el papel del $\mathrm{Cl}$, y en particular de la $\mathrm{CECl}$ en los circuitos de los reflejos acústico-motores (Huffman y Henson, 1990). Parham y Willot (1990) demostraron que tras lesiones electrolíticas en el $\mathrm{Cl}$ se produce primero una disminución de la amplitud del RAS, y luego una recuperación de esta respuesta. De esta forma, la ablación unilateral de la CA podría generar un efecto similar al reportado por estos autores, que estaría inducida en parte, por el descenso a los 15 días pl en la actividad del $\mathrm{Cl}$ observada por nosotros mediante el estudio de los potenciales evocados auditivos (v.s.).

El circuito que desencadena el RAS esta formado por las neuronas de la raíz coclear (NRC), neuronas gigantes de PnC y neuronas motoras (Lee y cols. 1996; 
Nodal y López, 2003), produciéndose tras el estímulo desencadenante, una brusca contracción muscular tras latencias muy cortas de $10 \mathrm{~ms}$ (Cassella y cols., 1986, Caeser y cols., 1989). Por la corta latencia del RAS, el circuito responsable de modificar el umbral de disparo de las NRC debería ser corto y estar compuesto por pocas neuronas para permitir un efecto inhibitorio inmediato. Una disminución en la amplitud del RAS puede ser debida a cambios en la actividad de los aferentes primarios que provoquen una modificación del disparo de las NRCs (Pilz y cols., 1988). Se sabe que las NRCs responden a altos umbrales en una función de intensidad monotónica (Sinex y cols., 2001), por lo que deben ser sensibles a pequeños cambios en el procesamiento coclear y más en particular a cambios en el ritmo de descarga (rate level function) de los aferentes primarios. No hay demasiados estudios acerca de la contribución de la corteza auditiva y del cerebro medio al sistema eferente olivococlear, pero se sabe que el $\mathrm{Cl}$ posee la capacidad de influenciar y modular los niveles de excitabilidad de las neuronas olivococleares (Rajan, 1990) y Vetter y cols., (1993) sugieren que el $\mathrm{Cl}$ a través de sus terminaciones sobre el sistema olivococlear medial puede modular las respuestas cocleares. Además se ha comprobado que la estimulación de las neuronas del $\mathrm{Cl}$ puede producir una reducción en los cambios temporales de umbral del nervio auditivo (temporary treshold shift of the auditory whole-nerve) (Rajan, 1988; Rajan, 1989) o bien una atenuación entre 10$20 \mathrm{~dB}$ del umbral de respuesta de las fibras del nervio (Dolan y Nuttal, 1988). De esta forma, con la afectación directa del $\mathrm{Cl}$ sobre un núcleo tan importante para el desencadenamiento del RAS, podría modificarse indirectamente el RAS. Conceptualmente la alteración de la respuesta del RAS depende del disparo de un menor número de NRC y neuronas promotoras, y por lo tanto de la contracción de un menor número de fibras musculares (unidades motoras), que se traduzcan en una disminución de la amplitud de las respuestas. En nuestros experimentos, las alteraciones observadas en el umbral de disparo que inducen una disminución de amplitud de la respuesta motora, pueden ser consecuencia de cambios en los umbrales de respuesta al sonido, tal y como hemos comprobado en esta tesis doctoral mediante el estudio de los ABRs (Figura 11 ) (Clarkson y cols., 2009). El efecto de la lesión cortical auditiva sobre el RAS observada por nosotros, puede también relacionarse con la pérdida de la proyección corticofuga directa que termina bilateralmente en el núcleo ventral del cuerpo del trapezoide (VNTB) y que presumiblemente puede actuar sobre neuronas olivo-cocleares (Feliciano y cols., 1995).

El estudio longitudinal de la IPP en animales con lesiones unilaterales de la CA, muestra un descenso en el porcentaje de inhibición del RAS provocado por los diferentes pre-estímulos auditivos a los 15 y 90 días pl. Tras 180 días pl, la IPP no mostró ninguna diferencia significativa con respecto al grupo control.

A diferencia que en el RAS, en la inducción de la IPP, es bien conocido por estudios previos el papel del Cl (Li y cols., 1998; Fendt y cols., 2001; Li y Yue, 2002; Silva y cols., 2005; Yeomans y cols., 2006; Gómez-Nieto y cols., 2008). Sin 
embargo, no existe un acuerdo acerca de cuáles núcleos están involucrados en el circuito de la IPP (Fendt y cols., 2001; Swerdlow y cols., 2001; Yeomans y cols., 2006), pero en todo caso, se sabe que las señales inhibitorias finales deben ejercer su influencia sobre las neuronas de PnC o sobre las NRC.

Los modelos actuales del circuito de la PPI (Fendt y cols., 2001; Yeomans y cols., 2006) postulan que son las proyecciones colinérgicas las que actúan sobre PnC para mediar la IPP (Koch y cols., 1993; Koch, 1999, Fendt y cols., 2001). Más recientemente, ha sido descrita una proyección colinérgica directa desde VNTB a las NRCs que puede llevar información auditiva capaz de modular el RAS en las NRCs (Gómez-Nieto y cols. 2008). Registros electrofisiológicos en las NRC muestran que la aplicación de pre-estímulos auditivos inhibe la respuesta de estas neuronas (Gómez-Nieto y López, 2006), y por lo tanto, el núcleo VNTB puede elaborar prepulsos acústicos para la vía del RAS. Estas neuronas a su vez, reciben una proyección directa desde el Cl (Gómez-Nieto y cols., 2008). Por lo tanto este efecto inhibitorio sobre las NRCs puede estar regulado directamente por las neuronas del $\mathrm{Cl}$, que en nuestros experimentos (grupos 15 días pl) se encuentran afectadas en su procesamiento producto de la deprivación parcial del control descendente (Figura 11). Los cambios en la respuesta de las neuronas del $\mathrm{Cl}$ tras lesión cortical han sido analizados previamente por diversos autores (Nwabueze-Ogbo y cols, 2002; Syka y cols., 2002; Popelar y cols., 2003, Rybalko y cols., 2006; Clarkson y cols., 2009), si bien falta por demostrar que estos cambios afecten directa o indirectamente a los circuitos implicados en la IPP. Un dato a favor de esta hipótesis es la pérdida tras lesión cortical auditiva en la capacidad de detección de gaps del sonido (Ison y cols., 1991; Bowen y cols., 2003) que podría permitir comprender en nuestros experimentos como una incorrecta codificación del onset - offset de los pre- estímulos o una alteración en determinar la diferencia de tiempo entre el estímulo previo y el pulso de intensidad que desencadena el reflejo afecta el porcentaje de inhibición de éste.

\section{c-Fos}

Hay estudios que demuestran que tras estimulación con tonos puros la expresión de c-Fos marca bandas en el $\mathrm{Cl}$ con ubicación cocleotópica (Ehret y Fischer, 1991; Friauf, 1992; Rouillier y cols., 1992; Pierson y Snyder-Keller, 1994; Saint-Marie y cols., 1999). Nosotros observamos tanto en los grupos controles como en los lesionados, una distribución homogénea de las neuronas c-Fosinmunorreactivas y de localización preferente en la región más dorsal del $\mathrm{Cl}$. En nuestro sistema de estimulación homologado y basado en el diseño de caja de estimulación en campo abierto propuesto por Yoshida y cols., (2006) ha sido comprobado tanto la intensidad de la frecuencia fundamental del tono puro como la de sus armónicos. El armónico más alto de $10 \mathrm{kHz}$ registrado fue de 30 $\mathrm{dB}, \mathrm{y}$ las siguientes presentaron valores aún inferiores, de tal modo que una estimulación de todo el rango de octavas desde la frecuencia de estimulación queda a todos los efectos descartada. La explicación más plausible para las 
diferencias observadas respecto a otros autores que identifican bandas tonotópicas (Ehret y Fischer, 1991; Friauf, 1992; Rouillier y cols., 1992; Pierson y Snyder-Keller, 1994; Saint-Marie y cols., 1999) y nosotros, sería el hecho de haber utilizado animales bajo anestesia en campo abierto, ya que se conoce que aplicación de anestesia en los animales durante la estimulación, puede producir la pérdida parcial de la codificación espectral (Sun y cols., 2007). Sin embargo, en el $\mathrm{Cl}$ la ubicación de la región de $5 \mathrm{KHz}$ (frecuencia fundamental utilizada por nosotros) tiene según diversos estudios fisiológicos (Ehret y Fischer, 1991; SaintMarie y cols., 1999) una localización en la zona mas dorsal del NC, coincidiendo con la mayor concentración de núcleos c-Fos-IRrs observada en nuestros experimentos. Otra explicación para justificar la distribución no tonotópica de los núcleos inmunorreactivos es las sensibilidades de los anticuerpos comerciales para c-Fos utilizados por nosotros, y por otros autores que encuentran tonotopía utilizando c-Fos como marcador (Ehret y Fischer, 1991: anti-c-Fos 456, Medac; Rouillier y cols., 1992, Pierson y Snyder-Keller, 1994: anti-c-Fos, Cambridge Research Biochemicals). En este estudio en particular, seleccionamos de entre 4 anticuerpos (Ab-5 Oncogen Research; SC-52 Santa Cruz Biotecnologic; SC-253 Santa Cruz Biotecnologic; SC-7202 Santa Cruz Biotecnologic) aquel que produjo un mayor número de neuronas inmunorreactivas en el $\mathrm{Cl}$. Por lo tanto, es posible que la utilización de un anticuerpo más específico y en consecuencia más sensible para la detección de c-Fos, genere un mayor número de marcas positivas y por lo tanto se difumine el bandeado tonotópico, sin descartar que esté ahí.

El estudio en los diferentes grupos experimentales de la inmunorreactividad para c-Fos en el $\mathrm{Cl}$, indica que a los 15 días $\mathrm{pl}$ se produce una disminución tanto en el número como en la intensidad de la inmunorreacción y en el perímetro de los núcleos positivos. Además, los valores de estos parámetros en los grupos con tiempos de supervivencia postlesión de go días, se asemejan a los del grupo control.

Es conocido que la acumulación de la proteína c-Fos en los núcleos de las células, depende de la elevación de las concentraciones intracelulares de calcio y segundos mensajeros, y son consecuencia de cambios en la actividad neuronal (Morgan y Curran, 1987; Sheng y cols., 1990). Además también se conoce, que la activación por sonido del sistema auditivo provoca un incremento de c-Fos estímulo -dependiente en diferentes niveles de las vías auditivas, y más en particular en el Cl (Ehret y Fischer, 1991; Pierson y Snyder-Keller, 1994; Friauf, 1995; Saint-Marie y cols., 1999). Los datos presentados en el apartado anterior de este trabajo de tesis doctoral muestran que, la actividad eléctrica evocada de la vía auditiva disminuye en todas las estaciones tronco-encefálicas, incluido el $\mathrm{Cl}$ a los 15 días pl, y posteriormente el sistema recupera su función al nivel del grupo control (Figura 11) en grupos experimentales lesionados y con similares tiempos de supervivencia postlesión. 
Se ha establecido que c-Fos se expresa en el sistema auditivo en función de la actividad evocada por sonidos (Ehret y Fischer, 1991; Pierson y Snyder-Keller, 1994; Friauf, 1995; Saint-Marie y cols., 1999) y que según nuestros datos procedentes del estudio de potenciales evocados y RAS/IPP, podemos concluir que la disminución en número, densidad y perímetro de los núcleos c-Fos inmunorreactivos son indicadores de que la deaferentación de la vía corticocolicular induce un descenso global y sostenido de la actividad de las neuronas del $\mathrm{Cl}$ a los 15 días pl. Además, el análisis de los grupos experimentales con tiempos de supervivencia postlesión más largos avala, la existencia de una capacidad de recuperación funcional tras lesión en el sistema auditivo de la rata adulta.

En el momento actual no existen estudios previos que demuestren que la densidad o el perímetro de las partículas c-Fos-IRr sean variables útiles para valorar cambios en la actividad neuronal. Sin embargo, los estudios de Lu y cols., (2009), demuestran que la inmunorreacción se produce sobre un conglomerado de histonas que aumenta el tamaño de los núcleos según se incrementa la estimulación de las células. En consecuencia, cabe esperar que a mayor actividad celular el tamaño de los núcleos y la cantidad de cromógeno depositado en los mismos aumente y en consecuencia lo haga el perímetro de los mismos. Nuestros experimentos apoyan esta consideración metodológica puesto que en los casos de 15 días pl disminuye la densidad de la inmunorreacción y el perímetro de los núcleos positivos y aumenta a los go días pl hasta el nivel de los controles, en correlación clara con las oscilaciones de la actividad eléctrica entre grupos experimentales. En resumen concluimos que, la tinción para c-Fos no sigue un principio de todo o nada (positivo o negativo) sino que la densidad del cromógeno y el perímetro nuclear es variable y por tanto es función-dependiente.

La subdivisión del $\mathrm{Cl}$ en la que más se modificaron todos los parámetros analizados de la inmunorreactividad para c-Fos (número, densidad y perímetro de núcleos c-Fos-IRr), fue la CDCl (Figura 19). Se conoce, tras la inyección de trazadores anterógrados en la CA de la rata que ésta es la subdivisión que recibe de forma bilateral la proyección más densa desde las CAs (Saldaña y cols., 1996) y por lo tanto, se puede plantear que siendo la proyección descendente excitatoria y glutamatérgica, los mayores descensos de actividad neuronal y por tanto de la inmunorreactividad para c-Fos, se produzcan en esta subdivisión tras la ablación cortical. Esta hipótesis debe confirmarse mediante registros electrofisiológicos que demuestren que estos cambios en la actividad tienen una base sustentada en alteraciones en el ritmo de descarga de las neuronas coliculares deaferentadas. Más aún, cuando se conoce que el $\mathrm{Cl}$ per se está dotado de un potente contingente de neuronas de proyección intrínseca y comisural (Saldaña y Merchán, 1992), que contienen neurotransmisores tanto excitatorios como inhibitorios (Saint-Marie, 1996; Malmierca y cols., 2003; Merchán y cols., 2005). De este modo, la proyección intrínseca y contralateral 
intacta, podría compensar mediante la activación de neuronas excitatorias propias del $\mathrm{Cl}$, la deprivación de la proyección del lado lesionado. En este sentido conviene resaltar que, a diferencia de otras subdivisiones del $\mathrm{Cl}$, la $\mathrm{CDCl}$ es diana prácticamente única de las neuronas propias del $\mathrm{Cl}$ (Huffman y Henson, 1990) y a la vez es la región del núcleo con una mayor densidad de campos terminales procedentes de las cortezas auditivas (Saldaña y cols., 1996). Por ser la región de mayor convergencia y densidad de las proyecciones descendentes y comisurales se podrían explicar los efectos más llamativos, tanto de la lesión como de la posterior recuperación de la inmunorreactividad para c-Fos.

\section{Calcio y Calretinina.}

En este trabajo se analizan los cambios cuantitativos y cualitativos en la inmunorreactividad para Calretinina de las neuronas del Colículo Inferior tras lesión unilateral de la corteza auditiva. Se estudiaron estos cambios en tiempos largos tras la ablación (15, 90, 180 y 240 días).

De esta forma, se comparó en conjunto el $\mathrm{Cl}$ del lado ipsilateral con el lado contralateral y cada una de sus subdivisiones entre sí. En el grupo control fueron observadas neuronas inmunorreactivas localizadas en la cápsula fibrodendrítica de la $\mathrm{CECl}$ y en las capas más superficiales de la $\mathrm{CDCl}$, con escasas neuronas positivas en el $\mathrm{NCCl}$. Se evidenció un aumento en la intensidad de la reacción a los 15 días pl, por el incremento en la densidad de tinción de los somas y de los árboles dendríticos. Tanto la inmunorreactividad de somas y dendritas como el número de neuronas CR-IRr, se incrementó progresivamente en las tres subdivisiones del $\mathrm{Cl}$ a los 15, 90 y 180 días pl. Además, se produjo un aumento en el número de neuronas en los grupos de 15, 90 y 180 días pl, distribuido desde la periferia del $\mathrm{Cl}$ hacia el centro, observándose en los casos de mayor inmunorreactividad (180 día pl) neuronas abundantes en el núcleo central prácticamente inexistentes en esta subdivisión en los casos controles. El grupo experimental analizado a los 240 días pl mostró una intensidad de inmunorreacción y número de neuronas similar al grupo control.

Cuando se analizó el número de neuronas cuantificadas por estereología por subdivisiones del $\mathrm{Cl}$ y comparando los valores entre el lado ipsilateral y el contralateral a la zona de ablación de la CA, solamente se observaron diferencias significativas en el número de neuronas $\mathrm{CR}-\mathrm{IRr}$ en la $\mathrm{CECl}$ contralateral a la lesión a los go días pl, y en el NCCl ipsilateral a los 15 días pl.

La Calretinina contribuye a la homeostasis neuronal frente a cambios en la concentración intracelular de $\mathrm{Ca}^{2+}$, comportándose como un buffer al igual que otras PLC, pero se le asigna además otras funciones. En este sentido esta PLC de la familia de las EF-hand puede actuar como un $\mathrm{Ca}^{2+}$-sensor/modulador implicado en cascadas de señalización celular (Mockel y Fisher, 1994; Kuznicki y cols., 1996; Schurmans y cols., 1997; Billing-Marczak y cols., 1999; Isaacs y cols., 
2000), y como un tampón transportador de la difusión del $\mathrm{Ca}^{2+}$ móvil a los sitios presinápticos (Edmonds y cols., 2000). Se trata en resumen de una proteína de tamponado rápido del $\mathrm{Ca}^{2+}$ que se ha relacionado con la protección frente a la excitotoxicidad inducida por el glutamato (Lukas y Jones, 1994; D'Orlando y cols., 2002, 2001), con la transmisión sináptica rápida y ajuste del ritmo de disparo (Haedo y Golowasch, 2006), el crecimiento axónico (Wu y cols., 2007) y la transcripción génica (Buckingham y cols., 2008).

Existe información suficiente que permite considerar que tras inactivación o lesión de la CA se producen cambios profundos en el procesamiento de las propiedades temporales, espectrales y binaurales del sonido en el sistema auditivo (Melo y cols., 1997; Talwar y cols., 2001; Nwabueze-Ogbo y cols., 2002; Syka y cols., 2002; Popelar y cols., 2003; Bowen y cols., 2003; Rybalko y cols., 2006; Cooke y cols., 2007; Threlkeld y cols., 2008). Dentro de este sistema, debemos recordar que el $\mathrm{Cl}$ es una estación de relevo obligatoria para las proyecciones ascendentes y descendentes de la vía auditiva y es una diana de las eferencias corticales descendentes (rata: Druga y Syka, 1984 a, b; Herbert y cols., 1991; Saldaña y cols., 1996).

El sistema nervioso auditivo se caracteriza en todos sus niveles, y también en el $\mathrm{Cl}$, por generar una actividad sináptica muy rápida. En particular, se acepta que algunas de las respuestas que requieren una más rápida y precisa descarga son las de codificación de las propiedades tanto temporales como espectrales o binaurales del sonido, fenómenos en los que, como veremos, la corteza auditiva esta directamente implicada. Sabemos que tras inactivación de la corteza auditiva primaria con muscimol, Talwar y cols., (2001) observaron que ésta se encuentra íntimamente ligada con la percepción de la intensidad y frecuencia del sonido. Por otra parte, se ha reportado que tras lesión bilateral de las CAs, las ratas sufren un déficit persistente en la detección de los ruidos de amplitud modulada, indicando que la CA es una estructura crucial para el mantenimiento de una sensibilidad normal necesaria para la modulación temporal de los estímulos auditivos (Cooke y cols., 2007). También se conoce que el $\mathrm{Cl}$ es clave en el refinamiento de las propiedades temporales y espectrales del sonido (Suga y cols., 2000, 2002). El efecto de la proyección descendente en la descarga neuronal del $\mathrm{Cl}$ ha sido demostrado tras estimulación eléctrica de las CAs (Syka y Popelar, 1984; Torterolo y cols., 1998). Nwabueze-Ogbo y cols., (2002) observaron tras inactivación funcional de la CA por tetrodotoxina una prolongación significativa de las latencias y cambios en el ritmo de descarga neuronal que incluían tanto la elevación como el descenso del mismo. Popelar y cols., (2003) observaron igualmente que el ritmo de descarga (firing rate) de las neuronas del $\mathrm{Cl}$ aumenta en unos casos (40\% de las neuronas), disminuye en otros ( $44 \%$ ) o no se modifica ( $16 \%$ ). Es posible que tras lesión cortical auditiva, el aumento del ritmo de descarga de unas neuronas o la disminución de otras en el $\mathrm{Cl}$, se deba a la desaparición del efecto de la estimulación sináptica descendente sobre neuronas bien excitatorias o inhibitorias del Cl (Faingold y cols., 1991; 
Oliver y cols., 1994; Feliciano y Potashner, 1995; Merchán y cols., 2005). Puesto que la proyección descendente utiliza el Glutamato como neurotransmisor (Feliciano y Potashner, 1995), las neuronas del $\mathrm{Cl}$ disponen de abundantes receptores postsinápticos para éste. En consecuencia, el aumento de actividad de descarga neuronal observado por diferentes autores tras inactivación cortical (Nwabueze-Ogbo y cols., 2002; Popelar y cols., 2003) tiene como base la activación directa de un mayor número de receptores postsinápticos de glutamato. Se conoce que la mayoría de los tipos de receptores ionotrópicos de glutamato, son capaces de permitir la entrada de $\mathrm{Ca}^{2+}$ a la neurona. Así, el aumento de células inmunorreactivas observado en nuestros experimentos, podría deberse a un fenómeno de sobre-regulación de esta proteína inducido por la entrada de $\mathrm{Ca}^{2+}$ en los tipos neuronales, que incrementan su actividad de descarga tras la lesión cortical unilateral. Apoyando esta hipótesis, nuestros datos muestran una relación entre las subdivisiones del $\mathrm{Cl}$ más densamente inervadas por la proyección glutamatérgica descendente (Saldaña y cols., 1996), y por tanto potencialmente más abundantes en receptores postsinápticos glutamatérgicos, con los mayores incrementos en el número de neuronas $C R-I R r$ (Figura 25).

Por lo tanto, el aumento de neuronas inmunorreactivas para CR observada por nosotros mediante inmunohistoquímica hasta los 180 días pl, estaría relacionado con la función de mantener la precisión frente a ritmos altos de descarga neuronal. Mientras que la disminución del número de neuronas inmunorreactivas observada a los 240 días pl en el $\mathrm{Cl}$, podría ser consecuencia de la recuperación del adecuado balance de excitación /inhibición, y en consecuencia de los ritmos de descarga normales, reflejando así una recuperación funcional del $\mathrm{Cl}$.

Sin embargo, no debemos olvidar el papel de la CR en los fenómenos de protección para la apoptosis (Turner y cols., 2007). Si el papel de neuroprotección refleja en el fondo un mecanismo de muerte neuronal inducido por la entrada anormal de $\mathrm{Ca}^{2+}$, no es posible descartar el que el descenso en el número de neuronas a los 240 días pl refleje en realidad la claudicación del sistema y la muerte de las neuronas. Siguiendo con esta idea podríamos decir que, por lo tanto, en los casos lesionados la inmunorreactividad frente a CR estaría identificando las células del $\mathrm{Cl}$ con mayor entrada de $\mathrm{Ca}^{2+}$ y por tanto las más susceptibles a desencadenar procesos de apoptosis tras lesión. Pero el papel específico de la CR en los efectos neuroprotectivos, es hoy en día muy controvertido (Para una revisión ver: D'Orlando y cols., 2002). Habrá que realizar experimentos específicos con marcadores de apoptosis para interpretar la disminución hasta valores controles del número de neuronas CR-IRr a los 240 días pl.

El recrecimiento axonal (collateral sprouting) fue demostrado por primera vez en el cerebro en el núcleo del septo por Raisman (1969), y es una reacción 
plástica común observada en el cerebro medio y en el tálamo (Angelucci y cols., 1998; Caleo y cols., 2009). Por otra parte se ha puesto en relación un aumento del $\mathrm{Ca}^{2+}$ intracelular con la remodelación axonal o dendrítica tanto en el desarrollo como tras lesiones del sistema nervioso. Wu y cols., (2007), demostraron recientemente en células en cultivo que la combinación de GM1 Gangliosido con CTxB induce la estimulación del crecimiento axonal y que éste depende de la entrada de $\mathrm{Ca}^{2+}$. Para estos autores, la combinación de $\mathrm{GM}_{1}$ con alfa5beta1 integrina es la responsable de abrir canales de $\mathrm{Ca}^{2+}$ específicos y desencadenar las cascadas de señalización que inducen el crecimiento axonal.

Por otra parte, han sido publicados previamente que se producen cambios en la concentración de $\mathrm{Ca}^{2+}$ intracelular vinculados a un aumento de $\mathrm{CR}$ y a un proceso de sinaptogénesis reactiva (Prang y cols., 2003). Específicamente, en el sistema auditivo tras lesión coclear unilateral en hurones, Alvarado y cols., (2005) demostraron un aumento de fibras y terminales CR-IRr, que los autores relacionan con un posible proceso de proliferación axonal. En nuestro material, no hemos podido observar un aumento significativo de inmunorreactividad de los terminales sinápticos aunque si de los axones a los 180 días pl (Figura 21). A la vista de nuestros resultados no se puede descartar además de lo expuesto, la existencia de una relación entre el aumento de inmunorreactividad a CR tras lesiones corticales y fenómenos de remodelación axonal o dendrítica, un fenómeno observado por nosotros en nuestro modelo experimental (datos preliminares $v . i$.).

Recientemente se ha estudiado en animales transgénicos con déficit de CR la actividad de los granos del cerebelo mediante técnicas de patch clamp (Gall y cols., 2003, 2005; Roussel y cols., 2006). Estos estudios, planteados desde un modelo matemático predictivo y que se han contrastado con los resultados de la electrofisiología en las neuronas del cerebelo de los animales knock out, permiten establecer una relación directa entre la expresión de CR y la excitabilidad de la membrana. Los fundamentos teóricos obtenidos, apoyados también en estudios previos de neuronas de hipocampo (Lancaster y Nicoll, 1987), permiten concluir que determinadas proteínas ligadoras de Calcio y en particular la $\mathrm{CR}$, pueden relacionarse directamente tanto con la potencia sináptica (synaptic strenght), como con la excitabilidad de la membrana (Canales de Potasio dependientes de $\mathrm{Ca}^{2+}$ ). Estas dos propiedades asignadas recientemente de forma específica para la $C R$ permiten plantear que el aumento de neuronas inmunorreactivas para $C R$ observado por nosotros puede tener relación con los fenómenos de compensación productos de la pérdida del balance de excitación/inhibición y permite de este modo relacionar indirectamente la expresión de la CR con los principios formulados para el equilibrio homeostático (Turriguano y cols., 1999). 


\section{Receptores lonotrópicos de Glutamato.}

Los cambios observados en el conjunto de todas las subunidades de los iGluRs (Figura 25) estudiadas en este trabajo, muestran un descenso significativo en los niveles de expresión génica de éstos a los 15 días pl, y un incremento con respecto a este grupo, a los 90 y 180 días pl.

De igual forma, el análisis cuantitativo mostró que a los 15 y 90 días pl la pérdida unilateral de la proyección descendente de la CA disminuye los niveles de expresión del mRNA de las subunidades de los iGluRs AMPA (GluR1, GluR2), NMDA (NR1, NR2A) y Kainato (GluR5 y GluR6). A los 180 días pl obtuvimos valores próximos a los del grupo control para estas mismas subunidades (Figura 26). Los experimentos controles con lesiones parciales en cortezas no auditivas, no mostraron a los 15 días pl, alteraciones en la expresión de los iGluRs (datos no ilustrados). Estos resultados indican que los cambios observados en la expresión del mRNA de los iGluRs son consecuencia de las lesiones en CA y no un efecto indirecto inespecífico.

La Pcc se origina fundamentalmente de las pirámides de la capa $V$ de la CA (Beyerl, 1978; Kelly y Wong, 1981; Games y Winer 1988, Meredith y Clemo, 1989, Weedman y Ryugo, 1996; Winer y Prieto, 2001; Bajo y cols., 2007) y su carácter excitatorio y glutamatérgico fue demostrado por Feliciano y Potashner (1995) tras producir lesiones unilaterales de la corteza auditiva. Estos autores, tras siete días pl, demostraron además la existencia de una degeneración preterminal en el $\mathrm{Cl}$. Esta degeneración que representa una pérdida de aferencias sinápticas estaría en relación con la menor expresión de las subunidades de los iGluRs observadas en nuestros experimentos a los 15 días pl. Si bien, debemos también considerar un efecto más que pasivo tanto en la permeabilidad al calcio como en la regulación, tráfico y ensamblado de estos receptores durante el período hasta los 90 días $\mathrm{pl}$ en el que se recuperan parcialmente sus valores.

El descenso de las subunidades que regulan la permeabilidad al Calcio de los iGluRs, visto tanto en el análisis semicuantitativo, como en el cuantitativo, hacen pensar que los receptores de las neuronas del $\mathrm{Cl}$ deaferentadas pueden ser más permeables al calcio (Burnashev y cols., 1995; Liu y cols., 2006; Bassani y cols., 2009). Posiblemente estos datos puedan explicar en parte la regulación positiva de la CR observada por nosotros, que actuaría tanto tamponando el $\mathrm{Ca}^{2+}$ excedente como posiblemente en su papel de señalizador celular para la biosíntesis. Existen datos previos que demuestran cambios en la expresión de los iGluRs en el $\mathrm{Cl}$ tras lesión farmacológica de la cóclea de ratas recién nacidas, (Marianowski y cols., 2000; Liao y cols., 2000) o tras ablación coclear bilateral Holt y cols., (2005). Estos últimos autores demostraron variaciones en los genes que regulan la expresión de los receptores y también un aumento de los iGluRs 
en el $\mathrm{Cl}$ de la rata. Estos cambios revierten, como los nuestros, tras períodos de tiempo de hasta 90 días pl. De acuerdo con estos trabajos y los planteamientos de sus autores, cabe sugerir la idea de que la caída y posterior recuperación en las subunidades iGluR observada tras 90 y 180 días pl deben ir precedidas de un cambio en la regulación de los genes implicados en la biosíntesis. Actualmente se están realizando en nuestro laboratorio estudios complementarios de análisis genómicos (DNA MicroArrays) para llegar a conocer la afectación de la síntesis y/o de las rutas de señalización y el tráfico de los iGluRs (v.i.). Es conocido que una parte de las subunidades de los iGluRs dependen de la actividad sináptica para su ensamblado (Malinow y cols., 2000; Passafaro y cols., 2001; Shi y cols., 2001), y también de la activación función-dependiente de multitud de moléculas que regulan su biosíntesis (Rivera-Cervantes y cols., 2004; Asrar y cols., 2009). Tras la deaferentación cortical la actividad eléctrica (ABRs Figura 11) la función (Figuras 12 y 14) y la biosíntesis (Figuras 16-19) del Cl están afectadas a la baja como consecuencia de la degeneración de los campos terminales de la proyección descendente. De este modo debe existir un momento entre los 15 días y los go días postlesión en el cual las células del $\mathrm{Cl}$ cambian la regulación de los iGluRs de negativa a positiva. Este punto de reencendido de la vía debe estar desencadenado por fenómenos de plasticidad dentro del $\mathrm{Cl}$, que pueden relacionarse con: la generación de circuitos de novo por la aparición de nuevas células, la creación de colaterales axónicas nuevas o cambios en la eficacia de las sinapsis existentes, tanto por cambios en el tipo de actividad de las conexiones extrínsecas -redes, como por cambios en el número de receptores postsinápticos existentes en las neuronas del $\mathrm{Cl}$.

Es en este campo en el que los postulados de la plasticidad homeostática deben ser valorados. La correlación entre la caída de los valores de los receptores iGluRs a los 15 días pl y su posterior recuperación en coincidencia con los datos de la actividad funcional del sistema (ABRs, RAS/IPP, c-Fos-IRr) pueden ser el sustrato de un fenómeno de sobre regulación positiva para aumentar a escala de todo el núcleo la actividad sináptica (quantal scaling). Los aumentos en la regulación de CR por su parte pueden reflejar también tanto un intento de mantener la transmisión sináptica (tamponado rápido), modular la excitabilidad neuronal o ser el reflejo de la activación de las rutas vinculadas al tráfico de receptores postsinápticos.

Algunos de los genes que se sobre-regulan a los go días pl y que hemos valorado en el estudio preliminar de MicroArrays de DNA y que adjuntamos como apéndice apoyan un intento de las células del $\mathrm{Cl}$ de incrementar tanto la síntesis como el tráfico de receptores y moléculas responsables de la neurotransmisión excitatoria.

Para elevar estas afirmaciones a la categoría de hipótesis de trabajo, será necesario completar los estudios en curso. Finalmente, cabe resaltar que experimentos también preliminares de nuestro laboratorio han puesto en 
evidencia un fenómeno de recrecimiento axonal producido desde los axones de la corteza contralateral intacta ( $v$.i.). Posiblemente estos fenómenos instaurados entre los 15 días y los 90 días pl sean el punto de partida para activar el equilibrado homeostático del sistema. La conclusión de estos experimentos y otros en marcha en el laboratorio deberán aclarar estos extremos. 
CONCLUSIONES 


\section{CONCLUSIONES.}

1. Se requiere una proyección corticofuga intacta para el mantenimiento óptimo de la actividad del sistema auditivo en la rata adulta.

2. Tras la deaferentación unilateral de la proyección descendente de la corteza auditiva, la actividad eléctrica evocada del tronco del encéfalo disminuye tras 15 días de supervivencia postlesión y se recupera en períodos largos de hasta go días postlesión.

3. La deaferentación unilateral de la proyección corticofugal induce a corto plazo una sordera bilateral que conduce a una supresión, tanto de las respuestas del Reflejo Auditivo del Sobresalto como de la Inhibición por estímulo previo que resultan ser reversibles tras largos períodos de tiempo postlesión.

4. Las lesiones unilaterales de la corteza auditiva generan la caída reversible del número de neuronas que expresan c-Fos tras estimulación sonora. Por ello, es posible plantear que se produce un descenso (15 días potlesión) y posterior recuperación (9o días postlesión) en la actividad de las neuronas sensibles a la estimulación sonora en el Colículo Inferior.

5. La inmunorreación frente a la proteína c-Fos en el Colículo Inferior no sigue un principio de todo o nada (positivo o negativo), sino que la densidad del cromógeno y el perímetro nuclear aumentan o disminuyen en relación con la función en las neuronas sensibles a la estimulación sonora.

6. El Colículo Inferior reacciona frente a la pérdida unilateral de la proyección glutamatérgica cortico-colicular provocando un aumento reversible tras largos períodos postlesionales en el número de neuronas inmunorrreactivas para calretinina. Conocidas las funciones de esta proteína ligadora de Calcio, este modo de reaccionar de las neuronas coliculares refleja variaciones en la concentración del calcio intracelular. Este fenómeno se puede relacionar con el esfuerzo neuronal para mantener la precisión y el ritmo de disparo neuronal previo a la deaferentación.

7. En el Colículo Inferior, producto de la ablación unilateral de la corteza auditiva se produce un bloqueo de la síntesis y la expresión de los receptores ionotrópicos de glutamato, que es reversible tras largos periodos postlesión. 


\section{Conclusión General}

- En esta Tesis Doctoral se demuestra que la lesión por ablación unilateral de la corteza auditiva provoca una pérdida de la función de la vía auditiva, basada principalmente en el bloqueo de la síntesis de los receptores ionotrópicos de glutamato con una alteración del balance de la concentración de calcio intracelular en el Colículo Inferior. Este núcleo reacciona tras períodos largos de tiempo compensando este fenómeno mediante un proceso reparativo que comparte características compatibles con fenómenos de plasticidad homeostática (quantal scaling de receptores ionotrópicos de glutamato y equilibrio del $\mathrm{Ca}^{2+}$ intracelular). Estos cambios, entre otros posibles, ocasionan la reactivación funcional del sistema auditivo, pudiendo considerarse como procesos de plasticidad neuronal a largo plazo . 
TRABAJOS EN CURSO 
De los resultados y conclusiones de este trabajo de tesis doctoral se derivan diversos interrogantes que en el momento, se están tratando de responder en nuestro laboratorio con la puesta en marcha de experimentos concretos, de los cuales existen yá datos disponibles preliminares. En este apartado aportaremos alguna información nueva que puede ayudar al lector a comprender mejor los resultados de esta tesis doctoral y cuáles son las líneas que se derivan a partir de nuestros datos. Se derivan entre otras, dos preguntas inmediatas de los resultados obtenidos en este trabajo:

1- Sobre la base de los postulados de la plasticidad homeostática ¿Se producen cambios en la biosíntesis de moléculas implicadas en la neurotransmisión, en la conductancia de las membranas o en el tráfico y ensamblado de los receptores postsinápticos en el proceso de reparación tras ablación unilateral de la corteza?

2 - La reactivación del Colículo Inferior (neuronal set point) tras lesiones unilaterales de la corteza es activada por un fenómeno de recrecimiento axonal a partir de las conexiones procedentes de las áreas corticales no lesionadas o contralaterales?

Al observar los cambios funcionales, biosintéticos y de los receptores postsinápticos que se producen tras deaferentación cortical auditiva unilateral (v.s.), decidimos explorar las modificaciones en la expresión génica de las neuronas del colículo inferior. Con tal fin, se analizaron las muestras de tres grupos experimentales cuya localización de las lesiones corticales se muestra en la Figura 8 (grupos 24-26, $n=3$ Tabla $N^{\circ} 1$ ), utilizando la tecnología de los DNA MicroArrays. Estos estudios nos permitieron de forma probabilística realizar un barrido de todos los cambios inducidos por los procesos lesionales en este núcleo. En este momento, estos resultados se encuentran en el estado de análisis primario. Podemos sin embargo indicar en líneas generales, que tras el análisis de los 24694 genes contenidos en nuestros arrays, encontramos al comparar el grupo control con los 15 días pl, cambios en los niveles de expresión de 975 de ellos, con un fold-change de 1.5, de los cuales 794 tenían una significancia estadística (ANOVA: $\mathrm{p}<0.05$ ). En la mayoría de los datos de este grupo encontramos una infra-regulación de los niveles de expresión génica (ver figura adjunta). Cuando se analizan los cambios utilizando un fold-change de 2 , encontramos sólamente 135 genes afectados, de los cuales 117 mostraron una $\mathrm{p}<0.05$. Cuando comparamos los casos controles y los lesionados a los 90 días, hemos encontrado el efecto contrario al observado a los 15 días pl, es decir una sobre-regulación en los niveles de expresión, que estaría muy de acuerdo con los datos presentados en esta tesis doctoral. Estos experimentos ya se han analizado de forma primaria, y con este número de casos, hemos podido observar cambios significativos en genes tan importantes para la plasticidad homeostatática como Arc/Arg 3.1 (Arc: activity-regulated cytoskeleton-associated protein), pués se sabe que la expresión del este gen bloquea el incremento homeostático de la función de los rAMPA inducidos por inactividad neuronal 
crónica, mientras que la pérdida de la expresión de Arc resulta en un incremento en la función de estos receptores, aboliendo además el scaling homeostático de los rAMPA, de esta forma se conoce que la expresión dinámica de Arc ejerce un control preciso sobre la fuerza sináptica y la excitabilidad celular mediada por los rAMPA (Shepherd y cols., 2006) y cambios en el gen Lin7, que se conoce que forma el complejo de CASK junto con Mint (Lin10) y KIF17, que a la vez unido con SAP97 altera el tráfico de los rNMDA dentro de los subcompartimientos del retículo endoplásmico dendrítico (Jeyifous y cols., 2009).

Al día de hoy, hemos realizado ya un nuevo grupo de casos lesionados, de 15 y 90 días ( $n=3$ c/grupo), con el fin de duplicar el número de casos estudiados por MicroArrays de DNA, y tener datos definitivos acerca de los cambios génicos producidos por la ablación unilateral de la corteza auditiva, además de complementarlo con técnicas de GPCR, en aquellos en donde observemos los cambios más relevantes.

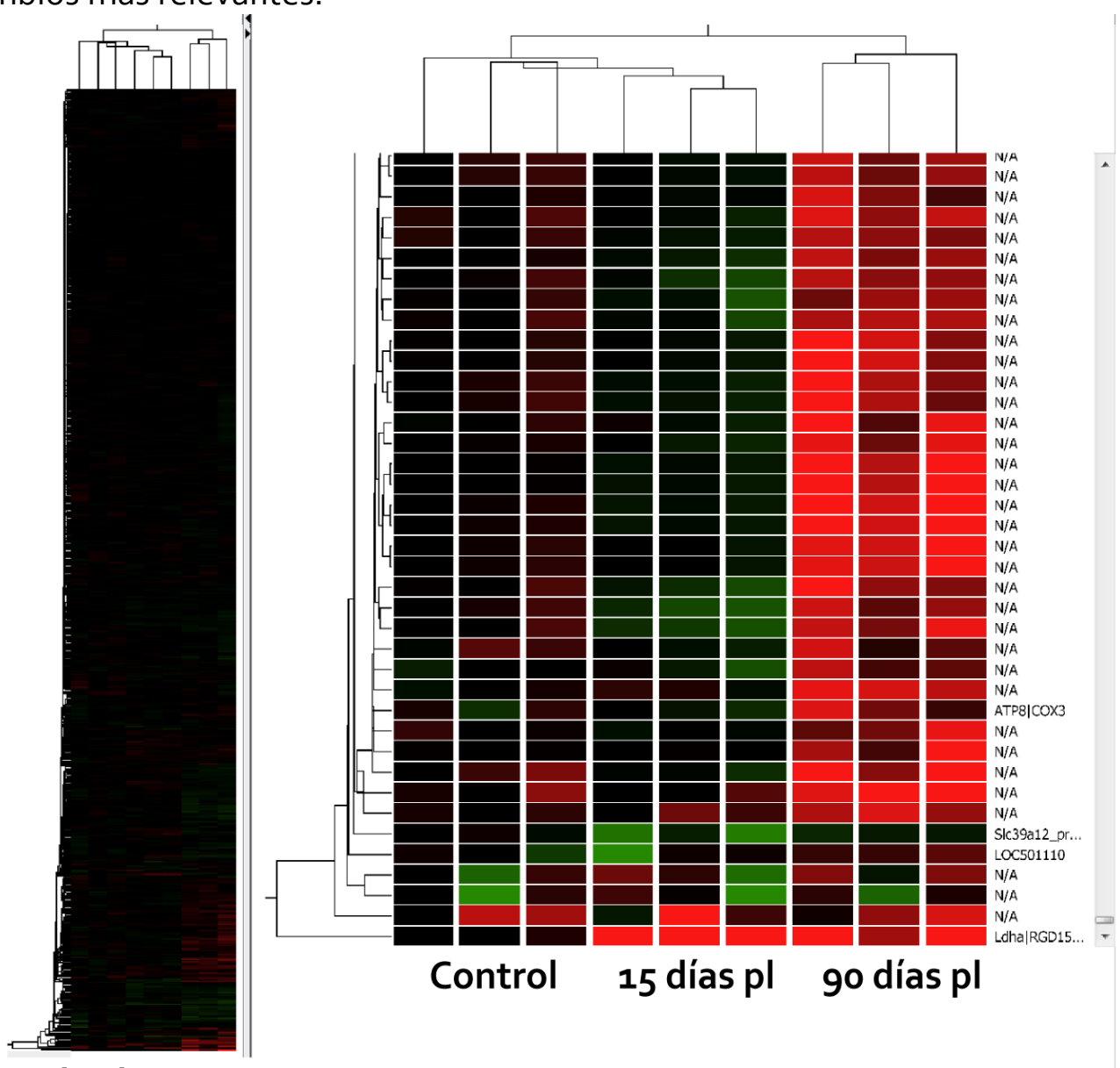

Todos los genes

En esta representación, se observa parte de los genes estudiados en los 3 diferentes grupos estudiados. En verde se muestran los genes en infraregulación y en rojo los genes en supra-regulación. 
Finalmente, queremos añadir la evidencia obtenida mediante estudios con trazadores en la corteza auditiva contralateral intacta de un proceso de recrecimiento axonal generado desde la corteza contralateral a la zona deaferentada. El experimento que se ilustra en la figura adicional corresponde a un animal, no inlcuido en el material y métodos de este trabajo (experimentos prelminares) al que se ha realizado una lesión en la corteza auditiva izquierda y una inyección esterotáxica del trazador neuroanatómico BDA en la región de bajas frecuencias de la corteza auditiva derecha. El grupo de animales ( $n=3)$, fué sacrificado a los 15 días pl. En la imagen (flecha) se observan fibras marcadas en la corteza externa izquierda del coliculo inferior. Dado que sabemos por estudios previos de trazadores realizados en rata, por Saldaña y col., (1996), la corteza externa del $\mathrm{Cl}$ no recibe proyección de la corteza auditiva contralateral y por lo tanto concluímos que se ha producido una reinervación de este territorio por acción de la corteza intacta. Estos experimentos y otros programados en los que pretendemos contar botones sinápticos inmunorreactivos frente a proteínas sinápticas (Bassoon, sinaptofisina, etc) nos permitirán entender algo mejor el papel del sprouting en la reparación a largo plazo del colículo inferior.

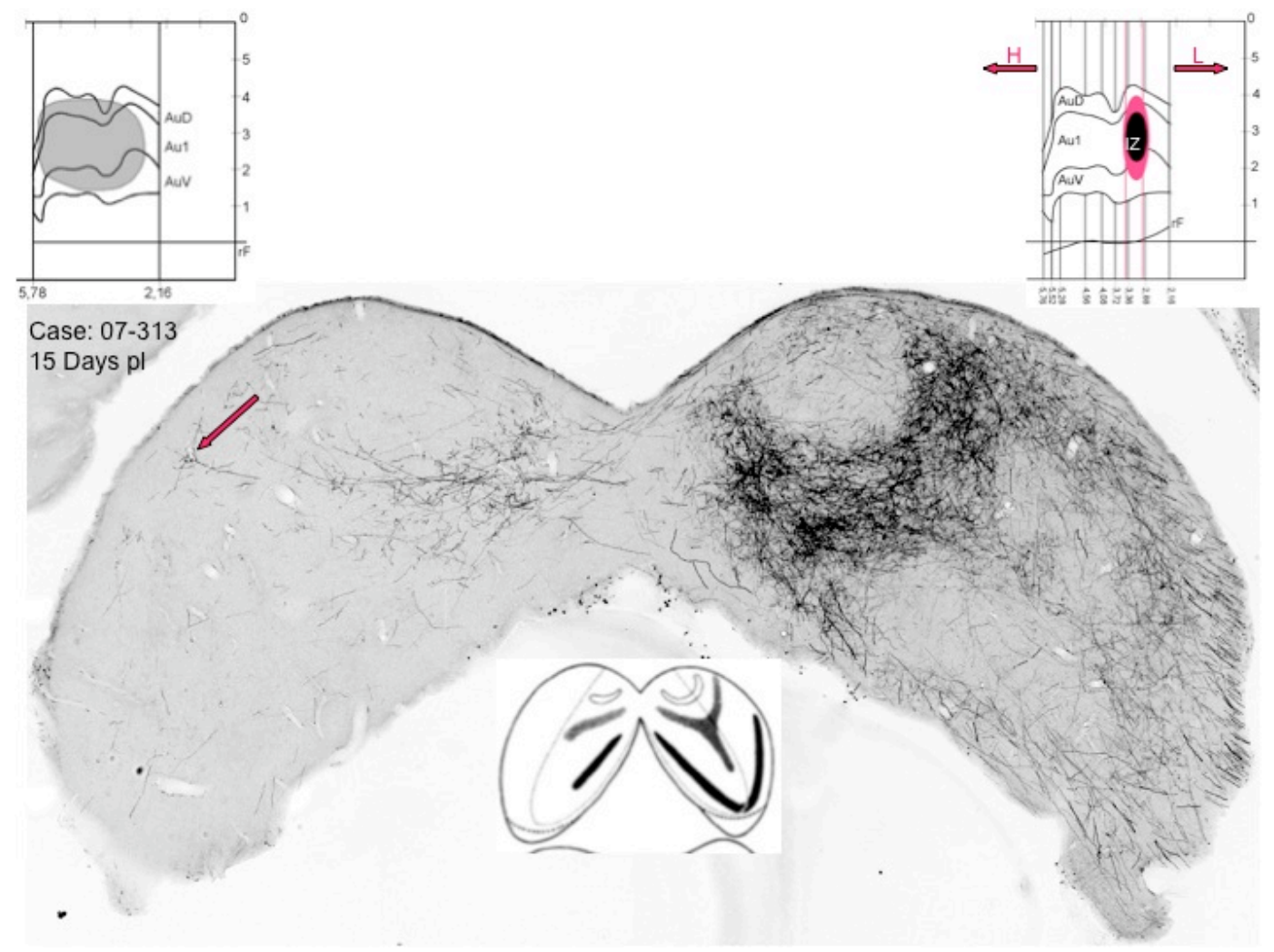


BIBLIOGRAFÍA 
Abbott LF, Nelson SB. 2000. Synaptic plasticity: taming the beast. Nature neuroscience 3 Suppl:1178-1183.

Adams JC. 1979. Ascending projections to the inferior colliculus. The Journal of comparative neurology 183(3):519-538.

Adams JC. 1995. Sound stimulation induces Fos-related antigens in cells with common morphological properties throughout the auditory brainstem. The Journal of comparative neurology $361(4): 645-668$.

Adams JC, Mugnaini E. 1984. Dorsal nucleus of the lateral lemniscus: a nucleus of GABAergic projection neurons. Brain research bulletin 13(4):585-590.

Adams JC, Wenthold RJ. 1979. Distribution of putative amino acid transmitters, choline acetyltransferase and glutamate decarboxylase in the inferior colliculus. Neuroscience 4(12):1947-1951.

Aitkin LM, Boyd J. 1978. Acoustic input to the lateral pontine nuclei. Hear Res. 1(1):67-77.

Aitkin LM, Dickhaus H, Schult W, Zimmermann M. 1978. External nucleus of inferior colliculus: auditory and spinal somatosensory afferents and their interactions. Journal of neurophysiology 41(4):837-847.

Alibardi L. 1998. Ultrastructural and immunocytochemical characterization of neurons in the rat ventral cochlear nucleus projecting to the inferior colliculus. Ann Anat 180(5):415-426.

Alt A, Weiss B, Ogden AM, Knauss JL, Oler J, Ho K, Large TH, Bleakman D. 2004. Pharmacological characterization of glutamatergic agonists and antagonists at recombinant human homomeric and heteromeric kainate receptors in vitro. Neuropharmacology 46(6):793-806.

Alvarado JC, Fuentes-Santamaria V, Franklin SR, Brunso-Bechtold JK, Henkel CK. 2005. Unilateral cochlear ablation in adu\{Adams, 1979 \#19\}lt ferrets results in upregulation in calretinin immunostaining in the central nucleus of the inferior colliculus. Neuroscience 136(3):957969.

Andersen RA, Roth GL, Aitkin LM, Merzenich MM. 1980. The efferent projections of the central nucleus and the pericentral nucleus of the inferior colliculus in the cat. The Journal of comparative neurology 194(3):649-662.

Angelucci A, Clasca F, Sur M. 1998. Brainstem inputs to the ferret medial geniculate nucleus and the effect of early deafferentation on novel retinal projections to the auditory thalamus. The Journal of comparative neurology 400(3):417-439.

Arbuthnott GW, Ingham CA, Wickens JR. 2000. Dopamine and synaptic plasticity in the neostriatum. Journal of anatomy 196 ( Pt 4):587-596.

Arnault P, Roger M. 1990. Ventral temporal cortex in the rat: connections of secondary auditory areas Te2 and Te3. The Journal of comparative neurology 302(1):110-123.

Arundine M, Tymianski M. 2003. Molecular mechanisms of calcium-dependent neurodegeneration in excitotoxicity. Cell calcium 34(4-5):325-337.

Ascher P, Nowak L. 1988. The role of divalent cations in the N-methyl-D-aspartate responses of mouse central neurones in culture. The Journal of physiology 399:247-266.

Batch-y-Rita P. 1988. Brain Plasticity. In "Rehabilitation Medicine". J. Goodgold, ed. Mosby, St. Louis, MO, EEUU. pp. 113-118

Baimbridge KG, Celio MR, Rogers JH. 1992. Calcium-binding proteins in the nervous system. Trends in neurosciences 15(8):303-308.

Bajo VM, Merchan MA, Lopez DE, Rouiller EM. 1993. Neuronal morphology and efferent projections of the dorsal nucleus of the lateral lemniscus in the rat. The Journal of comparative neurology 334(2):241-262.

Bajo VM, Moore DR. 2005. Descending projections from the auditory cortex to the inferior colliculus in the gerbil, Meriones unguiculatus. The Journal of comparative neurology 486(2):101-116. 
Bajo VM, Nodal FR, Bizley JK, Moore DR, King AJ. 2007. The ferret auditory cortex: descending projections to the inferior colliculus. Cereb Cortex 17(2):475-491.

Bassani S, Valnegri P, Beretta F, Passafaro M. 2009. The GLUR2 subunit of AMPA receptors: synaptic role. Neuroscience 158(1):55-61.

Benes FM, Taylor JB, Cunningham MC. 2000. Convergence and plasticity of monoaminergic systems in the medial prefrontal cortex during the postnatal period: implications for the development of psychopathology. Cereb Cortex 10(10):1014-1027.

Beneyto M, Prieto JJ. 2001. Connections of the auditory cortex with the claustrum and the endopiriform nucleus in the cat. Brain research bulletin 54(5):485-498.

Berridge MJ, Bootman MD, Roderick HL. 2003. Calcium signalling: dynamics, homeostasis and remodelling. Nat Rev Mol Cell Biol 4(7):517-529.

Beyerl BD. 1978. Afferent projections to the central nucleus of the inferior colliculus in the rat. Brain Res 145(2):209-223.

Bigge CF. 1999. Ionotropic glutamate receptors. Current opinion in chemical biology 3(4):441-447.

Billing-Marczak K, Przybyszewska M, Kuznicki J. 1999. Measurements of [Ca2+] using fura-2 in glioma C6 cells expressing calretinin with GFP as a marker of transfection: no Ca2+buffering provided by calretinin. Biochimica et biophysica acta 1449(2):169-177.

Bleakman D, Gates MR, Ogden AM, Mackowiak M. 2002. Kainate receptor agonists, antagonists and allosteric modulators. Curr Pharm Des. 8(10):873-85. Review.

Bleakman D, Lodge D. 1998. Neuropharmacology of AMPA and kainate receptors. Neuropharmacology 37(10-11):1187-1204.

Bledsoe SC, Jr., Nagase S, Miller JM, Altschuler RA. 1995. Deafness-induced plasticity in the mature central auditory system. Neuroreport 7(1):225-229.

Bliem B, Muller-Dahlhaus JF, Dinse HR, Ziemann U. 2008. Homeostatic metaplasticity in the human somatosensory cortex. Journal of cognitive neuroscience 20(8):1517-1528.

Bowen GP, Lin D, Taylor MK, Ison JR. 2003. Auditory cortex lesions in the rat impair both temporal acuity and noise increment thresholds, revealing a common neural substrate. Cereb Cortex 13(8):815-822.

Bowie D, Mayer ML. 1995. Inward rectification of both AMPA and kainate subtype glutamate receptors generated by polyamine-mediated ion channel block. Neuron 15(2):453-462.

Braun K. 1990. Calcium-binding proteins in avian and mammalian central nervous system: localization, development and possible functions. Progress in histochemistry and cytochemistry 21(1):1-64.

Brewer GJ, Boehler MD, Pearson RA, DeMaris AA, Ide AN, Wheeler BC. 2009. Neuron network activity scales exponentially with synapse density. Journal of neural engineering 6(1):014001.

Brown MC, Liu TS. 1995. Fos-like immunoreactivity in central auditory neurons of the mouse. The Journal of comparative neurology 357(1):85-97.

Brunso-Bechtold JK, Thompson GC, Masterton RB. 1981. HRP study of the organization of auditory afferents ascending to central nucleus of inferior colliculus in cat. The Journal of comparative neurology 197(4):705-722.

Buckingham SD, Kwak S, Jones AK, Blackshaw SE, Sattelle DB. 2008. Edited GluR2, a gatekeeper for motor neurone survival? Bioessays 30(11-12):1185-1192.

Buchtel HA, Stewart JD. 1989. Auditory agnosia: apperceptive or associative disorder? Brain and language 37(1):12-25.

Bullitt E. 1990. Expression of c-fos-like protein as a marker for neuronal activity following noxious stimulation in the rat. The Journal of comparative neurology 296(4):517-530.

Burnashev N, Villarroel A, Sakmann B. 1996. Dimensions and ion selectivity of recombinant AMPA and kainate receptor channels and their dependence on $Q / R$ site residues. The Journal of physiology 496 ( Pt 1):165-173. 
Burnashev N, Zhou Z, Neher E, Sakmann B. 1995. Fractional calcium currents through recombinant GluR channels of the NMDA, AMPA and kainate receptor subtypes. The Journal of physiology 485 ( Pt 2):403-418.

Caeser M, Ostwald J, Pilz PK. 1989. Startle responses measured in muscles innervated by facial and trigeminal nerves show common modulation. Behavioral neuroscience 103(5):1075-1081.

Caicedo A, d'Aldin C, Eybalin M, Puel JL. 1997. Temporary sensory deprivation changes calciumbinding proteins levels in the auditory brainstem. The Journal of comparative neurology 378(1):1-15.

Caicedo A, Eybalin M. 1999. Glutamate receptor phenotypes in the auditory brainstem and midbrain of the developing rat. The European journal of neuroscience 11(1):51-74.

Caleo M, Tropea D, Rossi C, Gianfranceschi L, Maffei L. 2009. Environmental enrichment promotes fiber sprouting after deafferentation of the superior colliculus in the adult rat brain. Experimental neurology.

Calford MB. 2002. Dynamic representational plasticity in sensory cortex. Neuroscience 111(4):709738.

Callicott JH, Mattay VS, Verchinski BA, Marenco S, Egan MF, Weinberger DR. 2003. Complexity of prefrontal cortical dysfunction in schizophrenia: more than up or down. The American journal of psychiatry 160(12):2209-2215.

Cant NB, Benson CG. 2003. Parallel auditory pathways: projection patterns of the different neuronal populations in the dorsal and ventral cochlear nuclei. Brain research bulletin 6o(5-6):457-474.

Cant NB, Benson CG. 2006. Organization of the inferior colliculus of the gerbil (Meriones unguiculatus): differences in distribution of projections from the cochlear nuclei and the superior olivary complex. The Journal of comparative neurology 495(5):511-528.

Cant NB, Benson CG. 2008. Organization of the inferior colliculus of the gerbil (Meriones unguiculatus): projections from the cochlear nucleus. Neuroscience 154(1):206-217.

Carey CL, Webster DB. 1971. Ascending and descending projections of the inferior colliculus in the Kangaroo rat (Dipodomys merriami). Brain, behavior and evolution 4(6):401-412.

Cassella JV, Davis M. 1986. Neural structures mediating acoustic and tactile startle reflexes and the acoustically-elicited pinna response in rats: electrolytic and ibotenic acid studies. Soc Neurosci Abstr 12:1273.

Caspary DM, Helfert RH. 1993. Two populations of commissural projections connecting like regions of the inferior colliculus immunostain for different amino acid transmitters. Soc. Neurosci. Abstr. 19, 1425.

Caspary DM, Milbrandt JC, Helfert RH. 1995. Central auditory aging: GABA changes in the inferior colliculus. Experimental gerontology 30(3-4):349-360.

Caspary DM, Raza A, Lawhorn Armour BA, Pippin J, Arneric SP. 1990. Immunocytochemical and neurochemical evidence for age-related loss of GABA in the inferior colliculus: implications for neural presbycusis. J Neurosci 10(7):2363-2372.

Casseday JH, Jones DR, Diamond IT. 1979. Projections from cortex to tectum in the tree shrew, Tupaia glis. The Journal of comparative neurology 185(2):253-291.

Ceccatelli S, Villar MJ, Goldstein M, Hokfelt T. 1989. Expression of c-Fos immunoreactivity in transmitter-characterized neurons after stress. Proceedings of the National Academy of Sciences of the United States of America 86(23):9569-9573.

Cediel R, Riquelme R, Contreras J, Diaz A, Varela-Nieto I. 2006. Sensorineural hearing loss in insulinlike growth factor I-null mice: a new model of human deafness. The European journal of neuroscience 23(2):587-590.

Ciabarra AM, Sullivan JM, Gahn LG, Pecht G, Heinemann S, Sevarino KA. 1995. Cloning and characterization of chi-1: a developmentally regulated member of a novel class of the ionotropic glutamate receptor family. J Neurosci 15(10):6498-6508. 
Clarkson C, Lopez DE, Merchan MA. 2009. Long-term functional recovery in the rat auditory system after unilateral auditory cortex ablation. Acta oto-laryngologica:1-7.

Cole AJ, Saffen DW, Baraban JM, Worley PF. 1989. Rapid increase of an immediate early gene messenger RNA in hippocampal neurons by synaptic NMDA receptor activation. Nature 340(6233):474-476.

Coleman JR, Clerici WJ. 1987. Sources of projections to subdivisions of the inferior colliculus in the rat. The Journal of comparative neurology 262(2):215-226.

Collingridge GL, Lester RA. 1989. Excitatory amino acid receptors in the vertebrate central nervous system. Pharmacological reviews 41(2):143-210.

Contreras NE, Bachelard HS. 1979. Some neurochemical studies on auditory regions of mouse brain. Experimental brain research Experimentelle Hirnforschung 36(3):573-584.

Cooke JE, Zhang H, Kelly JB. 2007. Detection of sinusoidal amplitude modulated sounds: deficits after bilateral lesions of auditory cortex in the rat. Hearing research 231(1-2):90-99.

Coomes DL, Schofield RM, Schofield BR. 2005. Unilateral and bilateral projections from cortical cells to the inferior colliculus in guinea pigs. Brain Res 1042(1):62-72.

Coote EJ, Rees A. 2008. The distribution of nitric oxide synthase in the inferior colliculus of guinea pig. Neuroscience 154(1):218-225.

Cotman C, Nieto-San Pedro M. 1985. Progress in facilitating recovery of function after central nervous system trauma. Ann. N. Y. Acad. Sci. 457, 83-104.

Covey E, Casseday JH. 1986. Connectional basis for frequency representation in the nuclei of the lateral lemniscus of the bat Eptesicus fuscus. J Neurosci 6(10):2926-2940.

Covey E, Hall WC, Kobler JB. 1987. Subcortical connections of the superior colliculus in the mustache bat, Pteronotus parnellii. The Journal of comparative neurology 263(2):179-197.

Cull-Candy S, Brickley S, Farrant M. 2001. NMDA receptor subunits: diversity, development and disease. Current opinion in neurobiology 11(3):327-335.

Curran T, Morgan Jl. 1987. Memories of fos. Bioessays 7(6):255-258.

Choi DW. 1988. Calcium-mediated neurotoxicity: relationship to specific channel types and role in ischemic damage. Trends in neurosciences 11(10):465-469.

Chowdhury SA, Suga N. 2000. Reorganization of the frequency map of the auditory cortex evoked by cortical electrical stimulation in the big brown bat. Journal of neurophysiology $83(4): 1856-1863$.

Diamond, I.T., E.G. Jones, and T.P.S. Powell (1969) The projection of the auditory cortex upon the diencephalon and brainstem in the cat. Brain Res. 15305-340.

D'Orlando C, Celio MR, Schwaller B. 2002. Calretinin and calbindin D-28k, but not parvalbumin protect against glutamate-induced delayed excitotoxicity in transfected N18-RE 105 neuroblastoma-retina hybrid cells. Brain Res 945(2):181-190.

D'Orlando C, Fellay B, Schwaller B, Salicio V, Bloc A, Gotzos V, Celio MR. 2001. Calretinin and calbindin D-28k delay the onset of cell death after excitotoxic stimulation in transfected $\mathrm{P}_{19}$ cells. Brain Res 909(1-2):145-158.

Das S, Sasaki YF, Rothe T, Premkumar LS, Takasu M, Crandall JE, Dikkes P, Conner DA, Rayudu PV, Cheung W, Chen HS, Lipton SA, Nakanishi N. 1998. Increased NMDA current and spine density in mice lacking the NMDA receptor subunit NR3A. Nature 393(6683):377-381.

Davis GW. 2006. Homeostatic Control of Neural Activity: From Phenomenology to Molecular Design. Annual review of neuroscience.

Davis GW, Bezprozvanny I. 2001. Maintaining the stability of neural function: a homeostatic hypothesis. Annual review of physiology 63:847-869.

Davis KA. 2002. Evidence of a functionally segregated pathway from dorsal cochlear nucleus to inferior colliculus. Journal of neurophysiology 87(4):1824-1835.

Davis M, Gendelman DS, Tischler MD, Gendelman PM. 1982. A primary acoustic startle circuit: lesion and stimulation studies. J Neurosci 2(6):791-805. 
Deeg KE. 2009. Synapse-specific homeostatic mechanisms in the hippocampus. Journal of neurophysiology 101(2):503-506

Dingledine R, Borges K, Bowie D, Traynelis SF. 1999. The glutamate receptor ion channels. Pharmacological reviews 51(1):7-61.

Dolan DF, Nuttall AL. 1988. Masked cochlear whole-nerve response intensity functions altered by electrical stimulation of the crossed olivocochlear bundle. The Journal of the Acoustical Society of America 83(3):1081-1086.

Doron NN, Ledoux JE, Semple MN. 2002. Redefining the tonotopic core of rat auditory cortex: physiological evidence for a posterior field. The Journal of comparative neurology 453(4):345-360.

Doucet JR, Molavi DL, Ryugo DK. 2003. The source of corticocollicular and corticobulbar projections in area Te1 of the rat. Experimental brain research Experimentelle Hirnforschung $153(4): 461-466$.

Druga R, Syka J. 1984a. Ascending and descending projections to the inferior colliculus in the rat. Physiol Bohemoslov 33(1):31-42.

Druga R, Syka J. 1984b. Neocortical projections to the inferior colliculus in the rat. (An experimental study using anterograde degeneration techniques). Physiol Bohemoslov 33(3):251-253.

Druga R, Syka J. 1984C. Projections from auditory structures to the superior colliculus in the rat. Neuroscience letters 45(3):247-252.

Druga R, Syka J. 2001. Effect of auditory cortex lesions on NADPH-diaphorase staining in the inferior colliculus of rat. Neuroreport 12(8):1555-1559.

Druga R, Syka J, Rajkowska G. 1997. Projections of auditory cortex onto the inferior colliculus in the rat. Physiological research / Academia Scientiarum Bohemoslovaca 46(3):215-222.

Duprat F, Daw M, Lim W, Collingridge G, Isaac J. 2003. GluR2 protein-protein interactions and the regulation of AMPA receptors during synaptic plasticity. Philosophical transactions of the Royal Society of London 358(1432):715-720.

Edeline JM, Weinberger NM. 1991a. Subcortical adaptive filtering in the auditory system: associative receptive field plasticity in the dorsal medial geniculate body. Behavioral neuroscience 105(1):154-175.

Edeline JM, Weinberger NM. 1991b. Thalamic short-term plasticity in the auditory system: associative returning of receptive fields in the ventral medial geniculate body. Behavioral neuroscience 105(5):618-639.

Edeline JM, Weinberger NM. 1992. Associative retuning in the thalamic source of input to the amygdala and auditory cortex: receptive field plasticity in the medial division of the medial geniculate body. Behavioral neuroscience 106(1):81-105.

Edmonds B, Reyes R, Schwaller B, Roberts WM. 2000. Calretinin modifies presynaptic calcium signaling in frog saccular hair cells. Nature neuroscience $3(8): 786-790$.

Egebjerg J, Heinemann SF. 1993. Ca2+ permeability of unedited and edited versions of the kainate selective glutamate receptor GluR6. Proceedings of the National Academy of Sciences of the United States of America 9o(2):755-759.

Ehret G, Fischer R. 1991. Neuronal activity and tonotopy in the auditory system visualized by c-fos gene expression. Brain research 567(2):350-354.

Fahn S. 1976. Regional distribution studies of GABA and other putative neurotransmitters and their enzymes, in GABA in Nervous System Function. Raven Press. New York, pp. 169-186

Faingold CL. 2002. Role of GABA abnormalities in the inferior colliculus pathophysiology audiogenic seizures. Hearing research 168(1-2):223-237.

Faingold CL, Boersma Anderson CA, Caspary DM. 1991. Involvement of GABA in acoustically-evoked inhibition in inferior colliculus neurons. Hearing research 52(1):201-216. 
Faingold CL, Naritoku DK, Copley CA, Randall ME, Riaz A, Anderson CA, Arneric SP. 1992. Glutamate in the inferior colliculus plays a critical role in audiogenic seizure initiation. Epilepsy research 13(2):95-105.

Fallon JB, Irvine DR, Shepherd RK. 2008. Cochlear implants and brain plasticity. Hearing research 238(1-2):110-117.

Faye-Lund H. 1986. Projection from the inferior colliculus to the superior olivary complex in the albino rat. Anat Embryol (Berl) 175(1):35-52.

Faye-Lund H, Osen KK. 1985. Anatomy of the inferior colliculus in rat. Anat Embryol (Berl) 171(1):120.

Feliciano M, Saldaña E. 1991. The auditory cortex innervates the central nucleus of the inferior colliculus. Soc. Neurosci Abstr. 17:445.

Feliciano M, Potashner SJ. 1995. Evidence for a glutamatergic pathway from the guinea pig auditory cortex to the inferior colliculus. Journal of neurochemistry 65(3):1348-1357.

Fendt M. 1999. Enhancement of prepulse inhibition after blockade of GABA activity within the superior colliculus. Brain Res 833(1):81-85.

Fendt M, Koch M, Schnitzler HU. 1994. Sensorimotor gating deficit after lesions of the superior colliculus. Neuroreport 5(14):1725-1728.

Fendt M, Li L, Yeomans JS. 2001. Brain stem circuits mediating prepulse inhibition of the startle reflex. Psychopharmacology 156(2-3):216-224.

Finger S, Stein D. 1982. "Brain Damage and Recovery". Academic Press New York. EEUU.

FitzPatrick KA, Imig TJ. 1978. Projections of auditory cortex upon the thalamus and midbrain in the owl monkey. The Journal of comparative neurology 177(4):573-555.

Forbes BF, Moskowitz N. 1974. Projections of auditory responsive cortex in the squirrel monkey. Brain Res 67(2):239-254.

Forster CR, Illing RB. 2000. Plasticity of the auditory brainstem: cochleotomy-induced changes of calbindin-D28k expression in the rat. The Journal of comparative neurology 416(2):173-187.

Franks KM, Isaacson JS. 2005. Synapse-specific downregulation of NMDA receptors by early experience: a critical period for plasticity of sensory input to olfactory cortex. Neuron 47(1):101-114.

Frey MC, Sprengel R, Nevian T. 2009. Activity pattern-dependent long-term potentiation in neocortex and hippocampus of GluA1 (GluR-A) subunit-deficient mice. J Neurosci 29(17):5587-5596.

Friauf E. 1992. Tonotopic Order in the Adult and Developing Auditory System of the Rat as Shown by c-fos Immunocytochemistry. The European journal of neuroscience 4(9):798-812.

Friauf E, Kandler K. 1990. Auditory projections to the inferior colliculus of the rat are present by birth. Neuroscience letters 120(1):58-61.

Fuentes-Santamaria V, Alvarado JC, Brunso-Bechtold JK, Henkel CK. 2003. Upregulation of calretinin immunostaining in the ferret inferior colliculus after cochlear ablation. The Journal of comparative neurology 460(4):585-596.

Gainey MA, Hurvitz-Wolff JR, Lambo ME, Turrigiano GG. 2009. Synaptic scaling requires the GluR2 subunit of the AMPA receptor. J Neurosci 29(20):6479-6489.

Gall D, Roussel C, Susa I, D'Angelo E, Rossi P, Bearzatto B, Galas MC, Blum D, Schurmans S, Schiffmann SN. 2003. Altered neuronal excitability in cerebellar granule cells of mice lacking calretinin. J Neurosci 23(28): 9320-9327.

Gall D, Roussel C, Nieus T, Cheron G, Servais L, D'Angelo E, Schiffmann SN. 2005. Role of calcium binding proteins in the control of cerebellar granule cell neuronal excitability: experimental and modeling studies. Prog Brain Res. 148:321-8.

Games KD, Winer JA. 1988. Layer $V$ in rat auditory cortex: projections to the inferior colliculus and contralateral cortex. Hearing research 34(1):1-25. 
Gao E, Suga N. 2000. Experience-dependent plasticity in the auditory cortex and the inferior colliculus of bats: role of the corticofugal system. Proc Natl Acad Sci U S A. 97(14):8081-6.

Gao E, Suga N. 1998. Experience-dependent corticofugal adjustment of midbrain frequency map in bat auditory system. Proceedings of the National Academy of Sciences of the United States of America 95(21):12663-12670.

Glendenning KK, Baker BN. 1988. Neuroanatomical distribution of receptors for three potential inhibitory neurotransmitters in the brainstem auditory nuclei of the cat. The Journal of comparative neurology 275(2):288-308.

Goldsmith JD, Kujawa SG, McLaren JD, Bledsoe SC, Jr. 1995. In vivo release of neuroactive amino acids from the inferior colliculus of the guinea pig using brain microdialysis. Hearing research 83(1-2):80-88.

Gomez-Nieto R, Horta-Junior JA, Castellano O, Herrero-Turrion MJ, Rubio ME, Lopez DE. 2008. Neurochemistry of the afferents to the rat cochlear root nucleus: possible synaptic modulation of the acoustic startle. Neuroscience 154(1):51-64.

Gonzalez-Hernandez T, Mantolan-Sarmiento B, Gonzalez-Gonzalez B, Perez-Gonzalez H. 1996. Sources of GABAergic input to the inferior colliculus of the rat. The Journal of comparative neurology 372(2):309-326.

Goto K, Ueki A, Iso H, Morita Y. 2002. Reduced prepulse inhibition in rats with entorhinal cortex lesions. Behavioural brain research 134(1-2):201-207.

Greenberg ME, Ziff EB. 1984. Stimulation of ${ }_{3} T_{3}$ cells induces transcription of the c-fos protooncogene. Nature 311(5985):433-438.

Griffiths S, Scott H, Glover C, Bienemann A, Ghorbel MT, Uney J, Brown MW, Warburton EC, Bashir ZI. 2008. Expression of long-term depression underlies visual recognition memory. Neuron 58(2):186-194.

Groves P, Palczewska M. 2001. Cation binding properties of calretinin, an EF-hand calcium-binding protein. Acta biochimica Polonica 48(1):113-119.

Gundersen HJ, Jensen EB, Kieu K, Nielsen J. 1999. The efficiency of systematic sampling in stereology--reconsidered. Journal of microscopy 193(Pt 3):199-211.

Guo YP, Sun X, Li C, Wang NQ, Chan YS, He J. 2007. Corticothalamic synchronization leads to c-fos expression in the auditory thalamus. Proceedings of the National Academy of Sciences of the United States of America 104(28):11802-11807.

Hack NJ, Wride MC, Charters KM, Kater SB, Parks TN. 2000. Developmental changes in the subcellular localization of calretinin. J Neurosci 20(7):RC67.

Haedo RJ, Golowasch J. 2006. Ionic mechanism underlying recovery of rhythmic activity in adult isolated neurons. Journal of neurophysiology 96(4):1860-1876.

Hebb DO (1949) The organization of behaviour. A neuropsychological theory. Wiley, New York.

Held, H. 1983. Die centralem Bahnen des Nervus acusticus bei der Katz. Arch. Anat. Abtheil. 15, 190-271.

Helfert RH, Bonneau JM, Wenthold RJ, Altschuler RA. 1989. GABA and glycine immunoreactivity in the guinea pig superior olivary complex. Brain Res 501(2):269-286.

Helfert RH, Snead CR, Altschuler RA. 1991. The Ascending Auditory Pathways. In: Neurobiology of Hearing: The Central Auditory System, Raven Press, New York, pp. 1-25

Helfert RH, Sommer TJ, Meeks J, Hofstetter P, Hughes LF. 1999. Age-related synaptic changes in the central nucleus of the inferior colliculus of Fischer-344 rats. The Journal of comparative neurology 406(3):285-298.

Henkel CK, Brunso-Bechtold JK. 1993. Laterality of superior olive projections to the inferior colliculus in adult and developing ferret. The Journal of comparative neurology 331(4):458-468.

Henkel CK, Brunso-Bechtold JK. 1995. Development of glycinergic cells and puncta in nuclei of the superior olivary complex of the postnatal ferret. The Journal of comparative neurology 354(3):470-480. 
Henkel CK, Spangler KM. 1983. Organization of the efferent projections of the medial superior olivary nucleus in the cat as revealed by HRP and autoradiographic tracing methods. The Journal of comparative neurology 221(4):416-428.

Herbert H, Aschoff A, Ostwald J. 1991. Topography of projections from the auditory cortex to the inferior colliculus in the rat. The Journal of comparative neurology 304(1):103-122.

Herdegen T, Claret FX, Kallunki T, Martin-Villalba A, Winter C, Hunter T, Karin M. 1998. Lasting Nterminal phosphorylation of c-Jun and activation of c-Jun $\mathrm{N}$-terminal kinases after neuronal injury. J Neurosci 18(14):5124-5135.

Hernandez O, Rees A, Malmierca MS. 2006. A GABAergic component in the commissure of the inferior colliculus in rat. Neuroreport 17(15):1611-1614.

Herrera DG, Robertson HA. 1996. Activation of c-fos in the brain. Progress in neurobiology 50(23):83-107.

Hess G. 2004. Synaptic plasticity of local connections in rat motor cortex. Acta neurobiologiae experimentalis 64(2):271-276.

Hillman DE, Gordon CE, Troublefield Y, Stone E, Giacchi RJ, Chen S. 1997. Effect of unilateral tympanotomy on auditory induced c-fos expression in cochlear nuclei. Brain research 748(12):77-84.

Hoddevik GH, Brodal A, Kawamura K, Hashikawa T. 1977. The pontine projection to the cerebellar vermal visual area studied by means of the retrograde axonal transport of horseradish peroxidase. Brain Res 123(2):209-227.

Hoffman and Searle 1965 H.S. Hoffman and J.L. Searle, Acoustic variables in the modification of startle reaction in the rat, $J$ Comp Physiol Psychol 60 (1965), pp. 53-58.

Hoffman HS, Searle JL. 1968. Acoustic and temporal factors in the evocation of startle. The Journal of the Acoustical Society of America 43(2):269-282.

Hoffman HS, Wible BL. 1970. Role of weak signals in acoustic startle. The Journal of the Acoustical Society of America 47(2):489-497.

Hoffman and Fleshler 1963 H.S. Hoffman and M. Fleshler, Startle reaction: Modification by background acoustic stimulation,Science 141 (1963), pp. 928-930.

Holt AG, Asako M, Duncan RK, Lomax CA, Juiz JM, Altschuler RA. 2006. Deafness associated changes in expression of two-pore domain potassium channels in the rat cochlear nucleus. Hearing research 216-217:146-153.

Holt AG, Asako M, Lomax CA, MacDonald JW, Tong L, Lomax MI, Altschuler RA. 2005. Deafnessrelated plasticity in the inferior colliculus: gene expression profiling following removal of peripheral activity. Journal of neurochemistry 93(5):1069-1086.

Hollmann M, Heinemann S. 1994. Cloned glutamate receptors. Annual review of neuroscience 17:31108.

Howe JR. 1996. Homomeric and heteromeric ion channels formed from the kainate-type subunits GluR6 and KA2 have very small, but different, unitary conductances. Journal of neurophysiology 76(1):510-519.

Huettner JE. 2003. Kainate receptors and synaptic transmission. Progress in neurobiology 70(5):387407.

Huffman RF, Henson OW, Jr. 1990. The descending auditory pathway and acousticomotor systems: connections with the inferior colliculus. Brain research 15(3):295-323.

Hughes P, Lawlor P, Dragunow M. 1992. Basal expression of Fos, Fos-related, Jun, and Krox 24 proteins in rat hippocampus. Brain Res Mol Brain Res 13(4):355-357.

Hunter KP, Willott JF. 1993. Effects of bilateral lesions of auditory cortex in mice on the acoustic startle response. Physiology \& behavior 54(6):1133-1139.

Hurley LM, Thompson AM, Pollak GD. 2002. Serotonin in the inferior colliculus. Hearing research 168(1-2):1-11. 
Hutson KA, Glendenning KK, Masterton RB. 1991. Acoustic chiasm. IV: Eight midbrain decussations of the auditory system in the cat. The Journal of comparative neurology 312(1):105-131.

Ibata K, Sun Q, Turrigiano GG. 2008. Rapid synaptic scaling induced by changes in postsynaptic firing. Neuron 57(6):819-826.

Ikura M. 1996. Calcium binding and conformational response in EF-hand proteins. Trends Biochem Sci 21(1):14-17.

Illing RB, Kraus KS, Meidinger MA. 2005. Reconnecting neuronal networks in the auditory brainstem following unilateral deafening. Hearing research 206(1-2):185-199.

Illing RB, Michler SA, Kraus KS, Laszig R. 2002. Transcription factor modulation and expression in the rat auditory brainstem following electrical intracochlear stimulation. Experimental neurology 175(1):226-244.

Illing RB, Reisch A. 2006. Specific plasticity responses to unilaterally decreased or increased hearing intensity in the adult cochlear nucleus and beyond. Hearing research 216-217:189-197.

Impagnatiello F, Guidotti AR, Pesold C, Dwivedi Y, Caruncho H, Pisu MG, Uzunov DP, Smalheiser NR, Davis JM, Pandey GN, Pappas GD, Tueting P, Sharma RP, Costa E. 1998. A decrease of reelin expression as a putative vulnerability factor in schizophrenia. Proceedings of the National Academy of Sciences of the United States of America 95(26):15718-15723.

Inagaki N, Toda K, Taniuchi I, Panula P, Yamatodani A, Tohyama M, Watanabe T, Wada H. 199o. An analysis of histaminergic efferents of the tuberomammillary nucleus to the medial preoptic area and inferior colliculus of the rat. Experimental brain research Experimentelle Hirnforschung 8o(2):374-380.

Irvine DR, Fallon JB, Kamke MR. 2006. Plasticity in the Adult Central Auditory System. Acoustics Australia / Australian Acoustical Society 34(1):13-17.

Isaacs KR, Wolpoe ME, Jacobowitz DM. 2000. Vulnerability to calcium-induced neurotoxicity in cultured neurons expressing calretinin. Experimental neurology 163(2):311-323.

Ishikawa M, Mizukami K, Iwakiri M, Hidaka S, Asada T. 2004. Immunohistochemical and immunoblot study of GABA(A) alpha1 and beta2/3 subunits in the prefrontal cortex of subjects with schizophrenia and bipolar disorder. Neuroscience research 50(1):77-84.

Ison JR, O'Connor K, Bowen GP, Bocirnea A. 1991. Temporal resolution of gaps in noise by the rat is lost with functional decortication. Behavioral neuroscience 105(1):33-40.

Jain R, Shore S. 2006. External inferior colliculus integrates trigeminal and acoustic information: unit responses to trigeminal nucleus and acoustic stimulation in the guinea pig. Neuroscience letters 395(1):71-75.

James W (1890) Principles of psychology, 2 vols. MacMillan, London.

Jen $\mathrm{PH}$, Chen OC, Sun XD. 1998. Corticofugal regulation of auditory sensitivity in the bat inferior colliculus. Journal of comparative physiology 183(6):683-697.

Jen PH, Zhang JP. 1999. corticofugal regulation of excitatory and inhibitory frequency tuning curves of bat inferior collicular neurons. Brain Res 841(1-2):184-188.

Jia WW, Wang Y, Qiang D, Tufaro F, Remington R, Cynader M. 1996. A bcl-2 expressing viral vector protects cortical neurons from excitotoxicity even when administered several hours after the toxic insult. Brain Res Mol Brain Res 42(2):350-353.

Jones EG, Rockel AJ. 1973. Observations on complex vesicles, neurofilamentous hyperplasia and increased electron density during terminal degeneration in the inferior colliculus. J Comp Neurol. 147(1):93-118.

Kaas JH, Hackett TA. 2000. Subdivisions of auditory cortex and processing streams in primates. Proceedings of the National Academy of Sciences of the United States of America 97(22):11793-11799.

Kamboj SK, Swanson GT, Cull-Candy SG. 1995. Intracellular spermine confers rectification on rat calcium-permeable AMPA and kainate receptors. The Journal of physiology 486 ( Pt 2):297303. 
Kandler K. 2004. Activity-dependent organization of inhibitory circuits: lessons from the auditory system. Current opinion in neurobiology 14(1):96-104.

Kawamura K. 1975. The pontine projection from the inferior colliculus in the cat. An experimental anatomical study. Brain Res 95(2-3):309-322.

Kawamura K, Brodal A. 1973. The tectopontine projection in the cat: an experimental anatomical study with comments on pathweays for teleceptive impulses to the cerebellum. The Journal of comparative neurology 149(3):371-390.

Kawamura K, Hashikawa T. 1981. Projections from the pontine nuclei proper and reticular tegmental nucleus onto the cerebellar cortex in the cat. An autoradiographic study. The Journal of comparative neurology 201(3):395-413.

Kayadjanian N, Heavens RP, Besson MJ, Sirinathsinghji DJ. 1996. Striatal NMDAR2B mRNA expression after bilateral cortical and unilateral nigral deafferentation. Neuroreport 7(3):713-716.

Kelly JB, Rooney BJ, Phillips DP. 1996. Effects of bilateral auditory cortical lesions on gap-detection thresholds in the ferret (Mustela putorius). Behavioral neuroscience 110(3):542-550.

Kelly JB, Zhang H. 2002. Contribution of AMPA and NMDA receptors to excitatory responses in the inferior colliculus. Hearing research 168(1-2):35-42.

Kelly JP, Wong D. 1981. Laminar connections of the cat's auditory cortex. Brain Res 212(1):1-15.

Keuroghlian AS, Knudsen El. 2007. Adaptive auditory plasticity in developing and adult animals. Progress in neurobiology 82(3):109-121.

Kew JN, Kemp JA. 2005. Ionotropic and metabotropic glutamate receptor structure and pharmacology. Psychopharmacology 179(1):4-29.

Kim JE, Kwak SE, Kim DS, Won MH, Kwon OS, Choi SY, Kang TC. 2006. Reduced calcium binding protein immunoreactivity induced by electroconvulsive shock indicates neuronal hyperactivity, not neuronal death or deactivation. Neuroscience 137(1):317-326.

Kirov SA, Harris KM. 1999. Dendrites are more spiny on mature hippocampal neurons when synapses are inactivated. Nature neuroscience 2(10):878-883.

Klepper A, Herbert H. 1991. Distribution and origin of noradrenergic and serotonergic fibers in the cochlear nucleus and inferior colliculus of the rat. Brain Res 557(1-2):190-201.

Koch M. 1999. The neurobiology of startle. Progress in neurobiology 59(2):107-128.

Koch M, Kungel M, Herbert $H$. 1993. Cholinergic neurons in the pedunculopontine tegmental nucleus are involved in the mediation of prepulse inhibition of the acoustic startle response in the rat. Exp Brain Res. 97(1):71-82.

Koch M, Robbins TW. 2001. Special issue on the psychopharmacology of prepulse inhibition: basic and clinical studies. Psychopharmacology 156(2-3):115-116.

Koch M, Schnitzler HU. 1997. The acoustic startle response in rats--circuits mediating evocation, inhibition and potentiation. Behavioural brain research 89(1-2):35-49.

Kopniczky Z, Dobo E, Borbely S, Vilagi I, Detari L, Krisztin-Peva B, Bagosi A, Molnar E, Mihaly A. 2005. Lateral entorhinal cortex lesions rearrange afferents, glutamate receptors, increase seizure latency and suppress seizure-induced c-fos expression in the hippocampus of adult rat. Journal of neurochemistry 95(1):111-124.

Kovacs KJ. 2008. Measurement of immediate-early gene activation- c-fos and beyond. Journal of neuroendocrinology 20(6):665-672.

Kral A, Tillein J. 2006. Brain plasticity under cochlear implant stimulation. Advances in oto-rhinolaryngology 64:89-108.

Krieg WJS. 1947. Connections of the cerebral cortex. I. The Albino Rat. C. Extrinsic connections. J Comp Neurol. 86:267:394.

Kudo M. 1981. Projections of the nuclei of the lateral lemniscus in the cat: an autoradiographic study. Brain Res. 221(1):57-69. 
Kulesza RJ, Jr., Berrebi AS. 2000. Superior paraolivary nucleus of the rat is a GABAergic nucleus. J Assoc Res Otolaryngol 1(4):255-269.

Kuypers HG, Lawrence DG. 1967. Cortical projections to the red nucleus and the brain stem in the Rhesus monkey. Brain Res 4(2):151-188.

Kuznicki J, Isaacs KR, Jacobowitz DM. 1996. The expression of calretinin in transfected PC12 cells provides no protection against $\mathrm{Ca}(2+)$-overload or trophic factor deprivation. Biochimica et biophysica acta 1313(3):194-200.

Lancaster B, Nicoll RA. 1987. Properties of two calcium-activated hyperpolarizations in rat hippocampal neurones. The Journal of physiology 389:187-203.

Lee Y, López DE, Meloni EG, Davis M. 1996. A primary acoustic startle pathway: obligatory role of cochlear root neurons and the nucleus reticularis pontis caudalis. J Neurosci 16(11):37753789 .

Leitner DS, Cohen ME. 1985. Role of the inferior colliculus in the inhibition of acoustic startle in the rat. Physiology \& behavior 34(1):65-70.

LeMasson G, Marder E, Abbott LF. 1993. Activity-dependent regulation of conductances in model neurons. Science (New York, NY 259(5103):1915-1917.

Lenarz M, Lim HH, Patrick JF, Anderson DJ, Lenarz T. 2006. Electrophysiological validation of a human prototype auditory midbrain implant in a guinea pig model. J Assoc Res Otolaryngol $7(4): 383-398$.

Lewis DA. 1997. Schizophrenia and disordered neural circuitry. Schizophrenia bulletin 23(3):529-531.

Li L, Korngut LM, Frost BJ, Beninger RJ. 1998a. Prepulse inhibition following lesions of the inferior colliculus: prepulse intensity functions. Physiology \& behavior 65(1):133-139.

Li L, Priebe RP, Yeomans JS. 1998b. Prepulse inhibition of acoustic or trigeminal startle of rats by unilateral electrical stimulation of the inferior colliculus. Behavioral neuroscience 112(5):1187-1198.

Li L, Yue Q. 2002. Auditory gating processes and binaural inhibition in the inferior colliculus. Hearing research 168(1-2):98-109.

Liao WH, Van Den Abbeele T, Herman P, Frachet B, Huy PT, Lecain E, Marianowski R. 2000. Expression of NMDA, AMPA and GABA(A) receptor subunit mRNAs in the rat auditory brainstem. II. Influence of intracochlear electrical stimulation. Hear Res. 150(1-2):12-26.

Lim HH, Lenarz M, Lenarz T. 2009. Auditory midbrain implant: a review. Trends in amplification 13(3):149-180.

Lim HH, Lenarz T, Joseph G, Battmer RD, Patrick JF, Lenarz M. 2008. Effects of phase duration and pulse rate on loudness and pitch percepts in the first auditory midbrain implant patients: Comparison to cochlear implant and auditory brainstem implant results. Neuroscience 154(1):370-380.

Lissin DV, Gomperts SN, Carroll RC, Christine CW, Kalman D, Kitamura M, Hardy S, Nicoll RA, Malenka RC, von Zastrow M. 1998. Activity differentially regulates the surface expression of synaptic AMPA and NMDA glutamate receptors. Proceedings of the National Academy of Sciences of the United States of America 95(12):7097-7102.

Liu B, Liao M, Mielke JG, Ning K, Chen Y, Li L, El-Hayek YH, Gomez E, Zukin RS, Fehlings MG, Wan Q. 2006. Ischemic insults direct glutamate receptor subunit 2-lacking AMPA receptors to synaptic sites. J Neurosci 26(20):5309-5319.

Loftus WC, Bishop DC, Saint Marie RL, Oliver DL. 2004. Organization of binaural excitatory and inhibitory inputs to the inferior colliculus from the superior olive. The Journal of comparative neurology 472(3):330-344.

Loftus WC, Malmierca MS, Bishop DC, Oliver DL. 2008. The cytoarchitecture of the inferior colliculus revisited: a common organization of the lateral cortex in rat and cat. Neuroscience. 154(1):196-205. 
Lu HP, Chen ST, Poon PW. 2009. Nuclear size of c-Fos expression at the auditory brainstem is related to the time-varying nature of the acoustic stimuli. Neuroscience letters 451(2):139143.

Lugaro E (1898a) Le resistenze nell'evoluzione della vita. Rivista moderna di cultura 1:29-6o

Lugaro E (1898b) Sulle modiWcazioni morfologiche funzionali dei dendriti delle cellule nervose. Riv Patol Nerv Ment 3:337-359

Lugaro E (1906) I problemi odierni della psichiatria. Sandron, Milano

Lugaro E (1909) Modern problems in psychiatry. Translated by D Orr and RG Rows. The University Press, Manchester

Lukas W, Jones KA. 1994. Cortical neurons containing calretinin are selectively resistant to calcium overload and excitotoxicity in vitro. Neuroscience 61(2):307-316.

Ma X, Suga N. 2001a. Corticofugal modulation of duration-tuned neurons in the midbrain auditory nucleus in bats. Proceedings of the National Academy of Sciences of the United States of America 98(24):14060-14065.

Ma X, Suga N. 2001b. Plasticity of bat's central auditory system evoked by focal electric stimulation of auditory and/or somatosensory cortices. Journal of neurophysiology 85(3):1078-1087.

Ma X, Suga N. 2005. Long-term cortical plasticity evoked by electric stimulation and acetylcholine applied to the auditory cortex. Proceedings of the National Academy of Sciences of the United States of America 102(26):9335-9340.

Maffei A, Nelson SB, Turrigiano GG. 2004. Selective reconfiguration of layer 4 visual cortical circuitry by visual deprivation. Nature neuroscience 7(12):1353-1359.

Maffei A, Turrigiano GG. 2008. Multiple modes of network homeostasis in visual cortical layer 2/3. J Neurosci 28(17):4377-4384.

Malmierca MS, Hernandez O, Falconi A, Lopez-Poveda EA, Merchan M, Rees A. 2003. The commissure of the inferior colliculus shapes frequency response areas in rat: an in vivo study using reversible blockade with microinjection of kynurenic acid. Experimental brain research Experimentelle Hirnforschung 153(4):522-529.

Malmierca MS, Hernández O, Falconi A, Merchán M, Rees A. 2001. The commissure of the inferior colliculus, anatomical and physiological correlates. ARO abstr. 24, 191.

Malmierca MS, Hernandez O, Rees A. 2005. Intercollicular commissural projections modulate neuronal responses in the inferior colliculus. The European journal of neuroscience 21(10):2701-2710.

Marder E, Prinz AA. 2002. Modeling stability in neuron and network function: the role of activity in homeostasis. Bioessays 24(12):1145-1154.

Marder E, Prinz AA. 2003. Current compensation in neuronal homeostasis. Neuron 37(1):2-4.

Marianowski R, Liao WH, Van Den Abbeele T, Fillit P, Herman P, Frachet B, Huy PT. 200o. Expression of NMDA, AMPA and GABA(A) receptor subunit mRNAs in the rat auditory brainstem. I. Influence of early auditory deprivation. Hear Res. 150(1-2):1-11.

Matsuda K, Kamiya Y, Matsuda S, Yuzaki M. 2002. Cloning and characterization of a novel NMDA receptor subunit $\mathrm{NR}_{3} \mathrm{~B}$ : a dominant subunit that reduces calcium permeability. Brain Res Mol Brain Res 100(1-2):43-52.

Mayer ML, Armstrong N. 2004. Structure and function of glutamate receptor ion channels. Annual review of physiology 66:161-181.

Mayer ML, Westbrook GL. 1987. Permeation and block of N-methyl-D-aspartic acid receptor channels by divalent cations in mouse cultured central neurones. The Journal of physiology 394:501-527.

Mayer ML, Westbrook GL, Guthrie PB. 1984. Voltage-dependent block by Mg2+ of NMDA responses in spinal cord neurones. Nature 309(5965):261-263.

Mcllhinney RA, Philipps E, Le Bourdelles B, Grimwood S, Wafford K, Sandhu S, Whiting P. 2003. Assembly of N-methyl-D-aspartate (NMDA) receptors. Biochem Soc Trans 31(Pt 4):865-868. 
Melo LL, Brandao ML, Graeff FG, Sandner G. 1997. Bilateral ablation of the auditory cortex in the rat alters conditioned emotional suppression to a sound as appraised through a latent inhibition study. Behavioural brain research 88(1):59-65.

Mellor JR. 2006. Synaptic plasticity of kainate receptors. Biochem Soc Trans 34(Pt 5):949-951.

Merchan M, Aguilar LA, Lopez-Poveda EA, Malmierca MS. 2005. The inferior colliculus of the rat: quantitative immunocytochemical study of GABA and glycine. Neuroscience 136(3):907-925.

Merchan MA, Berbel P. 1996. Anatomy of the ventral nucleus of the lateral lemniscus in rats: a nucleus with a concentric laminar organization. The Journal of comparative neurology 372(2):245-263.

Meredith MA, Clemo HR. 1989. Auditory cortical projection from the anterior ectosylvian sulcus (Field AES) to the superior colliculus in the cat: an anatomical and electrophysiological study. The Journal of comparative neurology 289(4):687-707.

Michaelis EK. 1998. Molecular biology of glutamate receptors in the central nervous system and their role in excitotoxicity, oxidative stress and aging. Progress in neurobiology 54(4):369-415.

Milbrandt JC, Holder TM, Wilson MC, Salvi RJ, Caspary DM. 2000. GAD levels and muscimol binding in rat inferior colliculus following acoustic trauma. Hearing research 147(1-2):251-260.

Miller KD. 1996. Synaptic economics: competition and cooperation in synaptic plasticity. Neuron 17(3):371-374.

Misra C, Brickley SG, Wyllie DJ, Cull-Candy SG. 2000. Slow deactivation kinetics of NMDA receptors containing NR1 and NR2D subunits in rat cerebellar Purkinje cells. The Journal of physiology 525 Pt 2:299-305.

Mitani A, Shimokouchi M, Nomura S. 1983. Effects of stimulation of the primary auditory cortex upon colliculogeniculate neurons in the inferior colliculus of the cat. Neuroscience letters 42(2):185-189.

Mockel V, Fischer G. 1994. Vulnerability to excitotoxic stimuli of cultured rat hippocampal neurons containing the calcium-binding proteins calretinin and calbindin D28K. Brain Res 648(1):109-120.

Monyer H, Burnashev N, Laurie DJ, Sakmann B, Seeburg PH. 1994. Developmental and regional expression in the rat brain and functional properties of four NMDA receptors. Neuron 12(3):529-540.

Moore DR. 1991. Anatomy and physiology of binaural hearing. Audiology 30(3):125-134.

Moore JK, Moore RY. 1987. Glutamic acid decarboxylase-like immunoreactivity in brainstem auditory nuclei of the rat. The Journal of comparative neurology 260(2):157-174.

Moore RY, Goldberg JM. 1966. Projections of the inferior colliculus in the monkey. Experimental neurology 14(4):429-438.

Morley BJ, Happe HK. 2000. Cholinergic receptors: dual roles in transduction and plasticity. Hearing research 147(1-2):104-112.

Mossop JE, Wilson MJ, Caspary DM, Moore DR. 2000. Down-regulation of inhibition following unilateral deafening. Hearing research 147(1-2):183-187.

Motts SD, Schofield BR. 2009. Sources of cholinergic input to the inferior colliculus. Neuroscience 160(1):103-114.

Moucha R, Pandya PK, Engineer ND, Rathbun DL, Kilgard MP. 2005. Background sounds contribute to spectrotemporal plasticity in primary auditory cortex. Experimental brain research Experimentelle Hirnforschung 162(4):417-427.

Mu Y, Otsuka T, Horton AC, Scott DB, Ehlers MD. 2003. Activity-dependent mRNA splicing controls ER export and synaptic delivery of NMDA receptors. Neuron 40(3):581-594.

Mueller HT, Meador-Woodruff JH. 2004. NR3A NMDA receptor subunit mRNA expression in schizophrenia, depression and bipolar disorder. Schizophrenia research 71(2-3):361-370.

Murthy VN, Schikorski T, Stevens CF, Zhu Y. 2001. Inactivity produces increases in neurotransmitter release and synapse size. Neuron 32(4):673-682. 
Nagase S, Miller JM, Dupont J, Lim HH, Sato K, Altschuler RA. 2000. Changes in cochlear electrical stimulation induced Fos expression in the rat inferior colliculus following deafness. Hearing research 147(1-2):242-250.

Nagase S, Mukaida M, Miller JM, Altschuler RA. 2003. Neonatal deafening causes changes in Fos protein induced by cochlear electrical stimulation. Journal of neurocytology 32(4):353-361.

Nakamura M, Rosahl SK, Alkahlout E, Gharabaghi A, Walter GF, Samii M. 2003. C-Fos immunoreactivity mapping of the auditory system after electrical stimulation of the cochlear nerve in rats. Hearing research 184(1-2):75-81.

Nakamura M, Rosahl SK, Alkahlout E, Walter GF, Samii MM. 2005. Electrical stimulation of the cochlear nerve in rats: analysis of c-Fos expression in auditory brainstem nuclei. Brain research 1031(1):39-55.

Neff, W.D., Diamond, I.T., Casseday, J.H., 1975. Behavioral studies of auditory discrimination: Central nervous system. In: Keidel, W.D., Neff, W.D. (Eds.), Handbook of Sensory Physiology. Auditory System, Anatomy, Physiology, vol. V, part 2. Springer-Verlag, Berlin. pp. 307-400.

Nishi M, Hinds $H$, Lu HP, Kawata M, Hayashi Y. 2001. Motoneuron-specific expression of NR3 $B$, a novel NMDA-type glutamate receptor subunit that works in a dominant-negative manner. J Neurosci 21(23):RC185.

Nishimura M, Shirasawa H, Kaizo H, Song WJ. 2007. New field with tonotopic organization in guinea pig auditory cortex. Journal of neurophysiology 97(1):927-932.

Nodal FR, Lopez DE. 2003. Direct input from cochlear root neurons to pontine reticulospinal neurons in albino rat. The Journal of comparative neurology 460(1):80-93.

Norena AJ, Gourevitch B, Aizawa N, Eggermont JJ. 2006. Spectrally enhanced acoustic environment disrupts frequency representation in cat auditory cortex. Nature neuroscience 9(7):932-939.

Nwabueze-Ogbo FC, Popelar J, Syka J. 2002. Changes in the acoustically evoked activity in the inferior colliculus of the rat after functional ablation of the auditory cortex. Physiological research / Academia Scientiarum Bohemoslovaca 51 Suppl 1:S95-S104.

O'Brien RJ, Kamboj S, Ehlers MD, Rosen KR, Fischbach GD, Huganir RL. 1998. Activity-dependent modulation of synaptic AMPA receptor accumulation. Neuron 21(5):1067-1078.

Oliver DL, Hall WC. 1978. The medial geniculate body of the tree shrew, Tupaia glis. I. Cytoarchitecture and midbrain connections. The Journal of comparative neurology 182(3):423-458.

Oliver DL, Morest DK. 1984. The central nucleus of the inferior colliculus in the cat. The Journal of comparative neurology 222(2):237-264.

Oliver DL, Potashner SJ, Jones DR, Morest DK. 1983. Selective labeling of spiral ganglion and granule cells with D-aspartate in the auditory system of cat and guinea pig. J Neurosci 3(3):455-472.

Oliver DL, Winer JA, Beckius GE, Saint Marie RL. 1994. Morphology of GABAergic neurons in the inferior colliculus of the cat. The Journal of comparative neurology 340(1):27-42.

Palomero-Gallagher N, Zilles K. 2004. Isocortex. In G. Paxinos (Ed.), The Rat Nervous System, $3^{\text {rd }}$, Elsevier Academic Press, San Diego.

Parham K, Willott JF. 1990. Effects of inferior colliculus lesions on the acoustic startle response. Behavioral neuroscience 104(6):831-840.

Parks TN. 2000. The AMPA receptors of auditory neurons. Hearing research 147(1-2):77-91.

Paxinos G, Watson C. 2005. "The Rat Brain in Stereotaxic Coordinates" 5ta Ed. Elsevier Academic Press, Burlington.

Perez-Otano I, Ehlers MD. 2005. Homeostatic plasticity and NMDA receptor trafficking. Trends in neurosciences 28(5):229-238.

Perez-Otano I, Schulteis CT, Contractor A, Lipton SA, Trimmer JS, Sucher NJ, Heinemann SF. 2001. Assembly with the $\mathrm{NR}_{1}$ subunit is required for surface expression of $\mathrm{NR}_{3} \mathrm{~A}$-containing NMDA receptors. J Neurosci 21(4):1228-1237. 
Petralia RS, Wenthold RJ. 1992. Light and electron immunocytochemical localization of AMPAselective glutamate receptors in the rat brain. The Journal of comparative neurology 318(3):329-354.

Pierson M, Snyder-Keller A. 1994. Development of frequency-selective domains in inferior colliculus of normal and neonatally noise-exposed rats. Brain research 636(1):55-67.

Pilz PK, Schnitzler HU, Menne D. 1987. Acoustic startle threshold of the albino rat (Rattus norvegicus). J Comp Psychol. 101(1):67-72.

Pilz PK, Caeser M, Ostwald J. 1988. Comparative threshold studies of the acoustic pinna, jaw and startle reflex in the rat. Physiology \& behavior 43(4):411-415.

Pilz PK, Schnitzler HU. 1996. Habituation and sensitization of the acoustic startle response in rats: amplitude, threshold, and latency measures. Neurobiology of learning and memory 66(1):67-79.

Platenik J, Kuramoto N, Yoneda Y. 2000. Molecular mechanisms associated with long-term consolidation of the NMDA signals. Life sciences 67(4):335-364.

Pollak GD, Burger RM, Park TJ, Klug A, Bauer EE. 2002. Roles of inhibition for transforming binaural properties in the brainstem auditory system. Hearing research 168(1-2):60-78.

Pollok B, Schnitzler I, Stoerig P, Mierdorf T, Schnitzler A. 2005. Image-to-sound conversion: experience-induced plasticity in auditory cortex of blindfolded adults. Experimental brain research Experimentelle Hirnforschung 167(2):287-291.

Popelar J, Nwabueze-Ogbo FC, Syka J. 2003. Changes in neuronal activity of the inferior colliculus in rat after temporal inactivation of the auditory cortex. Physiological research / Academia Scientiarum Bohemoslovaca 52(5):615-628.

Prang P, Del Turco D, Deller T. 2003. Associational sprouting in the mouse fascia dentata after entorhinal lesion in vitro. Brain Res 978(1-2):205-212.

Prieto JJ, Winer JA. 1999. Layer VI in cat primary auditory cortex: Golgi study and sublaminar origins of projection neurons. The Journal of comparative neurology 404(3):332-358.

Qu M, Mittmann T, Luhmann HJ, Schleicher A, Zilles K. 1998. Long-term changes of ionotropic glutamate and GABA receptors after unilateral permanent focal cerebral ischemia in the mouse brain. Neuroscience 85(1):29-43.

Rabinowitch I, Segev I. 2006. The endurance and selectivity of spatial patterns of long-term potentiation/depression in dendrites under homeostatic synaptic plasticity. J Neurosci 26(52):13474-13484.

Rabinowitch I, Segev I. 2008. Two opposing plasticity mechanisms pulling a single synapse. Trends in neurosciences 31(8):377-383.

Raisman G. 1969. Neuronal plasticity in the septal nuclei of the adult rat. Brain Res 14(1):25-48.

Rajan R. 1988. Effect of electrical stimulation of the crossed olivocochlear bundle on temporary threshold shifts in auditory sensitivity. II. Dependence on the level of temporary threshold shifts. Journal of neurophysiology 6o(2):569-579.

Rajan R. 1989. Tonic activity of the crossed olivocochlear bundle in guinea pigs with idiopathic losses in auditory sensitivity. Hearing research 39(3):299-308.

Rajan R. 1990. Electrical stimulation of the inferior colliculus at low rates protects the cochlea from auditory desensitization. Brain Res 506(2):192-204.

Ramón y Cajal S (1894a) La Wne structure des centres nerveux. Proc Roy Soc London 55:444-468

Ramón y Cajal S (1894b) Allgemeine Betrachtungen über die Morphologie der Nervenzelle. Arch Anat Physiol Anat Abth 187-201.

Ramón y Cajal S (1911) Histologie du Système Nerveux de l'Hommeet des Vertébrés. tome II. Maloine, Paris

Rampon C, Jiang CH, Dong H, Tang YP, Lockhart DJ, Schultz PG, Tsien JZ, Hu Y. 20oo. Effects of environmental enrichment on gene expression in the brain. Proceedings of the National Academy of Sciences of the United States of America 97(23):12880-12884. 
Rao A, Craig AM. 1997. Activity regulates the synaptic localization of the NMDA receptor in hippocampal neurons. Neuron 19(4):801-812.

Ravizza RJ, Straw RB, Long PD. 1976. Laminar origin of efferent projections from auditory cortex in the golden Syrian hamster. Brain Res 114(3):497-500.

Raza A, Milbrandt JC, Arneric SP, Caspary DM. 1994. Age-related changes in brainstem auditory neurotransmitters: measures of GABA and acetylcholine function. Hearing research 77(12):221-230.

Reale RA, Imig TJ. 1980. Tonotopic organization in auditory cortex of the cat. The Journal of comparative neurology 192(2):265-291.

Reijmers LG, Peeters BW. 1994. Effects of acoustic prepulses on the startle reflex in rats: a parametric analysis. Brain Res 661(1-2):174-180.

Reisch A, Illing RB, Laszig R. 2007. Immediate early gene expression invoked by electrical intracochlear stimulation in some but not all types of neurons in the rat auditory brainstem. Experimental neurology 208(2):193-206.

Riquelme R, Saldana E, Osen KK, Ottersen OP, Merchan MA. 2001. Colocalization of GABA and glycine in the ventral nucleus of the lateral lemniscus in rat: an in situ hybridization and semiquantitative immunocytochemical study. The Journal of comparative neurology 432(4):409-424.

Roberts RC, Ribak CE. 1987. GABAergic neurons and axon terminals in the brainstem auditory nuclei of the gerbil. The Journal of comparative neurology 258(2):267-280.

Rockel AJ, Jones EG. 1973. The neuronal organization of the inferior colliculus of the adult cat. II. The pericentral nucleus. The Journal of comparative neurology 149(3):301-334.

Ross LS, Pollak GD, Zook JM. 1988. Origin of ascending projections to an isofrequency region of the mustache bat's inferior colliculus. The Journal of comparative neurology 270(4):488-505.

Rouiller EM, Wan XS, Moret V, Liang F. 1992. Mapping of c-fos expression elicited by pure tones stimulation in the auditory pathways of the rat, with emphasis on the cochlear nucleus. Neuroscience letters 144(1-2):19-24.

Roussel C, Erneux T, Schiffmann SN, Gall D. 2006. Modulation of neuronal excitability by intracellular calcium buffering: from spiking to bursting. Cell calcium 39(5):455-466.

Rubel EW, Hyson RL, Durham D. 1990. Afferent regulation of neurons in the brain stem auditory system. Journal of neurobiology 21(1):169-196.

Rubio ME. 2006. Redistribution of synaptic AMPA receptors at glutamatergic synapses in the dorsal cochlear nucleus as an early response to cochlear ablation in rats. Hearing research 216217:154-167.

Rutkowski RG, Miasnikov AA, Weinberger NM. 2003. Characterisation of multiple physiological fields within the anatomical core of rat auditory cortex. Hearing research 181(1-2):116-130.

Rutkowski RG, Weinberger NM. 2005. Encoding of learned importance of sound by magnitude of representational area in primary auditory cortex. Proceedings of the National Academy of Sciences of the United States of America 102(38):13664-13669.

Rybalko N, Suta D, Nwabueze-Ogbo F, Syka J. 2006. Effect of auditory cortex lesions on the discrimination of frequency-modulated tones in rats. The European journal of neuroscience 23(6):1614-1622.

Saint Marie RL. 1996. Glutamatergic connections of the auditory midbrain: selective uptake and axonal transport of D-[3H]aspartate. The Journal of comparative neurology 373(2):255-270.

Saint Marie RL, Baker RA. 1990. Neurotransmitter-specific uptake and retrograde transport of $[3 \mathrm{H}]$ glycine from the inferior colliculus by ipsilateral projections of the superior olivary complex and nuclei of the lateral lemniscus. Brain Res 524(2):244-253.

Saint Marie RL, Luo L, Ryan AF. 1999. Effects of stimulus frequency and intensity on c-fos mRNA expression in the adult rat auditory brainstem. The Journal of comparative neurology 404(2):258-270. 
Saint Marie RL, Ostapoff EM, Morest DK, Wenthold RJ. 1989. Glycine-immunoreactive projection of the cat lateral superior olive: possible role in midbrain ear dominance. The Journal of comparative neurology 279(3):382-396.

Saito H, Miller JM, Pfingst BE, Altschuler RA. 1999. Fos-like immunoreactivity in the auditory brainstem evoked by bipolar intracochlear electrical stimulation: effects of current level and pulse duration. Neuroscience 91(1):139-161.

Saldana E, Berrebi AS. 2000. Anisotropic organization of the rat superior paraolivary nucleus. Anat Embryol (Berl) 202(4):265-279.

Saldana E, Feliciano M, Mugnaini E. 1996. Distribution of descending projections from primary auditory neocortex to inferior colliculus mimics the topography of intracollicular projections. The Journal of comparative neurology 371(1):15-40.

Saldana E, Merchan MA. 1992. Intrinsic and commissural connections of the rat inferior colliculus. The Journal of comparative neurology 319(3):417-437.

Samii A, Lenarz M, Majdani O, Lim HH, Samii M, Lenarz T. 2007. Auditory midbrain implant: a combined approach for vestibular schwannoma surgery and device implantation. Otol Neurotol 28(1):31-38.

Sanes DH, Geary WA, Wooten GF, Rubel EW. 1987. Quantitative distribution of the glycine receptor in the auditory brain stem of the gerbil. J Neurosci 7(11):3793-3802.

Sans N, Moniot B, Raymond J. 1995. Distribution of calretinin mRNA in the vestibular nuclei of rat and guinea pig and the effects of unilateral labyrinthectomy: a non-radioactive in situ hybridization study. Brain Res Mol Brain Res 28(1):1-11.

Sasaki YF, Rothe T, Premkumar LS, Das S, Cui J, Talantova MV, Wong HK, Gong X, Chan SF, Zhang D, Nakanishi N, Sucher NJ, Lipton SA. 2002. Characterization and comparison of the NR3A subunit of the NMDA receptor in recombinant systems and primary cortical neurons. Journal of neurophysiology 87(4):2052-2063.

Sato K, Houtani T, Ueyama T, Ikeda M, Yamashita T, Kumazawa T, Sugimoto T. 1993. Identification of rat brainstem sites with neuronal Fos protein induced by acoustic stimulation with pure tones. Acta Otolaryngol Suppl 500:18-22.

Schofield BR. 2009. Projections to the inferior colliculus from layer VI cells of auditory cortex. Neuroscience 159(1):246-258.

Schofield BR, Coomes DL. 2005. Projections from auditory cortex contact cells in the cochlear nucleus that project to the inferior colliculus. Hearing research 206(1-2):3-11.

Schuller G, Covey E, Casseday JH. 1991. Auditory Pontine Grey: Connections and Response Properties in the Horseshoe Bat. The European journal of neuroscience 3(7):648-662.

Schurmans S, Schiffmann SN, Gurden H, Lemaire M, Lipp HP, Schwam V, Pochet R, Imperato A, Bohme GA, Parmentier M. 1997. Impaired long-term potentiation induction in dentate gyrus of calretinin-deficient mice. Proceedings of the National Academy of Sciences of the United States of America 94(19):10415-10420.

Seeburg PH. 1993. The TiPS/TINS lecture: the molecular biology of mammalian glutamate receptor channels. Trends Pharmacol Sci 14(8):297-303.

Sewell, W.F., 1997. Biochemistry and pharmacology of the auditory system. In: Crocker, M.J. (Ed.), Encyclopedia of Acoustics. J. Wiley and Sons, New York, pp. 1401^1408.

Sheng M, McFadden G, Greenberg ME. 1990. Membrane depolarization and calcium induce c-fos transcription via phosphorylation of transcription factor CREB. Neuron 4(4):571-582.

Shepherd JD, Rumbaugh G, Wu J, Chowdhury S, Plath N, Kuhl D, Huganir RL, Worley PF. 2006. Arc/Arg3.1 mediates homeostatic synaptic scaling of AMPA receptors. Neuron 52(3):475484.

Shneiderman A, Henkel CK. 1987. Banding of lateral superior olivary nucleus afferents in the inferior colliculus: a possible substrate for sensory integration. The Journal of comparative neurology $266(4): 519-534$. 
Siesjo BK, Bengtsson F. 1989. Calcium fluxes, calcium antagonists, and calcium-related pathology in brain ischemia, hypoglycemia, and spreading depression: a unifying hypothesis. J Cereb Blood Flow Metab 9(2):127-140.

Silva RC, Sandner G, Brandao ML. 2005. Unilateral electrical stimulation of the inferior colliculus of rats modifies the prepulse modulation of the startle response (PPI): effects of ketamine and diazepam. Behavioural brain research 16o(2):323-330.

Sinex DG, Lopez DE, Warr WB. 2001. Electrophysiological responses of cochlear root neurons. Hearing research 158(1-2):28-38.

Smith PH. 1992. Anatomy and physiology of multipolar cells in the rat inferior collicular cortex using the in vitro brain slice technique. J Neurosci 12(9):3700-3715.

Sng JC, Taniura H, Yoneda Y. 2004. A tale of early response genes. Biological \& pharmaceutical bulletin 27(5):606-612.

Soloaga A, Thomson S, Wiggin GR, Rampersaud N, Dyson MH, Hazzalin CA, Mahadevan LC, Arthur JS. 2003. MSK2 and MSK1 mediate the mitogen- and stress-induced phosphorylation of histone $\mathrm{H}_{3}$ and $\mathrm{HMG}-14$. The EMBO journal 22(11):2788-2797.

Sommer B, Kohler M, Sprengel R, Seeburg PH. 1991. RNA editing in brain controls a determinant of ion flow in glutamate-gated channels. Cell 67(1):11-19.

Spangler, K.M., and W.B. Warr (1991) The descending auditory pathway. InR.A. Altschuler, R.P. Bobbin, B.M. Clopton, and D.W. Hoffman (eds): Neurobiology of Hearing: The Central Auditory System. New York: Raven Press, pp. 2745.

Stack KE, Code RA. 2000. Calretinin expression in the chick cochlear nucleus after deafferentation. Brain Res 873(1):135-139.

Stecker GC, Harrington IA, Macpherson EA, Middlebrooks JC. 2005. Spatial sensitivity in the dorsal zone (area DZ) of cat auditory cortex. Journal of neurophysiology 94(2):1267-1280.

Stellwagen D, Malenka RC. 2006. Synaptic scaling mediated by glial TNF-alpha. Nature 440(7087):1054-1059.

Steriade M. 2000. Corticothalamic resonance, states of vigilance and mentation. Neuroscience 101(2):243-276.

Stotler WA. 1953. An experimental study of the cells and connections of the superior olivary complex of the cat. The Journal of comparative neurology 98(3):401-431.

Suga N. 2008. Role of corticofugal feedback in hearing. J Comp Physiol A Neuroethol Sens Neural Behav Physiol 194(2):169-183.

Suga N, Gao E, Zhang Y, Ma X, Olsen JF. 2000. The corticofugal system for hearing: recent progress. Proc Natl Acad Sci U S A. 97(22):11807-14.

Suga N, Xiao Z, Ma X, Ji W. 2002. Plasticity and corticofugal modulation for hearing in adult animals. Neuron 36(1):9-18.

Sun X, Chen QC, Jen PH. 1996. Corticofugal control of central auditory sensitivity in the big brown bat, Eptesicus fuscus. Neuroscience letters 212(2):131-134.

Sun X, Guo YP, Shum DK, Chan YS, He J. 2009. Time course of cortically induced Fos expression in auditory thalamus and midbrain after bilateral cochlear ablation. Neuroscience.

Sun X, Xia Q, Lai CH, Shum DK, Chan YS, He J. 2007. Corticofugal modulation of acoustically induced Fos expression in the rat auditory pathway. The Journal of comparative neurology 501(4):509-525.

Suneja SK, Benson CG, Gross J, Potashner SJ. 1995. Uptake and release of D-aspartate, GABA, and glycine in guinea pig brainstem auditory nuclei. Journal of neurochemistry 64(1):147-160.

Suneja SK, Potashner SJ, Benson CG. 2000. AMPA receptor binding in adult guinea pig brain stem auditory nuclei after unilateral cochlear ablation. Experimental neurology 165(2):355-369.

Swanson LW. 1992. Brain Maps: Structure of the Rat Brain. New York: Elsevier. 
Swanson GT, Feldmeyer D, Kaneda M, Cull-Candy SG. 1996. Effect of RNA editing and subunit coassembly single-channel properties of recombinant kainate receptors. The Journal of physiology 492 ( Pt 1):129-142.

Swerdlow NR, Geyer MA, Braff DL. 2001. Neural circuit regulation of prepulse inhibition of startle in the rat: current knowledge and future challenges. Psychopharmacology 156(2-3):194-215.

Syka J. 2002. Plastic changes in the central auditory system after hearing loss, restoration of function, and during learning. Physiological reviews 82(3):601-636.

Syka J, Popelar J. 1984. Inferior colliculus in the rat: neuronal responses to stimulation of the auditory cortex. Neuroscience letters 51(2):235-240.

Syka J, Rybalko N, Mazelova J, Druga R. 2002. Gap detection threshold in the rat before and after auditory cortex ablation. Hearing research 172(1-2):151-159.

Tadros SF, D'Souza M, Zettel ML, Zhu X, Waxmonsky NC, Frisina RD. 2007. Glutamate-related gene expression changes with age in the mouse auditory midbrain. Brain Res 1127(1):1-9.

Talwar SK, Musial PG, Gerstein GL. 2001. Role of mammalian auditory cortex in the perception of elementary sound properties. J Neurophysiol. 85(6):2350-8.

Tanzi E (1893) I fatti e le induzioni dell'odierna istologia del sistemanervoso. Riv Sper Fren Med Leg 19:419-472

Tarazi Fl, Baldessarini RJ. 1999. Regional localization of dopamine and ionotropic glutamate receptor subtypes in striatolimbic brain regions. J Neurosci Res 55(4):401-410.

Thiagarajan TC, Lindskog M, Tsien RW. 2005. Adaptation to synaptic inactivity in hippocampal neurons. Neuron 47(5):725-737.

Thompson GC, Cortez AM, Lam DM. 1985. Localization of GABA immunoreactivity in the auditory brainstem of guinea pigs. Brain Res 339(1):119-122.

Thompson GC, Thompson AM, Garrett KM, Britton BH. 1994. Serotonin and serotonin receptors in the central auditory system. Otolaryngol Head Neck Surg 110(1):93-102.

Threlkeld SW, Penley SC, Rosen GD, Fitch RH. 2008. Detection of silent gaps in white noise following cortical deactivation in rats. Neuroreport 19(8):893-898.

Tokunaga A, Sugita S, Otani K. 1984. Auditory and non-auditory subcortical afferents to the inferior colliculus in the rat. Journal fur Hirnforschung 25(4):461-472.

Torterolo P, Zurita P, Pedemonte M, Velluti RA. 1998. Auditory cortical efferent actions upon inferior colliculus unitary activity in the guinea pig. Neuroscience letters 249(2-3):172-176.

Toga AW, Mazziotta JC. 2000. Brain Mapping The Systems. Academic Press, San Diego, CA, EEUU pp. 365-397.

Toyoda H, Zhao MG, Xu H, Wu LJ, Ren M, Zhuo M. 2007. Requirement of extracellular signalregulated kinase/mitogen-activated protein kinase for long-term potentiation in adult mouse anterior cingulate cortex. Molecular pain 3:36.

Turner CP, Connell J, Blackstone K, Ringler SL. 2007. Loss of calcium and increased apoptosis within the same neuron. Brain Res 1128(1):50-60.

Turrigiano G. 2007. Homeostatic signaling: the positive side of negative feedback. Current opinion in neurobiology 17(3):318-324.

Turrigiano GG. 1999. Homeostatic plasticity in neuronal networks: the more things change, the more they stay the same. Trends in neurosciences 22(5):221-227.

Turrigiano GG. 2000. AMPA receptors unbound: membrane cycling and synaptic plasticity. Neuron 26(1):5-8.

Turrigiano GG. 2008. The self-tuning neuron: synaptic scaling of excitatory synapses. Cell 135(3):422435 .

Turrigiano GG, Leslie KR, Desai NS, Rutherford LC, Nelson SB. 1998. Activity-dependent scaling of quantal amplitude in neocortical neurons. Nature 391(6670):892-896.

Turrigiano GG, Nelson SB. 1998. Thinking globally, acting locally: AMPA receptor turnover and synaptic strength. Neuron 21(5):933-935. 
Turrigiano GG, Nelson SB. 2000. Hebb and homeostasis in neuronal plasticity. Curr Opin Neurobiol. 10(3):358-64. Review.

Turrigiano GG, Nelson SB. 2004. Homeostatic plasticity in the developing nervous system. Nature reviews 5(2):97-107.

Vale C, Sanes DH. 2002. The effect of bilateral deafness on excitatory and inhibitory synaptic strength in the inferior colliculus. The European journal of neuroscience 16(12):2394-2404.

van Noort J. 1969. The anatomical basis for frequency analysis in the cochlear nuclear complex. Psychiatria, neurologia, neurochirurgia 72(1):109-114.

van Rossum MC, Bi GQ, Turrigiano GG. 2000. Stable Hebbian learning from spike timing-dependent plasticity. J Neurosci 20(23):8812-8821.

van Straaten F, Muller R, Curran T, Van Beveren C, Verma IM. 1983. Complete nucleotide sequence of a human c-onc gene: deduced amino acid sequence of the human c-fos protein. Proceedings of the National Academy of Sciences of the United States of America 8o(11):3183-3187.

Vaudano E, Legg CR, Glickstein M. 1991. Afferent and Efferent Connections of Temporal Association Cortex in the Rat: A Horseradish Peroxidase Study. The European journal of neuroscience 3(4):317-330.

Vetter DE, Saldaña E, Mugnaini E. 1993. Input from the inferior colliculus to medial olivocochlear neurons in the rat: a double label study with PHA-L and cholera toxin. Hear Res. 1993 $\operatorname{Nov}_{i 70}(2): 173-86$.

Vischer MW, Hausler R, Rouiller EM. 1994. Distribution of Fos-like immunoreactivity in the auditory pathway of the Sprague-Dawley rat elicited by cochlear electrical stimulation. Neuroscience research 19(2):175-185.

Vital-Durand F, Jeannerod M. eds 1975. "Aspects of Neural Plasticity". INSERM. París, Francia.

Wang D, Cui Z, Zeng Q, Kuang H, Wang LP, Tsien JZ, Cao X. 2009. Genetic enhancement of memory and long-term potentiation but not $\mathrm{CA}_{1}$ long-term depression in $\mathrm{NR}_{2} \mathrm{~B}$ transgenic rats. PloS one 4(10):e7486.

Wang J, Salvi RJ, Powers N. 1996. Plasticity of response properties of inferior colliculus neurons following acute cochlear damage. Journal of neurophysiology 75(1):171-183.

Warr WB. 1975. Olivocochlear and vestibular efferent neurons of thefeline brain stem: their location, morphology and number determined by retrograde axonal transport and acetylcholinesterase histochemistry. J Comp Neurol. 161:159-182.

Watt AJ, van Rossum MC, MacLeod KM, Nelson SB, Turrigiano GG. 2000. Activity coregulates quantal AMPA and NMDA currents at neocortical synapses. Neuron 26(3):659-670.

Weedman DL, Ryugo DK. 1996. Pyramidal cells in primary auditory cortex project to cochlear nucleus in rat. Brain Res 706(1):97-102.

Wenthold RJ. 1991. Neurotransmitters of brainstem auditory nuclei. "Neurobiology of Hearing: The Central Auditory System". Raven Press, New York, pp. 121-139

Wenthold RJ, Hunter C, Petralia RS. 1993. Excitatory amino acid in the rat cochlear nucleus. The Mammalian Cochlear Nuclei. Organization and Function. Plenum Press, New York, pp. 179-194.

West MJ, Slomianka L, Gundersen HJ. 1991. Unbiased stereological estimation of the total number of neurons in thesubdivisions of the rat hippocampus using the optical fractionator. The Anatomical record 231(4):482-497.

Westbrook GL. 1994. Glutamate receptor update. Current opinion in neurobiology 4(3):337-346.

Wierenga CJ, Ibata K, Turrigiano GG. 2005. Postsynaptic expression of homeostatic plasticity at neocortical synapses. J Neurosci 25(11):2895-2905.

Wierenga CJ, Walsh MF, Turrigiano GG. 2006. Temporal regulation of the expression locus of homeostatic plasticity. J Neurophysiol. 96(4):2127-33. 
Willard FH, Martin GF. 1984. Collateral innervation of the inferior colliculus in the North American opossum: a study using fluorescent markers in a double-labeling paradigm. Brain Res 303(1):171-182.

Winer JA, Larue DT, Diehl JJ, Hefti BJ. 1998. Auditory cortical projections to the cat inferior colliculus. The Journal of comparative neurology 400(2):147-174.

Winer JA, Larue DT, Pollak GD. 1995. GABA and glycine in the central auditory system of the mustache bat: structural substrates for inhibitory neuronal organization. The Journal of comparative neurology 355(3):317-353.

Winer JA, Lee CC. 2007. The distributed auditory cortex. Hearing research 229(1-2):3-13.

Winer JA, Prieto JJ. 2001. Layer $\mathrm{V}$ in cat primary auditory cortex (Al): cellular architecture and identification of projection neurons. The Journal of comparative neurology 434(4):379-412.

Winsky L, Jacobowitz DM. 1995. Effects of unilateral cochlea ablation on the distribution of calretinin mRNA and immunoreactivity in the guinea pig ventral cochlear nucleus. The Journal of comparative neurology 354(4):564-582.

Wright DE, Seroogy KB, Lundgren KH, Davis BM, Jennes L. 1995. Comparative localization of serotonin $1 A, 1 C$, and 2 receptor subtype mRNAs in rat brain. The Journal of comparative neurology 351(3):357-373.

Wu MD, Kimura M, Hiromichi I, Helfert RH. 2008. A classification of NOergic neurons in the inferior colliculus of rat according to co-existence with classical amino acid transmitters. Okajimas folia anatomica Japonica 85(1):17-27.

Wu XE, Mel BW. 2009. Capacity-enhancing synaptic learning rules in a medial temporal lobe online learning model. Neuron 62(1):31-41.

Wu Y, Yan J. 2007. Modulation of the receptive fields of midbrain neurons elicited by thalamic electrical stimulation through corticofugal feedback. J Neurosci 27(40):10651-10658.

Wullner U, Standaert DG, Testa CM, Landwehrmeyer GB, Catania MV, Penney JB, Jr., Young AB. 1994. Glutamate receptor expression in rat striatum: effect of deafferentation. Brain Res 647(2):209-219.

Xia Z, Storm DR. 2005. The role of calmodulin as a signal integrator for synaptic plasticity. Nature reviews 6(4):267-276.

Yan J, Suga N. 1996. Corticofugal modulation of time-domain processing of biosonar information in bats. Science (New York, NY 273(5278):1100-1103.

Yeomans JS, Frankland PW. 1996. The acoustic startle reflex: neurons and connections. Brain research 21(3):301-314.

Yeomans JS, Lee J, Yeomans MH, Steidl S, Li L. 2006. Midbrain pathways for prepulse inhibition and startle activation in rat. Neuroscience 142(4):921-929.

Yoshida N, Hequembourg SJ, Atencio CA, Rosowski JJ, Liberman MC. 2000. Acoustic injury in mice: $129 / \mathrm{SvEv}$ is exceptionally resistant to noise-induced hearing loss. Hearing research 141(12):97-106.

Zettel ML, Frisina RD, Haider SE, O'Neill WE. 1997. Age-related changes in calbindin D-28k and calretinin immunoreactivity in the inferior colliculus of $\mathrm{CBA} / \mathrm{CaJ}$ and $\mathrm{C} 57 \mathrm{Bl} / 6$ mice. The Journal of comparative neurology 386(1):92-110.

Zettel ML, O'Neill WE, Trang TT, Frisina RD. 2001. Early bilateral deafening prevents calretinin upregulation in the dorsal cortex of the inferior colliculus of aged $\mathrm{CBA} / \mathrm{CaJ}$ mice. Hearing research 158(1-2):131-138.

Zhang JS, Kaltenbach JA, Wang J, Kim SA. 2003. Fos-like immunoreactivity in auditory and nonauditory brain structures of hamsters previously exposed to intense sound. Experimental brain research Experimentelle Hirnforschung 153(4):655-66o.

Zhang SO, Sun XD, Jen PH. 1987. Anatomical study of neural projections to the superior colliculus of the big brown bat, Eptesicus fuscus. Brain Res 416(2):375-380. 
Zhang W, Linden DJ. 2003. The other side of the engram: experience-driven changes in neuronal intrinsic excitability. Nature reviews 4(11):885-900.

Zhang Y, Suga N, Yan J. 1997. Corticofugal modulation of frequency processing in bat auditory system. Nature 387(6636):900-903.

Zhou J, Shore S. 2006. Convergence of spinal trigeminal and cochlear nucleus projections in the inferior colliculus of the guinea pig. The Journal of comparative neurology 495(1):100-112.

Zhou $\mathrm{X}$, Jen PH. 2000. Corticofugal inhibition compresses all types of rate-intensity functions of inferior collicular neurons in the big brown bat. Brain Res 881(1):62-68.

Zilles K. 1985. The Cortex of the Rat. A Stereotaxic Atlas. New York: Springer-Verlang.

Zilles K, Wree A. 1985. Cortex: Areal and laminar structue. In G. Paxinos 8ed): The Rat Nervous system. New York: Academic Press, pp: 375-415.

Zirpel L, Janowiak MA, Taylor DA, Parks TN. 2000. Developmental changes in metabotropic glutamate receptor-mediated calcium homeostasis. The Journal of comparative neurology 421(1):95-106.

Zirpel L, Lachica EA, Rubel EW. 1995. Activation of a metabotropic glutamate receptor increases intracellular calcium concentrations in neurons of the avian cochlear nucleus. J Neurosci 15(1 Pt 1):214-222.

Zirpel L, Lippe WR, Rubel EW. 1998. Activity-dependent regulation of [Ca2+]i in avian cochlear nucleus neurons: roles of protein kinases $A$ and $C$ and relation to cell death. Journal of neurophysiology 79(5):2288-2302.

Zook JM, Casseday JH. 1987. Convergence of ascending pathways at the inferior colliculus of the mustache bat, Pteronotus parnellii. The Journal of comparative neurology 261(3):347-361. 